\title{
Dual Purpose Canister Reactivity and Groundwater Absorption Analyses
}

\section{Spent Fuel and Waste Disposition}

Approved for Public Release. Distribution is Unlimited.

Prepared for

US Department of Energy Office of Spent Fuel and Waste Science and Technology J. B. Clarity, K. Banerjee,

L. P. Miller, S. Bhatt, and M. Swinney Oak Ridge National Laboratory

September 18, 2020 M3SF-20OR010305015 FCRD-UFD-2014-000520, Revision 6 ORNL/SPR-2020/1724 


\section{DISCLAIMER}

This information was prepared as an account of work sponsored by an agency of the U.S. Government. Neither the U.S. Government nor any agency thereof, nor any of their employees, makes any warranty, expressed or implied, or assumes any legal liability or responsibility for the accuracy, completeness, or usefulness, of any information, apparatus, product, or process disclosed, or represents that its use would not infringe privately owned rights. References herein to any specific commercial product, process, or service by trade name, trademark, manufacturer, or otherwise, does not necessarily constitute or imply its endorsement, recommendation, or favoring by the U.S. Government or any agency thereof. The views and opinions of authors expressed herein do not necessarily state or reflect those of the U.S. Government or any agency thereof. 


\section{REVISION HISTORY}

\begin{tabular}{|c|c|}
\hline Version & Description \\
\hline FCRD-UFD-2014-000520 & Initial Release \\
\hline $\begin{array}{l}\text { FCRD-UFD-2014-000520, } \\
\text { Revision } 1\end{array}$ & $\begin{array}{l}\text { Appendix A is added. Appendix A contains (1) post-closure } \\
\text { criticality results with principal set of } 29 \text { isotopes (recommended } \\
\text { for post-closure criticality analysis) for eight sites (total } 215 \\
\text { DPCs), (2) reactivity reduction study results by groundwater } \\
\text { species applied to as-loaded DPCs, and (3) reactivity impact of } \\
\text { filler material applied to as-loaded DPCs. In the main body, } \\
\text { Figures 2, 5-9, and } 11 \text { are updated to be consistent with FCRD- } \\
\text { UFD-2014-000069, Investigation of Dual-Purpose Canister Direct } \\
\text { Disposal Feasibility (FY14). Changes in the main body are } \\
\text { identified by a black vertical line in the margin. }\end{array}$ \\
\hline $\begin{array}{l}\text { FCRD-UFD-2014-000520, } \\
\text { Revision } 2\end{array}$ & $\begin{array}{l}\text { Appendix B is added. Appendix B contains (1) post-closure } \\
\text { criticality results for } 16 \text { new sites (total } 339 \text { DPCs), and } \\
\text { (2) reactivity reduction study by groundwater species }(\mathrm{NaCl}) \\
\text { applied to as-loaded DPCs at } 16 \text { sites. Changes in the main body } \\
\text { are identified by a black vertical line in the margin. }\end{array}$ \\
\hline $\begin{array}{l}\text { FCRD-UFD-2014-000520, } \\
\text { Revision } 3\end{array}$ & $\begin{array}{l}\text { Appendix } \mathrm{C} \text { is added. Appendix } \mathrm{C} \text { contains a misload } \\
\text { methodology for as-loaded disposal calculations and an evaluation } \\
\text { for misload of } 3 \text { sites and } 99 \text { canisters. Changes in the main body } \\
\text { are identified by a black vertical line in the margin. }\end{array}$ \\
\hline $\begin{array}{l}\text { FCRD-UFD-2014-000520, } \\
\text { Revision } 4\end{array}$ & $\begin{array}{l}\text { Appendix D is added. Appendix D contains (1) a description of the } \\
\text { criticality models for the NUHOMS }{ }^{\circledR} 24 P T 1-D S C \text { and NUHOMS } \\
32 \text { PT-DSC DPCs, (2) post-closure criticality calculation results } \\
\text { for five sites (total } 60 \text { DPCs), (3) reactivity reduction study results } \\
\text { by groundwater species applied to as-loaded DPCs, (4) misload } \\
\text { analyses assuming the worst fuel assembly configuration in an as- } \\
\text { loaded canister, and (5) a filler height scoping calculation. }\end{array}$ \\
\hline $\begin{array}{l}\text { FCRD-UFD-2014-000520, } \\
\text { Revision } 5\end{array}$ & $\begin{array}{l}\text { Appendix E is added. Appendix E contains: (1) a description of the } \\
\text { criticality models for the NUHOMS } \\
61 \text { BT-DSC loss of absorber models, (2) post-closure criticality } \\
\text { calculation results for five sites (total } 92 \text { DPCs), (3) reactivity } \\
\text { reduction study results by groundwater species applied to as- } \\
\text { loaded DPCs, and (4) misload analyses assuming the worst fuel } \\
\text { assembly configuration in an as-loaded canister. }\end{array}$ \\
\hline $\begin{array}{l}\text { FCRD-UFD-2014-000520, } \\
\text { Revision } 6\end{array}$ & $\begin{array}{l}\text { Appendix F is added. Appendix F contains calculations that } \\
\text { (1) extend the analytical timeline for the } 708 \text { canisters analyzed } \\
\text { through FY19 from } 22,000 \text { years to } 1,100,000 \text { years, } \\
\text { (2) characterize the effects of cementitious filler materials have on } \\
\text { post closure criticality scenarios, ( } 3 \text { ) provide post-closure } \\
\text { criticality calculation results for four sites ( } 66 \text { new DPCs), (4) } \\
\text { provide reactivity reduction study results by groundwater species } \\
\text { applied to as-loaded DPCs, and (5) present misload analyses } \\
\text { assuming the worst fuel assembly configuration in an as-loaded } \\
\text { canister. }\end{array}$ \\
\hline
\end{tabular}


This page is intentionally left blank. 


\section{CONTENTS}

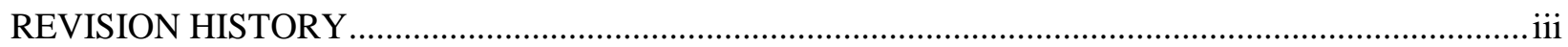

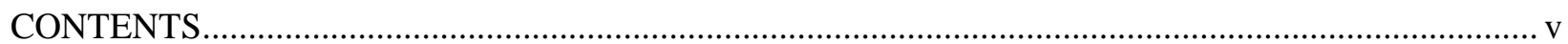

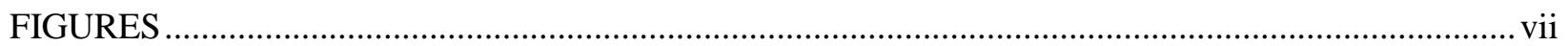

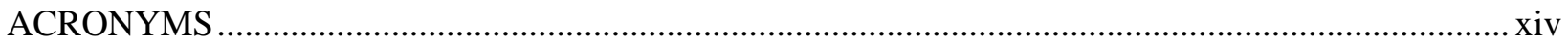

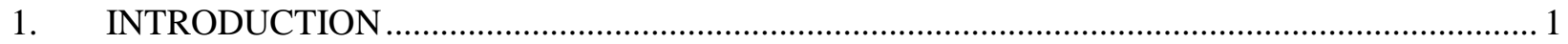

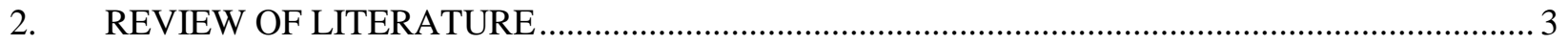

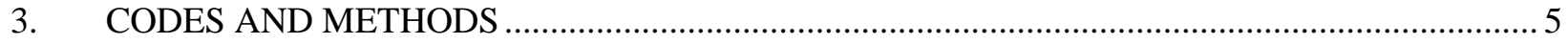

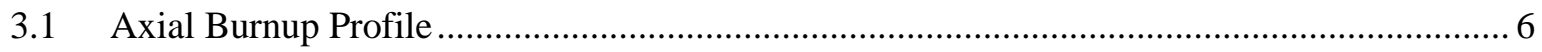

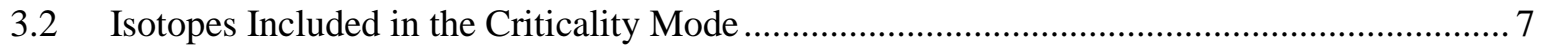

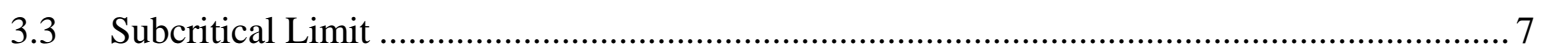

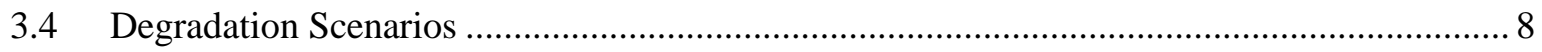

4. IMPACTS OF GROUNDWATER DISSOLVED AQUEOUS SPECIES .................................. 11

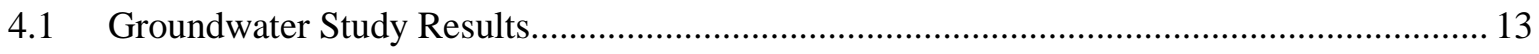

4.2 Hypothetical High Reactivity Configuration ................................................................. 19

5. ANALYSIS BY APPLYING THE ACTUAL CANISTER-SPECIFIC LOADING .....................21

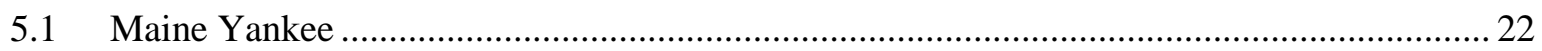

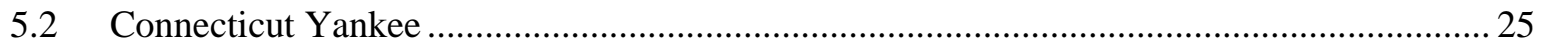

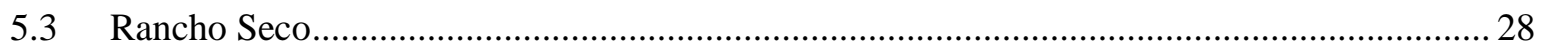

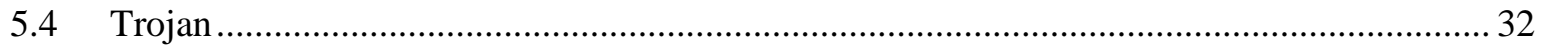

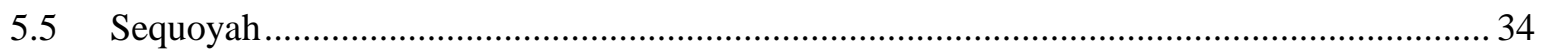

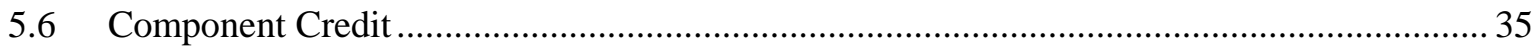

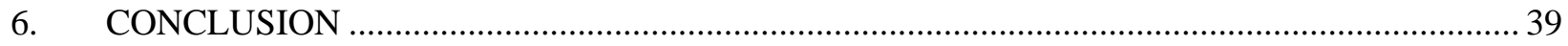

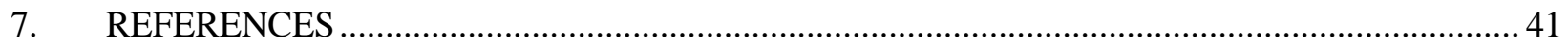

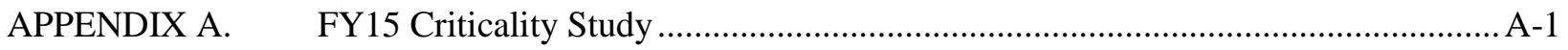

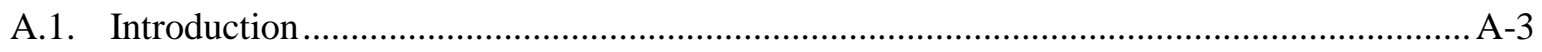

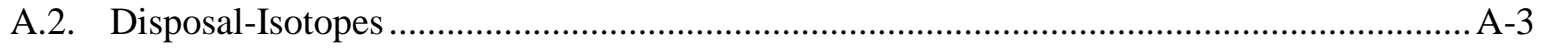

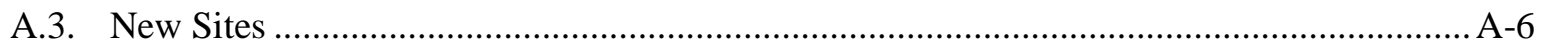

A.4. As-Loaded Criticality Analysis with Chlorides in Groundwater ..................................... A-10

A.5. As-Loaded Criticality Analysis with Engineering Filler Materials.................................. A-11

A.6. Reactivity Impact of ${ }^{10} \mathrm{~B}$ Areal Density for As-Loaded DPCs........................................ A-12

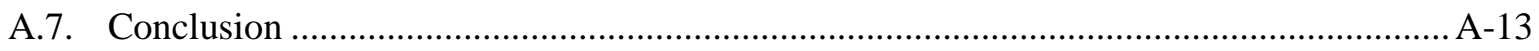

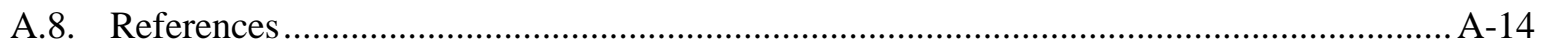




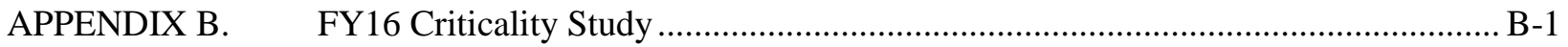

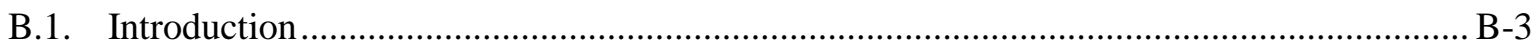

B.2. BWR As-Loaded Criticality Analysis Approach ............................................................ B-3

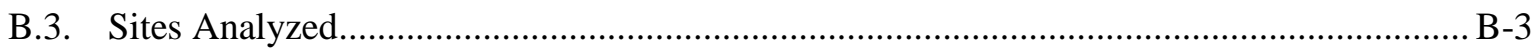

B.4. As-Loaded Criticality Analysis with Chlorides in Groundwater ...................................... B-5

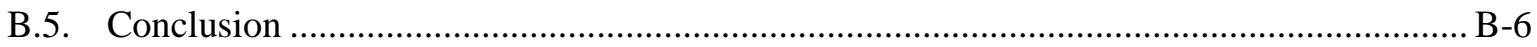

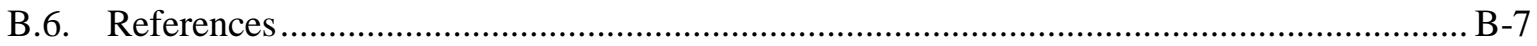

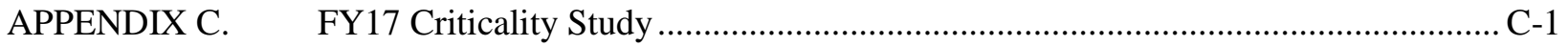

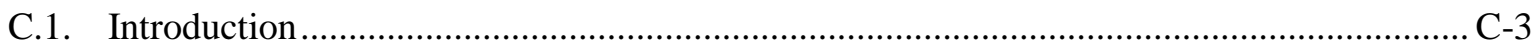

C.2. Misload Definition and Regulatory Guidance …............................................................ -3

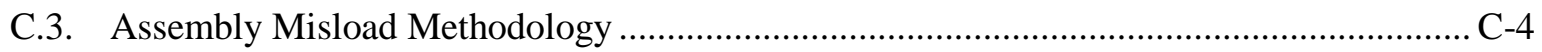

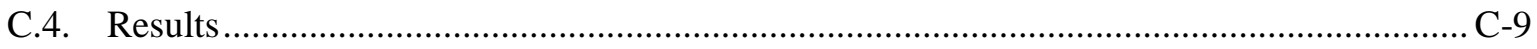

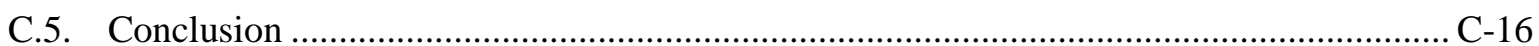

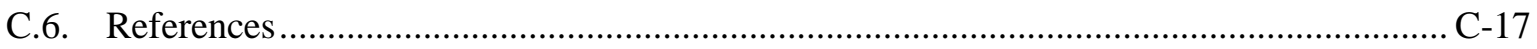

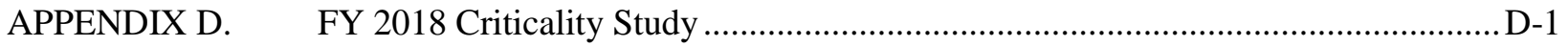

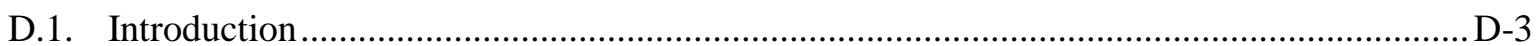

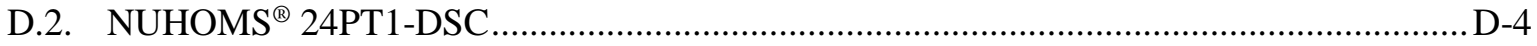

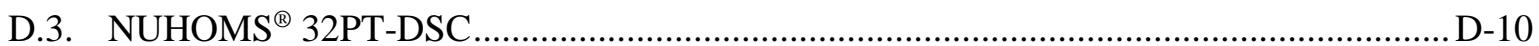

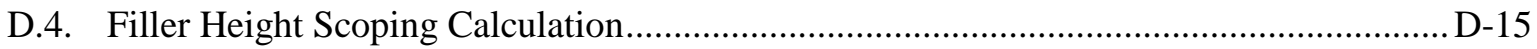

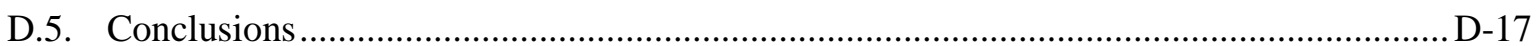

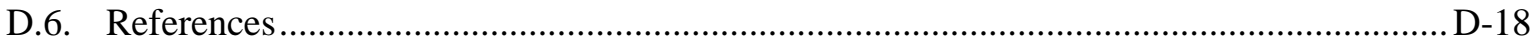

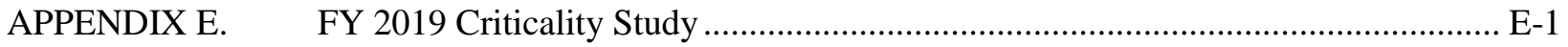

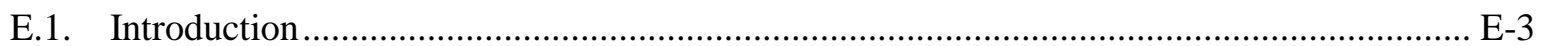

E.2. NUHOMS ${ }^{\circledR}$ 61BT-DSC loss of Neutron Absorber Model …........................................... E-4

E.3. Nine Mile Point, Cooper, and Monticello Criticality Calculations ...................................... E-4

E.4. NUHOMS ${ }^{\circledR} 32 \mathrm{PTH}-\mathrm{DSC}$ loss of Neutron Absorber Model ............................................. E-7

E.5. Crystal River Criticality Calculations …..................................................................... E-8

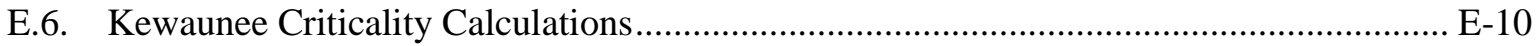

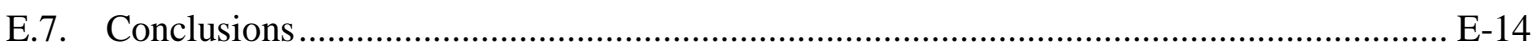

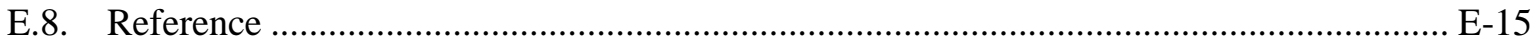

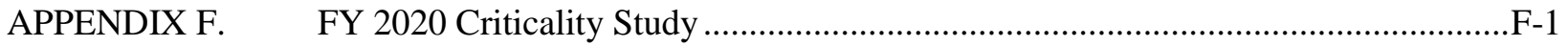

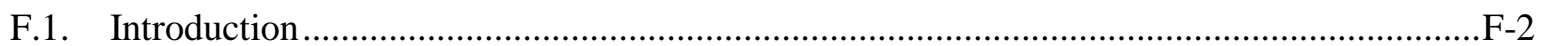

F.2. Extension of DPC calculations to Beyond 1,000,000 Years ..............................................3

F.3. Evaluation of Cementitious Filler Materials for Criticality Control ......................................9-9

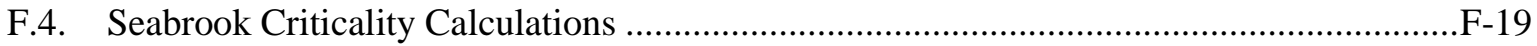

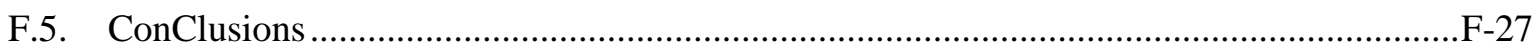

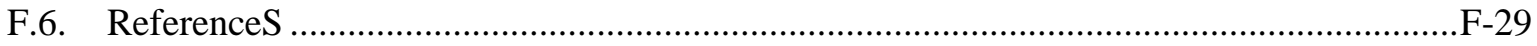




\section{FIGURES}

Figure 1. Pressurized-water reactor (PWR) 18 nodes, with 1 being the bottom of the assembly, axial burnup profiles with normalized distribution.

Figure 2. Reactivity impact of $\mathrm{B}^{10}$ areal density variation.

Figure 3. Graphical depiction of the center plane of the MPC-32 KENO model used for groundwater composition studies with varying $\mathrm{B}^{10}$ areal density in the neutron absorber panels.

Figure 4. KENO depiction of the MPC-32 degraded basket scenario.

Figure 5. (a) Reactivity impact of $\mathrm{Cl}$ concentration in groundwater for different levels of neutron absorber; (b) reactivity impact of $\mathrm{Cl}$ concentration in groundwater for degraded basket configuration

Figure 6. (a) Reactivity impact of Li concentration in groundwater for different levels of neutron absorber; (b) reactivity impact of Li concentration in groundwater for degraded basket configuration

Figure 7. (a) Reactivity impact of B concentration in groundwater for different levels of neutron absorber; (b) reactivity impact of B concentration in groundwater for degraded basket configuration

Figure 8. (a) Reactivity impact of $\mathrm{Br}$ and $\mathrm{Mn}$ concentration in groundwater for complete loss of neutron absorber; (b) reactivity impact of $\mathrm{Br}$ and $\mathrm{Mn}$ concentration in groundwater for degraded basket configuration......

Figure 9. (a) Reactivity impact of the rest of the ions' concentration in groundwater for complete loss of neutron absorber; (b) reactivity impact of the rest of the ions' concentration in groundwater for degraded basket configuration.

Figure 10. Disintegrated fuel rods configuration as modeled in KENO............................................... 19

Figure 11. Reactivity impact of $\mathrm{Cl}$ concentration in groundwater for high reactivity configuration..........20

Figure 12. NAC UMS 24-assembly basket without neutron absorber panels as modeled in SCALE. .23

Figure 13. Calculated $k_{\text {eff }}$ results for as-loaded MY 24-assembly DPCs with loss of neutron absorber panels.

Figure 14. Radial layout of the CY MPC-26 without neutron absorber panels as modeled in SCALE. .25

Figure 15. Radial layout of the CY MPC-24 without neutron absorber panels as modeled in SCALE. 26

Figure 16. Calculated $k_{\text {eff }}$ results for as-loaded CY DPCs with loss of neutron absorber panels. .27

Figure 17. 3D representation of the RS DPC as modeled in SCALE. .29

Figure 18. (a) Loss of neutron absorber configuration (RS) as modeled in KENO; (b) $k_{\text {eff }}$ as a function of time based on actual loading.

Figure 19. (a) Degraded spacer disks configuration (RS) as modeled in KENO; (b) $k_{\text {eff }}$ as a function of time based on actual loading.

Figure 20. Radial layout of the MPC-24E/EF without neutron absorber panels as modeled in SCALE. 
Figure 21. Calculated $k_{\text {eff }}$ results for as-loaded TJ DPCs with loss of neutron absorber panels. .33

Figure 22. Radial layout of the MPC-32 without neutron absorber panels as modeled in SCALE............ 34

Figure 23. Calculated $k_{\text {eff }}$ results for as-loaded SQ casks with loss of neutron absorber panels.................35

Figure 24. Radial view of the WABAs in the guide tube as modeled in SCALE for SQ DPCs. 37

Figure 25. DPC criticality analyses roadmap as described in Ref. [4] with the completion status; Yellow: work in progress and Green: completed.

Figure A-1. Comparison (in terms of reactivity) between disposal-isotopes and storagetransportation-isotopes for CY DPCs in the calendar year 9999. $\Delta \boldsymbol{k} \boldsymbol{e} \boldsymbol{f f}=$ keffdisposal - isotopes - keffstorage - transportation-isotopes. A-4

Figure A-2. $k_{\text {eff }}$ vs. calendar year for the loss-of-neutron-absorber case based on actual loading and disposal-isotopes.

Figure A-3. $k_{\text {eff }}$ vs. calendar year for the RS basket degradation case based on actual loading and disposal-isotopes.

Figure A-4. Holtec's MPC-HB 80-assembly basket without neutron absorber panels as modeled in KENO VI.

Figure A-5. $k_{\text {eff }}$ Vs. calendar year for the loss-of-neutron-absorber case, based on actual loading and disposal isotopes.

Figure A-6. $k_{\text {eff }}$ vs. NaCl concentration for the loss-of-neutron-absorber (MY, SQ CY, SL, and HB) and degraded basket (RS) cases based on actual loading.

Figure A-7. Reactivity as a function of aluminum and gibbsite volume fraction for DPCs at SQ site...

Figure A-8. Reactivity impact of ${ }^{10} \mathrm{~B}$ areal density variation for as-loaded SQ DPCs.

Figure B-1. $k_{\text {eff }}$ vs. calendar year for the loss-of-neutron-absorber case, based on actual loading and disposal-isotopes. The number within the bracket indicates number of DPCs.

Figure B-2. $k_{\text {eff }}$ vs. $\mathrm{NaCl}$ concentration for the DPCs with $k_{\text {eff }}>0.98$ for the loss-of-neutronabsorber scenario. (Numbers in brackets $=$ number of DPCs).

B-7

Figure C-1. Example distribution of $k_{\text {inf }}$ for all assemblies in a pool at the time of loading a specific canister at a specific site. Y-axis shows number of assemblies in each bin.

Figure C-2. The single severely underburned assembly (circled in red in the left plot) is the assembly with the highest $k_{i n f}$. The multiple moderately underburned assemblies (circled in red in the right plot) are selected as the number of assemblies corresponding to $50 \%$ of the cask payload with the lowest available reactivity that bounds $90 \%$ (red line in right plot) of the assemblies available in the pool. Y-axis shows number of assemblies in each bin.

Figure C-3. A loading independent criticality importance map (left) generated by ranking the highest (indicated by 1) to lowest number of fissions generated in each position (canister cell) of a uniformly loaded MPC-32 canister. Both E (edge) and C (corner) are excluded from misloads due to high leakage. The right figure shows the fission reaction rate at each cell location.

Figure C-4. Number of fissions (left) and individual assembly reactivity (right) for each position of an as-loaded MPC-32 cask. 
Figure C-5. Identified position for single assembly misload using highest reactivitiy approach (left) and neighbor nearest center with lowest reactivity approach (right)

Figure C-6. Increase in reactivity from misloading the position with the single severely underburned assembly.

Figure C-7. Loading priority for an example as-loaded canister with multiple moderately underburned assembly misload based on the importance map and position cell number. The red positions indicate misloaded positions, while the others are still the as-loaded positions.

Figure C-8. Individual assembly reactivity distribution for the pool inventory at Sequoyah 1 and 2. Y-axis shows number of assemblies in each bin.

Figure C-9. The red markers indicate the reactivity of the loaded canisters at Sequoyah, and the black lines are the ranges between optimum and worst possible loading for reactivity using the same canister inventory.

Figure C-10. Reactivity increase in pcm for each misload type and canister loaded at Sequoyah. Single Fission is the single assembly misload method misloading the position with the highest fission density, Single React is the single assembly misload method misloading the neighbor with lowest reactivity closest to the center, multiple is the multiple moderately underburned assembly misload and worst is the worst configuration misload.

Figure C-11. The as-loaded reactivity and the most bounding of the misload types.

Figure C-12. Individual assembly reactivity distribution for the pool inventory at Zion 1 and 2. Yaxis shows number of assemblies in each bin.

Figure C-13. Red markers indicate the reactivity of the loaded canisters at Zion, and the black lines are the ranges between optimized and worst possible loading for reactivity using the same canister inventory.

Figure C-14. Reactivity increase in pcm for each misload type and canister loaded at Zion. Single Fission is the single assembly misload method misloading the position with the highest fission density, Single React is the single assembly misload method misloading the neighbor with lowest reactivity closest to the center, multiple is the multiple moderately underburned assembly misload and worst is the worst configuration misload.

Figure C-15. The as-loaded reactivity and the most bounding of the misload types

Figure C-16. Individual assembly reactivity distribution for the pool inventory at Browns Ferry 2 and 3. Y-axis shows number of assemblies in each bin.

Figure C-17. Red markers indicate the reactivity of the loaded canisters at Browns Ferry, and black lines are the range between optimized and worst possible loading for reactivity using the same canister inventory. Notice that the range in $k_{\text {eff }}$ is much smaller than for Sequoyah and Zion.

Figure C-18. Reactivity increase in pcm for each misload type and canister loaded at Browns Ferry. Single Fission is the single assembly misload method misloading the position with the highest fission density, Single React is the single assembly misload method misloading the neighbor with lowest reactivity closest to the center, multiple is the multiple moderately underburned assembly misload and worst is the worst configuration misload. 
Figure C-19. The as-loaded reactivity and the most bounding of the misload types. C-16

Figure C-20. DPC criticality analyses roadmap as described in Ref. [4], with the color yellow indicating a work in progress and green indicating completion.

Figure D-1. Horizontal cross-sectional view of the XSO14W fuel assembly model. D-5

Figure D-2. Horizontal cross-sectional view of the MOX fuel assembly model. D-5

Figure D-3. Horizontal cross-sectional view of the NUHOMS ${ }^{\circledR}$ 24PT1-DSC model through a disc plate for the loss-of-neutron-absorber scenario.

Figure D-4. Horizontal cross-sectional view of the NUHOMS ${ }^{\circledR}$ 24PT1-DSC model for the degraded basket scenario.

Figure D-5. Illustration of fuel assembly ranking for the worst-misload configuration of the NUHOMS ${ }^{\circledR} 24 \mathrm{PT} 1-\mathrm{DSC}$.

Figure D-6. $k_{\text {eff }}$ vs. calendar year for the SONGS1 SNF canisters with degraded basket materials, no neutron absorber, and regular configurations.

Figure D-7. $k_{\text {eff }}$ vs. $\mathrm{NaCl}$ concentration for SONGS1 SNF canisters with $k_{\text {eff }}>0.98$ for the degraded basket scenario (numbers in brackets $=$ number of DPCs).

Figure D-8. $k_{\text {eff }}$ increase between the worst-misload scenario and the as-loaded configuration for six SONGS1 SNF canisters.

Figure D-9. Horizontal cross-sectional view of the XPA15C fuel assembly model.

D-12

Figure D-10. Horizontal cross-sectional view of the NUHOMS ${ }^{\circledR} 32 \mathrm{PT}-\mathrm{DSC}$ model for the lossof-neutron-absorber scenario.

Figure D-11. Illustration of fuel assembly ranking in the worst-misload configuration for the NUHOMS ${ }^{\circledR}$ 32PT-DSC.

Figure D-12. $k_{\text {eff }}$ vs. calendar year for the loss-of-neutron-absorber scenario, based on actual loading and disposal isotopes (numbers in brackets = number of DPCs).

Figure D-13. $k_{\text {eff }}$ vs. $\mathrm{NaCl}$ concentration for the DPCs with $k_{\text {eff }}>0.98$ for the loss-of-neutronabsorber scenario (numbers in brackets $=$ number of DPCs).

Figure D-14. $k_{\text {eff }}$ increase between the worst-misload scenario and the as-loaded configuration (numbers in brackets $=$ number of DPCs).

Figure D-15. (a) Vertical cross-sectional view and (b) horizontal cross-section view of the MPC32 disposal criticality model for filler height studies.

Figure E-1. Horizontal cross-sectional view of the NUHOMS® 61BT-DSC model for the lossof-neutron-absorber scenario. E-4

Figure E-2. $k_{e f f}$ vs. calendar year for the loss-of-neutron-absorber scenario based on actual loading and disposal isotopes for SNF canisters at Nine Mile Point, Cooper, and Monticello.

Figure E-3. $k_{\text {eff }}$ increase between the worst-misload scenario and the as-loaded configuration for 6 Nine Mile Point SNF canisters. E-6

Figure E-4. $k_{\text {eff }}$ increase between the worst-misload scenario and the as-loaded configuration for 8 Cooper SNF canisters. E-6

Figure E-5. $k_{\text {eff }}$ increase between the worst misload scenario and the as-loaded configuration for 10 Monticello SNF canisters. 
Figure E-6. Horizontal cross-sectional view of the NUHOMS ${ }^{\circledR} 32 \mathrm{PTH}-\mathrm{DSC}$ model for the lossof-neutron-absorber scenario.

Figure E-7. $k_{\text {eff }}$ vs. calendar year for the loss-of-neutron-absorber scenario based on actual loading and disposal isotopes for SNF canisters at Crystal River.

Figure E-8. $k_{\text {eff }}$ increase between the worst misload scenario and the as-loaded configuration for Crystal River SNF canisters.

Figure E-9. $k_{\text {eff }}$ vs. calendar year for the loss-of-neutron-absorber scenario based on actual loading and disposal isotopes for all SNF canisters at Kewaunee.

Figure E-10. $k_{\text {eff }}$ vs. calendar year for the degraded basket scenario, based on actual loading and disposal isotopes for the TSC-37 canisters at Kewaunee.

Figure E-11. $k_{\text {eff }}$ vs. NaCl concentration for the DPCs with $k_{\text {eff }}>0.98$ for the TSC-37 canisters at Kewaunee under the degraded basket scenario.

Figure E-12. $k_{\text {eff }}$ increase between the worst-misload scenario and the as-loaded configuration for the NUHOMS ${ }^{\circledR}$ 32PTH-DSCs at Kewaunee.

Figure E-13. $k_{\text {eff }}$ increase between the worst-misload scenario and the as-loaded configuration for the TSC-37 SNF canisters at Kewaunee.

Table E-1. Summary of the number of canisters meeting the subcritical limit.

Figure F-1. Degraded absorber calculations for PWR DPCs........................................................... F-4

Figure F-2. Degraded absorber calculations for BWR DPCs. .......................................................... F-5

Figure F-3.Degraded basket calculations for PWR DPCs. ............................................................... F-6

Table F-1. Chemical composition of filler materials. ........................................................................ F-9

A plot of the canisters analyzed this year along with the remainder of the canisters at Salem is shown in Figure F-26. Loss of neutron absorber case is shown as a gray line and the best and worst case misload calculations are shown as a pink band around the gray line. A summary of the direct disposal criticality calculations is provided in Table F-2. There are 774 canisters that have been analyzed through FY20 for this project. Of the canisters analyzed it was shown that $76 \%$ would remain subcritical under the loss-ofneutron-absorber scenario. When considering complete degradation of the baskets of canisters with non-stainless-steel structural components $66 \%$ of the canisters are shown to be subcritical. When further considering the potential for the worst-case arrangement of the most reactive fuel assemblies in each canister it is show that $65 \%$ of canisters would remain subcritical..

Table F-2. Summary of the number of canisters meeting the subcritical limit. 


\section{TABLES}

Table 1.18 node axial burnup profiles as a function of discharge burnup ............................................ 6

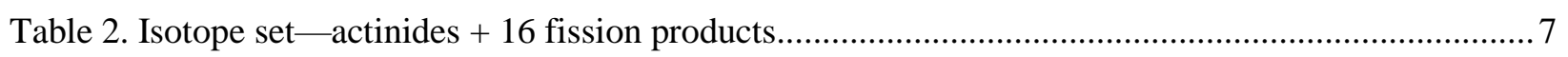

Table 3. Representative Rancho Seco DPC (NUHOMS-FC24P-P03) loading map (Service date:

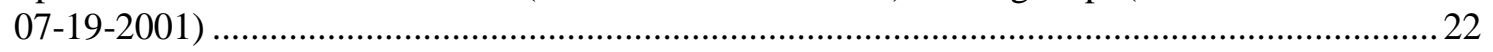

Table 4. Calculated degraded absorber $k_{\text {eff }}$ for the MY DPC with design basis fuel ...............................22

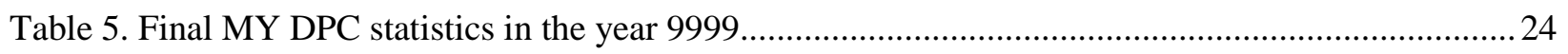

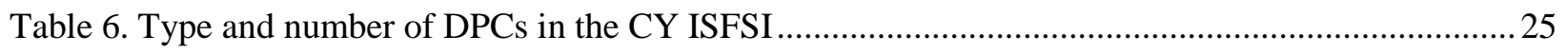

Table 7. Calculated degraded absorber $k_{\text {eff }}$ for the CY DPC with design basis fuel ................................26

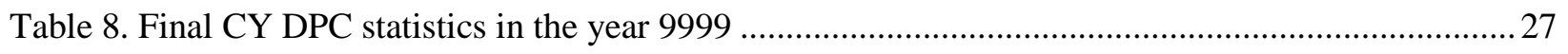

Table 9. Calculated $k_{e f f} \mathrm{~s}$ for the RS degradation scenarios with design basis fuel ...................................28

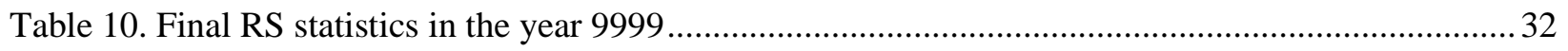

Table 11. Calculated degraded absorber $k_{\text {eff }}$ for the TJ DPC with design basis fuel................................ 33

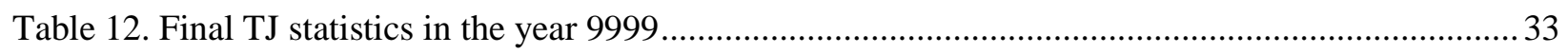

Table 13. Calculated degraded absorber $k_{\text {eff }}$ for the SQ DPC with design basis fuel................................ 34

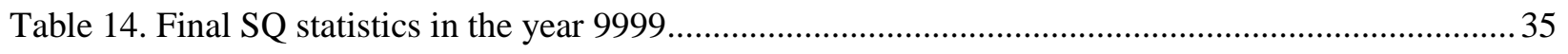

Table 15. Reactivity reduction from the components for SQ DPCs with loss of neutron absorber.............38

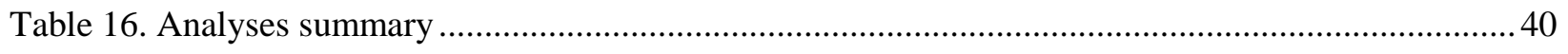

Table A-1. Principal set of isotopes for burnup credit post-closure criticality analysis ........................ A-4

Table A-2. Number of DPCs above subcritical limit with disposal-isotopes and storage-

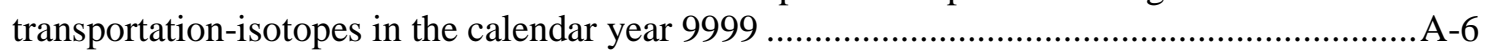

Table A-3. Calculated degraded absorber $k_{\text {eff }}$ for the MPC-HB with design basis fuel ........................... A-7

Table A-4. Summary of DPC As-loaded Criticality Analyses in the Calendar Year 9999 ........................9

Table B-1. List of sites and number of loaded DPCs assessed for criticality ........................................ B-4

Table B-2. Summary of DPC as-loaded criticality analyses in calendar year 9999 ................................ B-5

Table D-1. Final NUHOMS ${ }^{\circledR}$ 32PT-DSC statistics in the year 22,000 .............................................. D-15

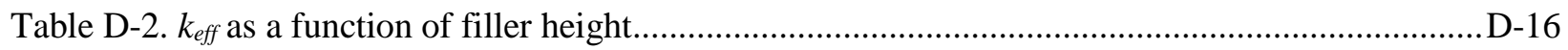


This page is intentionally left blank. 


\section{ACRONYMS}

2D

$\mathrm{B} \& \mathrm{~W}$

BPRA

BWR

CRA

CTB

CY

DFC

DOE

DPC

DSC

EPRI

FEP

FSAR

GWd/MTU

HB

ISFSI

ISG

MPC

MY

NE

OFA

PA

PWR

RS

SFP

SL

SNF

SQ

STD

UMS

UNF

UNF-ST\&DARDS two-dimensional

Babcock \& Wilcox

burnable poison rod assemblies

boiling water reactor

control rod assembly

Catawba

Connecticut Yankee Site

damaged fuel can

US Department of Energy

dual-purpose canister

dry shielded canisters

Electric Power Research Institute

features, events, processes

final safety analysis report

gigawatt-days per metric ton of uranium

Humboldt Bay

independent spent fuel storage installation

interim staff guidance

multipurpose canister

Maine Yankee Site

DOE Office of Nuclear Energy

optimized fuel assembly

performance assessment

pressurized water reactor

Rancho Seco

spent fuel pool

Salem

spent nuclear fuel ${ }^{*}$

Sequoyah Nuclear Plan

standard assembly

universal MPC system

used nuclear fuel*

UNF-Storage, Transportation \& Disposal Analysis Resource and Data System

* Note that the terms used and spent are used interchangeably by various organizations to describe nuclear fuel that has been irradiated in a nuclear reactor. 
Dual Purpose Canister Reactivity and Groundwater Absorption Analyses

WABA

wet annular burnable absorbers 



\section{SPENT FUEL AND WASTE SCIENCE AND TECHNOLOGY}

\section{DUAL PURPOSE CANISTER REACTIVITY AND GROUNDWATER ABSORPTION ANALYSES}

\section{INTRODUCTION}

The current spent nuclear fuel (SNF) management strategy includes reliance on dry storage. Utilities are meeting their interim storage needs on an individual basis with use of large-capacity dry storage casks, with a current focus on meeting existing storage and transportation requirements, as disposal requirements are not currently available. These casks are commonly known as dual-purpose (i.e., storage and transportation) canisters (DPCs). However, a small percentage of single-purpose (storage only) systems is also being used to meet storage needs. These are included under the "DPC" heading. This report investigates the postclosure criticality safety aspects of DPCs.

Placing large, heavy waste packages containing DPCs into a repository for direct disposal has not yet been implemented domestically or internationally. Therefore, direct disposal of DPCs represents new engineering and scientific challenges. Some of the engineering challenges that have already been addressed include handling and placement, use of ramps vs. shafts, use of hoists, use of transport equipment, and thermal management. Additionally, some studies have been conducted in the past regarding the feasibility of direct disposal from a criticality analysis perspective and have concluded that while possible, demonstrating subcriticality over the disposal time period is a challenge [1,2]. The alternative to direct disposal of DPCs into a repository is to repackage the SNF into different canisters. The direct disposal of DPCs without cutting them open and repackaging is appealing because it could be more cost-effective, reduce the complexity of fuel management operations both in and outside reactor facilities, and result in less cumulative worker dose during interim storage and handling before eventual disposal in a deep geologic repository.

The performance of the neutron absorber material as a function of time inside the canister is a key factor to demonstrating subcriticality. The neutron absorber panel material used in the majority of currently loaded DPCs is Boral $^{\circledR}$. Boral $^{\circledR}$ is composed of $\mathrm{B}_{4} \mathrm{C}$ particles and alloy 1100 aluminum that are hot rolled together to form a neutron-absorbing core. The neutron-absorbing core is then bonded to two outer layers of alloy 1100 aluminum. Various corrosion tests have been performed on this material because it is used in existing casks and in spent fuel pools (SFPs). Some of the corrosion tests were conducted under pool chemistry conditions and showed a 0.28 mil-per-year rate of cladding material loss, which equates to about a 40-year service (in the presence of water) life before degradation of the neutron-absorbing core. [1] Additionally, some tests of Boral ${ }^{\circledR}$ under simulated vacuum drying processes have shown the formation of blisters within the Boral ${ }^{\circledR}$ induced by the drying process. [3] Considering that the repository periods of interest are expected to be at least 10,000 years, it is not likely that the Boral ${ }^{\circledR}$ neutron absorber will maintain its criticality control function this long if the package cavity is exposed to an aqueous environment.

Within a repository performance assessment (PA), features, events, processes (FEPs), and sequences of FEPs that might affect the repository are examined. Criticality is considered an event within the FEPs nomenclature that has the potential to affect repository performance. Prior to conducting a PA, the FEPs that can affect repository performance are screened for inclusion or exclusion. Based on previous screening criteria, options available for excluding a FEP consisted of a low-probability criterion, a lowconsequence criterion, and by regulation. The objective of this report is to provide a baseline assessment 
of potential DPC reactivity changes over repository time frames and reactivity suppressing attributes that may be available to assist future FEP screening justifications. Reference [4] describes a comprehensive analysis framework for the evaluation of DPC postclosure criticality risks.

This report assesses potential DPC reactivity changes over repository time frames primarily because of various degradation mechanisms. Note that if water can be excluded from the repository or from entering a package, there would be essentially no potential for criticality. Licensed DPCs are loaded using welldefined assembly loading criteria such as specifications for approved contents in a storage cask system's certificate of compliance. These specifications define limiting (bounding) loading conditions and characteristics for which the DPC's safety analysis report has demonstrated compliance with the applicable regulatory requirements. In practice, because of the diversity in the discharged SNF available for loading (e.g., variations in SNF assembly burnup values, initial enrichments, and discharge date), it is not possible to load a DPC with SNF assemblies that correspond exactly to the limiting licensing conditions. Hence, DPCs are typically loaded with assemblies that satisfy the limiting loading conditions with some amount of unquantified, uncredited safety margin. By leveraging detailed information on the reactor in-service history of the assemblies and cask loadings, more realistic safety margins inherent within each loaded DPC can be determined. These safety margins may compensate for the reactivity increases during disposal time periods. This report examines (1) the uncredited margins associated with actual fuel loading compared with the regulatory licensing limits and (2) the increased reactivity resulting from canister flooding and the associated material and structural changes that can occur as a result of that flooding. As-loaded criticality analyses are performed for DPCs loaded at the decommissioned Maine Yankee (MY), Connecticut Yankee (CY), Rancho Seco (RS), and Trojan (TJ) nuclear power plant sites, as well as the Sequoyah Nuclear Plant (SQ). Additional as-loaded DPCs are evaluated in the appendices of this report. This report also investigates the reactivity impact of various dissolved aqueous species that could be present in the groundwater of a repository. In the main body of this report, generic loading configurations are used to evaluate the reactivity impact of various aqueous species and to determine the most viable aqueous species that could be credited in a licensing application. As-loaded configurations with the most viable aqueous species are then assessed in the appendices of this report. The results of the study presented in this report indicate that DPC disposal criticality safety demonstration could benefit from, and may require detailed canister-specific evaluation and credit for, neutron absorbers present in groundwater. This report is a continuation of the extension of the work presented in Ref. [5], where preliminary as-loaded canister-specific evaluations are documented for the MY and SQ sites. Throughout this report, a vendor-specific storage/transport canister (e.g., multipurpose canister [MPC], dry shielded canister [DSC], or transportable storage canister), is referred to as a DPC.

This report is organized as follows. The literature survey is presented in Sect. 2. Relevant information regarding the analysis codes and methods are provided in Sect. 3. Section 4 presents the groundwater composition studies relative to canister criticality, while Sect. 5 describes the as-loaded criticality assessment for five sites. Finally, Sect. 6 provides the conclusion. Appendix A presents (1) criticality analyses with 29 principal isotopes set recommended for post-closure criticality analysis [4],

(2) additional as-loaded DPCs (total 36), (3) reactivity reduction study by groundwater species applied to as-loaded DPCs, and the (4) reactivity impact of filler material applied to as-loaded DPCs. Appendix B contains (1) post-closure criticality results for 16 new sites (total 339 DPCs), and (2) reactivity reduction study by groundwater species $(\mathrm{NaCl})$ applied to as-loaded DPCs at 16 sites. Note that the results in Appendixes A and B supersede all previous results presented to date. A total of 554 canisters have been analyzed and are presented in this report and its appendices. Appendix $\mathrm{C}$ presents an assembly misload analysis methodology for as-loaded calculations including a misload evaluation for 99 canisters at three different sites and three different canister models. Appendix D provides post-closure criticality analyses for as-loaded canisters at 5 new sites (60 DPCs), including (1) $k_{\text {eff }}$ values for intact and material degradation configurations, (2) reactivity reduction by groundwater species $(\mathrm{NaCl})$ applied to as-loaded canisters, (3) misload analyses assuming worst fuel assembly configuration in an as-loaded canister, and 
(4) a scoping calculation evaluating filler height requirements to prevent canister criticality due to complete loss-of-neutron absorber.

\section{REVIEW OF LITERATURE}

Reference [1] documents work performed by the Electric Power Research Institute (EPRI) to examine the feasibility of directly disposing DPCs. For this work, two loaded MPC -32s were selected with assembly average burnup between approximately 30 gigawatt-days per metric ton of uranium $(\mathrm{GWd} / \mathrm{MTU})$ and 43 GWd/MTU. The MPC-32s were chosen at random from the SQ site, and their reactivity was examined given the fuel inventory under the assumption of fully degraded neutron absorbers but with the canister otherwise intact. The study used three different sets of burnup credit isotopes containing 5, 6, and 16 most important fission products with respect to fuel reactivity, respectively. Each of the sets of isotopes was evaluated at 5 years of cooling time. In addition to examining the as-loaded reactivity of the canisters, the study also analyzed the potential reactivity-suppressing effects of adding used burnable poison rod assemblies (BPRAs), surrogate control rods, and the use of alternative loading patterns in future canister loadings.

The EPRI study concluded that crediting the five most important fission products with respect to fuel reactivity was insufficient to show that the two canisters in question were subcritical; however, it showed that the canisters were marginally acceptable for disposal conditions by including the six most important fission products $\left(k_{\text {eff }} \sim 0.995\right)$. The study also showed that there is significant uncredited margin even when accounting for the 16 fission products when compared with the full inventory of fission products in the lattice code used in the study. Additionally, the study also showed a $2 \% \Delta k_{\text {eff }}$ decrease for modeling the used BPRAs in the canister. 
This page is intentionally left blank. 


\section{CODES AND METHODS}

Taking credit for the reduction in reactivity that results from fuel burnup is commonly referred to as burnup credit. Burnup credit criticality safety analysis for SNF in storage systems requires the determination of isotopic number densities for fuel assemblies by applying assembly-specific irradiation histories, commonly known as a depletion calculation. A depletion calculation is followed by a canister criticality evaluation which uses the isotopic number densities of the fuel from the depletion step to determine the neutron multiplication factor, $k_{\text {eff }}$ (also referred to as reactivity in this report). Both of these calculations - depletion and criticality-require different tools and methods to complete.

Various modules of the SCALE [6] code system are employed for the criticality analyses presented in this paper. The TRITON two-dimensional (2D) depletion sequence is used to perform depletion calculations that generate cross section libraries for generic assembly/reactor-specific classes and a range of fuel operating conditions. This information can subsequently be used by ORIGEN-ARP for rapid processing of problem-dependent cross sections. The TRITON 2D depletion calculation sequence employs CENTRM for multigroup cross section processing, NEWT for 2D discrete-ordinates transport calculations, and ORIGEN-S for depletion and decay calculations. The resultant nuclide concentrations are passed to the criticality analysis codes. The SCALE CSAS6 criticality analysis sequence is used to perform criticality calculations for a loaded fuel cask using the KENO-VI Monte Carlo code with the continuous-energy ENDF/B-VII cross section library to determine the effective neutron multiplication factor, $k_{\text {eff. }}$ Note that a pre-released version of SCALE 6.2, which is under development, is used for decay and continuous-energy criticality calculations.

The computational analyses of site-specific DPCs is evaluated by employing a comprehensive and integrated data and analysis tool-UNF-Storage, Transportation \& Disposal Analysis Resource and Data System (UNF-ST\&DARDS) —which is being developed at Oak Ridge National Laboratory [7] through a collaborative effort between multiple national laboratories and industry participants. UNF-ST\&DARDS employs the depletion, decay, and criticality analysis modules discussed previously. Although the groundwater study uses the criticality models developed within UNF-ST\&DARDS, the models are executed separately.

Reference [8] documents the UNF-ST\&DARDS detailed depletion calculation methodology, including the template generation scheme. Bounding irradiation parameters [8], which are intended to estimate the upper limit of the neutron multiplication after discharge, are used in this report.

Reference [9] reports the UNF-ST\&DARDS criticality model development activity with detailed model description. Criticality calculations are performed applying 18 node bounding axial burnup profiles for assemblies. Additionally, 12 actinides and 16 fission products are credited in the criticality analyses as described in Sect. 3.2.

The major conservative assumptions applied to the criticality evaluation are as follows.

- Depletion: Bounding depletion conditions are employed for the SNF isotopic composition determination including the burnable poison rod to be inserted in the fuel assembly guide tubes throughout the irradiation time.

- Criticality: Control elements (control rod assemblies, BPRAs, etc.) are not conservatively considered in the criticality calculations except for SQ. A conservative approach, as described in Sect. 5.6, is employed for the SQ as-loaded DPCs to account for the water displacement aspect of the control elements. Burnup is not credited for damaged fuels in the damaged fuel cans (DFCs). Instead, the canister's design basis assembly or bounding assembly for the DFC, as determined in the final safety analysis report (FSAR), is modeled for damaged fuel. However, high burnup (> 45 GWD/MTU) assemblies in a DFC (e.g., MY) are modeled as intact with 
accumulated burnup. As described below, bounding axial burnup profiles are used for the criticality calculations.

Therefore, the criticality analyses documented in this report are expected to be reasonably conservative.

\subsection{Axial Burnup Profile}

The axial burnup distribution is an important factor in determining the reactivity of fuel at a given average burnup. For example, two fuel assemblies with the same initial enrichment and average burnup could yield different reactivity levels depending on the axial burnup profiles of the assemblies at discharge. Reference [10] provides a set of bounding profiles based on the statistical analysis of 3,169 axial profiles taken from plant operating data covering 106 cycles of operation. Bounding axial burnup profiles, as shown in Table 1, are implemented through UNF-ST\&DARDS and are used in the criticality analysis of PWR fuel. Additionally, Figure 1 illustrates the burnup profiles.

Table 1.18 node axial burnup profiles as a function of discharge burnup

\begin{tabular}{rcccc}
\hline $\begin{array}{c}\text { Axial } \\
\text { zone no. }\end{array}$ & $\begin{array}{c}\text { Fraction of } \\
\text { active fuel height }\end{array}$ & $\begin{array}{c}\text { Burnup } \\
<\mathbf{1 8} \text { GWd/MTU }\end{array}$ & $\begin{array}{c}\mathbf{1 8} \leq \text { Burnup } \\
<\mathbf{3 0} \text { GWd/MTU }\end{array}$ & $\begin{array}{c}\text { Burnup } \\
\mathbf{3 0} \text { GWd/MTU }\end{array}$ \\
\hline 1 & 0.0278 & 0.649 & 0.668 & 0.652 \\
2 & 0.0833 & 1.044 & 1.034 & 0.967 \\
3 & 0.1389 & 1.208 & 1.15 & 1.074 \\
4 & 0.1944 & 1.215 & 1.094 & 1.103 \\
5 & 0.25 & 1.214 & 1.053 & 1.108 \\
6 & 0.3056 & 1.208 & 1.048 & 1.106 \\
7 & 0.3611 & 1.197 & 1.064 & 1.102 \\
8 & 0.4167 & 1.189 & 1.095 & 1.097 \\
9 & 0.4722 & 1.188 & 1.121 & 1.094 \\
10 & 0.5278 & 1.192 & 1.135 & 1.094 \\
11 & 0.5833 & 1.195 & 1.14 & 1.095 \\
12 & 0.6389 & 1.19 & 1.138 & 1.096 \\
13 & 0.6944 & 1.156 & 1.13 & 1.095 \\
14 & 0.75 & 1.022 & 1.106 & 1.086 \\
15 & 0.8056 & 0.756 & 1.049 & 1.059 \\
16 & 0.8611 & 0.614 & 0.933 & 0.971 \\
17 & 0.9167 & 0.481 & 0.669 & 0.738 \\
18 & 0.9722 & 0.284 & 0.373 & 0.462 \\
\hline
\end{tabular}




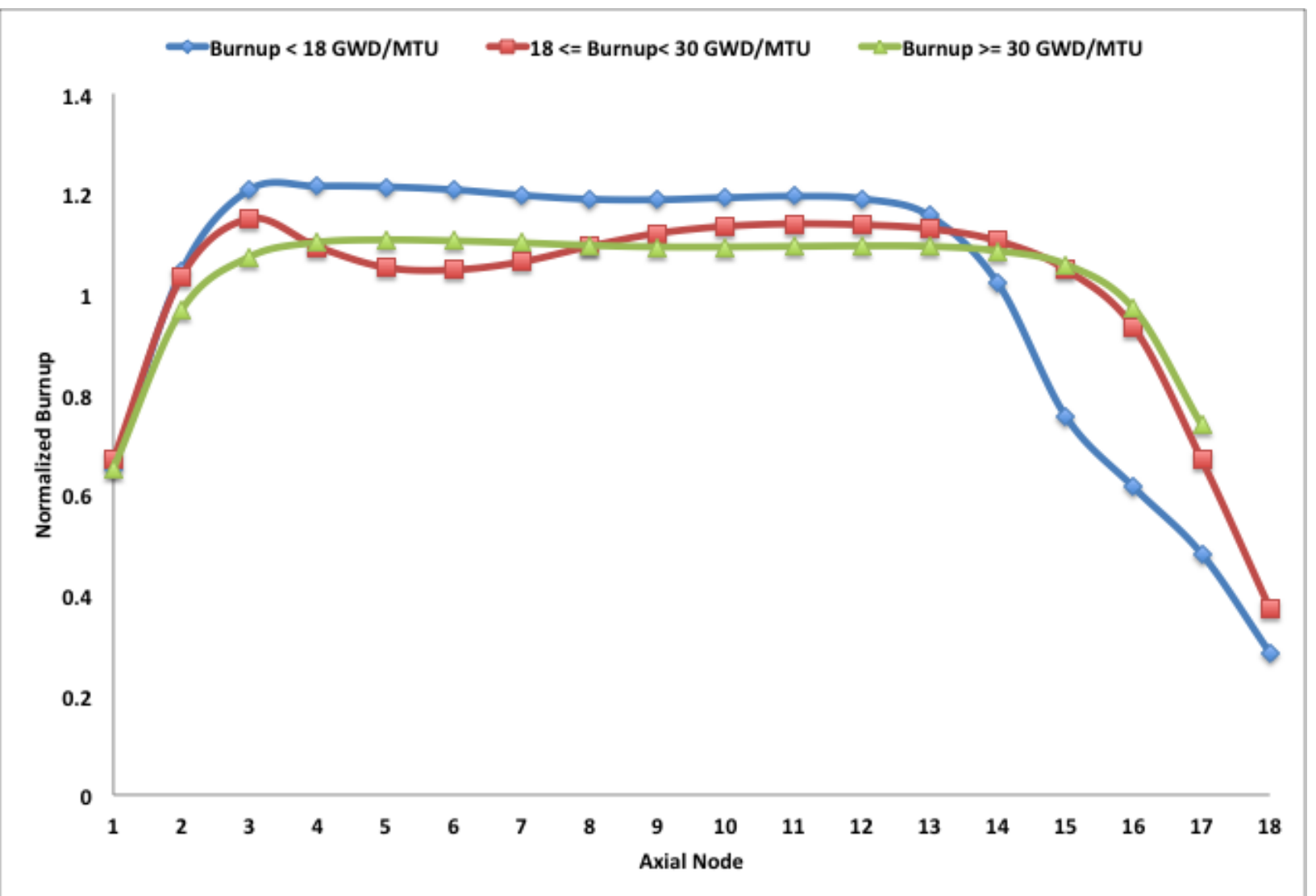

Figure 1. Pressurized-water reactor (PWR) 18 nodes, with 1 being the bottom of the assembly, axial burnup profiles with normalized distribution.

\subsection{Isotopes Included in the Criticality Mode}

The isotope set credited in the criticality calculations is selected based on the burnup credit isotopes recommended by NUREG/CR-7108 and -7109 [11,12] for SNF storage and transportation. The credited isotopes are listed in Table 2. This list will be revised in future to match with the principal isotopes provided in Ref. [13] for SNF disposal.

Table 2. Isotope set-actinides +16 fission products

\begin{tabular}{|c|c|c|c|c|c|}
\hline \multicolumn{6}{|c|}{ Actinides } \\
\hline${ }^{234} \mathrm{U}$ & ${ }^{235} \mathrm{U}$ & ${ }^{236} \mathrm{U}$ & ${ }^{238} \mathrm{U}$ & ${ }^{238} \mathrm{Pu}$ & ${ }^{239} \mathrm{Pu}$ \\
\hline${ }^{240} \mathrm{Pu}$ & ${ }^{241} \mathrm{Pu}$ & ${ }^{242} \mathrm{Pu}$ & ${ }^{241} \mathrm{Am}$ & ${ }^{243} \mathrm{Am}$ & ${ }^{237} \mathrm{~Np}$ \\
\hline \multicolumn{6}{|c|}{ Fission products } \\
\hline${ }^{95} \mathrm{Mo}$ & ${ }^{99} \mathrm{Tc}$ & ${ }^{101} \mathrm{Ru}$ & ${ }^{103} \mathrm{Rh}$ & ${ }^{109} \mathrm{Ag}$ & ${ }^{133} \mathrm{Cs}$ \\
\hline${ }^{143} \mathrm{Nd}$ & ${ }^{145} \mathrm{Nd}$ & ${ }^{147} \mathrm{Sm}$ & ${ }^{149} \mathrm{Sm}$ & ${ }^{150} \mathrm{Sm}$ & ${ }^{151} \mathrm{Sm}$ \\
\hline${ }^{152} \mathrm{Sm}$ & ${ }^{151} \mathrm{Eu}$ & ${ }^{153} \mathrm{Eu}$ & ${ }^{155} \mathrm{Gd}$ & & \\
\hline
\end{tabular}

\subsection{Subcritical Limit}

For simplicity, computational biases and uncertainties are not considered in this report. These uncertainties are simply estimated to be $2 \%\left(\Delta k_{\text {eff }}\right)$, resulting in a subcritical limit of $k_{\text {eff }}<0.98$. Time- 
dependent reactivity calculation results are provided for the time range between the calendar years 2001 and 9999 (i.e., approximately 8,000 years). Note that after the initial decrease, reactivity increases gradually from approximately 100 years to 10,000 years and beyond, and it reaches a second reactivity peak. [14] However, the expected reactivity increase between 8,000 years (used in this paper) and the second reactivity peak is not significant (less than $0.005 \Delta k_{\text {eff }}$. [14] As mentioned above, UNF-ST\&DARDS is employed to carry out the as-loaded criticality analyses. Currently, a database restriction allows UNF-ST\&DARDS to perform analyses only up to calendar year 9999. This restriction will be resolved in future to perform automated as-loaded calculations using UNF-ST\&DARDS beyond the calendar year 9999.

\subsection{Degradation Scenarios}

For criticality analysis, it is important to make the assumption that water enters a waste package at some point over the repository time frame. While different geologic settings and material degradation mechanisms might yield a large number of potential configurations, two simplified and potentially conservative configurations are used in this report to assess DPC reactivity changes that may occur over repository time frames:

1. total loss of neutron absorber from unspecified degradation and material transport processes, and

2. loss of the internal basket structure (including the neutron absorber) resulting in elimination of assembly-to-assembly spacing.

In this report, the aforementioned two configurations (degradation scenarios) are analyzed for DPCs flooded with fresh water as well as groundwater with different dissolved aqueous species. Criticality models from Ref. [9] are modified to represent the above two scenarios. The degradation mechanisms for both neutron absorber and basket structure components over repository timeframes are not well understood. However, sufficient information is not currently available to support a basis for assuming the neutron absorber's continued presence in the basket to provide criticality control. Therefore, the reactivity effect of gradual loss of the neutron absorber is also studied in this report. Figure 2 presents the reactivity reduction in terms of negative $\Delta k_{\text {eff }}$ of a 32 -assembly PWR canister as a function of ${ }^{10} \mathrm{~B}$ areal density in the neutron absorber panels, assuming the DPC is flooded with fresh water. For all the cases, $\Delta k_{\text {eff }}$ for each step is calculated with respect to the $k_{\text {eff }}$ corresponding to $0 \%$ of the minimum ${ }^{10} \mathrm{~B}$ areal density. This 32-assembly canister is the type of canister used in the SQ nuclear power plant. It contains Westinghouse (W) $17 \times 17 \mathrm{WL}$ (Lopar design) fuel assemblies. Reference [9] presents the detailed canister model description. The $\mathrm{B}^{10}$ areal density study is performed for three uniform canister loadings: $10 \mathrm{GWd} / \mathrm{MTU}$, $20 \mathrm{GWd} / \mathrm{MTU}$, and $30 \mathrm{GWd} / \mathrm{MTU}$ assemblies. The study uses 100 years of cooling time in all 32 locations. Consistent with NUREG-1536, [15] DPC licensing evaluations typically credit $75 \%$ of the minimum $\mathrm{B}^{10}$ areal density. Figure 2 indicates that loss of neutron absorber from the basket up to a certain threshold ${ }^{10} \mathrm{~B}$ areal density would not significantly increase reactivity. However, when the loss of neutron absorber from the basket passes the threshold ${ }^{10} \mathrm{~B}$ areal density, significant reactivity increase is expected. The actual extent of basket material degradation that must be accounted for should be revisited in the future, when more thorough corrosion data will be available under repository conditions and time frames. 


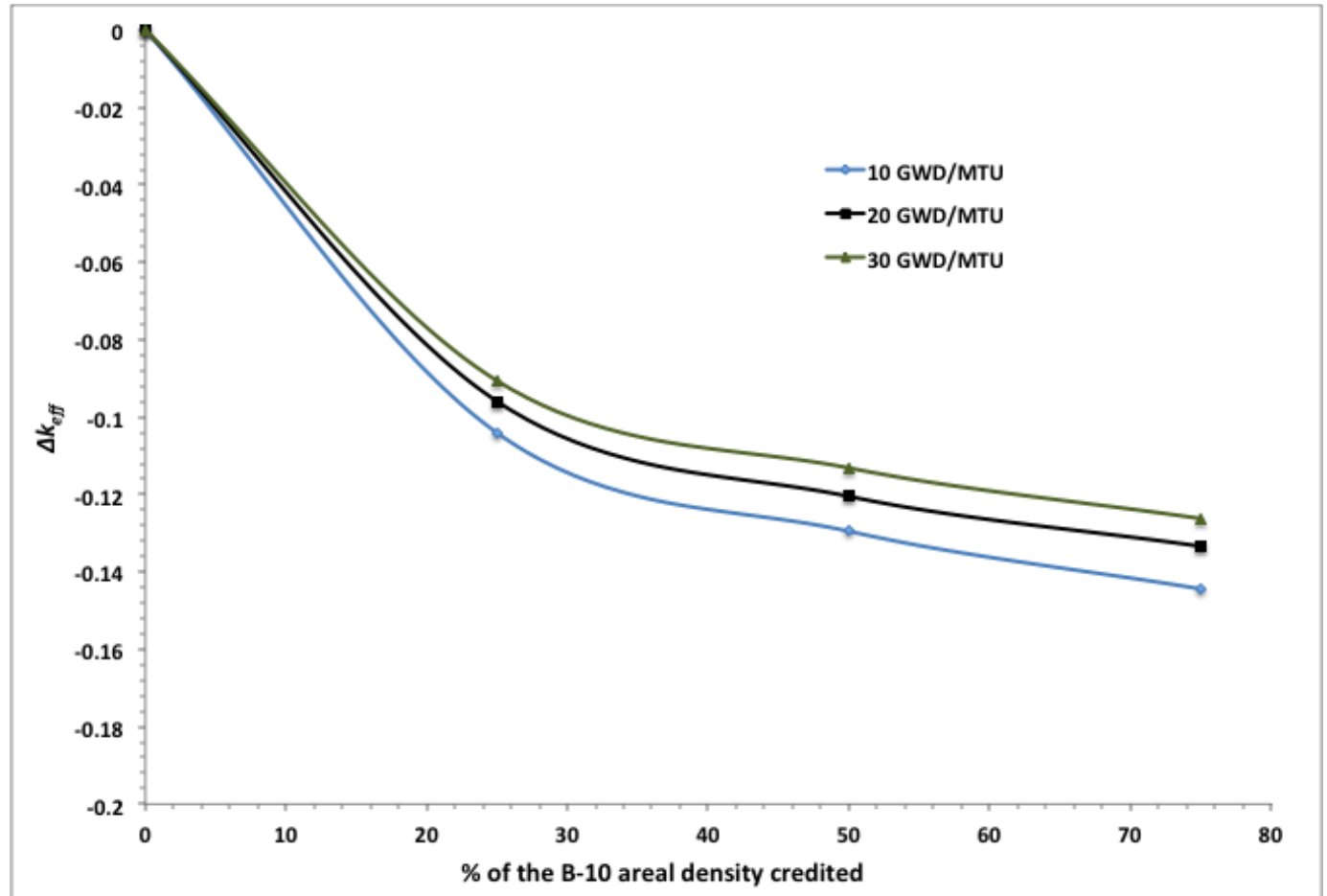

Figure 2. Reactivity impact of $\mathrm{B}^{10}$ areal density variation. 
This page is intentionally left blank. 


\section{IMPACTS OF GROUNDWATER DISSOLVED AQUEOUS SPECIES}

As mentioned previously, water (moderator) is needed to form a critical waste package configuration. However, the groundwater (pore water) that may breach the waste package confinement contains various dissolved aqueous species. The dissolved aqueous species in the groundwater can (1) act as a neutron absorber (e.g., ${ }^{35} \mathrm{Cl}$ and ${ }^{6} \mathrm{Li}$ ), and (2) displace moderating elements (e.g., H). Currently, a location for permanent geologic disposal has not been identified, and hence various geologic options for a repository are under consideration, including crystalline rock, clay/shale, bedded salt, and sedimentary rock, among others [16]. A brief review of available literature [17,18,19] shows that dissolved aqueous species available in the pore water vary widely, depending on the geochemistry of the repository concept. For example, pore water in Opalinus clay contains about $10,000 \mathrm{mg} / \mathrm{L}(\mathrm{ppm})$ of $\mathrm{Cl}$, [17] while the $\mathrm{Cl}$ content of a salt formation (brine) could be more than $150,000 \mathrm{mg} / \mathrm{L}$. [18] However, it is observed that the following are the most common dissolved aqueous species in various pore water compositions:

- $\quad \mathrm{Ca}, \mathrm{Li}, \mathrm{Na}, \mathrm{Mg}, \mathrm{K}, \mathrm{Fe}, \mathrm{Al}, \mathrm{Si}, \mathrm{Ba}, \mathrm{B}, \mathrm{Mn}, \mathrm{Sr}, \mathrm{Cl}, \mathrm{S}, \mathrm{Br}, \mathrm{N}$, and F.

In the absence of a defined chemical composition of the repository groundwater, the reactivity impact of each dissolved aqueous species is determined by varying the concentration levels over a wide range. Note that in this study, emphasis is given on the neutron absorption characteristics of the dissolved aqueous species. As mentioned in Sect. 3.4, the following two configurations are studied:

1. canister with different amounts of neutron absorber, and

2. canister with complete loss of basket structural components.

These studies are performed using Holtec International's MPC-32. [9] Uniform loading with specified burnup at all locations is assumed. Figure 3 and Figure 4 illustrate the criticality models with varying amounts of neutron absorber and complete loss of basket structures, respectively. The conceptual representation of the loss of basket structure in this section consists of the assembly-to-assembly spacing being reduced uniformly and forming into a close-packed cylindrical geometric configuration. This closepacked configuration increases neutron interaction in the system, which in turn increases system reactivity. The corrosion products from the basket materials are represented as displaced from between the fuel assemblies and flushed from the system. 


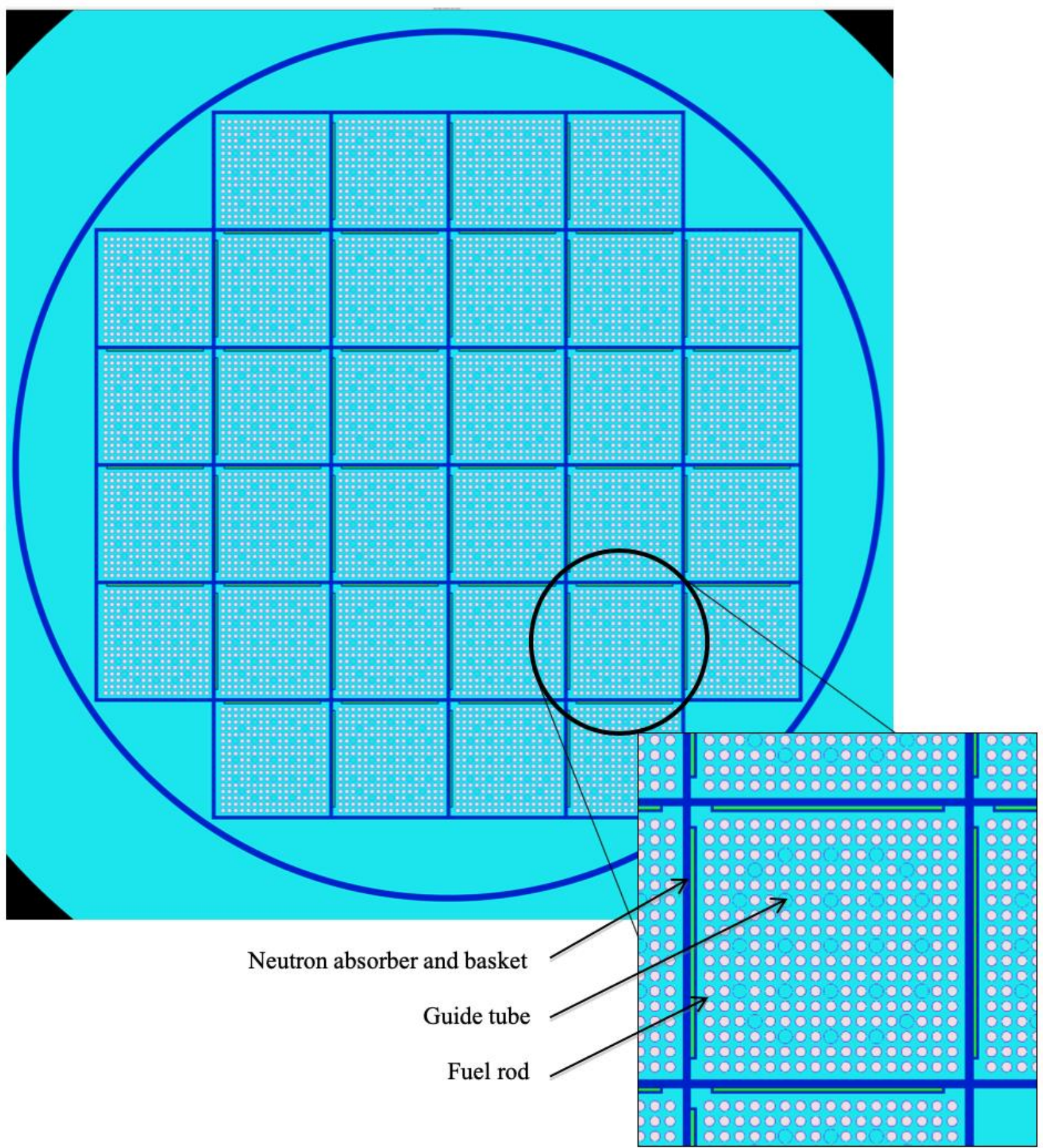

Figure 3. Graphical depiction of the center plane of the MPC-32 KENO model used for groundwater composition studies with varying $B^{10}$ areal density in the neutron absorber panels. 


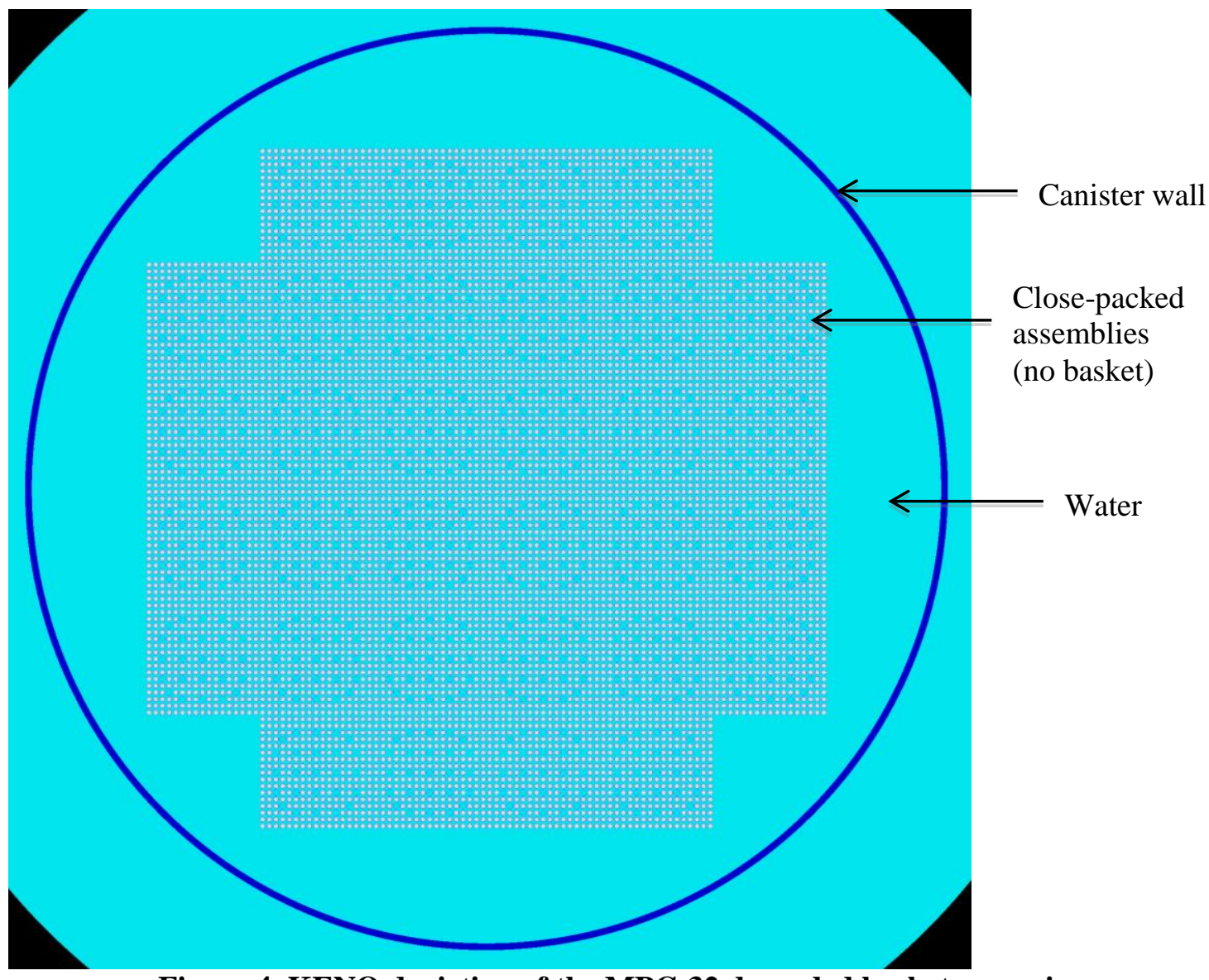

Figure 4. KENO depiction of the MPC-32 degraded basket scenario.

\subsection{Groundwater Study Results}

Among the dissolved aqueous species listed previously, $\mathrm{Cl}, \mathrm{Li}$, and $\mathrm{B}$ have the maximum reduction in canister reactivity because of their large neutron absorption cross sections. Figure 5(a) presents the impact of $\mathrm{Cl}$ concentration in groundwater on the reactivity of DPCs with different levels of neutron absorber in the basket, while Figure 5(b) illustrates the same for a degraded basket configuration. The negative $\Delta k_{\text {eff }}$ indicates reactivity reduction with respect to the $k_{\text {eff }}$ that corresponds to a configuration with fresh water. Similarly, Figure 6 and Figure 7 present the reactivity reduction as a function of Li and B content, respectively, in the groundwater for the two analyzed configurations. For the complete loss of basket (degraded basket), the dissolved aqueous species concentration is varied up to $150,000 \mathrm{ppm}$ because the degraded basket configuration (see Figure 4) is more reactive than the degraded absorber plate configuration (see Figure 3) due to its compact geometry. For the gradual loss of neutron absorber scenario, $\mathrm{Li}$ and $\mathrm{B}$ concentrations are varied up to $12,000 \mathrm{ppm}$, while $\mathrm{Cl}$ concentration is varied up to $100,000 \mathrm{ppm}$. Li and B concentrations are varied up to 12,000 ppm for the gradual loss of neutron absorber case because of their potentially limited availability in the groundwater. These plots could be used to determine the reactivity impact $\left(\Delta k_{\text {eff }}\right.$ ) for a specified amount of a dissolved element. For example, $100,000 \mathrm{ppm}(\mathrm{mg} / \mathrm{L})$ of $\mathrm{Cl}$ in brine provides around $-0.20 \Delta k_{\text {eff }}$ for a configuration with complete loss of neutron absorber and minimum burnup of $10 \mathrm{GWd} / \mathrm{MTU}$, which could be enough to show subcriticality of any perceivable configuration. It is observed that $\mathrm{Cl}$ is available in most of the repository concepts under consideration, including salt, clay/shale, granite, and crystalline rock. However, the quantity of available $\mathrm{Cl}$ in the groundwater varies widely between geological media. Additionally, currently available groundwater compositions show limited availability of the other important dissolved aqueous species (e.g., Li and B) that can provide any noticeable reactivity impact. 


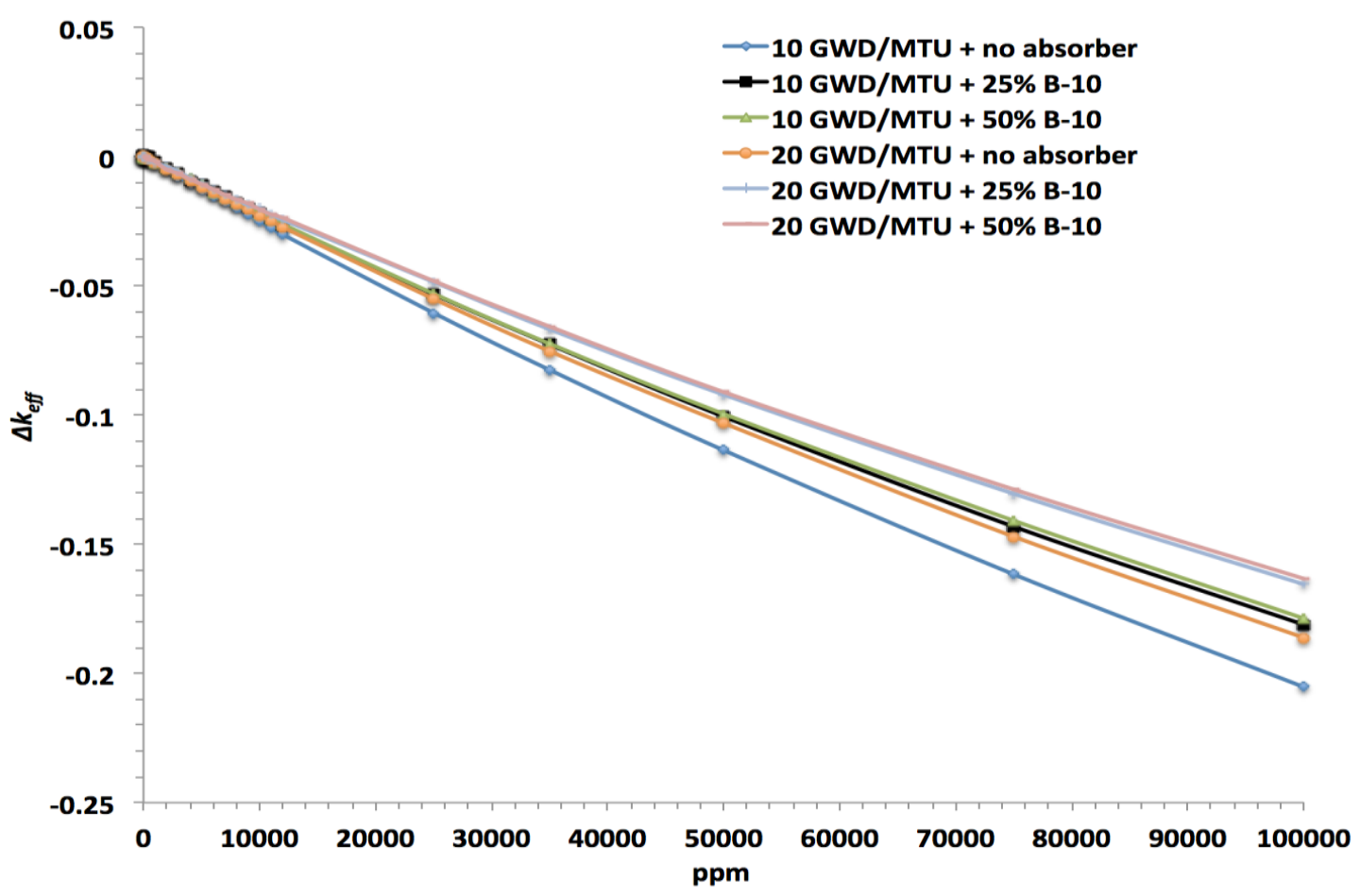

(a)

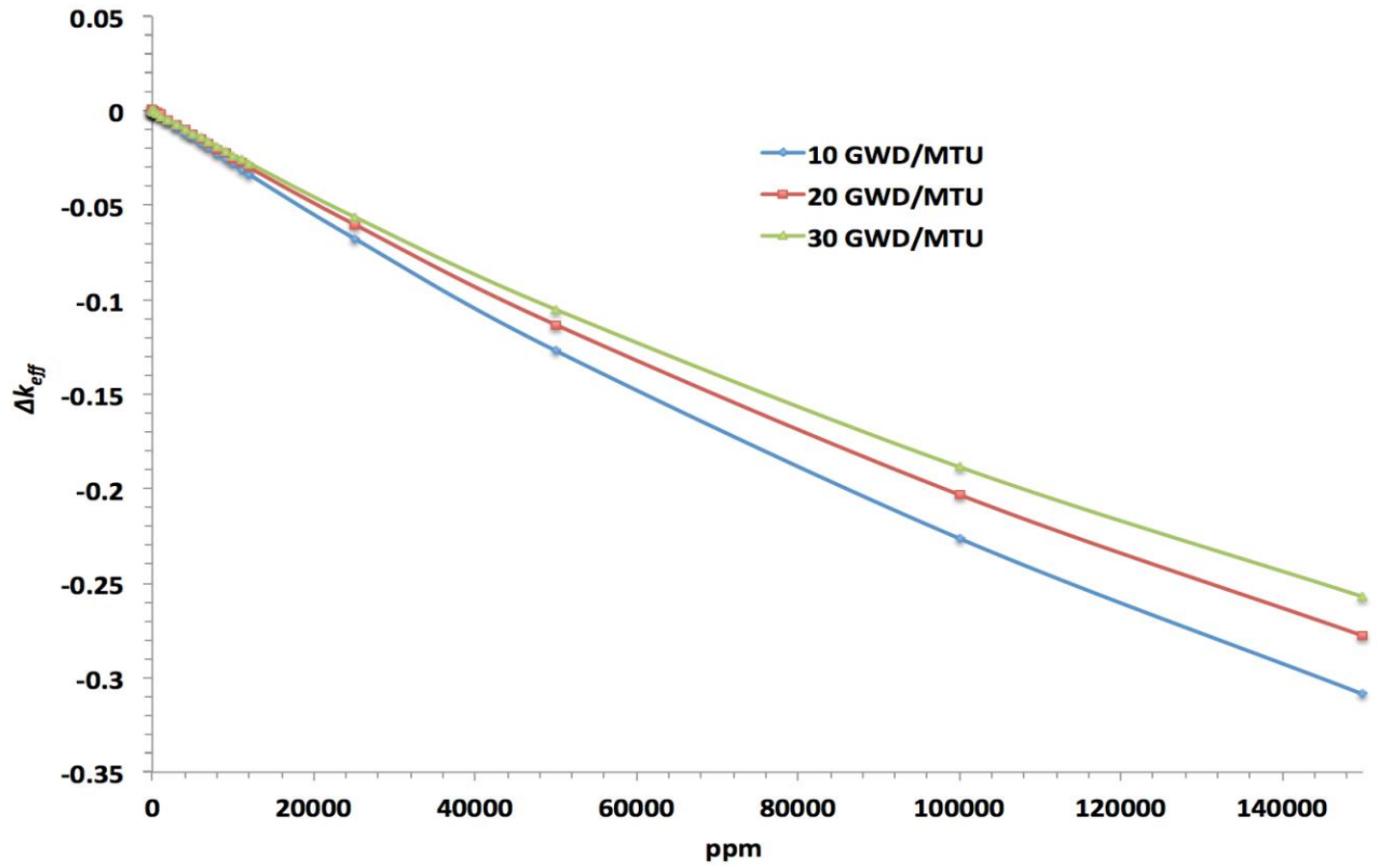

(b)

Figure 5. (a) Reactivity impact of Cl concentration in groundwater for different levels of neutron absorber; (b) reactivity impact of $\mathrm{Cl}$ concentration in groundwater for degraded basket configuration. 


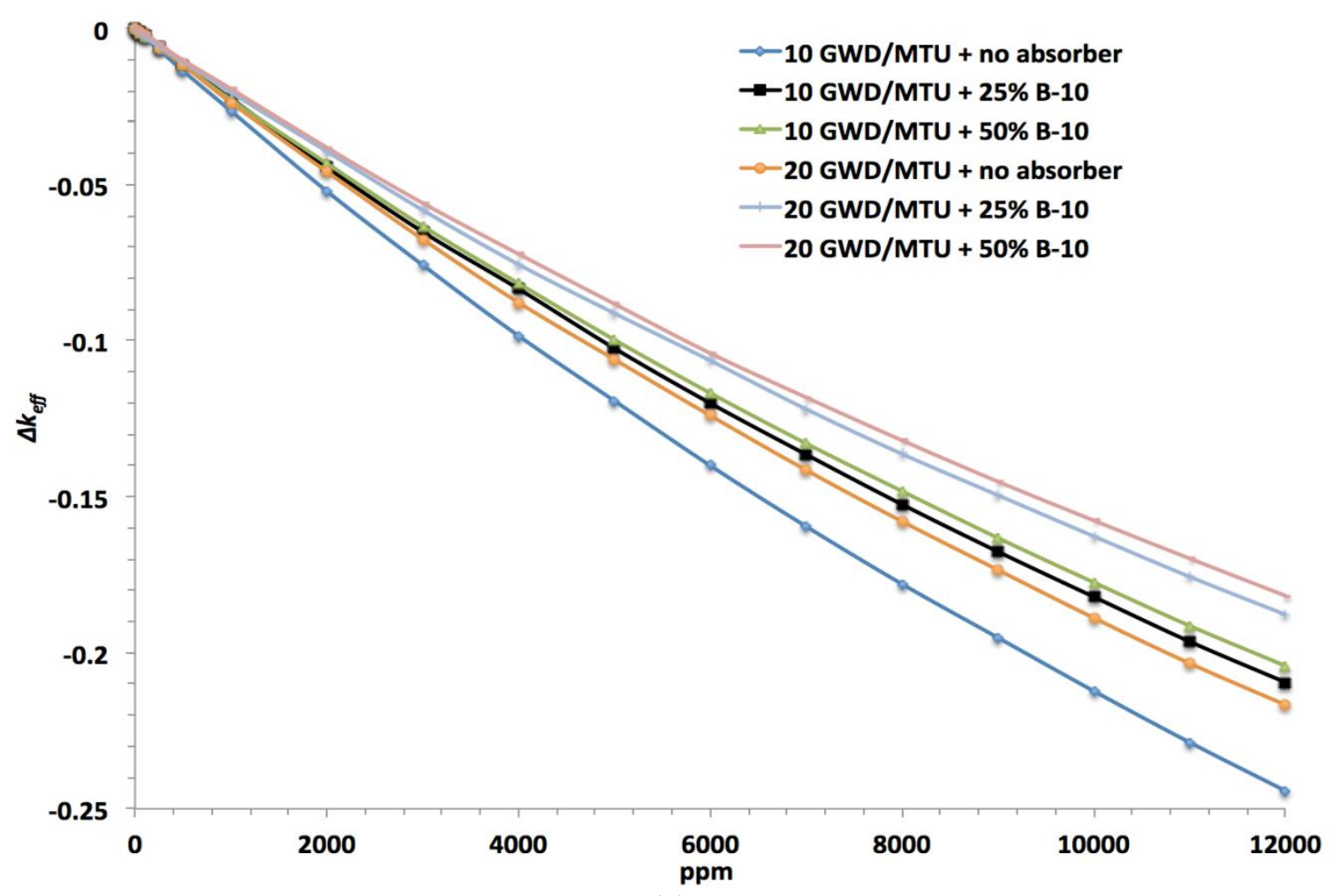

(a)

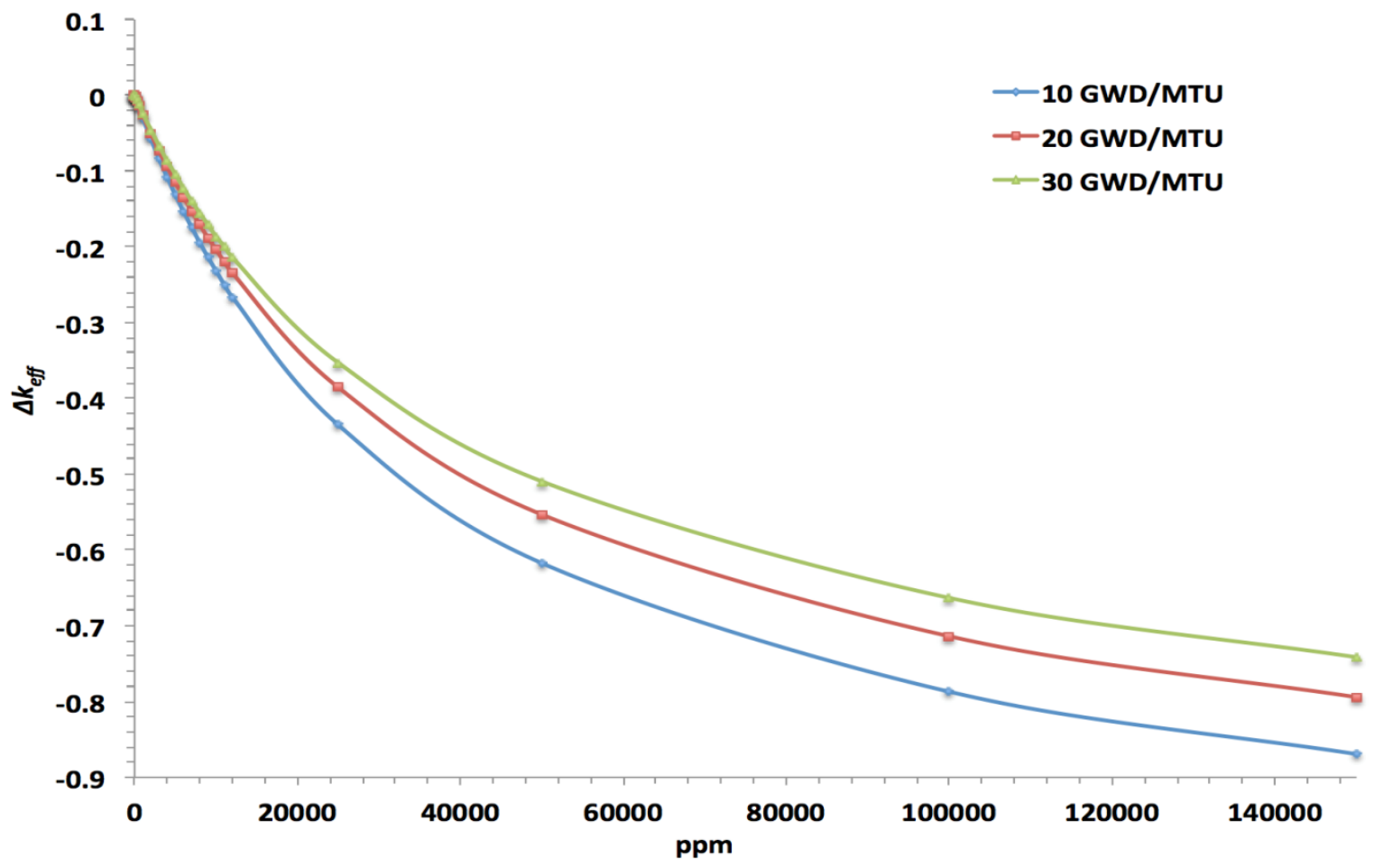

(b)

Figure 6. (a) Reactivity impact of Li concentration in groundwater for different levels of neutron absorber; (b) reactivity impact of Li concentration in groundwater for degraded basket configuration. 


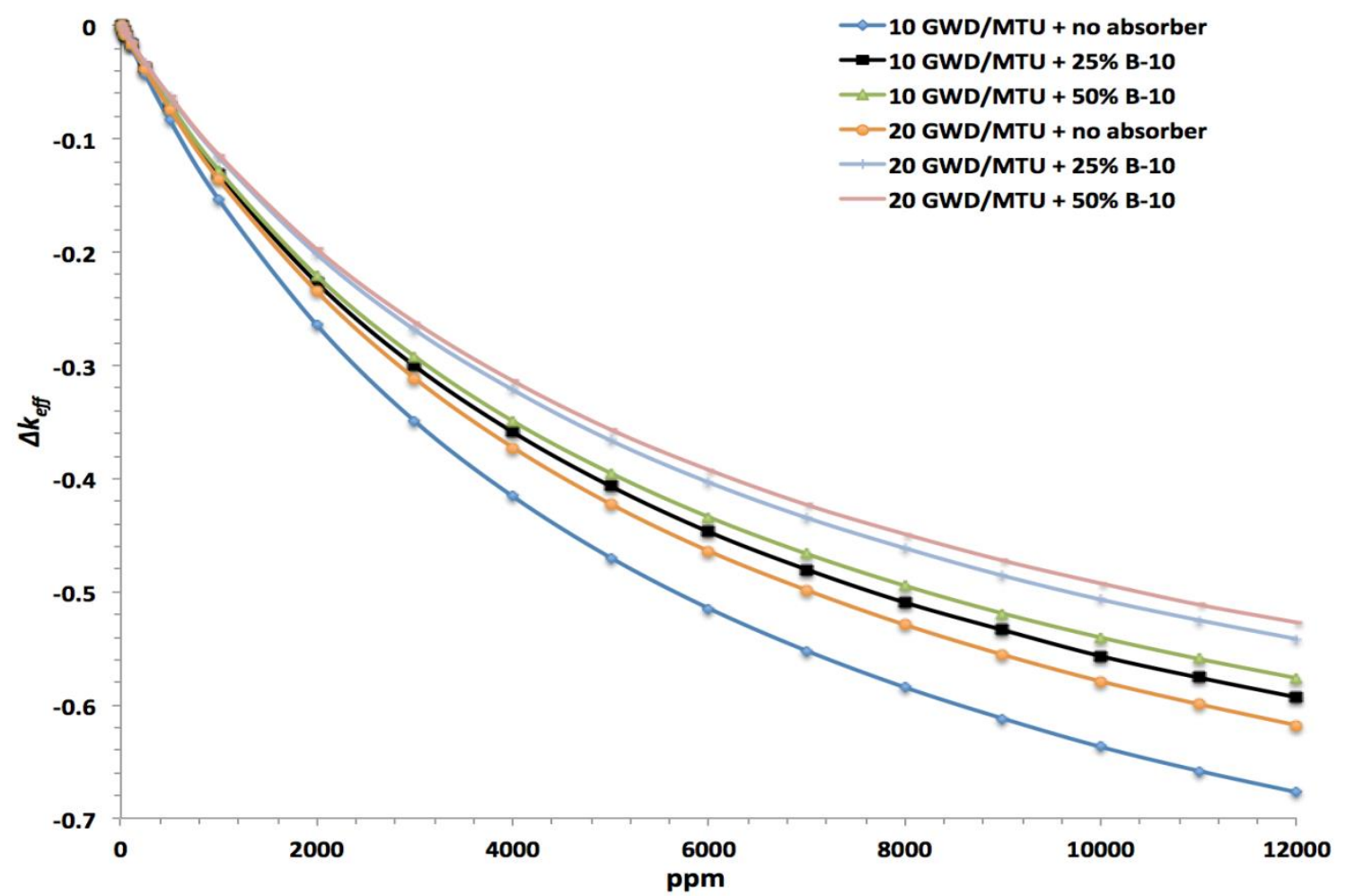

(a)

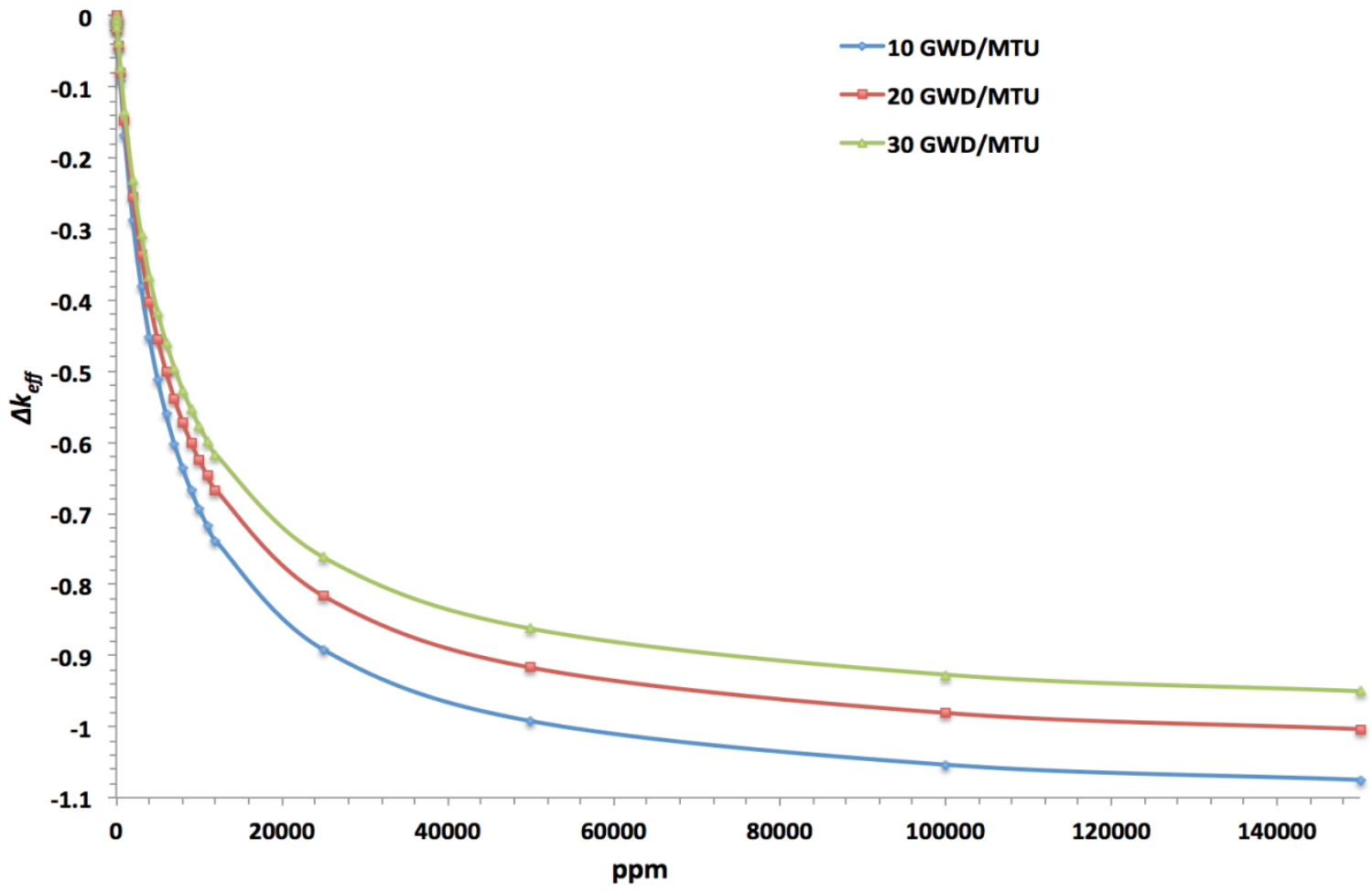

(b)

Figure 7. (a) Reactivity impact of $B$ concentration in groundwater for different levels of neutron absorber; (b) reactivity impact of B concentration in groundwater for degraded basket configuration. 
It is also observed that $\mathrm{Br}$ and $\mathrm{Mn}$ offer minor reactivity reduction, while the remaining the dissolved aqueous species ( $\mathrm{N}, \mathrm{Ba}, \mathrm{Mg}, \mathrm{F}, \mathrm{S}, \mathrm{Na}, \mathrm{K}, \mathrm{Sr}, \mathrm{Ca}, \mathrm{Fe}, \mathrm{Al}$, and $\mathrm{Si}$ ) do not have any significant impact. The $\mathrm{Br}$ and Mn study is presented in Figure 8, while Figure 9 depicts the reactivity changes as functions of the remaining ion concentrations for the two degraded configurations analyzed in this report.

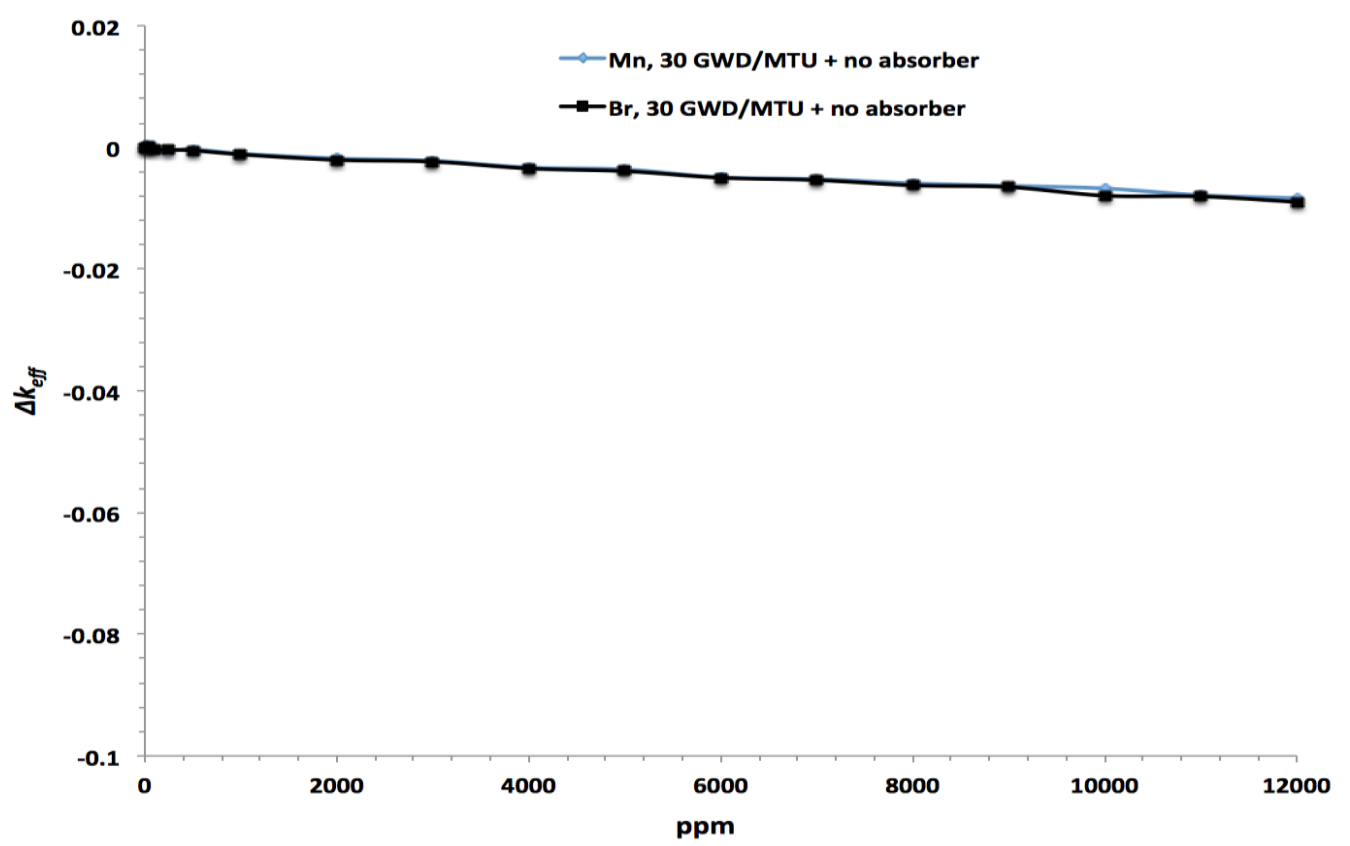

(a)

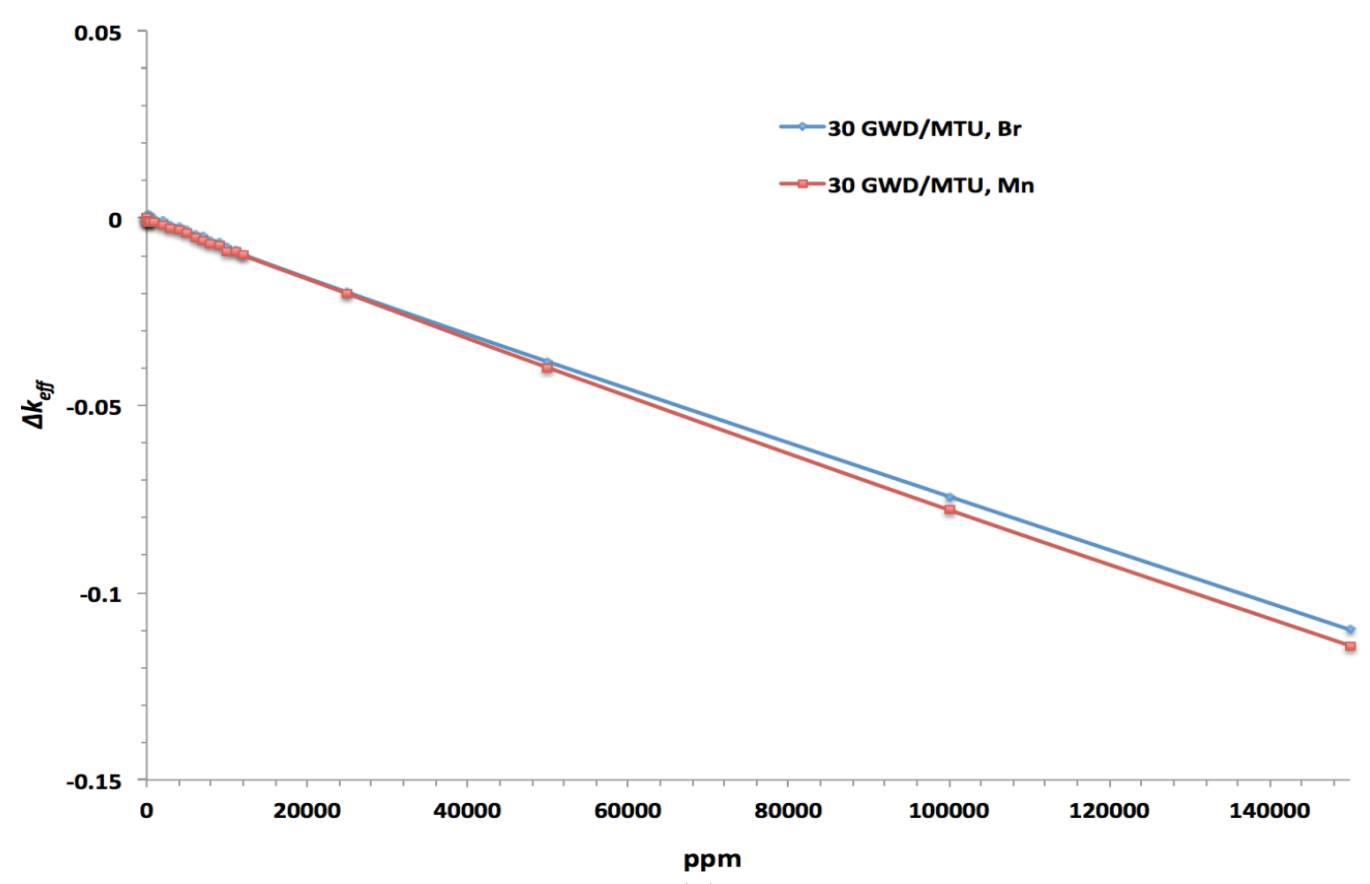

(b)

Figure 8. (a) Reactivity impact of $\mathrm{Br}$ and $\mathrm{Mn}$ concentration in groundwater for complete loss of neutron absorber; (b) reactivity impact of $\mathrm{Br}$ and $\mathrm{Mn}$ concentration in groundwater for degraded basket configuration. 


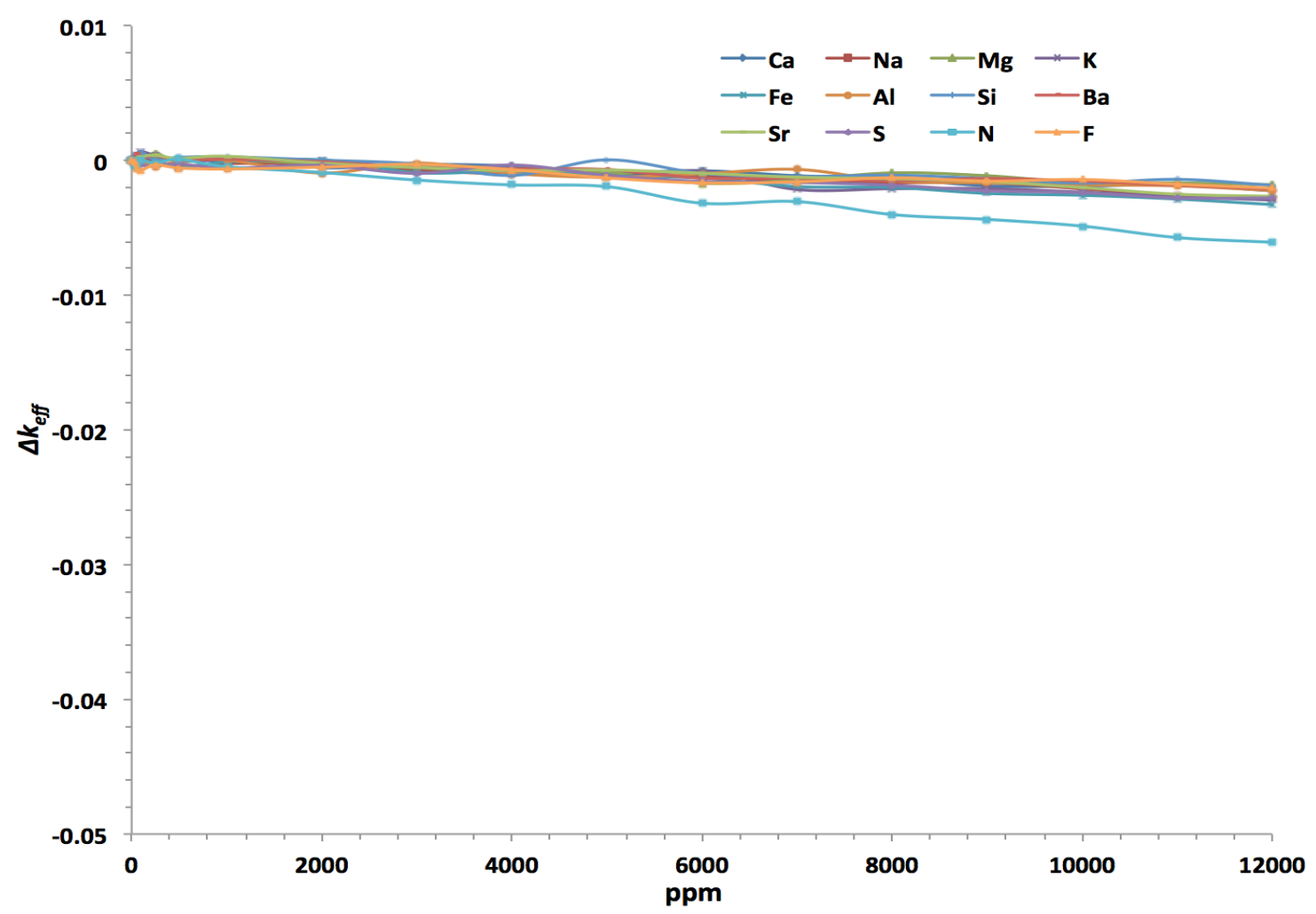

(a)

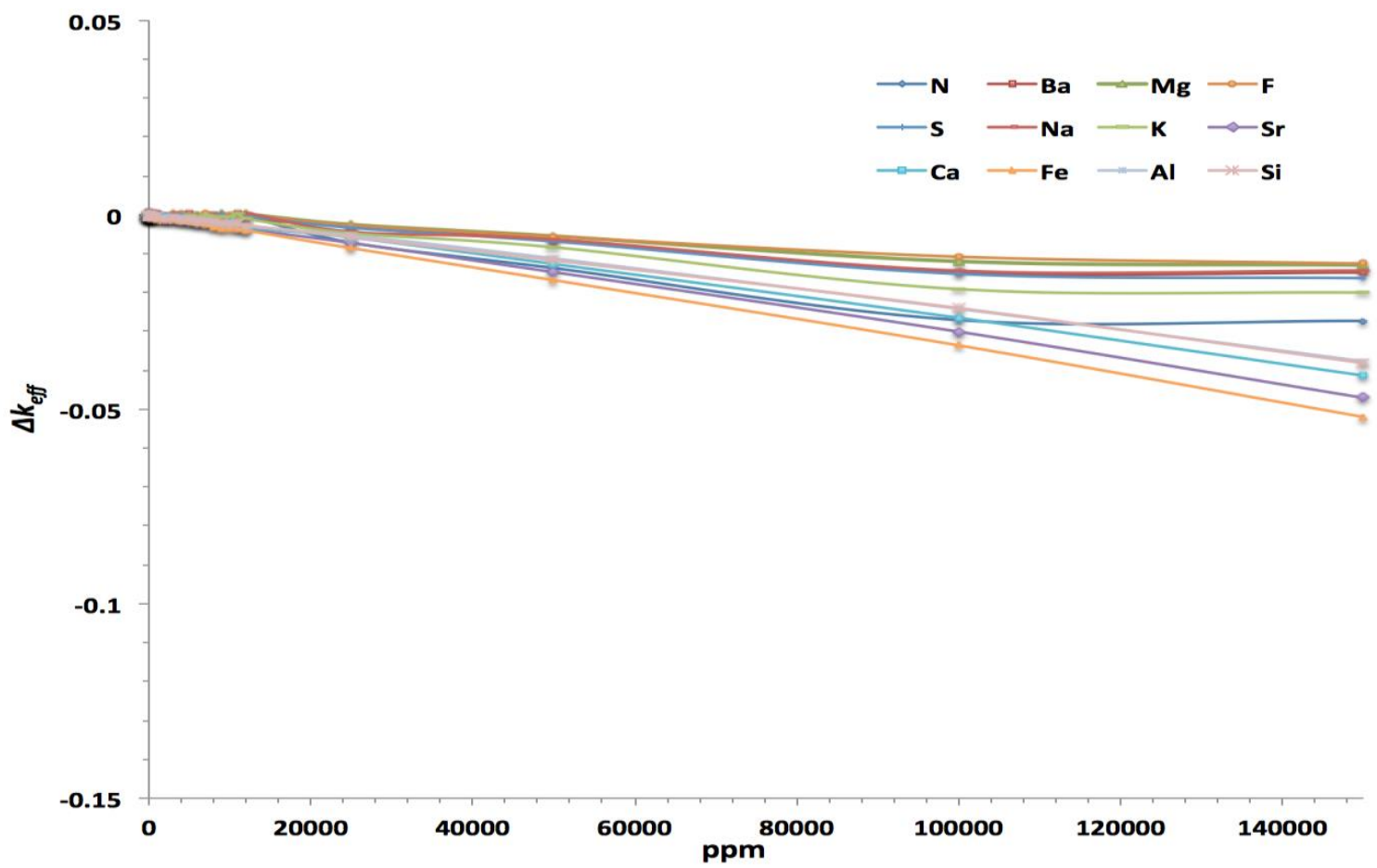

(b)

Figure 9. (a) Reactivity impact of the rest of the ions' concentration in groundwater for complete loss of neutron absorber; (b) reactivity impact of the rest of the ions' concentration in groundwater for degraded basket configuration. 


\subsection{Hypothetical High Reactivity Configuration}

A hypothetical high reactivity configuration that includes complete loss of basket structure and loss of lattice arrangement is studied. This configuration is developed for the purpose of using a conservative configuration with high reactivity to estimate the upper limit on the amount of $\mathrm{Cl}$ that may be needed to maintain subcriticality. Hence, this configuration is not intended to be credible. This scenario consists of intact fuel rods from the fuel assemblies distributed on a triangular pitch within the canister boundary. The following assumptions are used:

1. An MPC-32 loaded with W $17 \times 17 \mathrm{WL}$ assemblies is employed for this study, and $32 \mathrm{~W} 17 \times$ $17 \mathrm{WL}$ assemblies will contain 8,448 intact fuel rods for dispersal in the system. Because the model was simplified to use an infinite hexagonal array of intact fuel rods bounded by the canister boundary, the pitch of the hexagonal array is adjusted to model approximately 8,448 rods (e.g., calculated number of rods for the model used is 8,619 ) in the canister.

2. Guide tubes are not considered.

3. The fuel rods are modeled as fresh $\mathrm{UO}_{2}$ fuel with $4 \mathrm{wt} \%$ and $5 \mathrm{wt} \%{ }^{235} \mathrm{U}$ enrichment, and also with three uniform burnup distributions of 10,20 and $30 \mathrm{GWd} / \mathrm{MTU}$.

Although the objective of this study is to estimate the $\mathrm{Cl}$ requirement for a bounding scenario, a simple modeling approach, as described above, is used in this report. A sensitivity study is not performed to determine the absolute bounding fissile material configuration for the system. Therefore, future sensitivity studies are required to verify the bounding nature of the analysis presented here. Figure 10 illustrates the cross section of the canister with dispersed fuel rods as modeled in KENO, while Figure 11 presents the reactivity as a function of $\mathrm{Cl}$ concentration for this scenario. A saturated $\mathrm{NaCl}$ brine has a concentration of approximately 6 molal ( 158,000 ppm 5), which could ensure subcriticality of fresh fuel with $4 \%$ enrichment, or irradiated fuel with $5 \%$ enrichment and at least $10 \mathrm{GWd} / \mathrm{MTU}$ burnup (Figure 11). Because concentrated $\mathrm{Cl}$ brine would be needed to ensure subcriticality of these cases, the bounding-type approach is suited mainly for DPC disposal in salt.

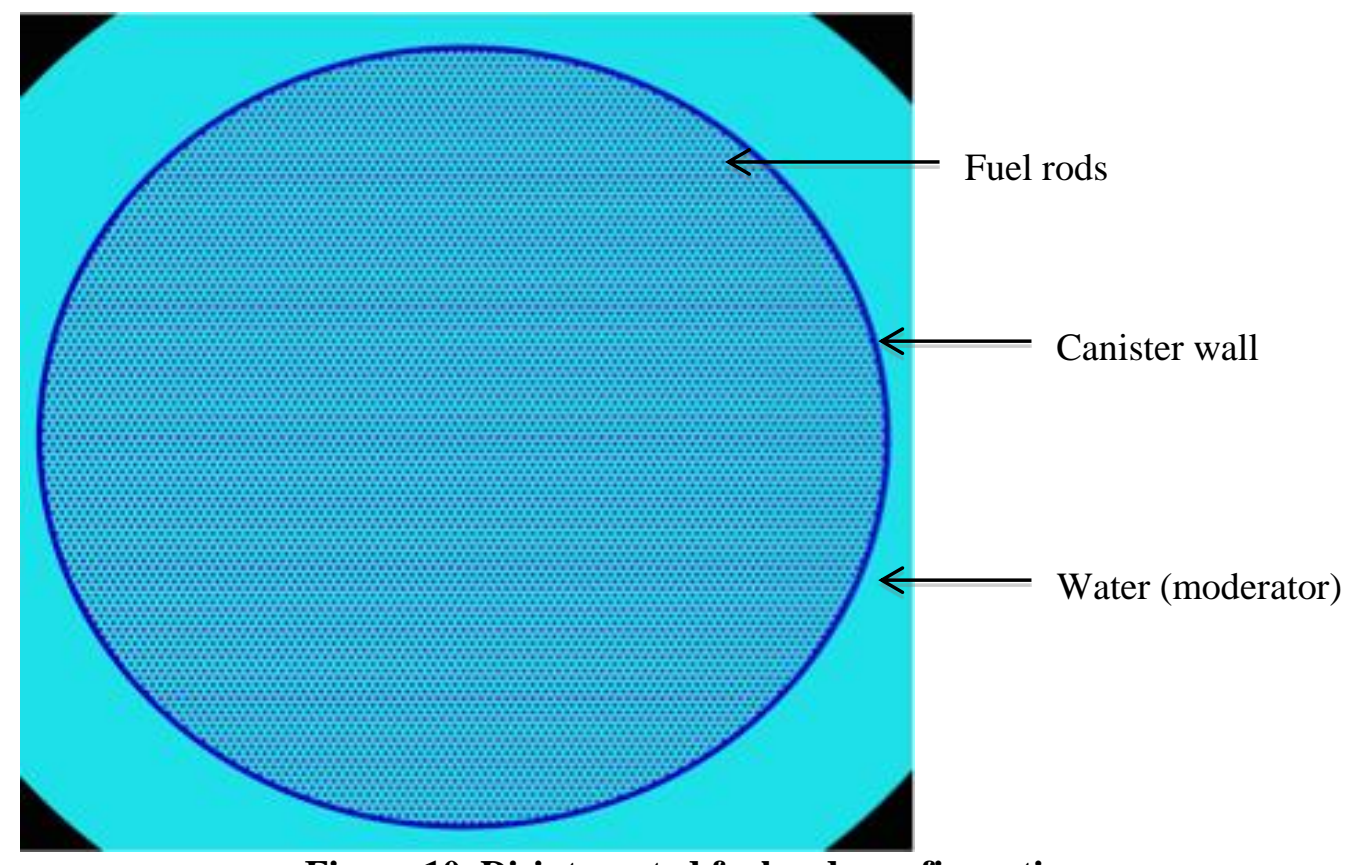

Figure 10. Disintegrated fuel rods configuration as modeled in KENO. 


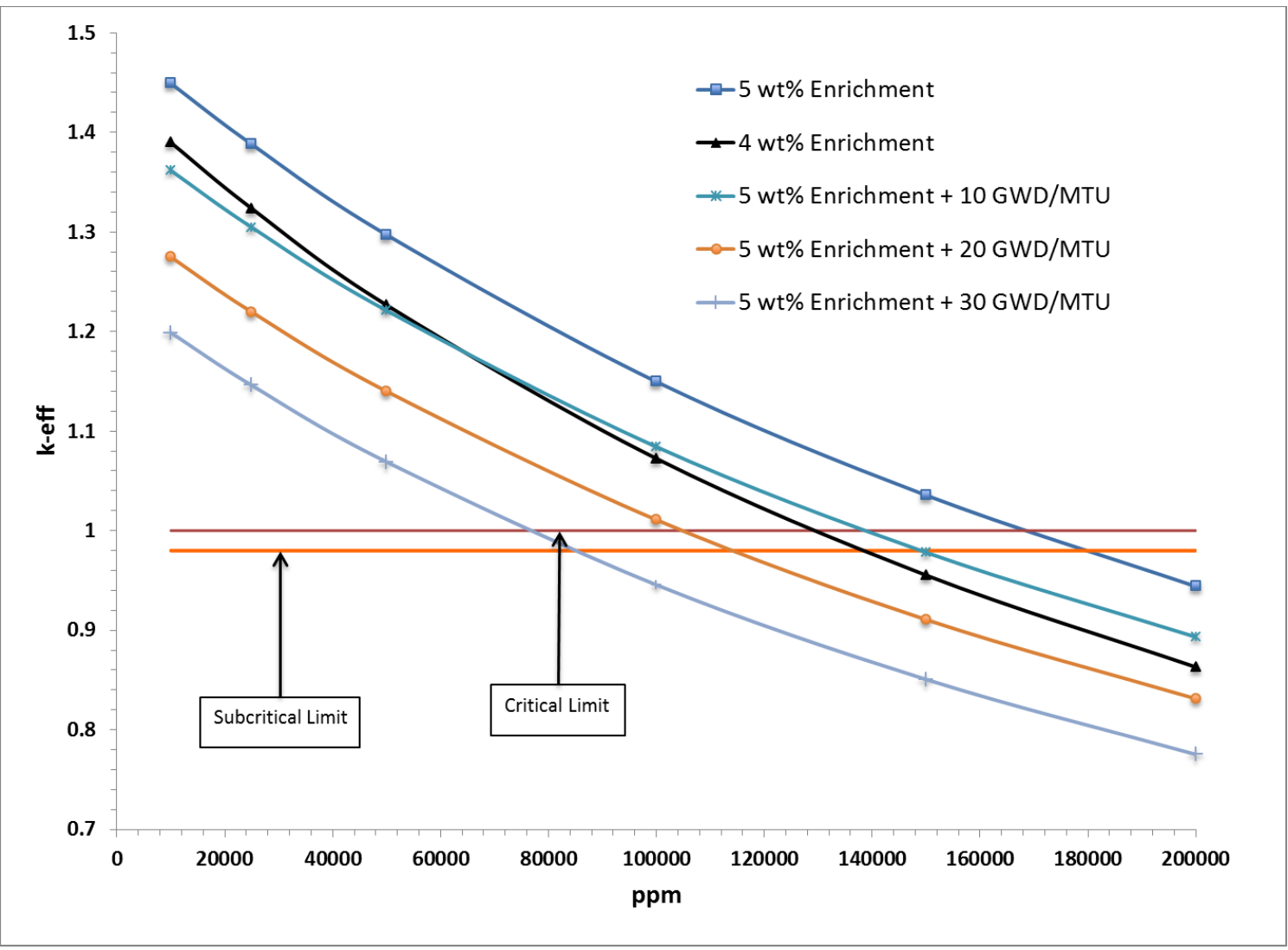

Figure 11. Reactivity impact of $\mathrm{Cl}$ concentration in groundwater for high reactivity configuration. 


\section{ANALYSIS BY APPLYING THE ACTUAL CANISTER-SPECIFIC LOADING}

The FSAR for a particular cask system documents the bounding models and calculations used to demonstrate that the system meets the regulatory requirements under all credible and hypothetical conditions (10 CFR 71.55 and 71.73). Note that FSAR calculations and approved content specifications are intended to be bounding in nature to certify cask systems for a variety of fuel characteristics without placing stringent used fuel-loading requirements. Therefore, in general, licensed cask systems possess excess and uncredited safety margins. The calculations performed in this report replicate representative conditions documented in the FSARs to the extent applicable, but with specific as-loaded fuel to determine the inherent uncredited safety margins. This section examines and quantifies these uncredited margins that could offset the reactivity increases because of canister flooding and associated structural changes over the repository time frame. It is assumed that the canister will be flooded with fresh water to produce significant moderation and that neutron absorber materials (panels) and coated carbon steel structural components will be completely degraded and transported away from the system. However, it is considered that the stainless steel structural components will maintain functional integrity over the repository time frame (e.g., 10,000 years). These assumptions should be scrutinized in the future when corrosion data are available to represent the specific disposal environment and time frame. Canisters loaded at five sites are investigated in this section including MY, CY, RS, TJ and SQ.

UNF-ST\&DARDS is employed for the as-loaded criticality analyses. UNF-ST\&DARDS performs neutronics calculations for each unique assembly design (e.g., Westinghouse $17 \times 17$ optimized fuel assembly [OFA] or standard assembly [STD]), initial enrichment and burnup, and decay time of each assembly stored at the different sites, and it generates explicit criticality models of each fuel assembly in its respective loading pattern as identified from canister-specific loading maps. Table 3 presents a typical RS DPC (NUHOMS-FC24P-P03) loading map. In this report, the criticality models are based on nominal dimensions. Additionally, the same criticality model is used for the design basis and as-loaded calculations. In the following subsections, the MY evaluations are described first, followed by the CY, RS, TJ, and SQ criticality analyses. 
Table 3. Representative Rancho Seco DPC (NUHOMS-FC24P-P03) loading map (Service date: 07-19-2001)

\begin{tabular}{lccc}
\hline Assembly ID & $\begin{array}{c}\text { Assembly average burnup } \\
\text { (MWd/MTU) }\end{array}$ & $\begin{array}{c}\text { Initial } \\
\text { enrichment }\end{array}$ & Assembly location \\
\hline NJ03GM & 10,000 & 3.062 & 1 \\
NJ02GF & 28,000 & 3.143 & 2 \\
1B06 & 25,397 & 2.673 & 3 \\
1B50 & 25,736 & 2.676 & 4 \\
NJ01GZ & 32,000 & 3.21 & 5 \\
NJ02F8 & 21,000 & 3.144 & 6 \\
NJ030H & 20,000 & 3.19 & 7 \\
1C07 & 31,914 & 2.99 & 8 \\
1B27 & 35,360 & 2.67 & 9 \\
NJ00DN & 38,016 & 3.2 & 10 \\
1B14 & 25,706 & 2.671 & 11 \\
1A17 & 16,998 & 2.007 & 12 \\
1C24 & 29,320 & 2.998 & 13 \\
1B54 & 28,420 & 2.664 & 14 \\
NJ00E0 & 36,545 & 3.19 & 15 \\
1C04 & 35,311 & 2.993 & 16 \\
1B20 & 27,611 & 2.671 & 17 \\
NJ03GA & 10,000 & 3.06 & 18 \\
NJ03FA & 10,000 & 3.056 & 19 \\
NJ017Y & 32,000 & 3.041 & 20 \\
NJ016G & 34,000 & 3.041 & 21 \\
NJ00DH & 28,054 & 3.188 & 22 \\
NJ0179 & 24,804 & 3.042 & 23 \\
NJ02FN & 21,000 & 3.141 & 24 \\
\hline
\end{tabular}

\subsection{Maine Yankee}

The MY Nuclear Power Plant, located at Wiscasset, Maine, began electricity production in 1972 and was closed for operation in 1996. The 1,434 SNF assemblies produced during MY's 25 years of service [20] are stored in 60 NAC, International's universal MPC system (UMS). [21] The UMS canisters (DPCs) used in MY can house up to 24 PWR fuel assemblies. Fuel assemblies inside the DPC are maintained in place by the stainless steel fuel tubes. Neutron absorber sheets are attached on the four sides of the fuel tube. The MY DPC basket components are stainless steel construction; hence, complete loss of neutron absorber is only considered as the potential degradation scenario. Figure 12 illustrates the MY 24assembly DPC basket without neutron absorber.

The UMS system applies $4.2 \mathrm{wt} \%$ enriched Westinghouse $17 \times 17$ OFA as the design basis. [21]

Table 4 shows the reactivity of the complete loss of neutron absorber scenario with the design basis assembly.

Table 4. Calculated degraded absorber $\boldsymbol{k}_{\text {eff }}$ for the MY DPC with design basis fuel

\begin{tabular}{ccc}
\hline $\begin{array}{c}\text { Enrichment } \\
\left(\mathbf{w} / \mathbf{o}^{\mathbf{2 3 5}} \mathbf{U}\right)\end{array}$ & $\begin{array}{c}\text { Burnup } \\
(\mathbf{G W d} / \mathbf{M T U})\end{array}$ & $\boldsymbol{k}_{\text {eff }}$ \\
\hline 4.2 & 0 & $1.16584 \pm 0.00040$ \\
\hline
\end{tabular}




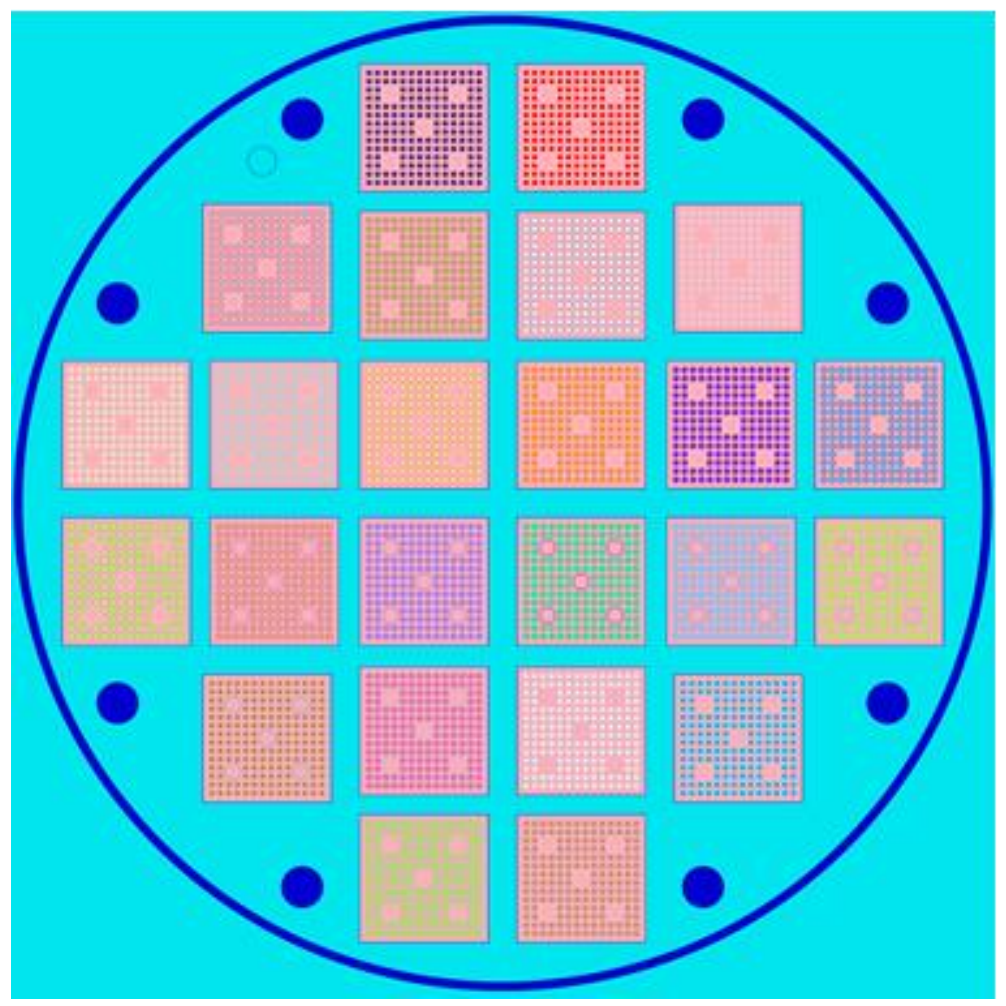

Figure 12. NAC UMS 24-assembly basket without neutron absorber panels as modeled in SCALE. 


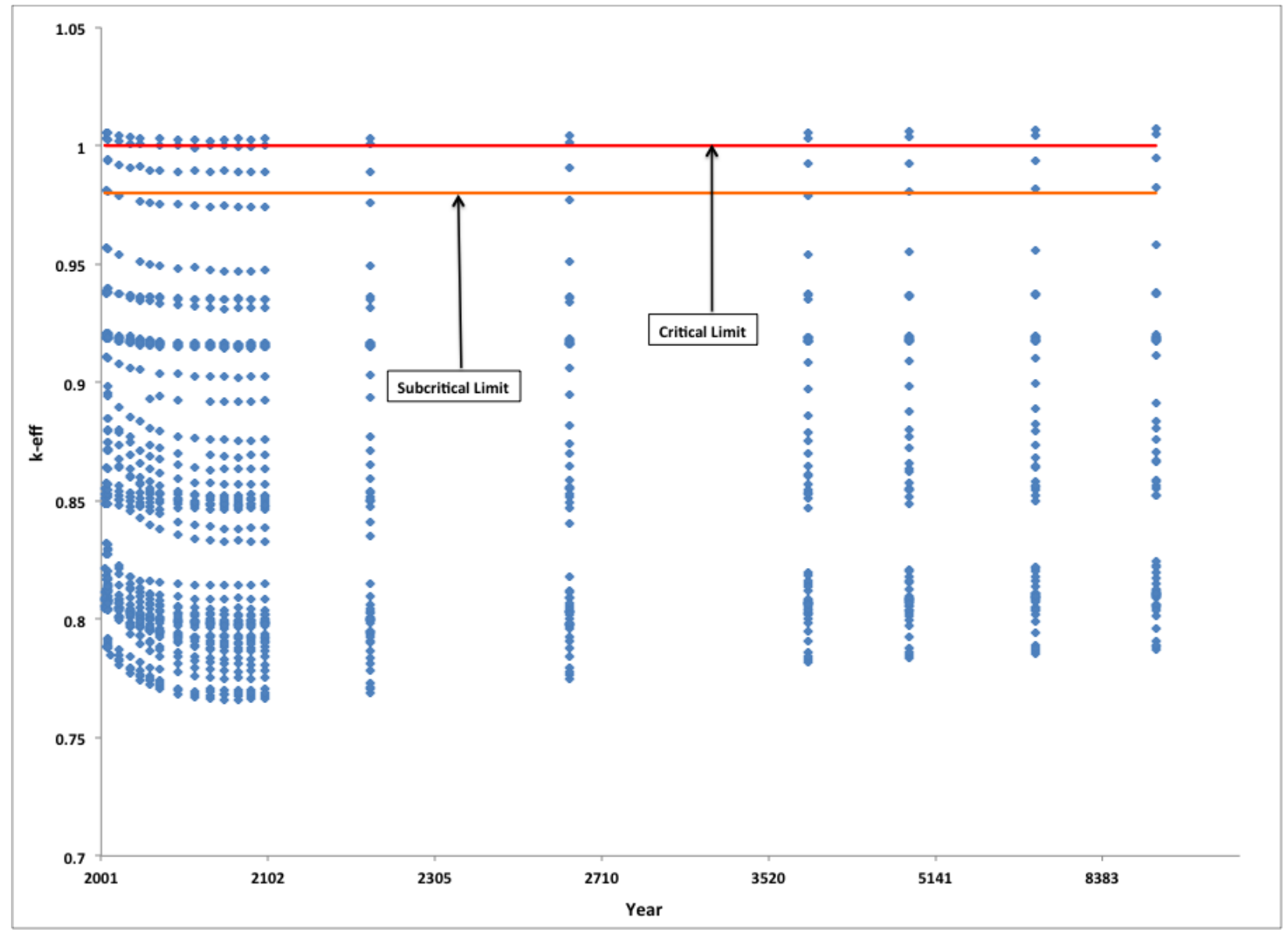

Figure 13. Calculated $\boldsymbol{k}_{\text {eff }}$ results for as-loaded MY 24-assembly DPCs with loss of neutron absorber panels.

Figure 13 presents the $k_{\text {eff }}$ of the loss of neutron absorber scenario as a function of time. Figure 13shows that a substantial number of DPCs over the analyzed time period are below the subcritical limit (0.98) defined in this report. This is attributed to the detailed modeling using actinides and fission product burnup credit in conjunction with canister-specific loading. As shown in Table 4, an analysis of this configuration using the design basis fuel assembly for which the DPC has been licensed results in $k_{\text {eff }}>1$ for all the DPCs. Table 5 shows the number of MY DPCs above the subcritical limit and the maximum $k_{\text {eff. }}$ Table 5 also reports the approximate amount of $\mathrm{Cl}$ required to maintain subcritical condition in the four identified canisters, which are above the subcritical limit with fresh water. The approximate $\mathrm{Cl}$ requirement is calculated by linearly interpolating the data presented in Figure 5(a).

Table 5. Final MY DPC statistics in the year 9999

\begin{tabular}{ll}
\hline Description & Values \\
\hline Number of canisters & 60 \\
Number of canisters with $k_{\text {eff }}>0.98$ (design basis analysis) & 60 \\
Number of canisters with $k_{\text {eff }}>0.98$ (as-loaded analysis) & 4 \\
Maximum $k_{\text {eff }}$ & 1.00696 \\
Approximate Cl requirement (linear interpolation) ${ }^{a}$ & $13,500 \mathrm{ppm}(\mathrm{mg} / \mathrm{L})$ \\
\hline${ }^{a}$ Cl reactivity worth based on a 32-assembly configuration is assumed \\
to be applicable for this DPC.
\end{tabular}




\subsection{Connecticut Yankee}

The CY Nuclear Power Plant began electricity production in 1967 and ceased operation in 1996. During CY's 30 years of electricity generation, 1,019 SNF assemblies [20] were discharged and are now stored in 40 NAC International's CY-MPC. However, the analyses are performed for 39 of the 40 MPCs. The fuel loading information for the canister with serial number 01, which is a 26 -assembly basket, is not available at this time. The CY-MPC (DPC) fuel basket is available for both 26 and 24 assembly configurations. These two baskets are identical except that the top weldment of the 24 assembly configuration consists of 24 fuel tube penetrations. [22] The 24 assembly basket is designed to accommodate higher enriched fuel assemblies than the 26 assembly basket. CY baskets are made of stainless steel. Therefore, the potential degradation scenario considered for CY is the loss of neutron absorber panels. Table 6 presents the number of each type of DPC loaded at the CY independent spent fuel storage installation (ISFSI). Figure 14 illustrates the 26 assembly basket without neutron absorber panels, while Figure 15 represents the 24 assembly basket without neutron absorber panels as modeled in SCALE.

Table 6. Type and number of DPCs in the CY ISFSI

\begin{tabular}{lc}
\hline $\begin{array}{c}\text { CY-MPC } \\
\text { configuration }\end{array}$ & Count \\
\hline 26 assembly & 37 \\
24 assembly & 3 \\
\hline
\end{tabular}

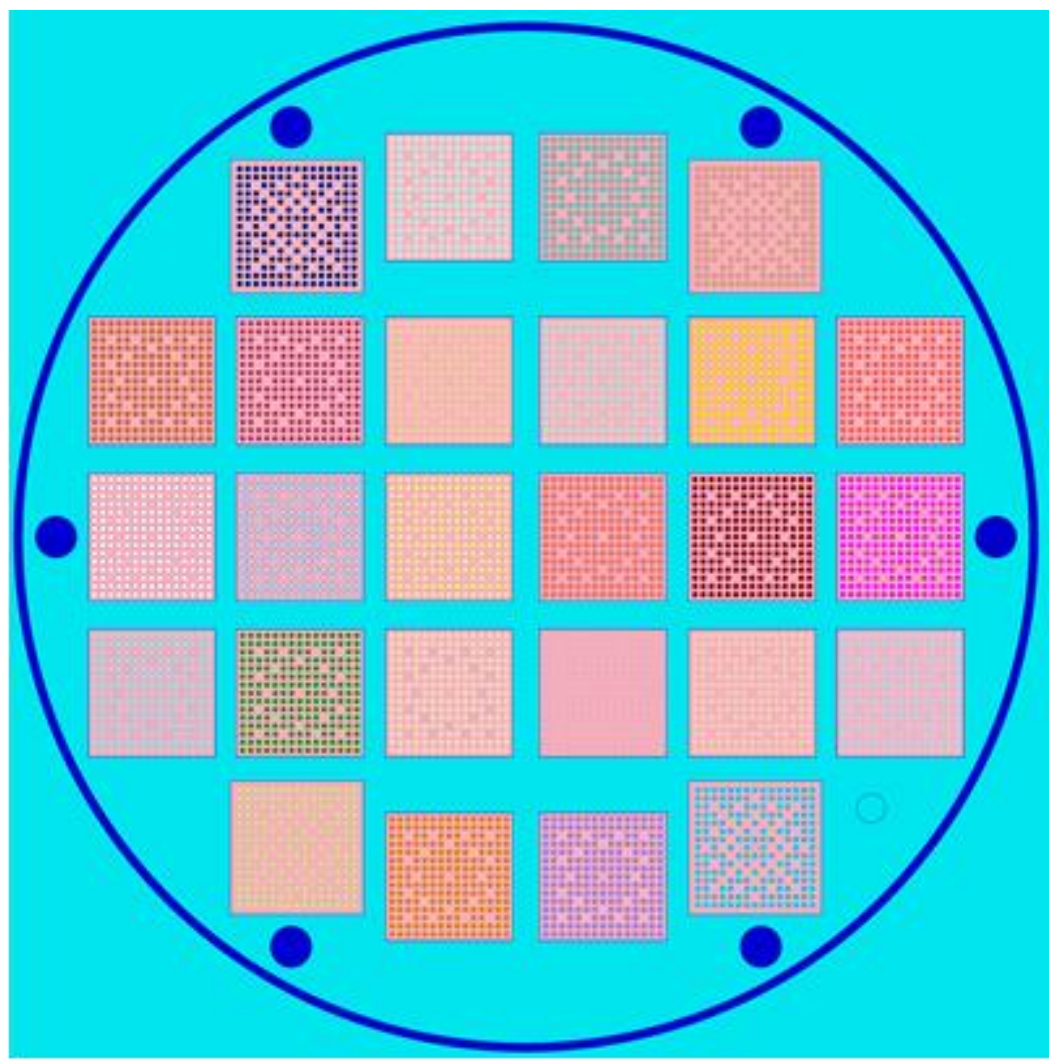

Figure 14. Radial layout of the CY MPC-26 without neutron absorber panels as modeled in SCALE. 


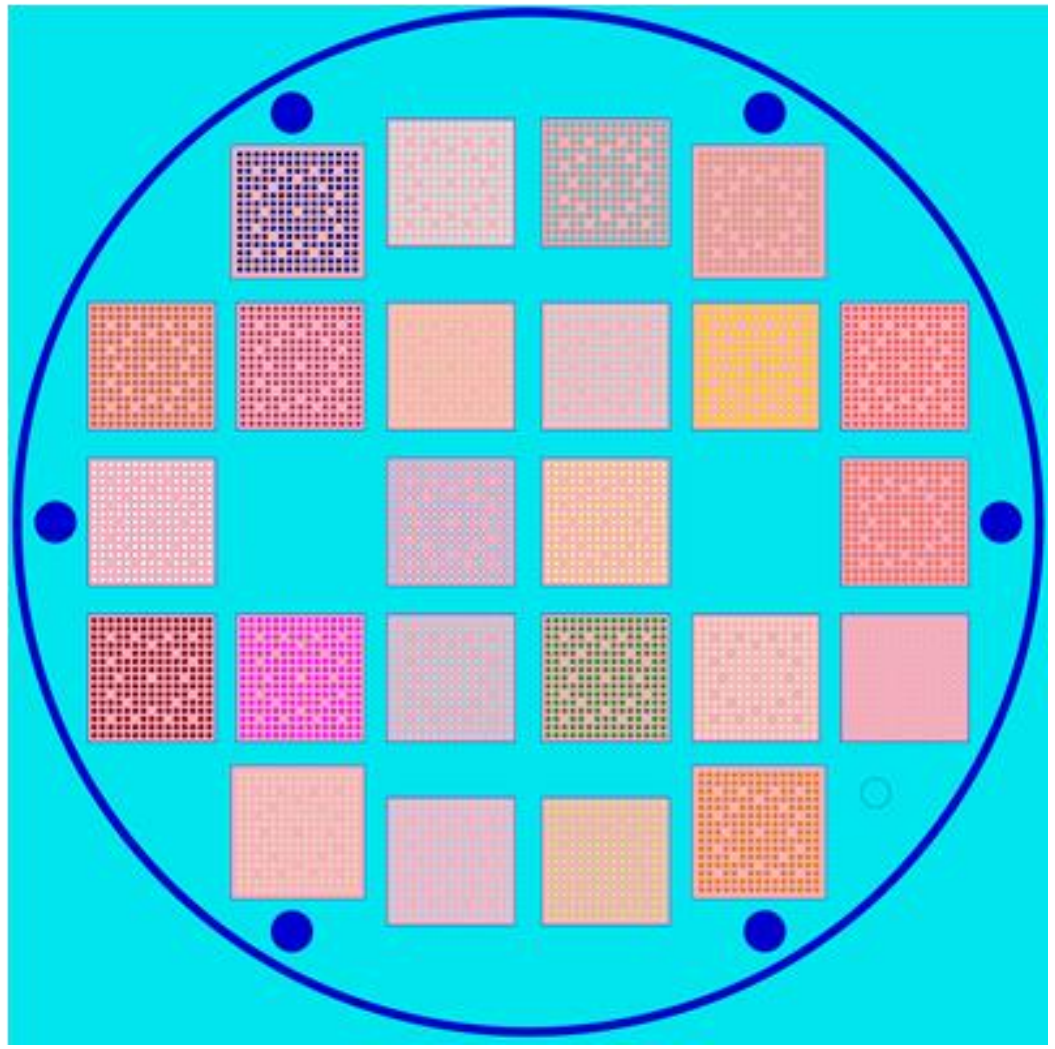

Figure 15. Radial layout of the CY MPC-24 without neutron absorber panels as modeled in SCALE.

CY licensing basis evaluations are performed using unirradiated (fresh) fuel assemblies. The licensing basis fuel assembly characteristics are defined as follows: [22]

- 26 assembly basket:

- $\quad 15 \times 15$ Zircaloy-clad fuel (Babcock and Wilcox [B\&W]) up to $3.93 \mathrm{wt} \%$ initial enrichment.

- $\quad 15 \times 15$ stainless steel-clad fuel up to $4.03 \mathrm{wt} \%$ initial enrichment. However, the stainless steel-clad assembly is bounded by the $3.93 \mathrm{wt} \%$ Zircaloy-clad fuel.

- 24 assembly basket:

- $\quad 15 \times 15$ Zircaloy-clad fuel (Westinghouse Vantage $5 \mathrm{H}$ ) up to $4.61 \mathrm{wt} \%$ initial enrichment.

- Assemblies allowed in the 26 assembly basket.

Table 7 shows the reactivity of the complete loss of neutron absorber scenario with the design basis assembly.

Table 7. Calculated degraded absorber $\boldsymbol{k}_{\text {eff }}$ for the CY DPC with design basis fuel

\begin{tabular}{cccc}
\hline MPC type & $\begin{array}{c}\text { Enrichment } \\
\left(\mathbf{w} / \mathbf{o}^{235} \mathbf{U}\right)\end{array}$ & $\begin{array}{c}\text { Burnup } \\
(\mathbf{G W d} / \mathbf{M T U})\end{array}$ & $\boldsymbol{k}_{\text {eff }}$ \\
\hline 24 assembly & 4.61 & 0 & $1.14546 \pm 0.00023$ \\
\hline 26 assembly & 3.93 & 0 & $1.14809 \pm 0.00024$ \\
\hline
\end{tabular}

Figure 16 presents the $k_{\text {eff }}$ for the loss of neutron absorber scenario as a function of time. Figure 16 shows that majority of the DPCs over the analyzed time period are below the subcritical limit (0.98) defined in this report as a result of the detailed modeling using actinides and fission product burnup credit in 
conjunction with canister-specific loading. As shown in Table 7, an analysis of the loss of neutron absorber configuration using the design basis fuel assemblies for which the canisters have been licensed yields $k_{\text {eff }}>1$ for all canisters. Table 8 reports the number of CY DPCs above the subcritical limit and the maximum $k_{\text {eff. }}$ Table 8 also shows the approximate amount of $\mathrm{Cl}$ required to maintain subcritical condition in the three identified DPCs, which are above the subcritical limit with fresh water. The $\mathrm{Cl}$ requirement is calculated by linearly interpolating the data presented in Figure 5(a).

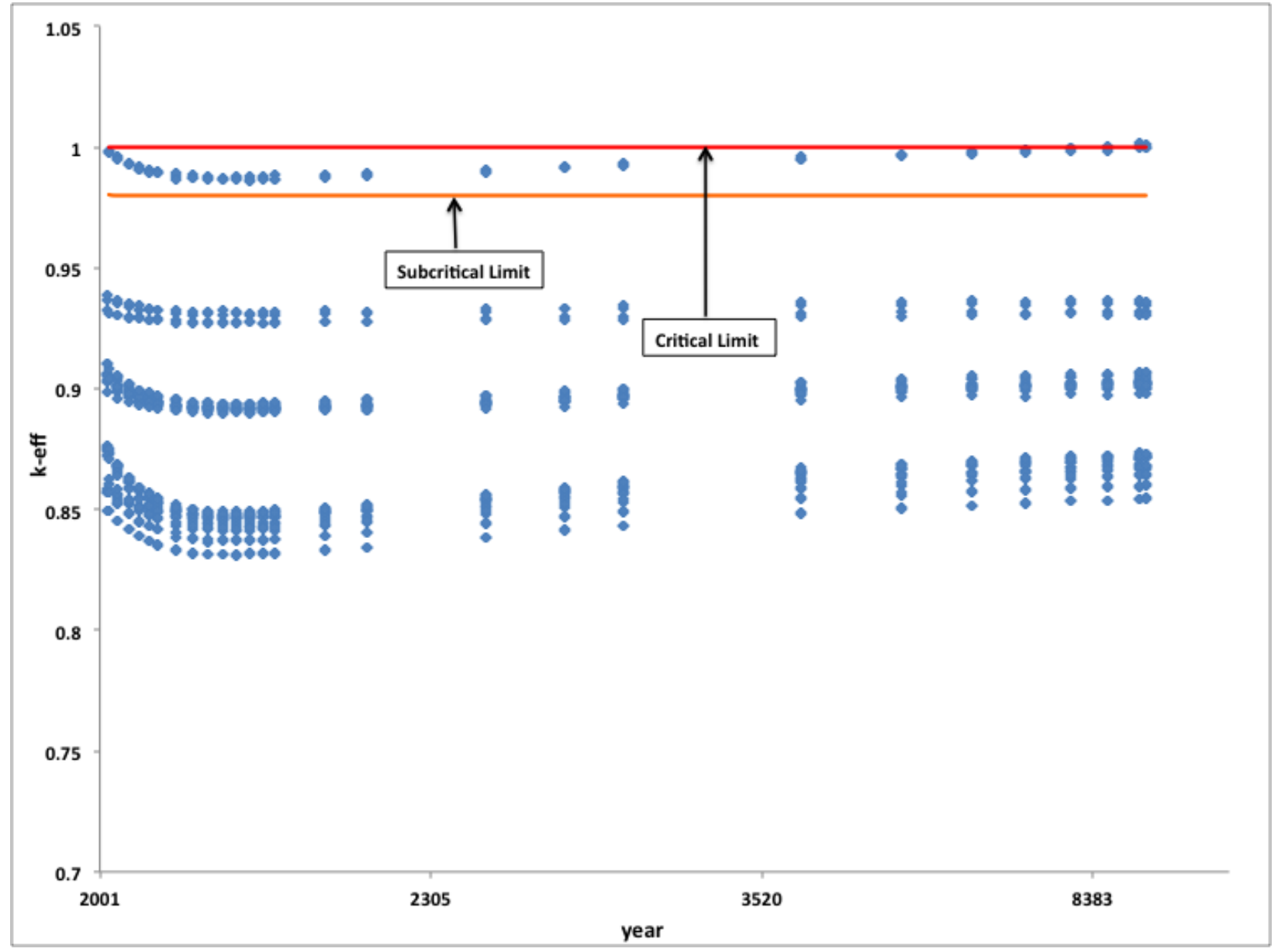

Figure 16. Calculated $\boldsymbol{k}_{\text {eff }}$ results for as-loaded CY DPCs with loss of neutron absorber panels.

Table 8. Final CY DPC statistics in the year 9999

\begin{tabular}{lc}
\hline \multicolumn{1}{c}{ Description } & Values \\
\hline Number of canisters & 39 \\
Number of canisters with $k_{\text {eff }}>0.98$ (design basis analysis) & 39 \\
Number of canisters with $k_{\text {eff }}>0.98$ (as-loaded analysis) & 3 \\
Maximum $k_{\text {eff }}$ & 1.00118 \\
Approximate Cl requirement (linear interpolation) ${ }^{\mathrm{a}}$ & $11,000 \mathrm{ppm}(\mathrm{mg} / \mathrm{L})$ \\
\hline${ }^{a}$ Cl reactivity worth based on a 32 assembly configuration is assumed to be \\
applicable for this DPC.
\end{tabular}




\subsection{Rancho Seco}

The Rancho Seco (RS) Nuclear Generation Station, operated by the Sacramento Municipal Utility District, began electricity production in 1975 and ceased operation in 1989. During its nuclear electricity generation lifetime, the plant produced 493 SNF assemblies. [20] These 493 assemblies are stored in 21 NUHOMS dry shielded canisters (DSCs). [23] RS DSCs (DPCs) can accommodate 24 intact PWR assemblies. Design basis criticality analyses are performed applying $3.43 \mathrm{wt} \%$ enriched B\&W $15 \times 15$ Mark B4 PWR intact fuel assemblies. [23]

As-loaded criticality calculations are performed for 20 DPCs. One of the DPCs (13 assembly configuration) only stores damaged fuel assemblies. The nature of damage to this fuel is not known sufficiently for criticality analysis, hence crediting burnup for such damaged fuel may lead to nonconservative $k_{\text {eff }}$ estimation and is not being implemented at this time. This failed fuel DPC is being treated as the design basis as defined in Ref. [23].

Fuel assemblies inside the DPCs are maintained in place by guide sleeves. Each guide sleeve assembly is made of stainless steel and neutron absorber panels. Neutron absorber panels are attached to the sides of every guide sleeve that faces another guide sleeve. The gaps between the neutron absorber panels facing each other form the flux-trap design. The guide sleeves are arranged inside the canister using axial spacer disks made of coated carbon steel to maintain the flux-trap configuration. Figure 17 illustrates the guide sleeves and the coated carbon steel spacer disk located axially. Because of the carbon steel component present in the DPC, the following two degradation scenarios are considered for RS.

1. Loss of neutron absorber. In this configuration, the neutron absorber is replaced by a moderator (freshwater). It is assumed that the degraded absorber materials are transported away from the canister while the guide sleeves are still in their original positions supported by the spacer disks. This hypothetical configuration could result from the likely situation in which the corrosionresistant properties of the fuel assemblies, stainless steel guide sleeves, and coated carbon steel spacer disks are superior to that of the neutron absorber. Figure 18(a) depicts the cross section of the canister as modeled in SCALE, while Figure 18(b) presents the $k_{\text {eff }}$ as a function of time. Figure 18(b) shows that the $k_{\text {eff }}$ values over the analyzed time interval are all substantially below the subcritical limit defined in this report (0.98) using actinides and fission product burnup credit in conjunction with canister-specific loading. However, the design basis $k_{\text {eff }}$ for this scenario, presented in Table 9, is greater than 1.

2. Degraded basket. In this case, the loss of neutron absorber configuration is extended to include complete degradation of the coated carbon steel spacer disks, resulting in a close-packed configuration of collapsed guide sleeves. The degraded material is replaced by freshwater. Figure 19(a) illustrates the cross section of the collapsed guide sleeves as modeled in KENO. The results of this analysis are presented in Figure 19(b), which shows that the $k_{\text {eff }}$ values associated with some of the DPCs are above the subcritical limit defined in this report. An analysis of this configuration using the design basis fuel, as shown in Table 9, for which the DPC has been licensed results in $k_{\text {eff }}>1$ for all the DPCs.

Table 9. Calculated $\boldsymbol{k}_{e f f} \mathrm{~S}$ for the RS degradation scenarios with design basis fuel

\begin{tabular}{lccc}
\hline Degradation scenario & $\begin{array}{l}\text { Enrichment } \\
\left(\mathbf{w} / \mathbf{o}^{235} \mathbf{U}\right)\end{array}$ & $\begin{array}{c}\text { Burnup } \\
\text { (GWd/MTU) }\end{array}$ & $\boldsymbol{k}_{\text {eff }}$ \\
\hline Loss of neutron absorber & 3.43 & 0 & $1.09358 \pm 0.00024$ \\
\hline $\begin{array}{l}\text { Loss of neutron absorber } \\
\text { and spacer disks }\end{array}$ & 3.43 & 0 & $1.27754 \pm 0.00019$ \\
\hline
\end{tabular}




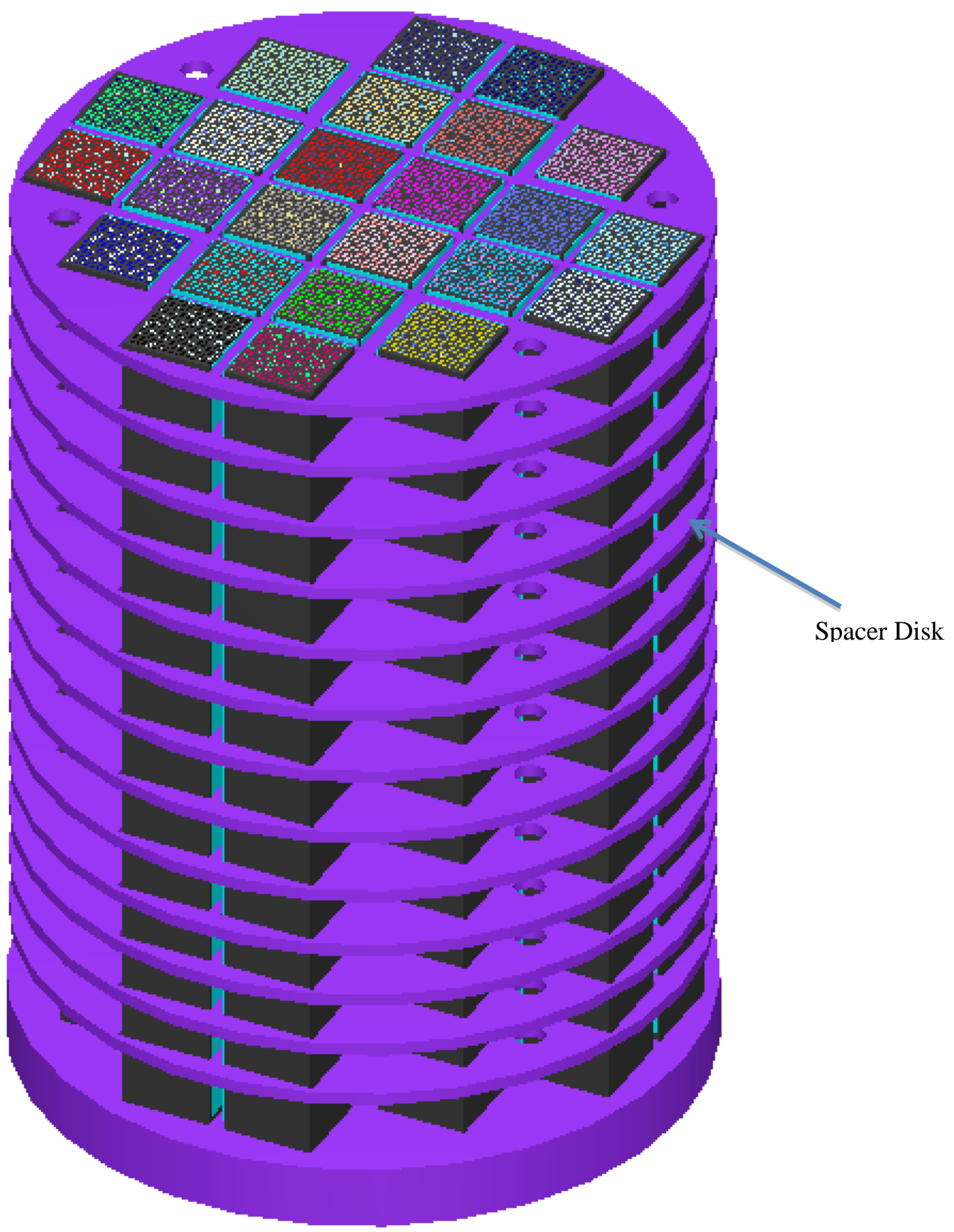

Figure 17. 3D representation of the RS DPC as modeled in SCALE. 


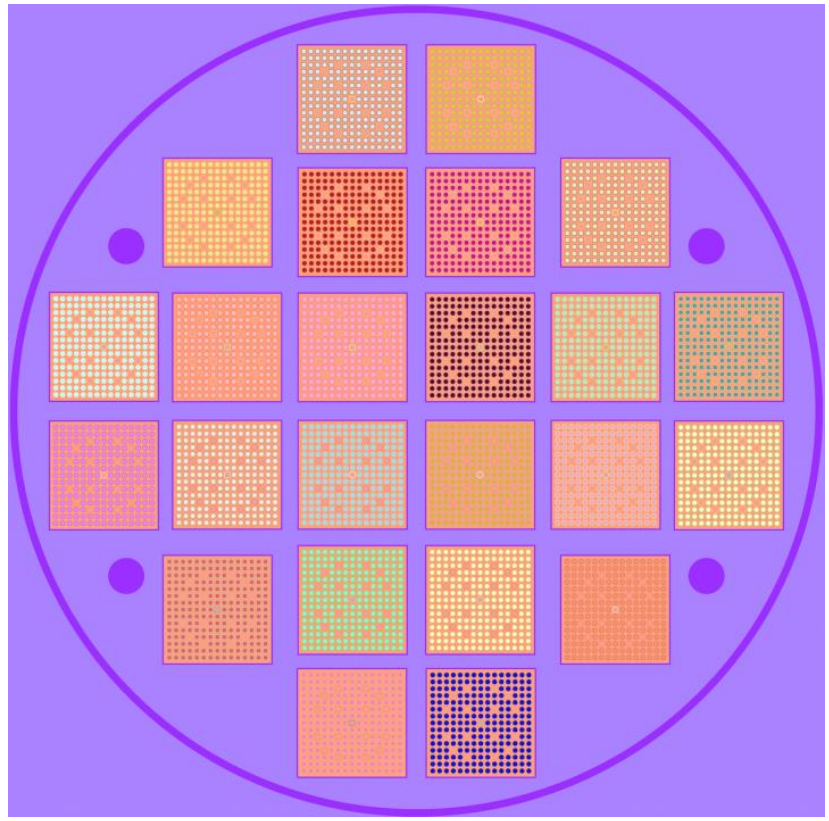

(a)

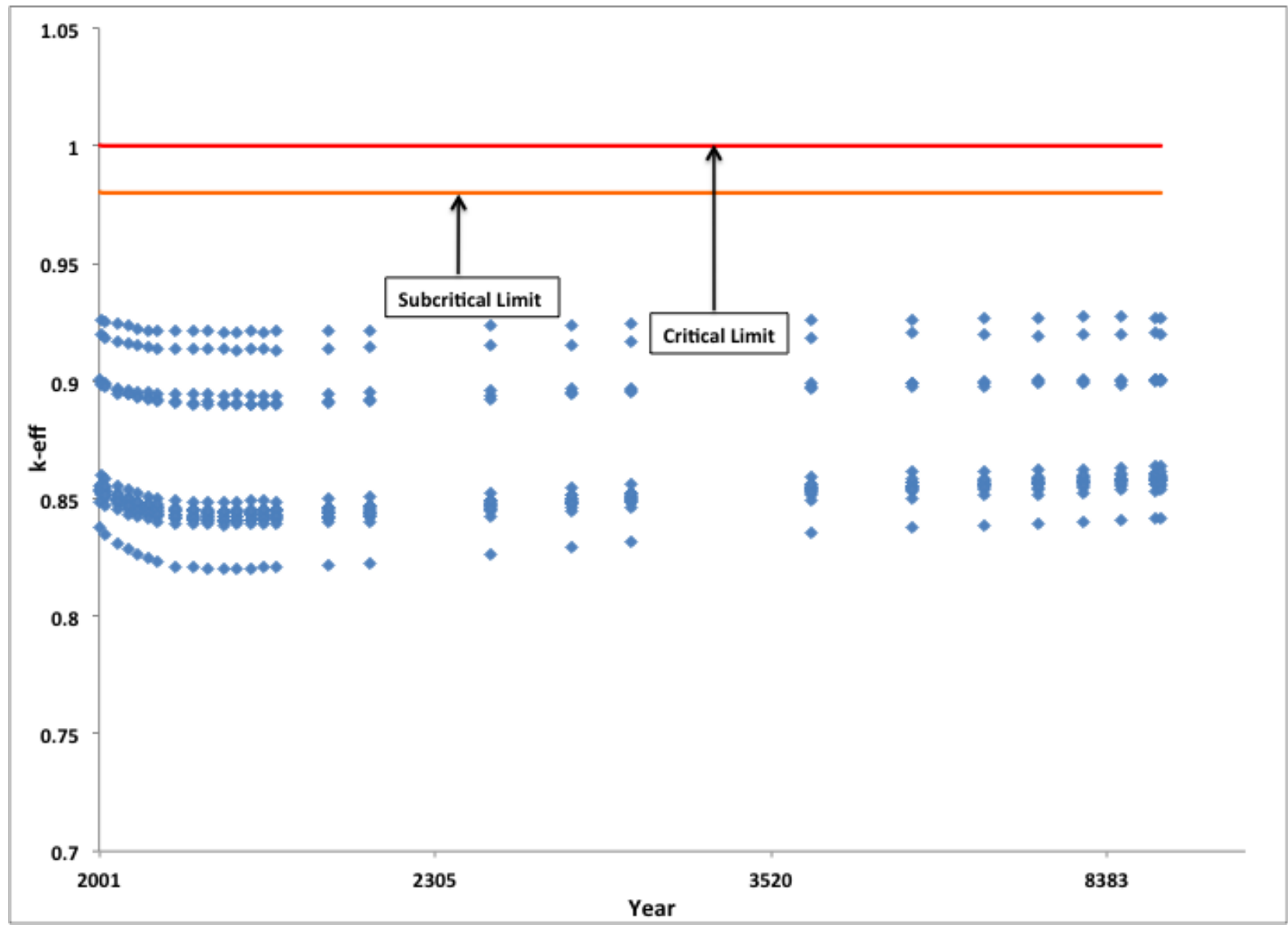

(b)

Figure 18. (a) Loss of neutron absorber configuration (RS) as modeled in KENO; (b) $k_{\text {eff }}$ as a function of time based on actual loading. 


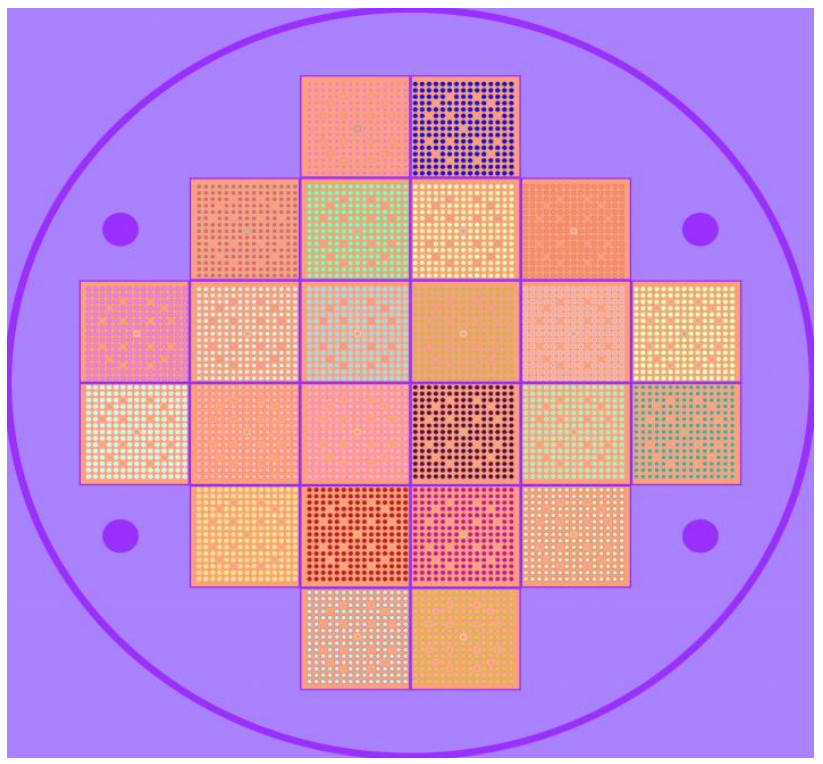

(a)

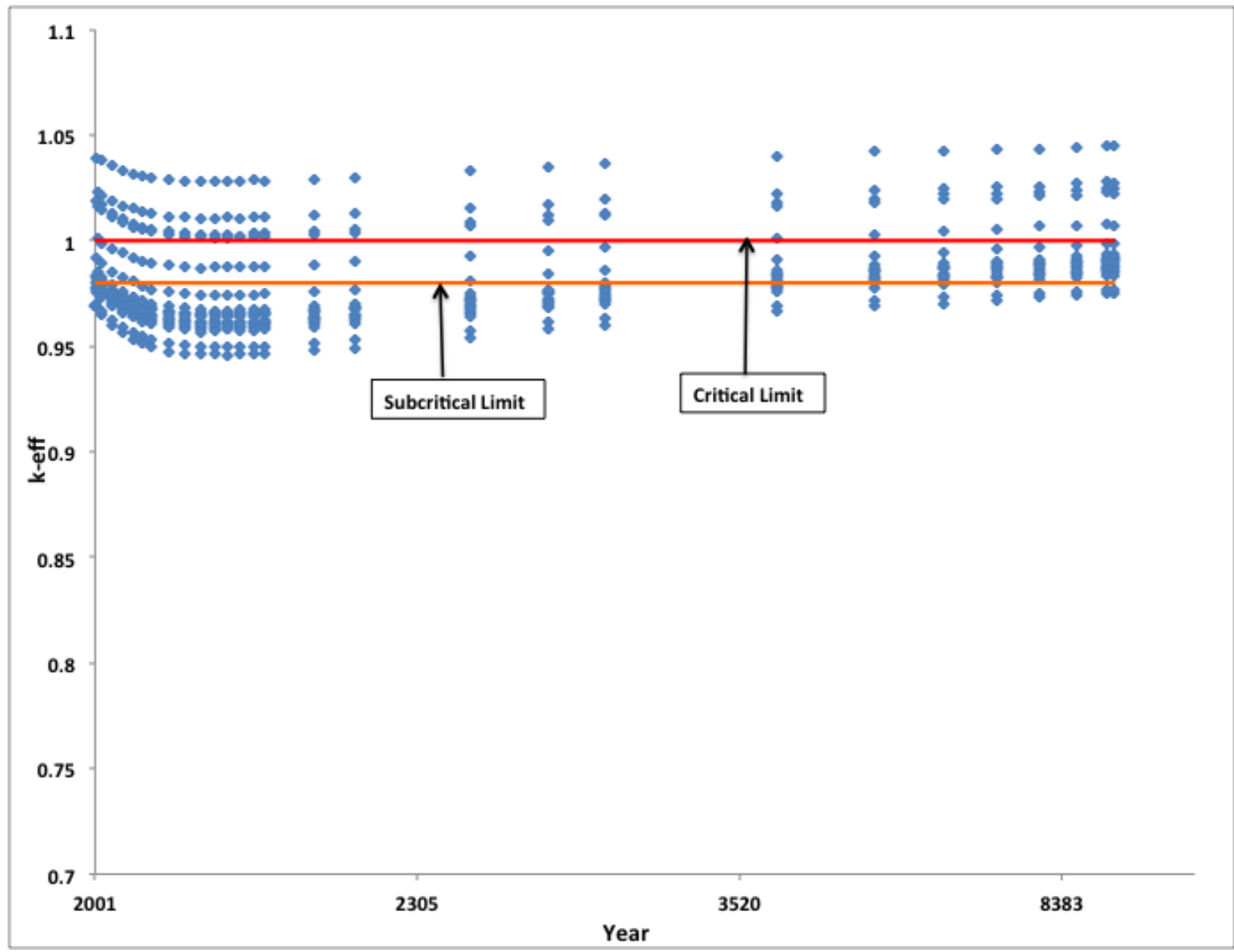

(b)

Figure 19. (a) Degraded spacer disks configuration (RS) as modeled in KENO; (b) $\boldsymbol{k}_{\text {eff }}$ as a function of time based on actual loading. 
Table 10 summarizes RS DPC results for the two analyzed degradation scenarios. Estimated $\mathrm{Cl}$ requirement for the degraded basket scenario to maintain subcritical configuration over the repository time frame is also presented in Table 10.

Table 10. Final RS statistics in the year 9999

\begin{tabular}{|c|c|c|}
\hline Description & $\begin{array}{l}\text { Values for loss of } \\
\text { neutron absorber }\end{array}$ & $\begin{array}{c}\text { Values for degraded } \\
\text { basket }\end{array}$ \\
\hline Number of DSCs & 20 & 20 \\
\hline Number of DSCs with $k_{\text {eff }}>0.98$ (design basis analysis) & 20 & 20 \\
\hline Number of DSCs with $k_{\text {eff }}>0.98$ (as-loaded analysis) & 0 & 18 \\
\hline Maximum $k_{e f f}$ & 0.92691 & 1.04468 \\
\hline Approximate $\mathrm{Cl}$ requirement (linear interpolation) ${ }^{a}$ & not applicable & 32,500 ppm (mg/L) \\
\hline
\end{tabular}

${ }^{a} \mathrm{Cl}$ reactivity worth based on a 32-assembly configuration is assumed to be applicable for this DPC.

\subsection{Trojan}

The Trojan (TJ) Nuclear Power Plant, located at Rainier, Oregon, began electricity production in 1976 and ceased operation in 1993. TJ SNF assemblies are stored in 34 Holtec International's MPC-24E/EF canisters (DPC). [24] The MPC-24E/EF can accommodate up to 24 SNF assemblies. The TJ basket is stainless steel construction; therefore, complete loss of neutron absorber is the only degradation scenario considered. Figure 20 illustrates the MPC-24E/EF basket without neutron absorber.

The MPC-24E/EF system applies $4.4 \mathrm{wt} \%$ enriched W $17 \times 17$ STD as the design basis. [24] Table 4 shows the reactivity of the complete loss of neutron absorber scenario with the design basis assembly.

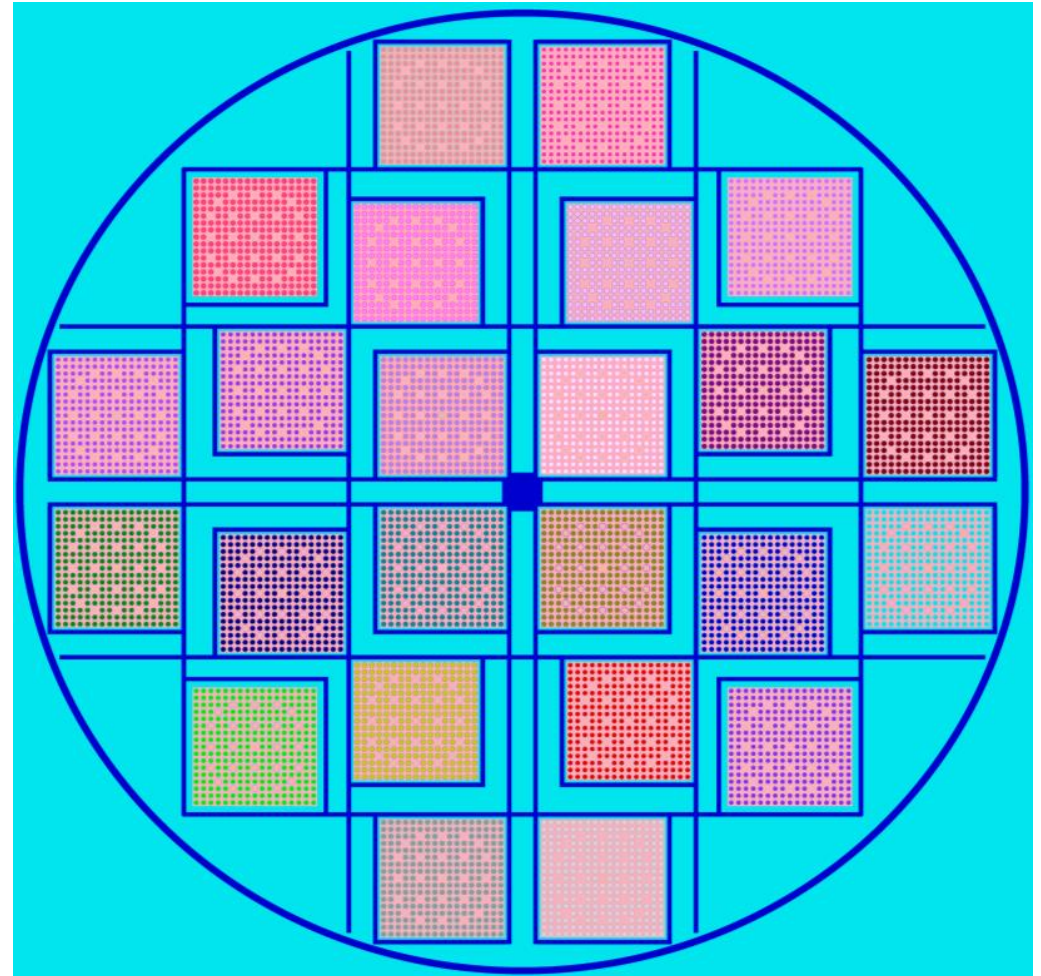

Figure 20. Radial layout of the MPC-24E/EF without neutron absorber panels as modeled in SCALE. 
Figure 21 presents the $k_{\text {eff }}$ of the loss of neutron absorber scenario as a function of time. Figure 21 shows that all of the canisters over the analyzed time period are below the subcritical limit (0.98) defined in this report. As shown in Table 11, an analysis of this configuration using the design basis fuel assembly for which the canister has been licensed yields $k_{\text {eff }}>1$ for all the canisters. Table 12 summarizes the TJ nuclear site results.

Table 11. Calculated degraded absorber $\boldsymbol{k}_{\text {eff }}$ for the TJ DPC with design basis fuel

\begin{tabular}{ccc}
\hline $\begin{array}{c}\text { Enrichment } \\
\left(\mathbf{w} / \mathbf{o}^{235} \mathbf{U}\right)\end{array}$ & $\begin{array}{c}\text { Burnup } \\
(\mathbf{G W d} / \mathbf{M T U})\end{array}$ & $\boldsymbol{k}_{\text {eff }}$ \\
\hline 3.7 & 0 & $1.00569 \pm 0.00020$ \\
\hline
\end{tabular}

Table 12. Final TJ statistics in the year 9999

\begin{tabular}{lc}
\hline \multicolumn{1}{c}{ Description } & Values \\
\hline Number of canisters & 34 \\
Number of canisters with $k_{\text {eff }}>0.98$ (design basis analysis) & 34 \\
Number of canisters with $k_{\text {eff }}>0.98$ (as-loaded analysis) & 0 \\
Maximum $k_{\text {eff }}$ & 0.90476 \\
Approximate $\mathrm{Cl}$ requirement (linear interpolation) & $\mathrm{NA}$ \\
\hline
\end{tabular}

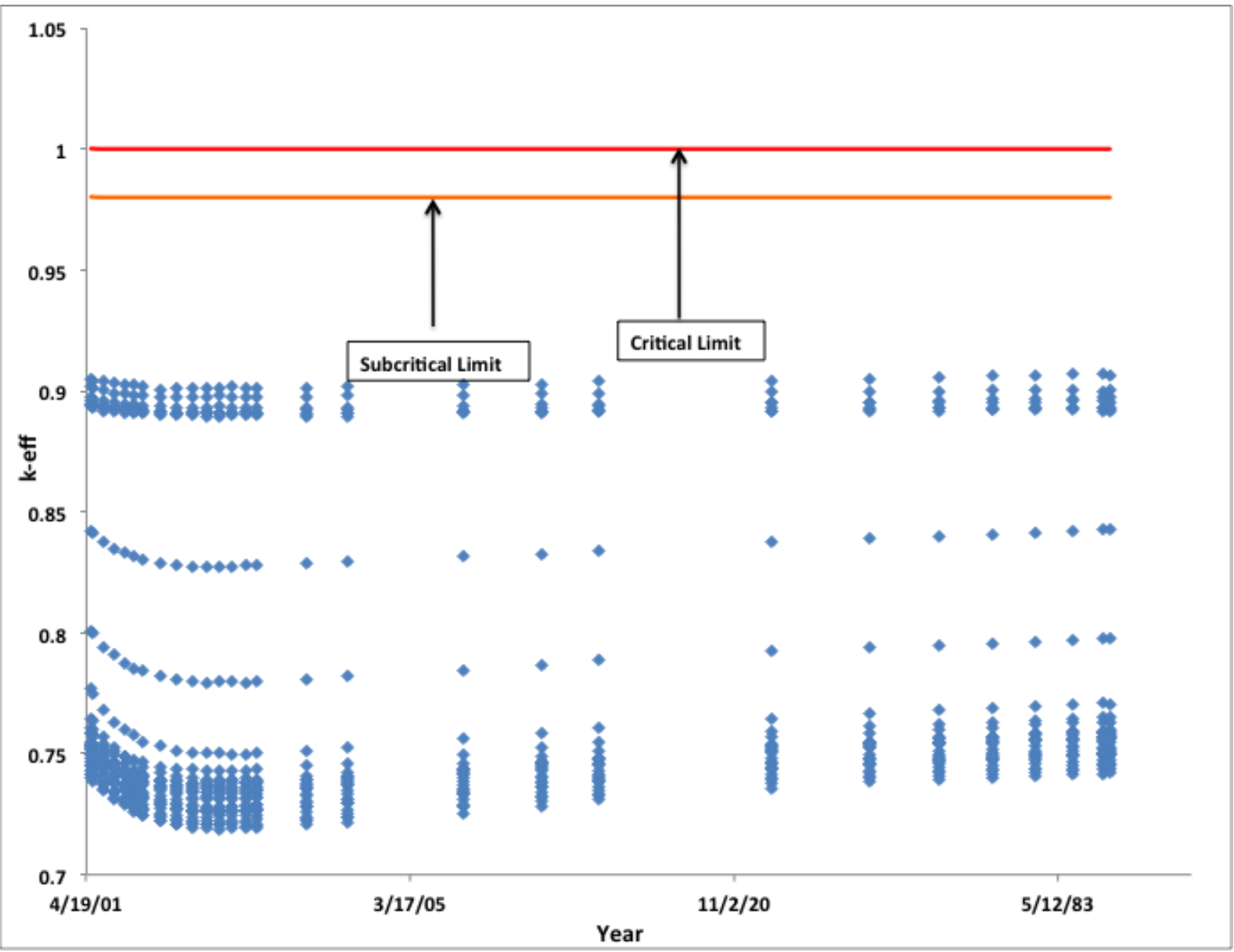

Figure 21. Calculated $\boldsymbol{k}_{\text {eff }}$ results for as-loaded TJ

DPCs with loss of neutron absorber panels. 


\subsection{Sequoyah}

The Sequoyah Nuclear Plant (SQ) is the only operating plant investigated in this report. SQ unit 1 started its operation in 1981, while unit 2 started producing electricity in 1982. SQ employs Holtec international's HI-STORM 100 systems with MPC-32 canisters (DPCs) for storing SNF. [25] The MPC32 is an all stainless steel canister that can accommodate 32 PWR assemblies and uses an egg-crate basket design with a single neutron absorber panel between adjacent assemblies. Accordingly, loss of neutron absorber is the only degradation scenario considered for the MPC-32. Figure 22 presents a cross section view of the SCALE MPC-32 model used for criticality analyses. Twenty-six loaded MPC-32 canisters for SQ are examined in this report.

Because of its high density, the MPC-32 is licensed (for transportation) by applying burnup credit. Table 13 presents the design basis reactivity for the complete loss of neutron absorber case. Design basis parameters are selected from Ref. 26.

Table 13. Calculated degraded absorber $k_{\text {eff }}$ for the SQ DPC with design basis fuel

\begin{tabular}{ccccc}
\hline Fuel type [26] & $\begin{array}{c}\text { Configuration } \\
{[\mathbf{2 6}]}\end{array}$ & $\begin{array}{c}\text { Enrichment } \\
\left(\mathbf{w} / \mathbf{o}^{\mathbf{2 3 5}} \mathbf{U}\right)\end{array}$ & $\begin{array}{c}\text { Burnup } \\
(\mathbf{G W d} / \mathbf{M T U})\end{array}$ & $\boldsymbol{k}_{\text {eff }}$ \\
\hline $17 \times 17 \mathrm{~A}, \mathrm{~B}, \mathrm{C}$ & $\mathrm{B}$ & 4.0 & 49 & $1.06812 \pm 0.00040$ \\
\hline
\end{tabular}

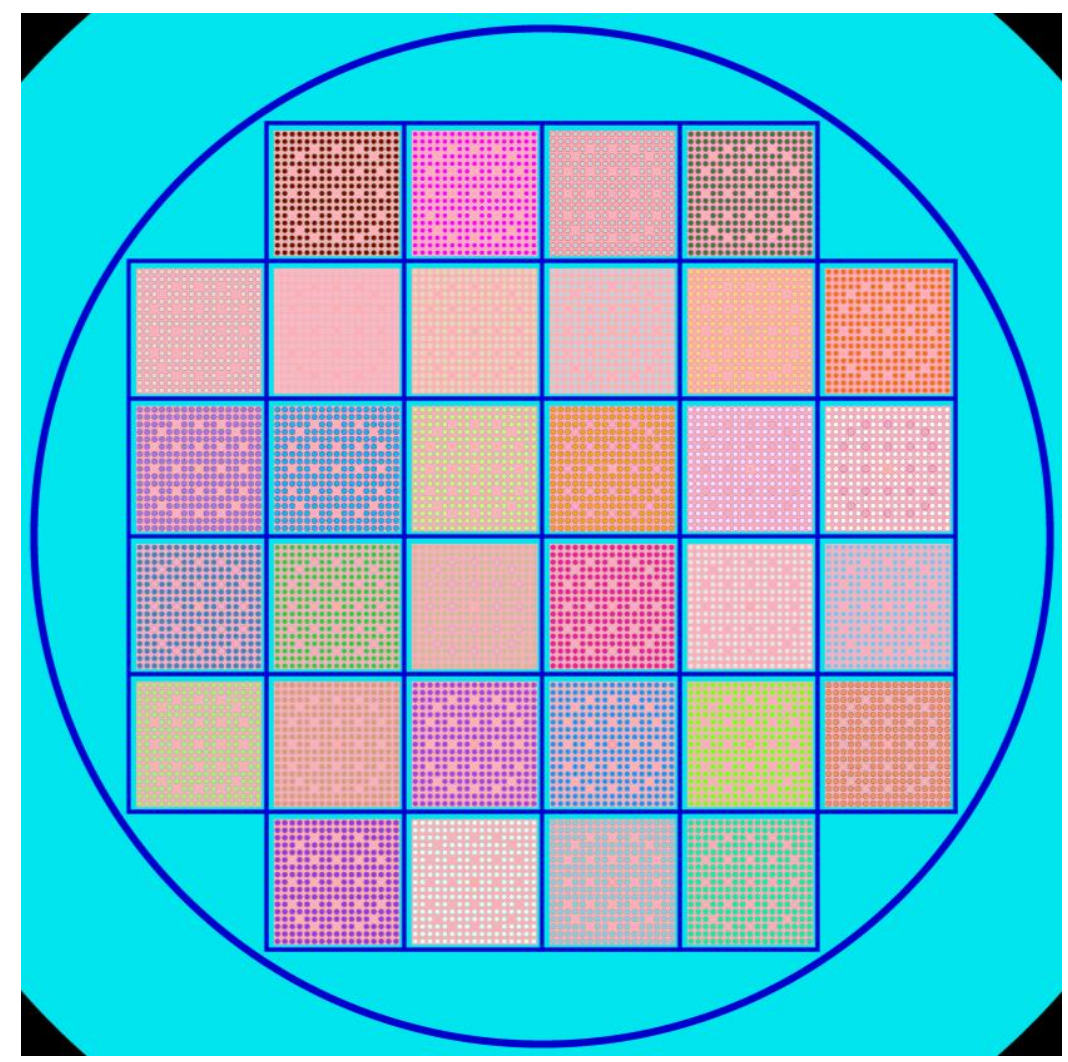

Figure 22. Radial layout of the MPC-32 without neutron absorber panels as modeled in SCALE.

Figure 23 presents the $k_{\text {eff }}$ of the loss of neutron absorber scenario as a function of time. As described in the following subsection, if components in the guide tubes are present, they are credited in this calculation. Figure 23 shows that some of the canisters over the analyzed time period are below the subcritical limit (0.98) defined in this report. As shown in Table 13, an analysis of this configuration 
using the design basis fuel assembly yields $k_{\text {eff }}>1$ for all the canisters. Table 14 shows the number of SQ DPCs above the subcritical limit and the maximum $k_{\text {eff. }}$ Table 14 also indicates the approximate amount of $\mathrm{Cl}$ required to maintain subcritical condition in the 16 identified DPCs, which are above subcritical limit with fresh water.

Table 14. Final SQ statistics in the year 9999

\begin{tabular}{lc}
\hline \multicolumn{1}{c}{ Description } & Values \\
\hline Number of canisters & 26 \\
Number of canisters with $k_{\text {eff }}>0.98$ (design basis analysis) & 26 \\
Number of canisters with $k_{\text {eff }}>0.98$ (as-loaded analysis) & 16 \\
Maximum $k_{\text {eff }}$ & 1.00623 \\
Approximate Cl requirement (linear interpolation) & ${ }^{a}$ \\
\hline
\end{tabular}

${ }^{a} \mathrm{Cl}$ reactivity worth based on a 32-assembly configuration

is assumed to be applicable for this DPC.

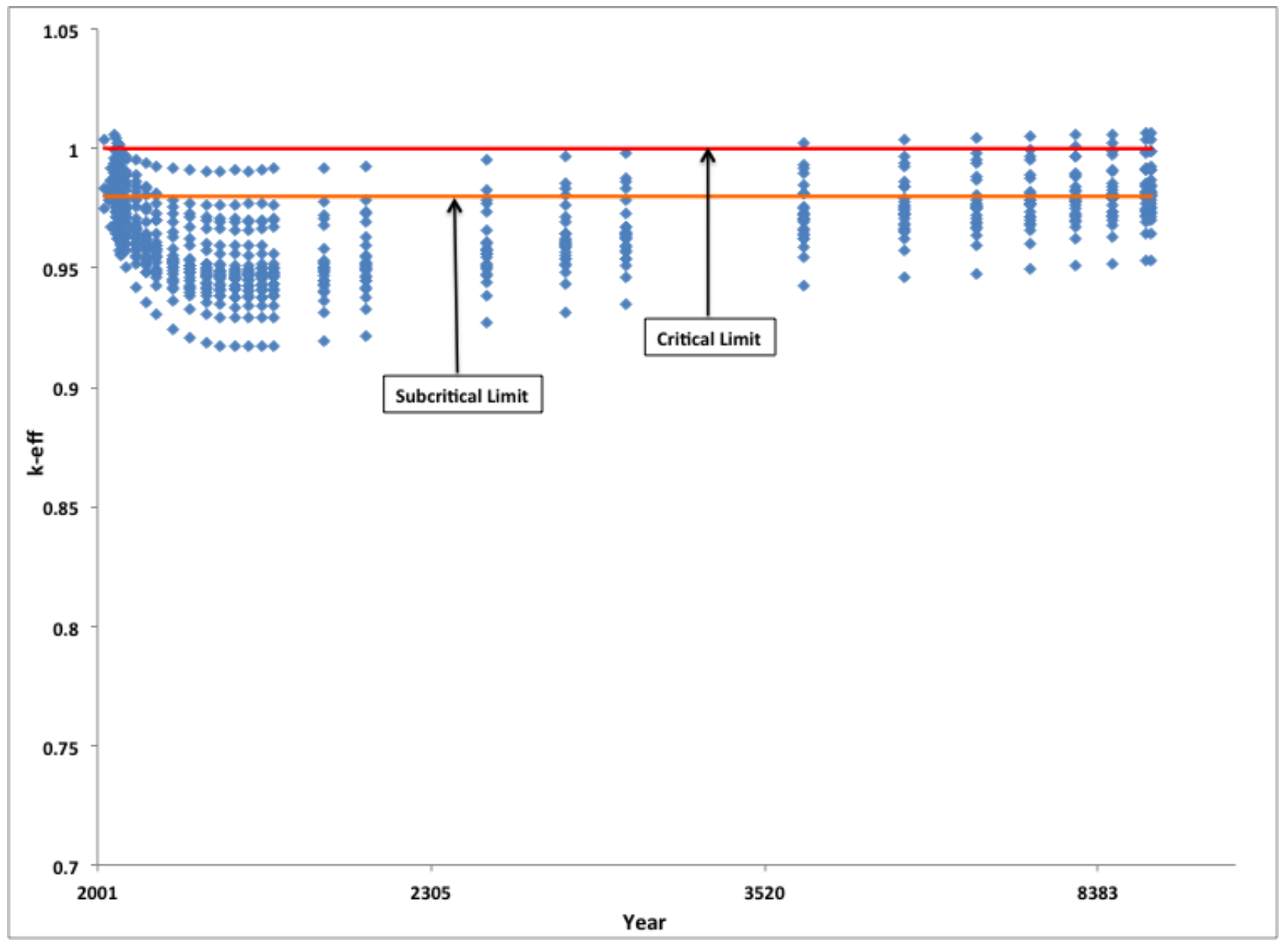

Figure 23. Calculated $k_{\text {eff }}$ results for as-loaded SQ casks with loss of neutron absorber panels.

\subsection{Component Credit}

Many utilities are currently placing discharged non-fuel components into the used fuel assemblies that are placed in DPCs. Interim Staff Guidance (ISG) - 9 [27] indicates that materials positioned or operated within the envelope of the fuel assembly during reactor operation may be approved for storage in the 
DPC. This includes items such as discharged burnable poison rods and control rods. ISG-9 states:

"Credit for water displacement may be taken provided adequate structural integrity and placement under accident conditions is demonstrated."

Different types of components are currently stored in the guide tubes of the SNF assemblies, including BPRAs, wet annular burnable absorbers (WABAs), and control rod assemblies (CRAs). BPRAs are either solid or annular (with dry annular gap) in design, while WABAs contain wet annular gaps. CRAs also contain solid rods. The number of rods (rodlets) in each type of component can also vary (e.g., W17 × 17, number of component rods varies from 4 to 24).

Some of the DPCs at SQ contain discharged components that include BPRAs and WABAs, with the number of rods varying from 4 to 24, including asymmetric configurations (e.g., with 9 rods). The results presented in Sect. 5.5 include a conservative model of components if they are stored with an assembly. Note that components are used in this analysis to credit the water displacement aspect only. A simplistic approach is used, because enough information is not presently available to model specific geometries of different components. The following assumptions are utilized:

- WABA design is considered for all the components, as it provides the least amount of water displacement because of its wet annular gap. Reference [28] provides the radial dimensions of the WABA. Although a WABA is longer than the active fuel length, when placed in the guide tube, the bottom end of a WABA is about $11 \mathrm{~cm}$ higher than that of the active fuel. In this analysis, WABAs are modeled to cover the entire axial length of the active fuel. However, the upper part of the WABA above the active length is not credited for water displacement. Figure 24 illustrates a cross section view of the WABA model used for the SQ DPCs.

- 16 WABA rods are considered for all components irrespective of the actual number of rods.

- The absorber material (e.g., $\mathrm{Al}_{2} \mathrm{O}_{3}-\mathrm{B}_{4} \mathrm{C}$ ) is modeled as void. 


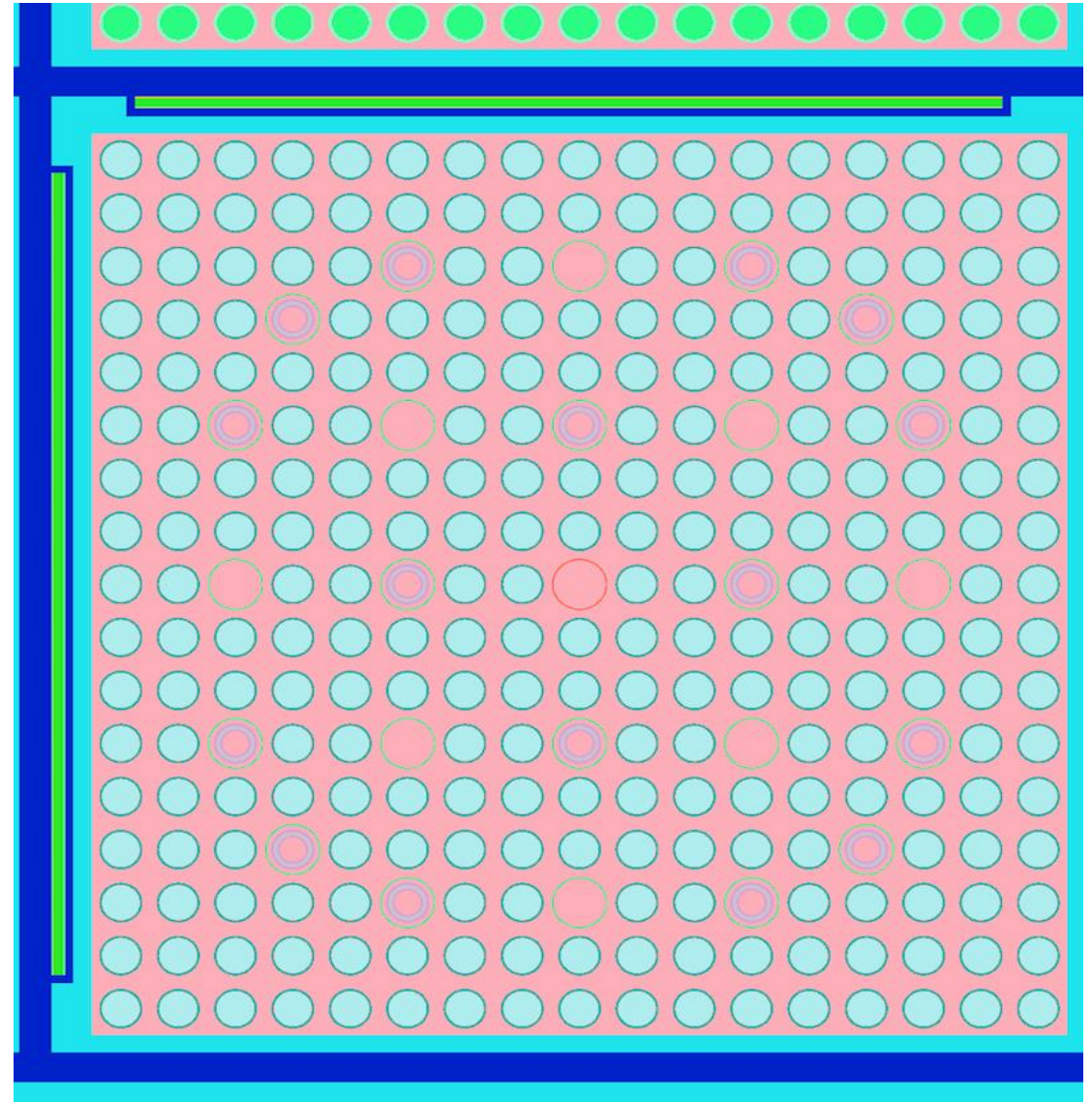

Figure 24. Radial view of the WABAs in the guide tube as modeled in SCALE for SQ DPCs.

This approach will be refined in the future to include the actual number and geometry of the components when more data will be available. Table 15 presents the typical reactivity reduction obtained from the water displacement by the components in the guide tubes. It is observed that a reactivity worth of approximately $0.06 \Delta k_{\text {eff }}$ is obtained with the simplified approach used in this report. 
Table 15. Reactivity reduction from the components for SQ DPCs with loss of neutron absorber

\begin{tabular}{cccc}
\hline SQ DPC & $\begin{array}{c}\boldsymbol{k}_{\text {eff }} \text { without } \\
\text { component @ 9999 }\end{array}$ & $\begin{array}{c}\boldsymbol{k}_{\text {eff }} \text { with } \\
\text { component } @\end{array}$ & $\boldsymbol{9 9 9 9}$ \\
\hline MPC-005 & 1.0048 & 0.99868 & $\mathbf{0 . 0 0 6 1 2}$ \\
MPC-006 & 0.9808 & 0.97466 & $\mathbf{0 . 0 0 6 1 4}$ \\
MPC-0109 & 0.9705 & 0.96418 & $\mathbf{0 . 0 0 6 3 2}$ \\
MPC-0110 & 0.95872 & 0.95314 & $\mathbf{0 . 0 0 5 5 8}$ \\
MPC-0177 & 0.99812 & 0.99254 & $\mathbf{0 . 0 0 5 5 8}$ \\
MPC-068 & 0.98747 & 0.9818 & $\mathbf{0 . 0 0 5 6 7}$ \\
MPC-070 & 0.97858 & 0.97276 & $\mathbf{0 . 0 0 5 8 2}$ \\
\hline
\end{tabular}




\section{CONCLUSION}

The analyses presented in this paper assume that waste package breach occurs at a relatively early time in the repository, allowing flooding of the canister to produce significant moderation and to degrade the internal components. Note that if water can be excluded or significantly delayed from entering the repository or from entering a package, there is little potential for criticality. Criticality analyses are performed (using fresh water) for two cases of canister degradation-loss-of-absorber and basket degradation - and for five types of DPCs located at five sites. Degraded material was assumed to be replaced by water moderator and to be completely removed from the DPC. Additionally, component credit to displace moderator from the guide tubes is applied for the DPCs at SQ ISFSI. The main sources of reactivity margin (relative to licensing design basis analyses) investigated in this paper include:

- $\quad$ burnup credit for 28 actinide and fission product nuclides previously demonstrated to exhibit a significant effect on fuel reactivity,

- use of actual as-loaded DPCs, and

- radionuclide inventory decay.

Analyses are also performed to generate the reactivity curves as functions of the concentration of various dissolved species in groundwater. These curves can be used to determine the reactivity impact for a specified amount of an element in different DPC configurations. However, currently available groundwater data indicates that $\mathrm{Cl}$ is the only naturally abundant, neutron-absorbing element in groundwater that can offer noticeable reactivity reduction. Table 16 summarizes the analyses performed in this report. Based on as-loaded canister-specific analyses, it can be concluded that credit for neutron absorbers present in groundwater is needed for $13 \%$ of the evaluated DPCs with loss of neutron absorber over the repository time frame, while credit for neutron absorbers present in groundwater is required for $23 \%$ of the analyzed DPC if degradation scenario includes loss of carbon steel structures and neutron absorber panels. Table 16 also presents the approximate $\mathrm{Cl}$ requirements to maintain subcritical configurations in all the 179 DPCs evaluated for both the degradation scenarios. About 2,000 DPCs have already been loaded with SNF and stationed in storage casks on ISFSI pads throughout the nation. Therefore, more DPCs are required to be evaluated to improve the overall statistics (probability of forming critical configurations over the repository time frame) following the criticality approach outlined in Ref. [4] for DPC direct disposal. The criticality roadmap from Ref. [4] is presented in Figure 25 with the completion status marked by yellow (work in progress) and green (completed) colors.

The analyses performed in this report indicate that subcriticality can be demonstrated for typical DPCs by detailed canister-specific analysis and by crediting the available groundwater composition if required. However, better understanding of the corrosion process of basket structural materials and their physical degradation mechanisms, as well as the probability of flooding or partial flooding, could further and significantly influence the projected likelihood of criticality events. Further, the possibility of one or more criticality events is not by itself a definitive indication that direct disposal of DPCs is infeasible for a given geologic setting and disposal concepts. In the past, stylized analyses have shown that the consequences of criticality, if properly weighted by probability, might not have a significant impact on waste isolation performance such that radionuclide releases from a repository would exceed safety standards. [29] 
Table 16. Analyses summary

\begin{tabular}{lcc}
\hline \multicolumn{1}{c}{ Description } & \multicolumn{2}{c}{ Values } \\
\hline $\begin{array}{l}\text { Total DPC analyzed } \\
\text { Fail subcriticality test with design } \\
\text { basis analysis }\end{array}$ & & 179 \\
\hline $\begin{array}{l}\text { Fail subcriticality test with as-loaded } \\
\text { analysis }\end{array}$ & $\begin{array}{c}\text { Loss of neutron } \\
\text { absorber }\end{array}$ & $\begin{array}{c}\text { Loss of neutron absorber } \\
\text { and carbon steel structures }\end{array}$ \\
\cline { 2 - 3 } & $23(13 \%)$ & $41(23 \%)$ \\
Approximate $\mathrm{Cl}$ requirement & $13,500 \mathrm{ppm}$ & $32,500 \mathrm{ppm}$ \\
& $(\mathrm{mg} / \mathrm{L})$ & $(\mathrm{mg} / \mathrm{L})$ \\
\hline
\end{tabular}

\begin{tabular}{|c|c|c|c|c|c|c|c|c|c|c|}
\hline \multicolumn{11}{|c|}{ Criticality Analysis Roadmap } \\
\hline \multirow{5}{*}{ 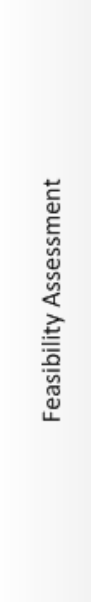 } & \multicolumn{10}{|c|}{ Identify sources of water and potential for pooling in DPC by host media } \\
\hline & $\begin{array}{l}\text { Perform DPC model } \\
\text { development to } \\
\text { establish baseline }\end{array}$ & \multicolumn{3}{|c|}{$\begin{array}{l}\text { Develop and apply } \\
\text { misload analysis } \\
\text { methodology }\end{array}$} & \multicolumn{2}{|c|}{$\begin{array}{l}\text { Assess radiolysis rates } \\
\text { required for significant } \\
\text { impact to in-package } \\
\text { chemistry }\end{array}$} & \multicolumn{3}{|c|}{$\begin{array}{l}\text { Groundwater analyses } \\
\text { for different geologies }\end{array}$} & $\begin{array}{l}\text { Identify performance } \\
\text { assessment parameters } \\
\text { directly influenced by } \\
\text { criticality consequence }\end{array}$ \\
\hline & \multicolumn{2}{|c|}{$\begin{array}{c}\text { Review neutron absorber and } \\
\text { basket material performance } \\
\text { data for existing DPCs }\end{array}$} & \multicolumn{3}{|c|}{$\begin{array}{l}\text { Development of BWR burnup } \\
\text { credit methodology }\end{array}$} & \multicolumn{3}{|c|}{$\begin{array}{l}\text { Evaluation of chemistry } \\
\text { ranges inside DPCs and } \\
\text { corrosion rates on primary } \\
\text { components }\end{array}$} & & $\begin{array}{l}\text { evelop probability based } \\
\text { sampling framework for } \\
\text { generic distributions }\end{array}$ \\
\hline & \multicolumn{2}{|c|}{$\begin{array}{c}\text { Perform envelope analysis on } \\
\text { key parameters that lead to } \\
\text { criticality }\end{array}$} & \multicolumn{3}{|c|}{$\begin{array}{l}\text { Evaluate probability of } \\
\text { criticality }\end{array}$} & \multicolumn{3}{|c|}{$\begin{array}{c}\text { Develop geochemisty models } \\
\text { accounting for in-package } \\
\text { chemistry effects }\end{array}$} & $\begin{array}{l}\text { Esta } \\
\text { reac }\end{array}$ & $\begin{array}{l}\text { blish model for evaluating } \\
\text { ction kinetics and impacts } \\
\text { on PA parameters }\end{array}$ \\
\hline & \multicolumn{3}{|c|}{$\begin{array}{c}\text { Evaluate envelope parameters against } \\
\text { geochemistry model results to refine } \\
\text { credible range }\end{array}$} & \multicolumn{4}{|c|}{$\begin{array}{l}\text { Evaluate criticality consequence effects } \\
\text { on repository distributions }\end{array}$} & \multicolumn{3}{|c|}{$\begin{array}{l}\text { Generate risk curves per influence } \\
\text { parameter }\end{array}$} \\
\hline 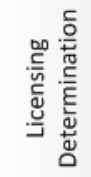 & \multicolumn{2}{|c|}{$\begin{array}{l}\text { Criticality validation (e.g., } \\
\text { experiments with } \mathrm{Cl}^{-} \text {in } \\
\text { solution, relevant } \\
\text { cofigurations) }\end{array}$} & \multicolumn{3}{|c|}{$\begin{array}{l}\text { Justify and incorporate site- } \\
\text { specific parameter } \\
\text { distributions }\end{array}$} & \multicolumn{3}{|c|}{$\begin{array}{l}\text { Justify use of non-bounding } \\
\text { assumptions }\end{array}$} & & $\begin{array}{l}\text { Validate site-specific } \\
\text { geochemistry models }\end{array}$ \\
\hline
\end{tabular}

Figure 25. DPC criticality analyses roadmap as described in Ref. [4] with the completion status; Yellow: work in progress and Green: completed. 


\section{REFERENCES}

1. Feasibility of Direct Disposal of Dual-Purpose Canisters: Options for Assuring Criticality Control, Electric Power Research Institute, Palo Alto, Calif., 2008.

2. The Potential of Using Commercial Dual Purpose Canisters for Direct Disposal, TDR-CRW-SE000030 Rev 00, US Department of Energy, Office of Civilian Radioactive Waste Management, November 2003.

3. Handbook of Neutron Absorber Materials for Spent Nuclear Fuel Transportation and Storage Applications, Electric Power Research Institute, Palo Alto, Calif., 2009.

4. J. M. Scaglione et al., Criticality Analysis Process for Direct Disposal of Dual Purpose Canisters, ORNL/LTR-2014/80, Oak Ridge National Laboratory, Oak Ridge, TN, March 2014.

5. J. B. Clarity et al., Feasibility of Direct Disposal of Dual Purpose Canisters - Criticality Evaluations, ORNL/LTR-2013/213, Oak Ridge National Laboratory, Oak Ridge, TN, June 2013.

6. Oak Ridge National Laboratory, SCALE: A Comprehensive Modeling and Simulation Suite for Nuclear Safety Analysis and Design, ORNL/TM-2005/39, Version 6.1, Radiation Safety Information Computational Center at Oak Ridge National Laboratory, Oak Ridge, Tenn., 2011.

7. J. M. Scaglione et al., Integrated Data and Analysis System for Commercial Used Nuclear Fuel Safety Assessments, Proceedings of the $17^{\text {th }}$ International Symposium on the Packaging and Transportation of Radioactive Materials (PATRAM), August 18-23, 2013, San Francisco, Calif.

8. H. Smith et al., Fuel Assembly Modeling for the Modeling and Simulation Toolset, ORNL/LTR2012-555, Oak Ridge National Laboratory, Oak Ridge, Tenn., November 2012.

9. J. Clarity et al., Report Documenting Models for Criticality Safety Analyses, Oak Ridge, TN, September 2013. (Draft report)

10. J. C. Wagner et al. Recommendations for Addressing Axial Burnup in PWR Burnup Credit Analyses, NUREG/CR-6801 (ORNL/TM-2001/273), prepared for the US Nuclear Regulatory Commission by Oak Ridge National Laboratory, Oak Ridge, Tenn., March 2003.

11. G. Radulescu et al., An Approach for Validating Actinide and Fission Product Burnup Credit Criticality Safety Analyses-Isotopic Composition Predictions, NUREG/CR-7108 (ORNL/TM2011/509), prepared for the US Nuclear Regulatory Commission by Oak Ridge National Laboratory, Oak Ridge, Tenn., April 2012.

12. J. M. Scaglione et al. An Approach for Validating Actinide and Fission Product Burnup Credit Criticality Safety Analyses-Criticality $\left(k_{\text {eff }}\right)$ Predictions, NUREG/CR-7109 (ORNL/TM2011/514), prepared for the US Nuclear Regulatory Commission by Oak Ridge National Laboratory, Oak Ridge, Tenn., April 2012.

13. US Department of Energy, Disposal Criticality Analysis Methodology Topical Report, YMP/TR004Q, Revision 0, Office of Civilian Radioactive Waste Management, November 1998.

14. J. C. Wagner et al., Recommendations on the Credit for Cooling Time in PWR Burnup Credit Analyses, NUREG/CR-6781 (ORNL/TM-2001/272), prepared for the US Nuclear Regulatory Commission by Oak Ridge National Laboratory, Oak Ridge, Tenn., January 2003.

15. Standard Review Plan for Spent Fuel Dry Storage Systems at a General License Facility, NUREG-1536, Rev. 1, Office of Nuclear Material Safety and Safeguards, July 2010.

16. E. Hardin et al., Repository Reference Disposal Concepts and Thermal Management Analysis. FCRD-USED-2012-000219 Rev. 2, US Department of Energy, Used Fuel Disposition R\&D Campaign, November 2012.

17. Y. Wang et al., Integrated Tool Development for Used Fuel Disposition Natural System Evaluation-Phase I Report, prepared for the US Department of Energy Used Fuel Disposition, FCRD-UFD-2012-000229 SAND2012-7073P, 2012.

18. J. Winterle et al., Geological Disposal of High-Level Radioactive Waste in Salt Formation, Center for Nuclear Waste Regulatory Analyses, San Antonio, Texas, March 2012. 
19. C. F. Jove Colon et al., Disposal Systems Evaluations and Tool Development-Engineered Barrier System (EBS) Evaluation, prepared for the US Department of Energy Used Fuel Disposition Campaign, SAND2010-8200, 2011.

20. E. I. A., RW-859 Nuclear Fuel Data, Washington, D.C.(Oct. 2004), Washington, DC, EIA, 2004.

21. NAC-UMS Final Safety Analyses Report, Rev. 3, US NRC Docket No. 72-1015, NAC International, January 2004.

22. NAC-STC Safety Analysis Report, Revision 15, US NRC Docket No. 71-9235, March 2004.

23. Transnuclear, Inc., Multi-Purpose Cask, Rev. 17, Safety Analysis Report-NUHOMS-MP187, Transnuclear, Inc., Fremont, Calif., July 2003 (Vendor Provided).

24. Holtec International, "HI-STAR SAR Report HI-951251", USNRC Docket No. 72-1014, Revision 15, October 11, 2010.

25. Holtec Final Safety Analysis Report for the HI-STORM 100 Cask System, Revision 9, February 13, 2010. ADAMS Accession Number ML101400161.

26. NRC Certificate Number 9261, Revision 8, Certificate of Compliance HI-STAR 100 for Radioactive Material Packages - HI-STAR 100.

27. U.S. Nuclear Regulatory Commission, Interim Staff Guidance - 9, Revision 1, Storage of Components Associated with Fuel Assemblies, Spent Fuel Project Office (2002).

28. Summary Report of Commercial Reactor Criticality Data for Sequoyah Unite 2, Revision 01, Civilian Radioactive Waste Management System, April 14, 1998.

29. S. Mohanty et al., System-Level Performance Assessment of the Proposed Repository at Yucca Mountain Using the TPA Version 4.1 Code, Center for Nuclear Waste Regulatory Analyses, San Antonio, Texas, Revision 2, March 2004. 
This page is intentionally left blank. 

This page is intentionally left blank. 


\section{A.1. INTRODUCTION}

This appendix documents work performed supporting the US Department of Energy (DOE) Nuclear Energy (NE) Fuel Cycle Technologies Used Fuel Disposition under work breakdown structure element 1.02.08.16 - DR, "Disposal of Dual Purpose Canisters." In particular, this appendix fulfills the M4 milestone, M4FT-15OR0816011, "Direct Disposal of DPC Reactivity and Criticality Evaluations" within work package FT-15OR0816001, "Disposal of Dual Purpose Canisters-ORNL."

This appendix presents the dual purpose canister (DPC) criticality evaluations performed in FY15 to support the feasibility determination of direct disposal of DPCs. This appendix extends the work reported in the main body of this report (performed in FY14). This appendix features:

1. updated criticality results with a set of 29 principal isotopes (henceforth referred to as disposalisotopes) from Ref. A-1;

2. three new sites including a boiling water reactor (BWR) site (additional 36 DPCs);

3. reactivity reduction by groundwater species $(\mathrm{Cl})$ applied to as-loaded DPCs (generic reactivity impact of groundwater is discussed in the main body);

4. reactivity impact of filler material applied to as-loaded DPCs; and

5. reactivity impact of ${ }^{10} \mathrm{~B}$ areal density variation applied to as-loaded DPCs.

\section{A.2. DISPOSAL-ISOTOPES}

The criticality results reported in the main body of this report were generated applying the isotopic set reported in Table 2 (main body). The set of isotopes reported in Table 2 is recommended for spent nuclear fuel (SNF) storage and transportation (henceforth referred to as storage-transportation-isotopes) burnup credit criticality analyses. This set of storage-transportation-isotopes is the default burnup credit criticality analysis option within UNF-ST\&DARDS. However, the storage-transportation-isotopes set is slightly different than that recommended in Ref. A-1 for disposal (post-closure) burnup credit criticality analyses. Table A-1 presents the principal set of isotopes for post-closure burnup credit criticality analysis. As stated in Ref. A-1, the principal isotopes for burnup credit includes a subset of the isotopes present in irradiated commercial fuel. They were selected considering the nuclear, physical, and chemical properties of the irradiated commercial fuel isotopes, such as cross sections and half-lives of the isotopes, concentrations (amount present in the irradiated fuel), and state (solid, liquid, or gas) of the isotopes, as well as volatility and solubility of the isotopes. Isotopic decay and build-up, as well as relative importance of isotopes for criticality (combination of cross sections and concentrations), were also considered in this selection process. No isotopes with significant positive reactivity effects (fissile isotopes with significant concentrations) were removed from consideration. Thus, the selection process was conservative.

UNF-ST\&DARDS has been recently updated to include disposal-isotopes for the post-closure criticality analysis. Figure A-1 presents a reactivity comparison between the disposal-isotopes and storagetransportation-isotopes. This reactivity comparison study was performed for all the CY DPCs in the calendar year 9999. Figure A-1 shows that the disposal-isotopes set yields marginally higher $k_{e f f}$ (up to $0.0038 \Delta k_{e f f}$ ) than that of the storage-transportation-isotopes. Perhaps this is because of the fission product isotope ${ }^{133} \mathrm{Cs}$ (a neutron poison), which is not present in the disposal-isotopes set. 
Table A-1. Principal set of isotopes for burnup credit post-closure criticality analysis

\begin{tabular}{lllll}
\hline${ }^{95} \mathrm{Mo}$ & ${ }^{145} \mathrm{Nd}$ & ${ }^{151} \mathrm{Eu}$ & ${ }^{236} \mathrm{U}$ & ${ }^{241} \mathrm{Pu}$ \\
${ }^{99} \mathrm{Tc}$ & ${ }^{147} \mathrm{Sm}$ & ${ }^{153} \mathrm{Eu}$ & ${ }^{238} \mathrm{U}$ & ${ }^{242} \mathrm{Pu}$ \\
${ }^{101} \mathrm{Ru}$ & ${ }^{149} \mathrm{Sm}$ & ${ }^{155} \mathrm{Gd}$ & ${ }^{237} \mathrm{~Np}$ & ${ }^{241} \mathrm{Am}$ \\
${ }^{103} \mathrm{Rh}$ & ${ }^{150} \mathrm{Sm}$ & ${ }^{233} \mathrm{U}$ & ${ }^{238} \mathrm{Pu}$ & ${ }^{242 m} \mathrm{Am}$ \\
${ }^{109} \mathrm{Ag}$ & ${ }^{151} \mathrm{Sm}$ & ${ }^{234} \mathrm{U}$ & ${ }^{239} \mathrm{Pu}$ & ${ }^{243} \mathrm{Am}$ \\
\hline
\end{tabular}

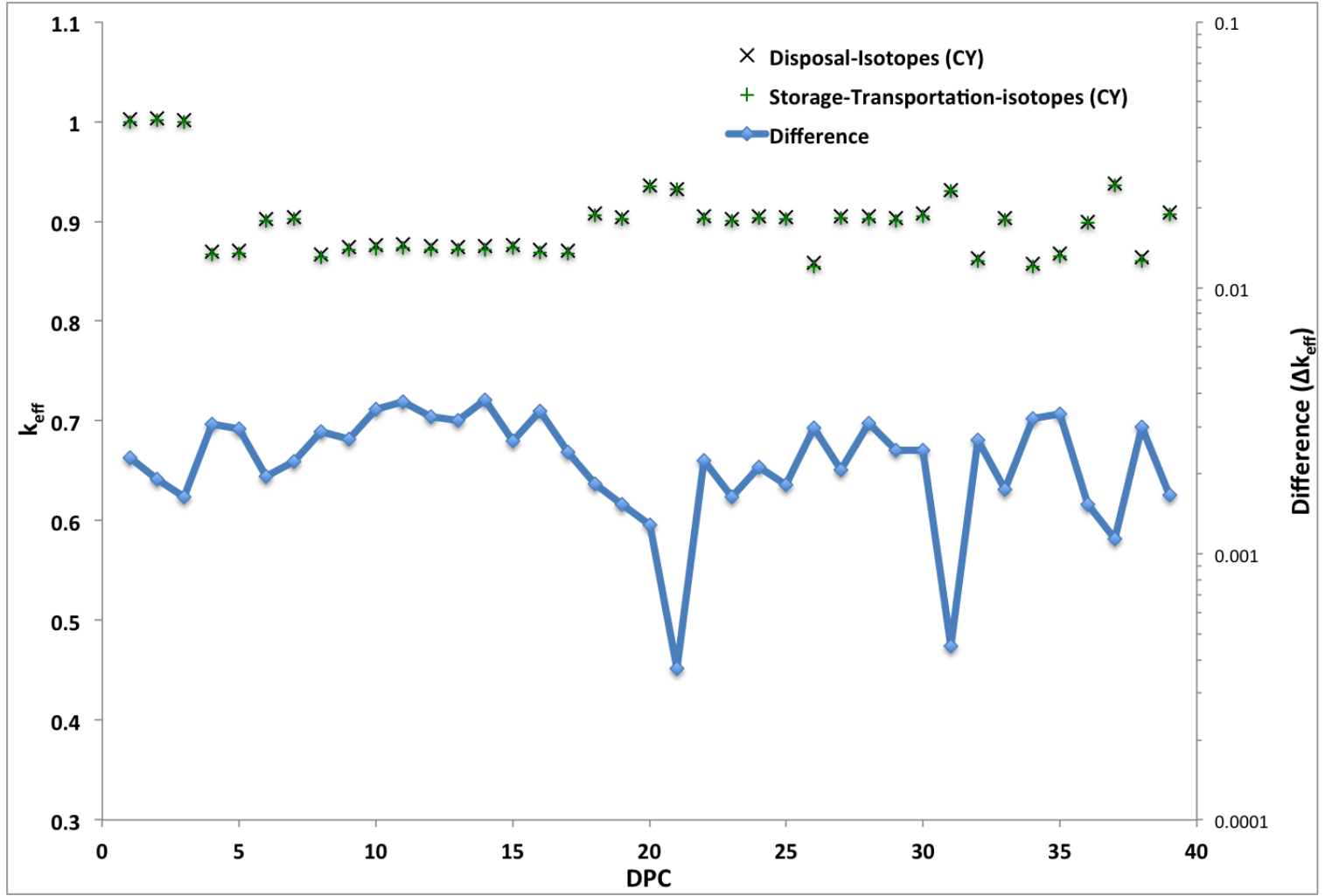

Figure A-1. Comparison (in terms of reactivity) between disposal-isotopes and storagetransportation-isotopes for CY DPCs in the calendar year 9999. $\Delta \boldsymbol{k}_{\text {eff }}=\boldsymbol{k}_{\text {eff }}($ disposal isotopes $)-k_{\text {eff }}($ storage - transportation - isotopes $)$.

Figure A-2 presents the as-loaded $k_{e f f}$ for the five sites (Maine Yankee [MY], Connecticut Yankee [CY], Rancho Seco [RS], Trojan [TJ], and Sequoyah [SQ]) analyzed in the main body of this report with disposal-isotopes for the loss-of-neutron-absorber scenario. As discussed in the main body, $k_{\text {eff }}<0.98$ is used in this study as a representative acceptance criterion for as-loaded calculations. However, if analyses like these are used to support future disposal licensing, additional validation and assessment of applicable biases will be required. Similar to the main body of this report, the time-dependent reactivity calculation results are provided for the time range between the calendar years 2001 and 9999 (i.e., approximately 8,000 years). Note that the disposal-isotopes set yielded 25 DPCs above the representative subcritical line in the year 9999, whereas 23 DPCs (as reported in Table 16) were above the representative subcritical limit using the storage-transportation-isotopes set. Two additional DPCs above the subcritical limit using the disposal-isotopes are from SQ site. As mentioned in the main body of this report, the degraded basket analysis was performed only for the RS site, as RS DPCs contain coated carbon steel spacer disks. Figure A-3 presents the RS basket degradation results reevaluated with disposal-isotopes. The disposal-isotopes 
set yielded 19 RS DPC above the representative subcritical limit (in the year 9999), whereas 18 RS DPCs (as reported in Table 10, main body) were above the representative subcritical limit using the storagetransportation-isotopes set. Table A-2 summarizes the number of DPCs above the representative subcritical limit with disposal-isotopes and storage-transportation-isotopes.

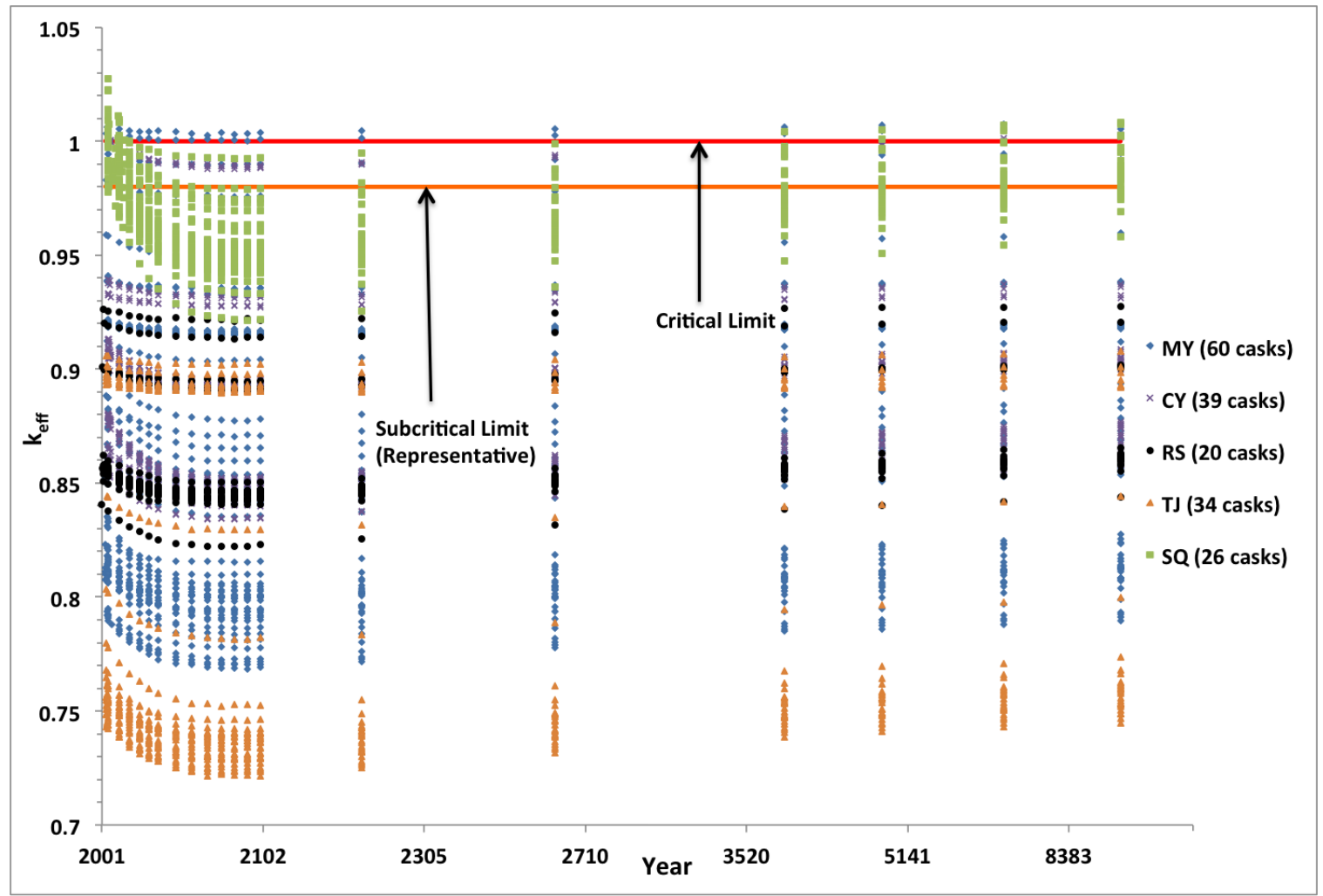

Figure A-2. $\boldsymbol{k}_{\text {eff }}$ vs. calendar year for the loss-of-neutron-absorber case based on actual loading and disposal-isotopes. 


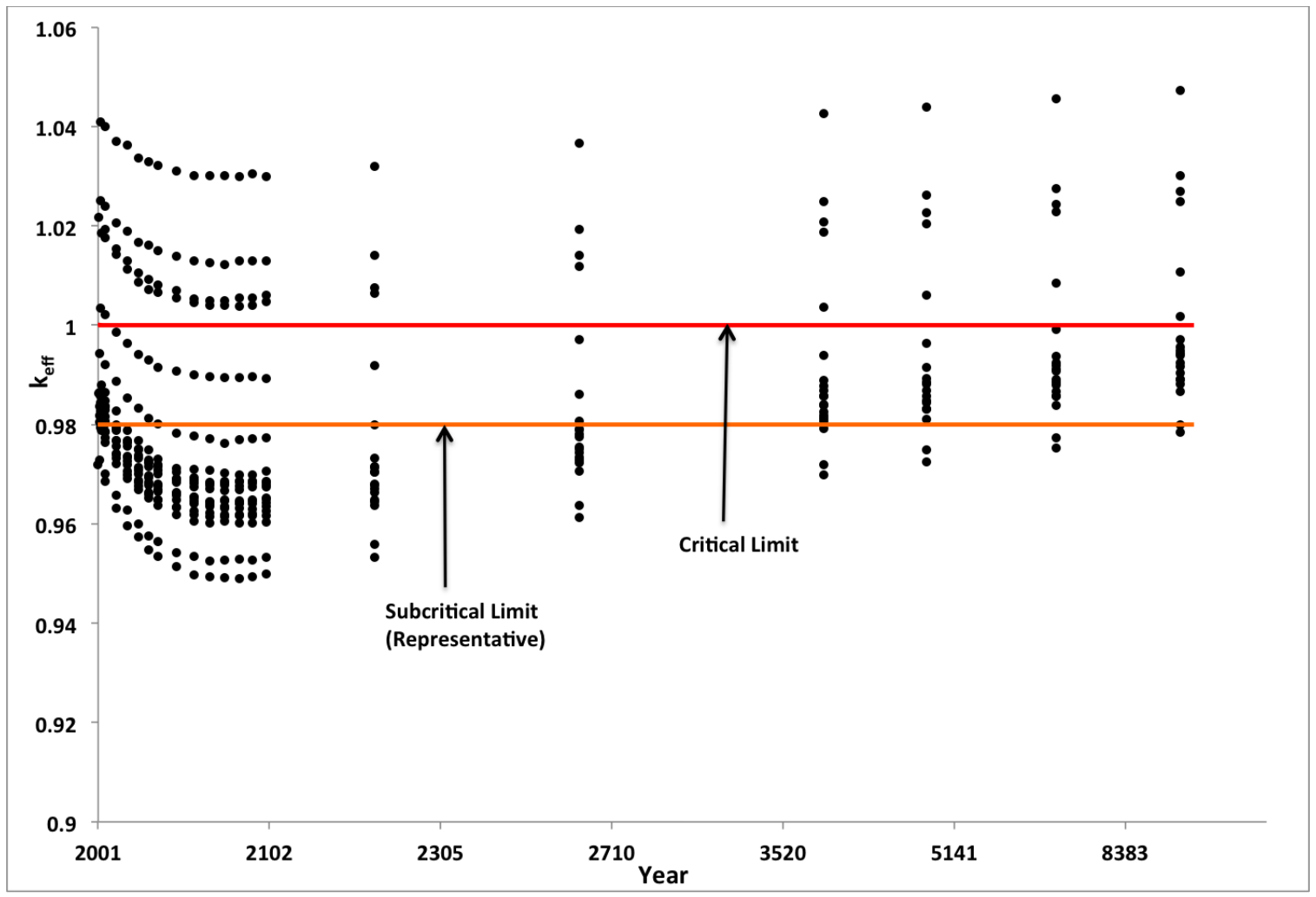

Figure A-3. $\boldsymbol{k}_{\text {eff }}$ vs. calendar year for the RS basket degradation case based on actual loading and disposal-isotopes.

Table A-2. Number of DPCs above subcritical limit with disposal-isotopes and storagetransportation-isotopes in the calendar year 9999

\begin{tabular}{lcc}
\hline \multicolumn{1}{c}{ Description } & $\begin{array}{c}\text { Disposal-isotopes } \\
\text { (this appendix) }\end{array}$ & $\begin{array}{c}\text { Storage- } \\
\text { transportation- } \\
\text { isotopes (main } \\
\text { body) }\end{array}$ \\
\hline $\begin{array}{l}\text { Number of DPCs with } k_{e f f}>0.98 \text { (loss-of absorber } \\
\text { case) }\end{array}$ & 25 & 23 \\
$\begin{array}{l}\text { Number of DPCs with } k_{e f f}>0.98 \text { (degraded basket } \\
\text { case) }\end{array}$ & 19 & 18 \\
\hline
\end{tabular}

\section{A.3. NEW SITES}

Three new sites were evaluated in FY15 and results are presented in this appendix including Humboldt Bay site, Catawba nuclear station, and Salem nuclear power plant. While Humboldt Bay (HB) is a shutdown BWR site, Catawba (CTB) and Salem (SL) are operating PWR nuclear power stations. The DPCs used in HB, CTB, and SM are briefly described below.

\section{Humboldt Bay (HB)}

The HB nuclear power plant, located southeast of Eureka, California, was operated commercially from 1963 to 1976. Produced during HB's 13 years of service, 390 assemblies [20] are stored in five Holtec's MPC-HB (DPC) canister. [24] MPC-HB can accommodate 80 fuel assemblies per canister, up to 40 of which may be damaged. The MPC-HB also uses single MetamicTM neutron absorber panels between 
storage locations to ensure criticality control. [24] The MPC-HB basket components are stainless steel construction; hence, complete loss of neutron absorber was only considered as the potential degradation scenario. Figure A-4 illustrates the MPC-HB 80-assembly DPC basket without neutron absorber.

The MPC-HB is loaded with $6 \times 6$ and $7 \times 7$ BWR assembly types. A planar average enrichment of 2.6 w/o ${ }^{235} \mathrm{U}$ was used for licensing calculations. Table A-3 shows the reactivity of the complete loss-ofneutron-absorber scenario with the design basis assembly $\left(6 \times 6\right.$ assembly type with 2.6 w/o $\left.{ }^{235} \mathrm{U}\right)$.

Table A-3. Calculated degraded absorber $\boldsymbol{k}_{\text {eff }}$ for the MPC-HB with design basis fuel

\begin{tabular}{ccc}
\hline $\begin{array}{c}\text { Enrichment } \\
\left(\mathbf{w} / \mathbf{o}^{235} \mathbf{U}\right)\end{array}$ & $\begin{array}{c}\text { Burnup } \\
(\mathbf{G W d} / \mathbf{M T U})\end{array}$ & $\boldsymbol{k}_{\text {eff }}$ \\
\hline 2.6 & 0 & $0.98787 \pm 0.00037$ \\
\hline
\end{tabular}

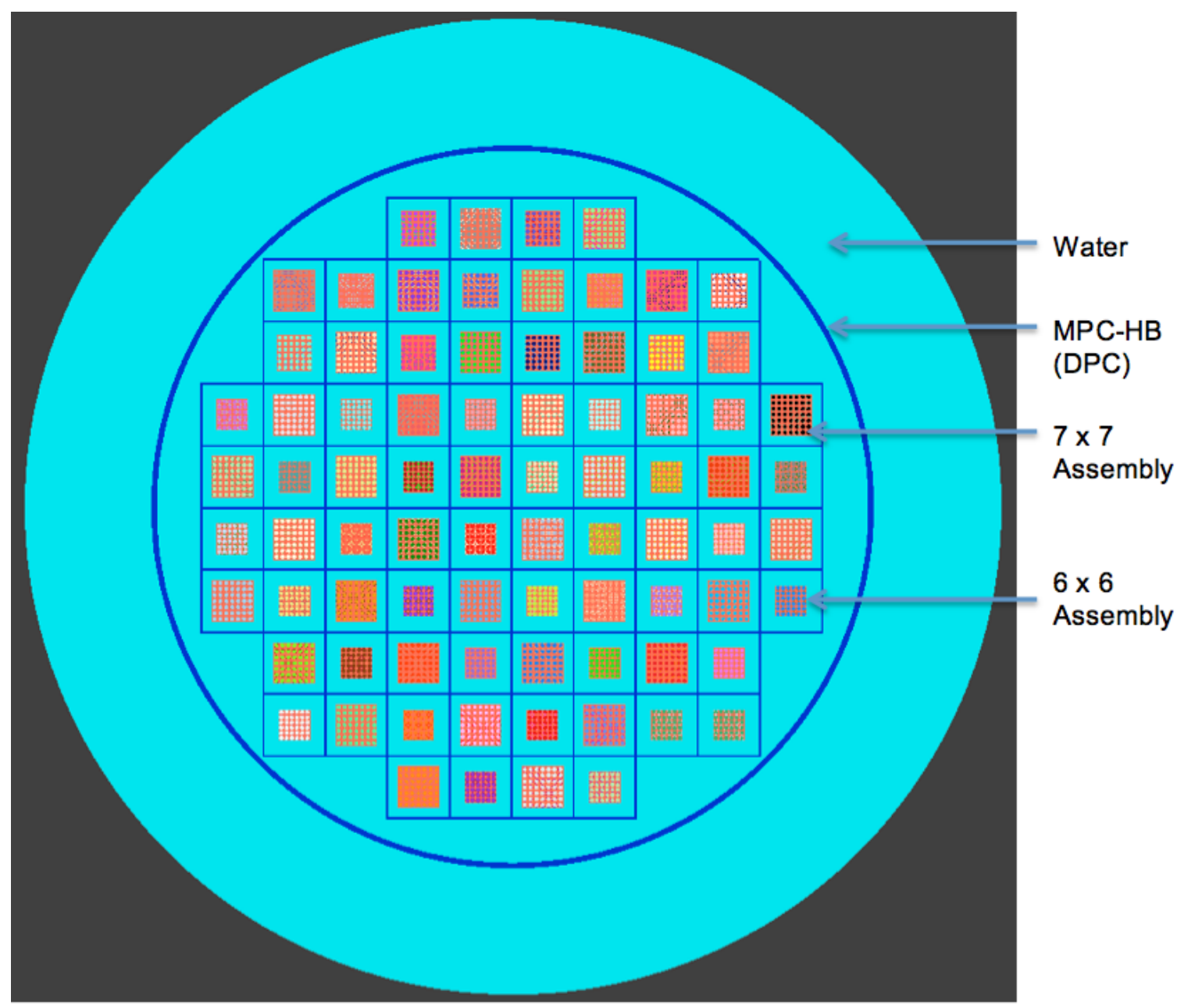

Figure A-4. Holtec's MPC-HB 80-assembly basket without neutron absorber panels as modeled in KENO VI. 
The following assumptions were applied for HB as-loaded calculations:

- Gadolinium ( $1 \mathrm{wt} \% \mathrm{Gd}_{2} \mathrm{O}_{3}$ in 2 rods) was conservatively ignored in the $6 \times 6 \mathrm{HB}$ assemblies. Control blade insertion was assumed during the depletion period. As stated in Ref. A-2, control blade insertion provides the greatest impact on reactivity. Use of a full-length control blade insertion over an extraordinarily long depletion period is bounding for all anticipated reactor operation scenarios and negates the need to model burnable absorbers.

- Moderator density was assumed to be $0.49 \mathrm{gm} / \mathrm{cc}$ for $\mathrm{HB}$ fuel assemblies, which corresponds to $35 \%$ core average void fraction. [A-3]

- A uniform burnup profile was employed for the BWR fuel assemblies at the HB site. HB irradiated fuel assemblies are low burnup assemblies ( 1.3 to $23 \mathrm{GWD} / \mathrm{MTU})$. For PWR fuel assemblies, Ref. [10] determined that a uniform axial distribution is typically bounding for low burnup assemblies.

- For the damaged fuel and fuel debris, the bounding model defined in the SAR [24] was adopted for UNF-ST\&DARDS HB criticality analysis. Damaged fuel assemblies in the DFCs were modeled with 0.488 " pellet diameter and a $7 \times 7$ array of bare (without cladding) rods. The pitch of the $7 \times 7$ array was determined by the inner DFC width. For the damaged fuel and fuel debris in the DFCs, it was assumed that the fuel was present along the entire length of the DFC, including the areas that were not covered by the poison in the basket.

\section{Catawba (CTB)}

CTB unit 1 started its operation in 1985, while unit 2 started producing electricity in 1986. CTB employs the NAC UMS system (described in the main body of this report), which was also used by MY. CTB uses W $17 \times 17$ fuel assemblies. Twenty-four as-loaded CTB DPCs were analyzed. The CTB DPC basket components are stainless steel construction; hence, complete loss of neutron absorber was only considered as the potential degradation scenario.

\section{$\underline{\text { Salem (SL) }}$}

SL unit 1 started its operation in 1977, while unit 2 started producing electricity in 1981. SL uses the Holtec International's MPC-32 (described in the main body of this report), which is also being used by SQ. SL uses W $17 \times 17$ fuel assemblies. Seven as-loaded SL MPC-32 (DPCs) were assessed. Similar to SQ (Section 5.6, main body), if control components were present, they were considered in the criticality analysis. The MPC-32 is an all stainless steel canister; therefore, loss of neutron absorber was the only degradation scenario considered for the MPC-32.

Figure A-5 presents the as-loaded $k_{\text {eff }}$ of the three new sites (HB, CTB, and SL) analyzed in this appendix for the loss-of-neutron-absorber scenario. These new sites were evaluated using disposal isotopes. All the seven DPCs from SL and two DPCs from HB are above the representative subcritical limit in the calendar year 9999 . 


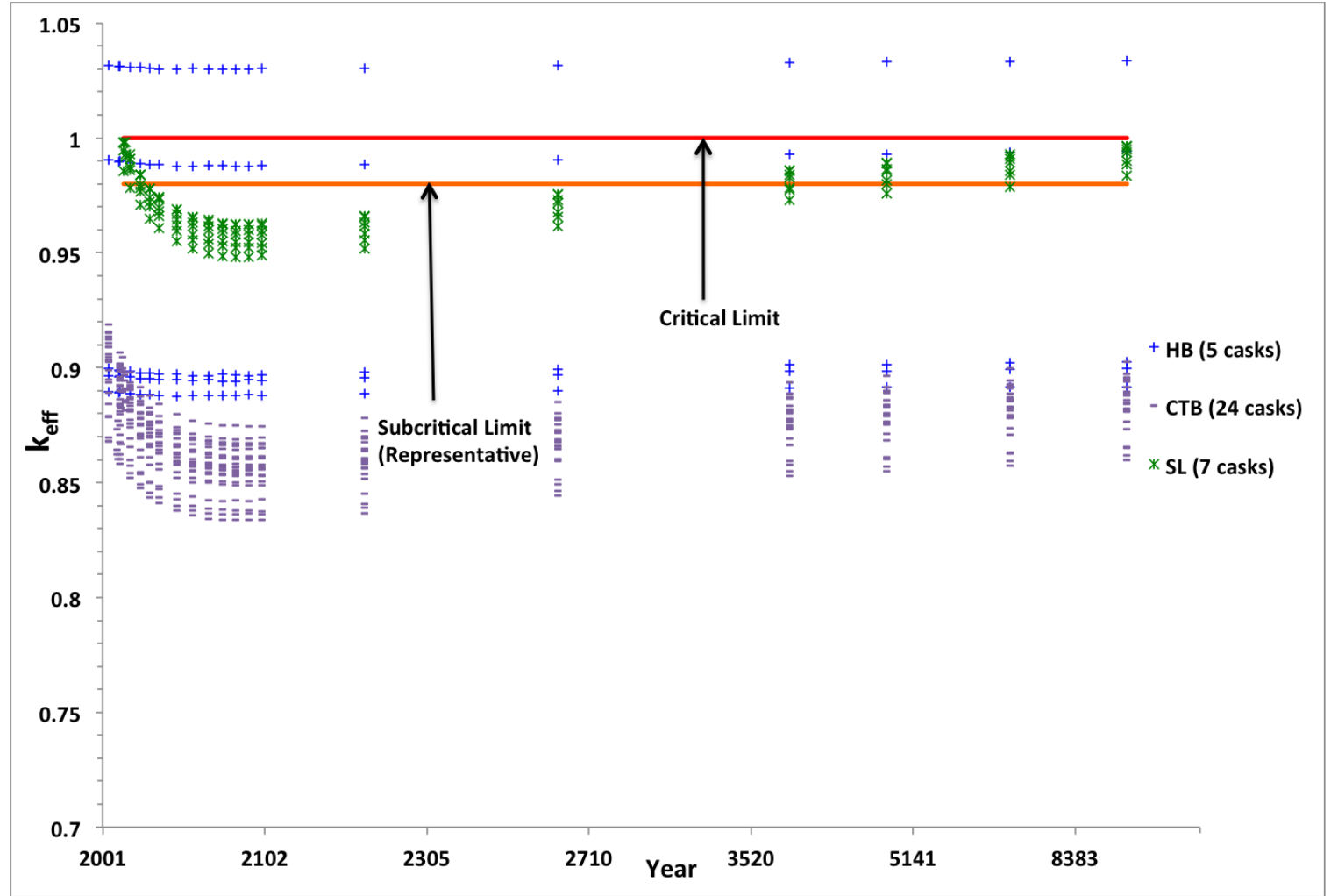

Figure A-5. $\boldsymbol{k}_{\text {eff }}$ vs. calendar year for the loss-of-neutron-absorber case, based on actual loading and disposal isotopes.

Table A-4 summarizes the analyses performed for the DPCs stored at the eight selected reactor sites. The summary results are presented for the calendar year 9999. Of the 215 DPCs analyzed, all would exceed the subcritical limit defined in this report $\left(k_{\text {eff }}>0.98\right)$ with loss of neutron absorbers if they were loaded with the design-basis fuel used for licensing. Using as-loaded fuel characteristics and burnup credit (29 nuclides), only 34 of the 184 (16\%) (none from RS site) would exceed the subcritical limit for the loss-of-neutron-absorber scenario. For the RS DPCs, 19 of the 20 DPCs would exceed the subcritical limit with the basket degradation scenario. Therefore, a total of 53 DPCs $(25 \%)$ would exceed the representative subcriticality limit with a loss-of-neutron-absorber scenario for MY, CY, TJ, SQ, HB, CTB, and SL sites and a loss-of-coated-carbon-steel-spacer-disks scenario for RS.

Table A-4. Summary of DPC As-loaded Criticality Analyses in the Calendar Year 9999

\begin{tabular}{ll}
\hline \multicolumn{1}{c}{ Description } & \multicolumn{1}{c}{ Value } \\
\hline $\begin{array}{l}\text { Total DPCs analyzed } \\
\text { Total DPCs that fail subcriticality with loss of neutron absorber (design- } \\
\text { basis loading) }\end{array}$ & 215 \\
\hline Total DPCs that fail subcriticality (as loaded) & $215(100 \%)$ \\
\hline Loss of neutron absorber & $34(16 \%)$ \\
Loss of neutron absorber and carbon steel structures & $53(34+19)$ \\
\end{tabular}




\section{A.4. AS-LOADED CRITICALITY ANALYSIS WITH CHLORIDES IN GROUNDWATER}

As mentioned in the main body report, neutron moderation by water is needed for a waste package to achieve criticality. However, the groundwater (or pore water) that may flood a breached DPC will contain various dissolved aqueous species. Seventeen species were studied in the main body and it was determined that $\mathrm{Cl}, \mathrm{Li}$, and $\mathrm{B}$ provide the maximum reduction in canister reactivity because of their large neutron absorption cross sections. However, available groundwater data indicate that $\mathrm{Cl}$ (as chloride) is the only naturally abundant neutron-absorbing element in groundwater that can provide significant reduction of reactivity and is available in most of the repository concepts under consideration in varying quantity.

In the main body of this report, three uniform canister loadings, namely, $10 \mathrm{GWd} / \mathrm{MTU}, 20 \mathrm{GWd} / \mathrm{MTU}$, and $30 \mathrm{GWd} / \mathrm{MTU}$ were used with a 32-assembly DPC and with different levels of neutron absorber in the basket for the study of reactivity reduction of dissolved aqueous species in groundwater. The objective of this generic study was to identify the most viable species that could be further credited in the as-loaded analysis. Additionally, the generic groundwater study presented in the main body could be used to approximately determine the reactivity impact $\left(\Delta k_{\text {eff }}\right)$ for a specified amount of a dissolved element.

In this section, the impact of $\mathrm{Cl}$ (in terms of $\mathrm{NaCl}$ ) concentration in groundwater on the reactivity of asloaded DPCs is studied. Figure A-6 presents the reactivity as a function of $\mathrm{NaCl}$ concentration in the calendar year 9999 for the DPCs at MY, SQ, CY, SL, and HB with loss of neutron absorber and at RS with a degraded basket. DPCs that yielded $k_{\text {eff }} 0.98$ or greater with fresh water were only analyzed with $\mathrm{NaCl}$ solution. Figure A-6 indicates that $\sim 0.9$ molal (moles of solute per kilograms of solvent) $\mathrm{NaCl}$ solution $(\sim 31,000 \mathrm{mg} / \mathrm{L} \mathrm{Cl})$ would be sufficient to maintain $k_{\text {eff }}$ below 0.98 for all the DPCs at MY, CY, RS, SQ, SL, and HB sites. Note that using the generic calculations in the main body it was approximated that $32,500 \mathrm{mg} / \mathrm{L} \mathrm{Cl}$ would be required to maintain $k_{\text {eff }}$ below 0.98 for the analyzed sites (Note that both in the main body and in this appendix a RS DPC yielded the maximum reactivity). In this context, it is also important to note that a saturated $\mathrm{NaCl}$ brine has a concentration of approximately 6 molal. 


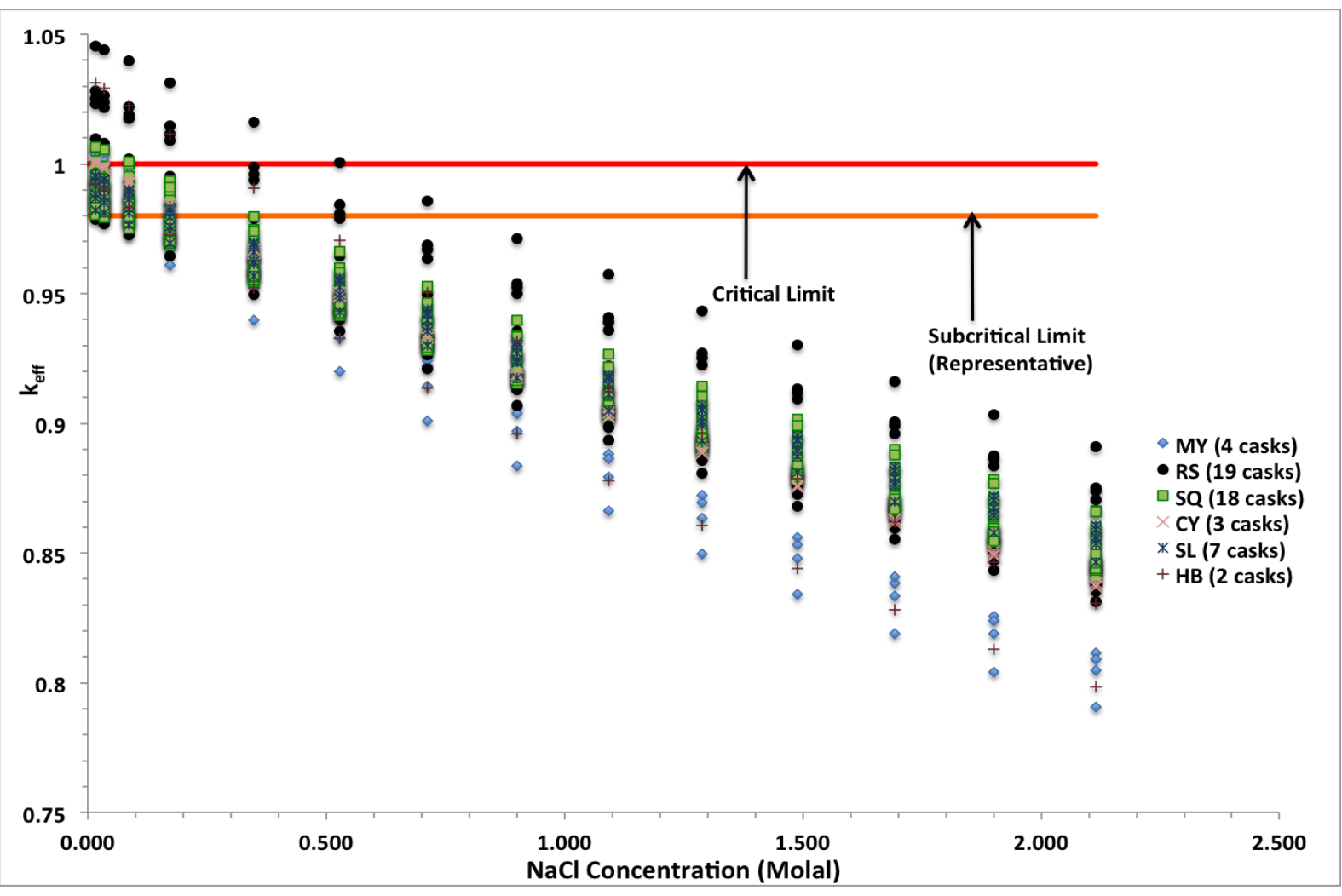

Figure A-6. $k_{\text {eff }}$ vs. NaCl concentration for the loss-of-neutron-absorber (MY, SQ CY, SL, and HB) and degraded basket (RS) cases based on actual loading.

\section{A.5. AS-LOADED CRITICALITY ANALYSIS WITH ENGINEERING FILLER MATERIALS}

An engineering option to mitigate the potential for DPC post-closure criticality is to fill the canister cavity with engineering filler materials that can prevent flooding of the DPC (moderator displacement) during the repository time frame. Filler material can also be selected to provide neutron absorption in addition to its moderator displacement functionality. Filler material options for direct disposal of DPCs are discussed in detail in Ref. A-4.

Criticality aspects (moderator displacement and neutron absorption) of filler materials are studied in Ref. A-4 using uniform DPC loading. In this section, the moderator displacement aspect of the filler materials is investigated using as-loaded DPCs at SQ. Aluminum was used as a representative filler material that only provides water displacement. Additionally, gibbsite $\left(\mathrm{Al}(\mathrm{OH})_{3}\right)$, which is a mineral of aluminum and can potentially form from aluminum in the presence of water over the repository performance period [A5], was also considered for this study. 58\% and 68\% volumetric mixtures of filler materials were considered. For example, $58 \%$ aluminum was modeled as aluminum slurry, which was a mixture of 58\% by volume aluminum powder and $42 \%$ by volume water. It is assumed that the filler material for the lossof-neutron-absorption scenario uniformly fills all the basket cells.

Figure A-7 presents reactivity as a function of filler material volume fraction for the DPCs at SQ (with loss of neutron absorber) for the calendar year 9999 . Only SQ DPCs that yielded $k_{\text {eff }} 0.98$ or greater with fresh water were analyzed with filler materials. The volume fraction was calculated by dividing the volume of the filler material in a basket cell by the free volume of that basket cell for the complete loss of neutron absorber case. Figure A-7 shows that about $34 \%$ volume (58\% volumetric mixture) is required to 
be filled (uniformly) by aluminum slurry to maintain $k_{\text {eff }}$ below 0.98 for all the DPCs at SQ in the year of 9999. The required filled volume fraction would be slightly lower with a $68 \%$ volumetric mixture of aluminum. However, if the aluminum turns into gibbsite (or other similar materials that react with water to form a hydrogenous compound) over the repository performance period, about $72.5 \%$ volume would be required to be filled. Any volume change that may occur because of aluminum to gibbsite conversion is not accounted for in this study. Note that aluminum is only used in this study as a representative material. Gibbsite (potential mineral form of aluminum over the repository performance period) is included in this study to show that the eventual mineral product(s) of a filler material and its criticality implication must be considered as a filler material selection criterion. Candidate filler materials and filling methods are discussed in Ref. A-4.

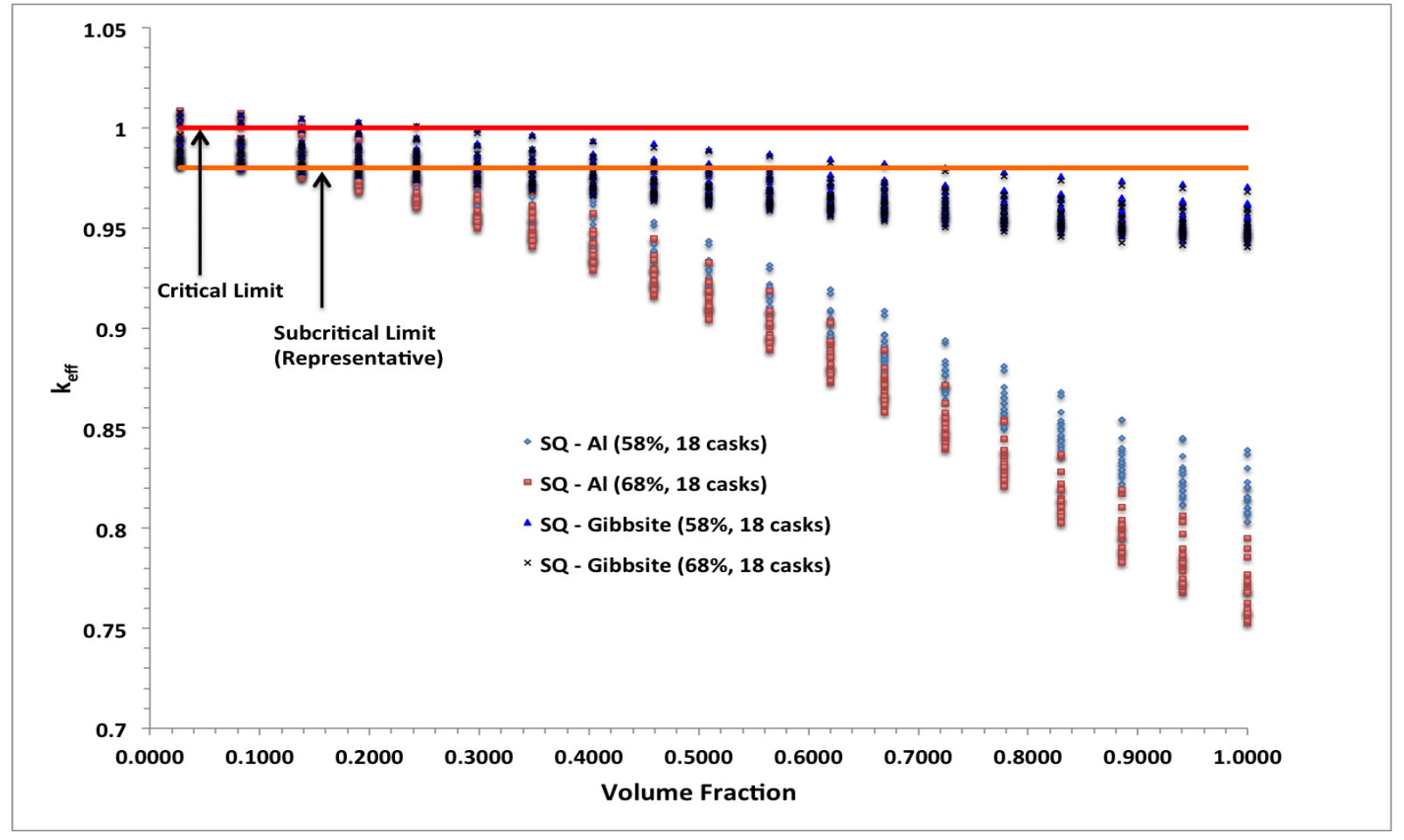

Figure A-7. Reactivity as a function of aluminum and gibbsite volume fraction for DPCs at SQ site.

\section{A.6. REACTIVITY IMPACT OF ${ }^{10} \mathrm{~B}$ AREAL DENSITY FOR AS- LOADED DPCS}

As mentioned in the main body of this report, the degradation mechanisms for both neutron absorber and basket structure components over repository timeframes are not well understood. However, sufficient information is not currently available to support a basis for assuming neutron absorber's continued presence in the basket to provide criticality control. As such, it is assumed that DPCs will lose their neutron absorber from the basket gradually over time. The reactivity effect of this gradual loss of neutron absorber is studied in this section. Note that only the ${ }^{10} \mathrm{~B}$ areal density has been varied for this study keeping the thickness of the absorber plates constant. Figure A-8 presents the reactivity variation of DPCs at SQ as a function of ${ }^{10} \mathrm{~B}$ areal density in the neutron absorber panels for the calendar year 9999 , assuming the DPC is flooded with fresh water. Only SQ DPCs (with complete loss of absorber) that yielded $k_{\text {eff }} 0.98$ or greater with fresh water were analyzed. Figure A-8 indicates that loss of neutron absorber from the basket up to a certain threshold ${ }^{10} \mathrm{~B}$ areal density would not significantly increase reactivity. However, when the loss of neutron absorber from the basket passes the threshold ${ }^{10} \mathrm{~B}$ areal 
density, significant reactivity increase is expected. Because only ${ }^{10} \mathrm{~B}$ areal density was varied for this study (keeping the thickness of the absorber plates constant), some of the DPCs, which were above 0.98 $\left(k_{e f f}\right)$ with complete loss of neutron absorber, are now slightly below 0.98 . This is expected as aluminum in the absorber plates provides some moderator displacement compared to the complete loss-of-absorber case. Note that the reactivity behavior with loss of neutron absorber from the basket is strongly related to the DPC geometry.

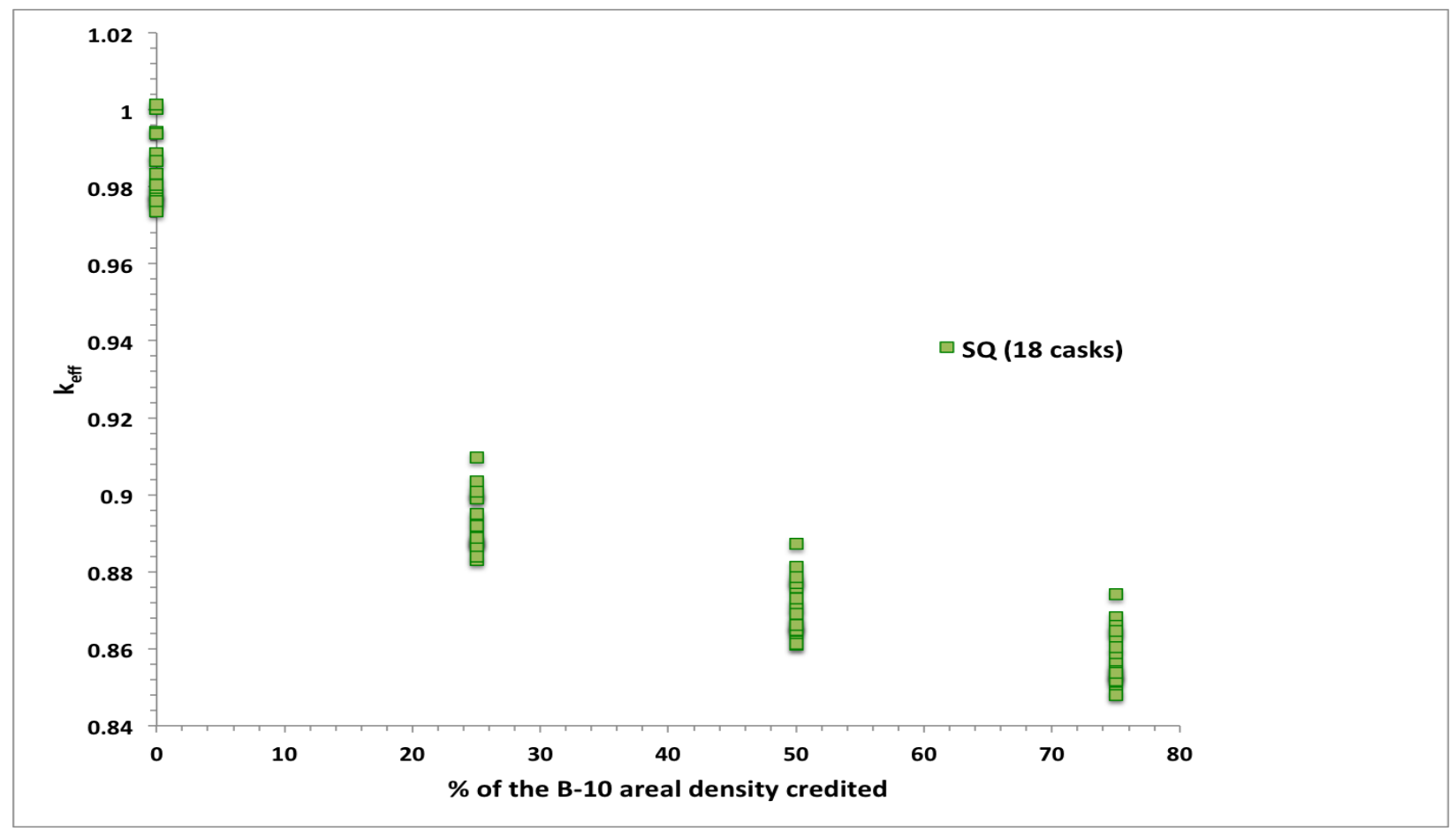

Figure A-8. Reactivity impact of ${ }^{10} B$ areal density variation for as-loaded SQ DPCs.

\section{A.7. CONCLUSION}

In this appendix, criticality analyses were performed using fresh water for six types of DPCs (total 215 DPCs) located at eight sites for two canister degradation scenarios: (1) loss of neutron absorber and (2) basket degradation. Twenty-nine principal isotopes as recommended in Ref. A-1 for post-closure criticality analysis were used. Conservatively, degraded materials (basket or absorber) were not credited in the criticality analysis because their locations within the basket were unknown. The main sources of reactivity margin (relative to licensing design basis analyses) investigated in this paper include:

- burnup credit for 29 actinide and fission product nuclides previously demonstrated to exhibit a significant effect on fuel reactivity, and

- use of actual as-loaded DPCs, crediting actual assembly design, and reactor depletion conditions.

Additional analyses were performed to calculate the amount of $\mathrm{Cl}$ required to maintain subcriticality (using the representative subcriticality limit) for the as-loaded DPCs at the eight evaluated sites. SQ DPCs were also analyzed with varying volume fractions of filler materials. The analyses performed in this report indicate that demonstrating subcriticality over a repository performance period may be attainable by combining detailed canister-specific analysis with full burnup credit and crediting $\mathrm{Cl}$ in the repository groundwater composition if it is available in high enough concentrations. Preconditioning measures such 
as adding filler materials to fill the canister void region and displace the moderator could be another option to mitigate post-closure criticality.

\section{A.8. REFERENCES}

A-1. US Department of Energy, Disposal Criticality Analysis Methodology Topical Report, YMP/TR004Q, Revision 2, Office of Civilian Radioactive Waste Management, October 2003.

A-2. J. M. Scaglione and J. C. Wagner, Review of Yucca Mountain Disposal Criticality Studies, Proceedings of the $13^{\text {th }}$ International High-Level Radioactive Waste Management Conference (IHLRWM), April 10-14, 2013, Albuquerque, NM.

A-3. Humboldt Bay site supplied document.

A-4. $\quad$ R. T. Jubin, K. Banerjee, and T. Severynse, Potential Dual-Purpose Canister (DPC) Filler Materials, FCRD-UFD-2014-000521 Rev. 0, US Department of Energy, Used Fuel Disposition R\&D Campaign, July 2014.

A-5. Office of Civilian Radioactive Waste Management Office of Repository Development, Geochemistry Model Validation Report: Material Degradation and Release Model, ANL-EBSGS-000001 REV 02 (September 2007). 


\section{APPENDIX B.} FY16 Criticality Study 
This page is intentionally left blank. 


\section{B.1. INTRODUCTION}

This appendix documents work performed supporting the US Department of Energy (DOE) Nuclear Energy (NE) Fuel Cycle Technologies Used Fuel Disposition under work breakdown structure element 1.02.08.03.07 - DR, "Disposal of Dual Purpose Canisters." In particular, this appendix fulfills the M4 milestone, M4FT-16OR080307011, "Update of DPC Direct Disposal Criticality Analysis Report" within work package FT-16OR08030701, "Disposal of Dual Purpose Canisters-ORNL."

This appendix presents the dual purpose canister (DPC) criticality evaluations performed in FY16 to support the feasibility determination of direct disposal of DPCs. This appendix extends the work reported in the main body of this report (FY14) and Appendix A (FY15). The main objectives of the FY16 DPC disposal criticality study included (1) development of a rule-based boiling water reactor (BWR) criticality analysis methodology to support as-loaded BWR analysis, (2) as-loaded criticality analysis of new sites, and (3) determination of maximum chlorine requirement to suppress criticality of canisters with potential to form critical configuration in a repository time frame. In FY16, 339 as-loaded canisters were analyzed from 16 sites, which extended the analyzed canister tally from 215 (analyzed over last two years) to 554 (23 sites).

\section{B.2. BWR AS-LOADED CRITICALITY ANALYSIS APPROACH}

The detailed justifications of the BWR as-loaded criticality analysis approach as implemented in UNF-ST\&DARDS is documented in Ref. B-1. UNF-ST\&DARDS uses the declared burnups and enrichments from DOE fuel inventory surveys [B-2] to perform criticality safety calculations that take full burnup credit (actinides and fission products) for BWR fuel bundles loaded in DPCs. Justification for the following features of the criticality analysis approach has been developed in Ref. B-1.

- Selection of axial burnup profiles for BWR fuel from publicly available sources (Selected profiles are meant to be conservative.)

- Justification for applying the selected axial burnup profiles to all types of BWR fuel

- Comparison of the axial features of the fuel from which the profiles were selected with the range of axial features of the population of fuel analyzed

- Justification for modeling the fuel assemblies with a uniform axial and radial enrichment (BWR fuel typically has a number of different enrichments which vary within a single axial segment [also known as a lattice] and as a function of elevation.)

- Justification for modeling the axial void profile as a single nominal value that does not change with elevation or time by using the margin associated with the conservative depletion assumption that control blades are fully inserted throughout the entire irradiation history of the fuel assembly

\section{B.3. SITES ANALYZED}

A total of 339 loaded DPCs at 16 sites were analyzed. Table B-1 presents the sites and DPCs analyzed. These 16 sites include three decommissioned sites: Zion, Yankee Rowe, and La Crosse. All the DPCs loaded at these sites were analyzed. The number of DPCs analyzed at each operating site is primarily based on the availability of DPC loading maps. Six DPC types were analyzed, including (1) Holtec International's MPC-32, (2) Holtec International's MPC-24, (3) Holtec International's MPC-68, (4) NAC International's TSC-37 (two variations with intact and damaged fuel assemblies), (5) NAC International's Yankee-MPC (36 assembly capacity), and (6) NAC International's MPC-LACBWR (68 assembly capacity). The criticality models of the DPC variants mentioned above are described in detail in Ref. B-1. Loss-of-neutron-absorber is the only degradation scenario considered in this appendix. 
Table B-1. List of sites and number of loaded DPCs assessed for criticality

\begin{tabular}{lccl}
\hline \multicolumn{1}{c}{ Site Name } & Number of DPCs & Fuel type & \multicolumn{1}{c}{ DPC type } \\
\hline Vermont Yankee & 13 & BWR & MPC-68 \\
Grand Gulf & 23 & BWR & MPC-68 \\
Columbia & 27 & BWR & MPC-68 \\
Salem & 9 & PWR & MPC-32 \\
Waterford & 9 & PWR & MPC-32 \\
Comanche Peak & 9 & PWR & MPC-32 \\
Browns Ferry & 40 & BWR & MPC-68 \\
River Bend & 19 & BWR & MPC-68 \\
Fitzpatrick & 21 & BWR & MPC-68 \\
Indian Point & 18 & PWR & MPC-32 \\
Farley & 21 & PWR & MPC-32 \\
Cook & 12 & PWR & MPC-32 \\
Arkansas Nuclear & 37 & PWR & MPC-24 and MPC-32 \\
One & & & \\
Zion & & PWR & TSC-37 \\
Yankee Rowe & 61 & PWR & Yankee-MPC \\
La Crosse & 15 & BWR & MPC-LACBWR \\
Total & 5 & & \\
\hline
\end{tabular}

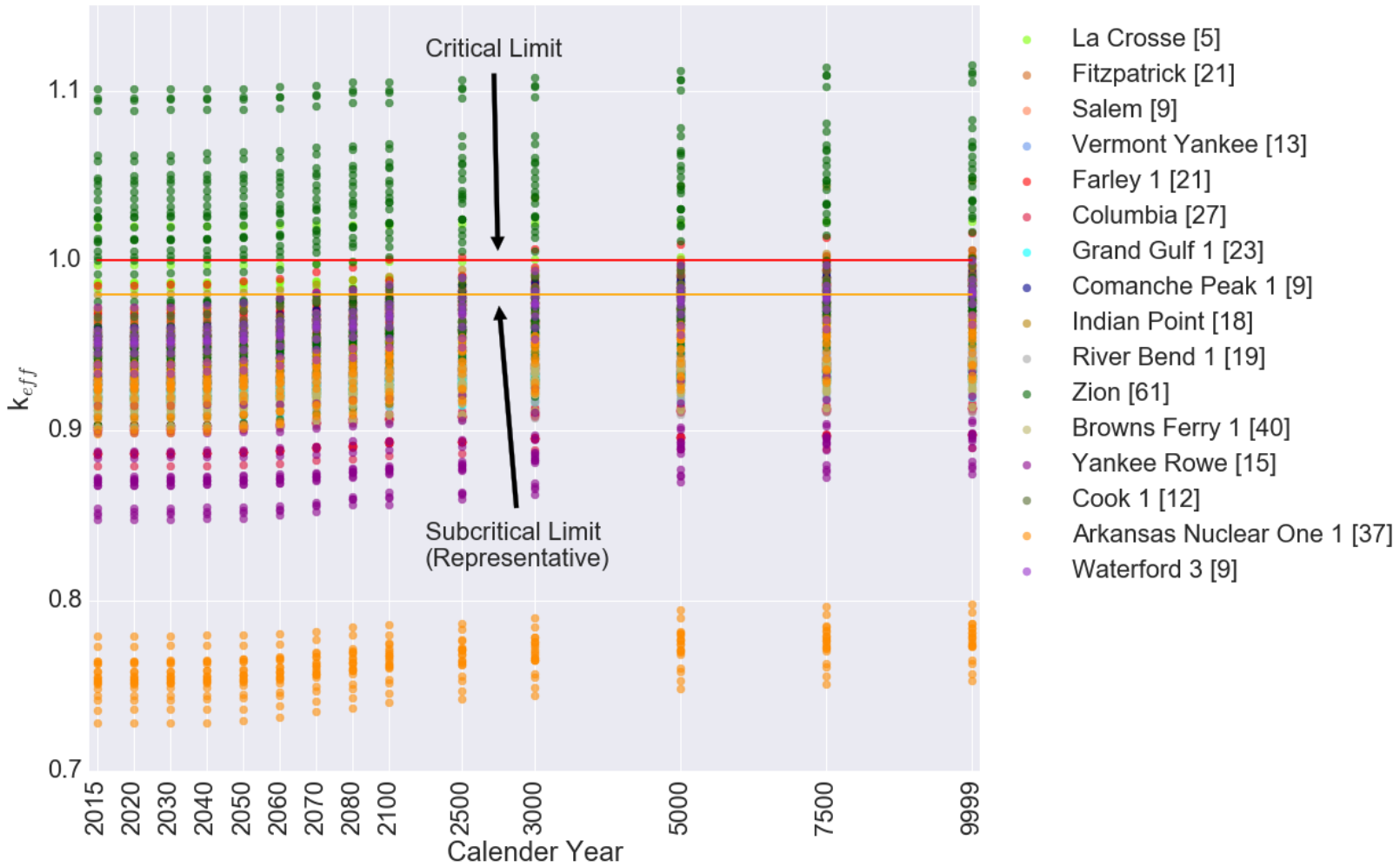

Figure B-1. $\boldsymbol{k}_{\text {eff }}$ vs. calendar year for the loss-of-neutron-absorber case, based on actual loading and disposal-isotopes. The number within the bracket indicates number of DPCs.

Figure B-1 presents the as-loaded $k_{\text {eff }} \mathrm{s}$ of the 16 sites analyzed in this appendix for the loss-of-neutronabsorber scenario. These new sites were evaluated using disposal isotopes (see Table A-1). Out of 339 DPCs, 92 are above the representative subcritical limit in the calendar year 9999. 
Table B-2 summarizes the criticality analysis performed for the DPCs to date. The summary results are presented for the calendar year 9999. Of the 554 DPCs (339 new and 215 from FY15) analyzed to date, all would exceed the subcritical limit defined in this report $\left(k_{e f f}>0.98\right)$ with loss of neutron absorbers if they were loaded with the design-basis fuel used for licensing. Using as-loaded fuel characteristics and burnup credit ( 29 nuclides), only 126 (92 + 34 from FY15 analysis) of the 554 (23\%) would exceed the subcritical limit for the loss-of-neutron-absorber scenario. Of the RS DPCs, 19 of the 20 DPCs would exceed the subcritical limit with the basket degradation scenario. Therefore, a total of 145 DPCs (26\%) would exceed the representative subcriticality limit with a loss-of-neutron-absorber scenario for all the analyzed DPCs and a loss-of-coated-carbon-steel-spacer-disks scenario for the RS site.

Table B-2. Summary of DPC as-loaded criticality analyses in calendar year 9999

\begin{tabular}{ll}
\hline \multicolumn{1}{c}{ Description } & \multicolumn{1}{c}{ Value } \\
\hline $\begin{array}{l}\text { Total DPCs analyzed } \\
\text { Total DPCs that fail subcriticality with loss of neutron absorber (design- } \\
\text { basis loading) }\end{array}$ & 514 \\
\hline Total DPCs that fail subcriticality (as loaded) & $215(100 \%)$ \\
\hline Loss of neutron absorber & $126(\sim 23 \%)$ \\
Loss of neutron absorber and carbon steel structures (RS only) & $145(126+19)$ \\
& $(\sim 26 \%)$ \\
\hline
\end{tabular}

\section{B.4. AS-LOADED CRITICALITY ANALYSIS WITH CHLORIDES IN GROUNDWATER}

In this section, the impact of $\mathrm{Cl}$ (in terms of $\mathrm{NaCl}$ ) concentration in groundwater on the reactivity of asloaded DPCs is studied. Figure B-2 presents the reactivity as a function of $\mathrm{NaCl}$ concentration in the calendar year 9999 for the DPCs at Farley, Indian Point, Cook, Salem, Waterford, Zion, La Crosse, and Comanche Peak with loss of neutron absorber. DPCs that yielded $k_{\text {eff }} 0.98$ or greater with fresh water and loss of neutron absorber were only analyzed with $\mathrm{NaCl}$ solution. Figure B-2 indicates that $\sim 1.8$ molal (moles of solute per kilograms of solvent) $\mathrm{NaCl}$ solution $(\sim 64,000 \mathrm{mg} / \mathrm{L} \mathrm{Cl})$ would be sufficient to maintain $k_{\text {eff }}$ below 0.98 for the analyzed DPCs at the 16 sites. In this context, it is also important to note that a saturated $\mathrm{NaCl}$ brine has a concentration of approximately 6 molal. 


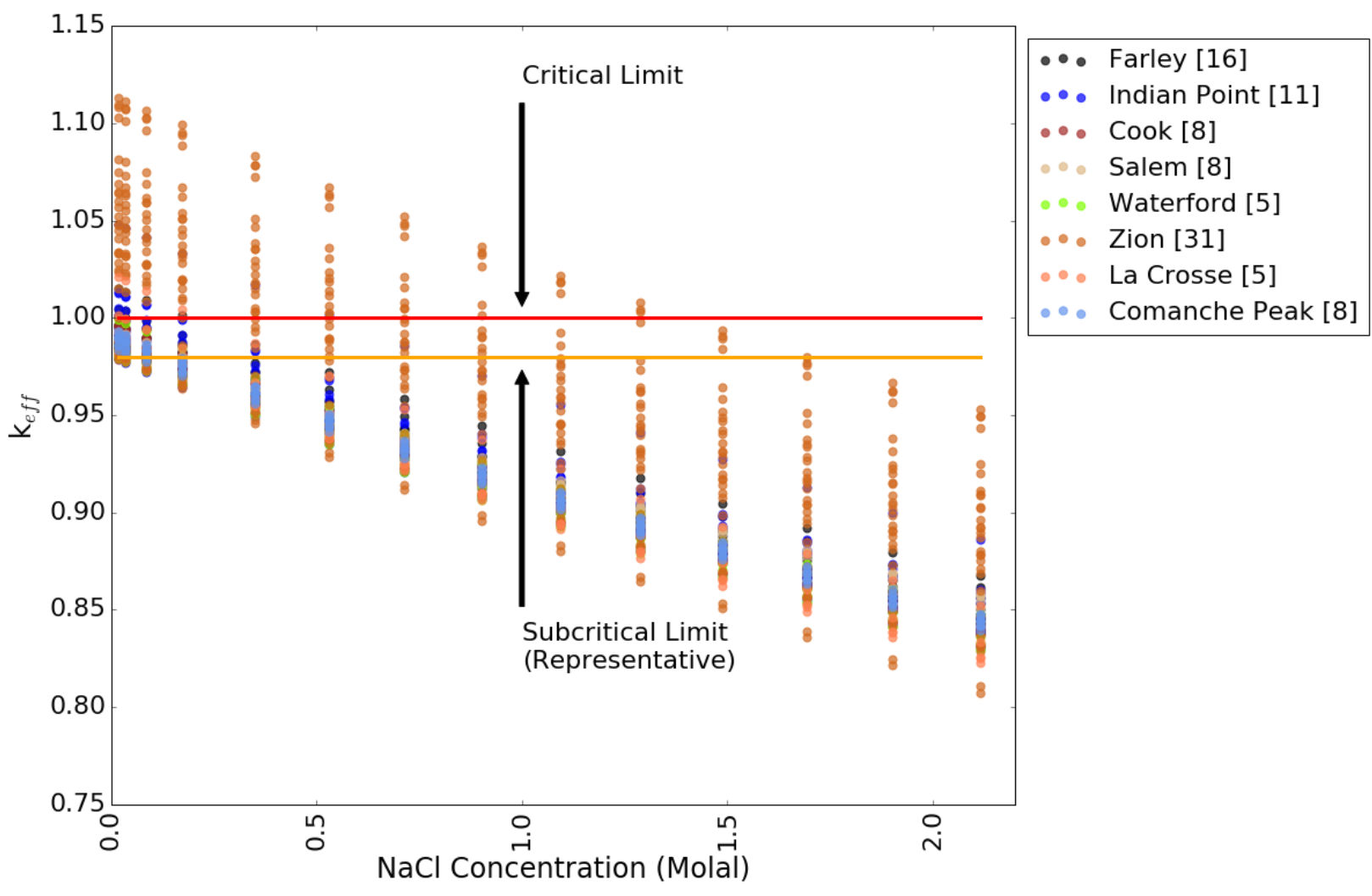

Figure B-2. $\boldsymbol{k}_{\text {eff }}$ vs. NaCl concentration for the DPCs with $\boldsymbol{k}_{\text {eff }}>\mathbf{0 . 9 8}$ for the loss-of-neutron-absorber scenario. (Numbers in brackets $=$ number of DPCs).

\section{B.5. CONCLUSION}

This appendix presents criticality analyses that were performed using fresh water for six types of DPCs (total 339 DPCs) located at 16 sites for loss-of-neutron-absorber degradation scenarios. Twenty-nine principal isotopes were used as recommended in Ref. A-1 for post-closure criticality analysis.

Conservatively, degraded materials (basket or absorber) were not credited in the criticality analysis because their locations within the basket were unknown. Figure B-3 presents the updated criticality roadmap from Figure 25 in the main body of this report. As noted above, this year an approach has been developed for as-loaded BWR criticality analysis. Although the BWR burnup credit methodology development box is marked as green in Figure B-3, the BWR analysis approach developed in FY16 may require some minor refinements to support all BWR fuel types.

Additional analyses were performed to calculate the amount of $\mathrm{Cl}$ required to maintain subcriticality (using the representative subcriticality limit) for the as-loaded DPCs at the 16 evaluated sites. Analyses performed as discussed in this appendix for the 339 as-loaded DPCs show that $\sim 1.8$ molal $\mathrm{NaCl}$ would be sufficient to maintain subcriticality in all the analyzed DPCs, while $\sim 0.9$ molal $\mathrm{NaCl}$ requirement were determined for the 215 DPCs analyzed and presented in Appendix A. The increase in reactivity and corresponding $\mathrm{NaCl}$ requirement are mainly due to the Zion canisters loaded with damaged fuel assemblies, which were modelled as unirradiated. Damaged fuel modeling approach needs to be refined for improved reactivity evaluation of loaded canisters with damaged fuels. Therefore, for all the analyzed DPCs (554), current maximum $\mathrm{NaCl}$ requirement would be $\sim 1.8$ molal. The analyses performed in this report indicate that demonstrating subcriticality over a repository performance period may require both detailed canister-specific analysis with full burnup credit and crediting $\mathrm{Cl}$ in the repository groundwater composition if it is available in high enough concentrations. Studies presented in Appendix A also show 
that preconditioning measures - such as adding filler materials to fill the canister void region and displace the moderator - could be another option to mitigate post-closure criticality. The next step in support of the filler material approach would be to conduct an experiment to determine the viability of filling a DPC up to a predetermined volume and using various filling options conceptualized in Ref. A-4.

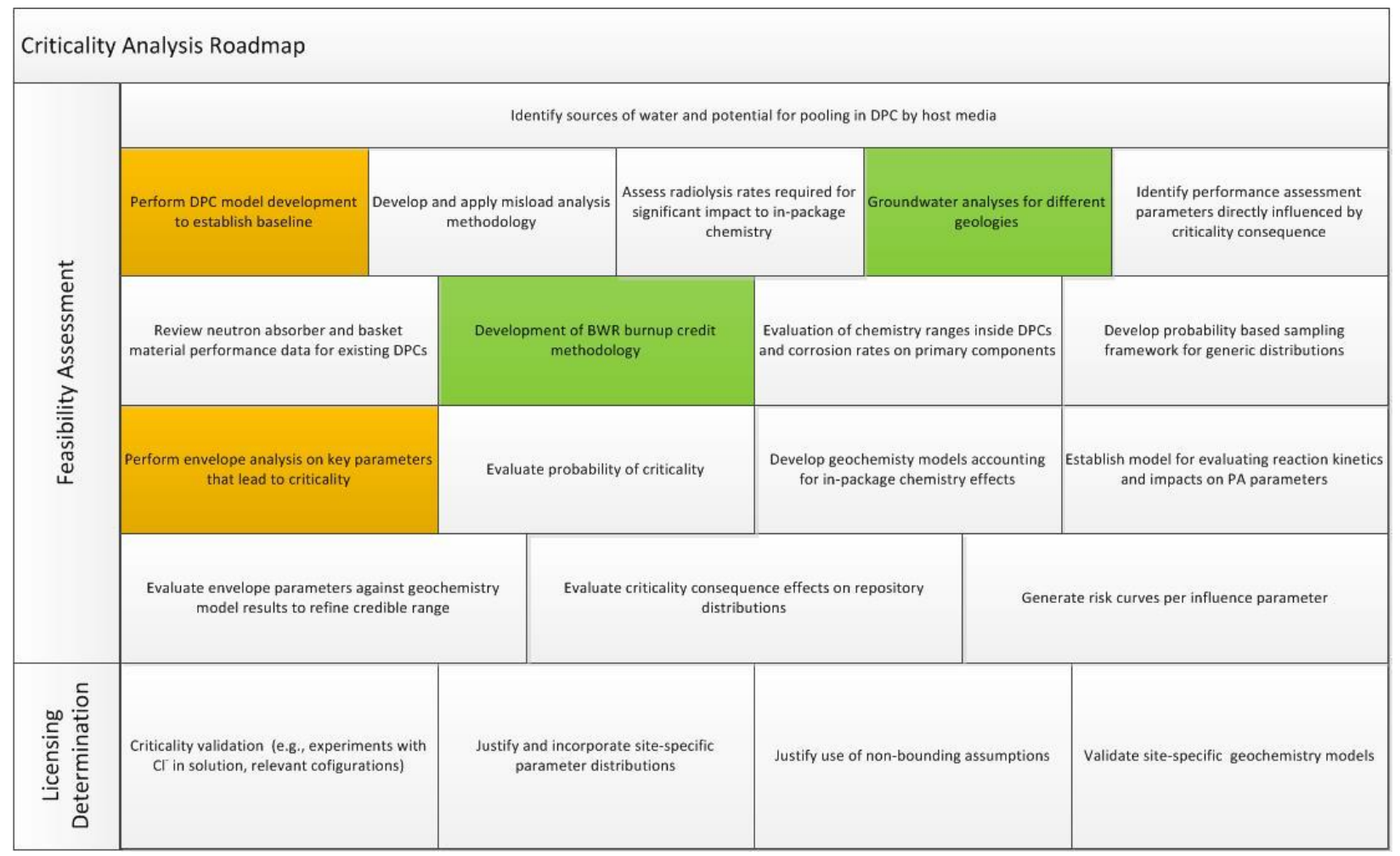

\section{B.6. REFERENCES}

B-1. J. B. Clarity, H. Liljenfeldt, and K. Banerjee, Criticality Process, Modeling and Status for UNFST\&DARDS, FCRD-NFST-2015-000440, Rev. 1, US Department of Energy, Nuclear Fuel Storage and Transportation Planning Projects (July 2016).

B-2. "Nuclear Fuel Data Survey," Form GC-859, EIA, Washington, DC (July 2012). 
This page is intentionally left blank. 
This page is intentionally left blank. 


\section{C.1. INTRODUCTION}

This appendix documents work performed supporting the US Department of Energy (DOE) Nuclear Energy (NE) Spent Fuel and Waste Disposition (SFWD) Spent Fuel and Waste Science and Technology under work breakdown structure element 1.08.01.03.05 "Direct Disposal of Dual Purpose Canisters." In particular, this appendix fulfills the M4 milestone, M4SF-17OR010305022, "Initial development of a misload analysis methodology" within work package SF-17OR01030502, "Direct Disposal of Dual Purpose Canisters - ORNL."

This appendix presents the assembly misload analysis methodology developed in FY17 to support the feasibility determination of the direct disposal of DPCs from a criticality perspective. The main objective was to develop a misload analysis methodology to support as-loaded criticality analysis of the loaded DPCs. The misload analysis has been applied to 99 loaded DPCs at three sites. The analyzed sites include both PWR and BWR reactors and three canister variants-MPC-32, TSC-37 and MPC-68.

\section{C.2. MISLOAD DEFINITION AND REGULATORY GUIDANCE}

In 2002, the US Nuclear Regulatory Commission issued the revision 2 to Interim Staff Guidance 8, "Burnup Credit in the Criticality Safety Analyses of PWR Spent Fuel in Transportation and Storage Casks" (ISG 8 rev. 2). This document provides guidance for taking burnup credit for storage and transportation casks. If the wrong assembly is placed in the right position, or if the right assembly is placed in the wrong position, it is considered a misload and requires analysis for any storage or transportation system that uses burnup credit. The ISG 8 rev. 2 only mentioned pool-side burnup measurements as an acceptable method to prevent misloads.

In 2012 the revision 3 of the Interim Staff Guidance 8 "Burnup Credit in the Criticality Safety Analyses of PWR Spent Fuel in Transportation and Storage Casks" (ISG 8 rev. 3), Reference C-1, was issued with updated guidance for misload analyses, stating that

Misload analyses may be performed in lieu of a burnup measurement. A misload analysis should address potential events involving the placement of assemblies into a SNF storage or transportation system that do not meet the proposed loading criteria... .

A misload analysis should consider:

- misloading of a single severely underburned assembly and,

- $\quad$ misloading of multiple moderately underburned assemblies.

ISG 8 rev. 3 continues, defining a single severely underburned assembly:

The severely underburned assembly for the single misload analysis should be chosen such that the misloaded assembly reactivity bounds $95 \%$ of the discharged PWR fuel population considered unacceptable for loading in a particular storage or transportation system with $95 \%$ confidence.

It also defines the moderately underburned assemblies:

The multiple moderately underburned assemblies for this analysis should be assumed to make up at least $50 \%$ of the system payload, and should be chosen such that the misloaded assemblies' reactivity bounds $90 \%$ of the total discharged PWR fuel population.

Finally, it designates the location in the cask where the misloaded assembly should be placed:

"The misload analysis should also consider the effects of placing the underburned assemblies in the most reactive positions within the loaded system (e.g., middle of the fuel basket)."

ISG 8 rev. 3 was written to support the current standard practice of design basis criticality analysis that uses uniform or symmetric zone loading with bounding fuel characteristics (e.g., fuel type, enrichment, burnup) to accommodate loading of discharged assemblies with diverse characteristics. For uniform and 
symmetric loading, it is straight forward to determine the most reactive position(s) in the canisters. On the other hand, the determination of the most reactive position(s) in an actual loaded canister for as-loaded criticality analysis being used for direct disposal of DPCs is more involved mainly due to the nonsymmetric reactivity distribution.

\section{C.3. ASSEMBLY MISLOAD METHODOLOGY}

This section describes a misload analysis methodology to support as-loaded criticality analysis for a given site and a given canister. The methodology is based on the ISG 8 rev. 3 but is extended to include BWR assemblies supported by the BWR burnup credit methodology described in Reference C-2 and also cover the scenario where the right assemblies are being placed in the wrong position. The placement of the right assembly in the wrong position is a more likely misload scenario to go undetected in the disposal scenario since taking the wrong assembly would be discovered in subsequent canister loadings.

The methodology has been fully implemented and automated in UNF-ST\&DARDS by using and extending the existing criticality analysis capabilities described in Reference C-2 including doing the analysis for year 9999 and using the assumptions for loss of neutron absorbers and degradation of carbon steel baskets. The misload analysis methodology is described below:

1. Select a site and canister.

2. Determine what discharged assemblies were in the pool (and any connected pool) during canister loading.

3. Determine the individual reactivity of each assembly available in the pool, as well as the assemblies in the loaded cask.

4. Identify the single severely underburned assembly and the multiple moderately underburned assemblies as described in Section C.3.1.

5. Generate a criticality importance map (i.e. how important is a canister position in terms of its contribution to the total criticality of the canister) for the canister model from fission densities using a uniform fuel loading as described in Section C.3.2.

6. Perform a criticality calculation using two approaches for a single assembly misload as described in Section C.3.3.

7. Perform a criticality calculation of the multiple assembly misload as described in Section C.3.4.

8. Perform a criticality calculation for the worst possible configuration assuming right assemblies were placed in wrong positions as described in Section C.3.5.

9. The highest $k_{\text {eff }}$ from steps $5-7$ above is the misload analysis result.

The methodology also assumes that damaged fuel loaded in damaged fuel cans has not been misloaded as the damaged fuel cans in general only fits in certain oversized positions inside the canister. It also assumes that no prior misloads have changed the inventory of the pools at the time of loading the analyzed canister.

\section{C.3.1. Identification of Underburned Assemblies}

To determine which underburned assemblies are to be considered for misload analysis, the Unified Database (UDB) within UNF-ST\&DARDS is queried for assemblies that were present in the pool at the time the canister was loaded. A criticality calculation is performed on each of those assemblies using UNF-ST\&DARDS and assuming one centimeter of water around the assembly, reflecting boundary conditions, a cooling time approximately the same as the analysis date (in our disposal case 7500 years) $n$, and using the disposal burnup credit isotopes presented in table 2. The result is a distribution of $k_{\text {inf }}$ (see Figure C-1) that can be used to rank the assemblies in the pool according to reactivity. 


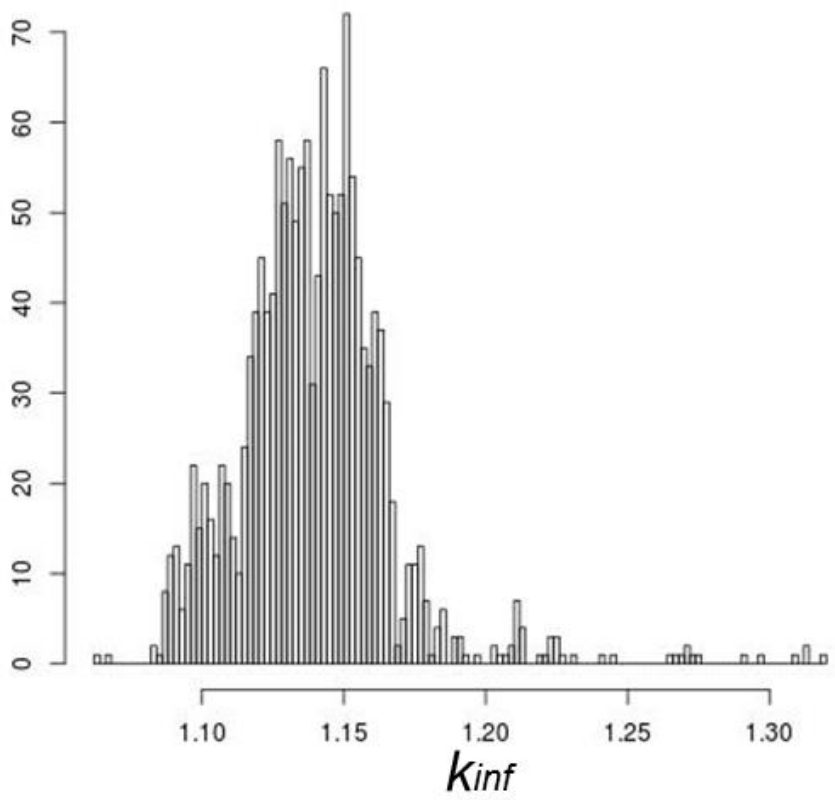

Figure C-1. Example distribution of $k_{\text {inf }}$ for all assemblies in a pool at the time of loading a specific canister at a specific site. $Y$-axis shows number of assemblies in each bin.

For the analysis of the single severely underburned assembly, the most reactive assembly available is used as shown in Figure C-2 (left figure). For the moderately underburned assemblies, the first step is to identify the assembly that bounds $90 \%$ of the available discharged inventory. The assemblies corresponding to $50 \%$ of the analyzed cask (e.g., 16 for MPC-32, 19 for TSC-37) are selected as the moderately underburned assemblies in ascending reactivity order from the assembly that bounds $90 \%$ of the discharged inventory (Figure C-2, right figure).
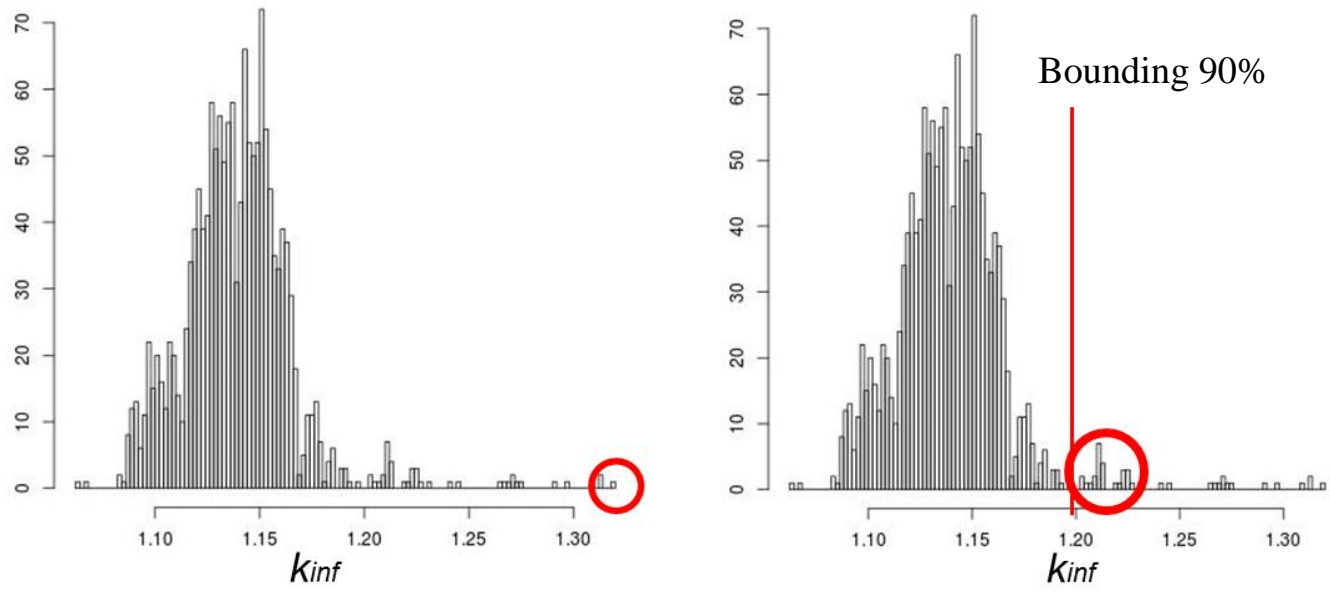

Figure C-2. The single severely underburned assembly (circled in red in the left plot) is the assembly with the highest $\boldsymbol{k}_{\text {inf }}$. The multiple moderately underburned assemblies (circled in red in the right plot) are selected as the number of assemblies corresponding to $50 \%$ of the cask payload with the lowest available reactivity that bounds $90 \%$ (red line in right plot) of the assemblies available in the pool. Y-axis shows number of assemblies in each bin. 


\section{C.3.2. Generation of Criticality Importance Map Independent of}

A criticality calculation is run to determine the most reactive region in a uniformly loaded canister. Based on the fission reaction rates in each position (canister cell), a zoned criticality importance map can be derived independent of actual loading (Figure C-3) for an MPC-32 cask design.
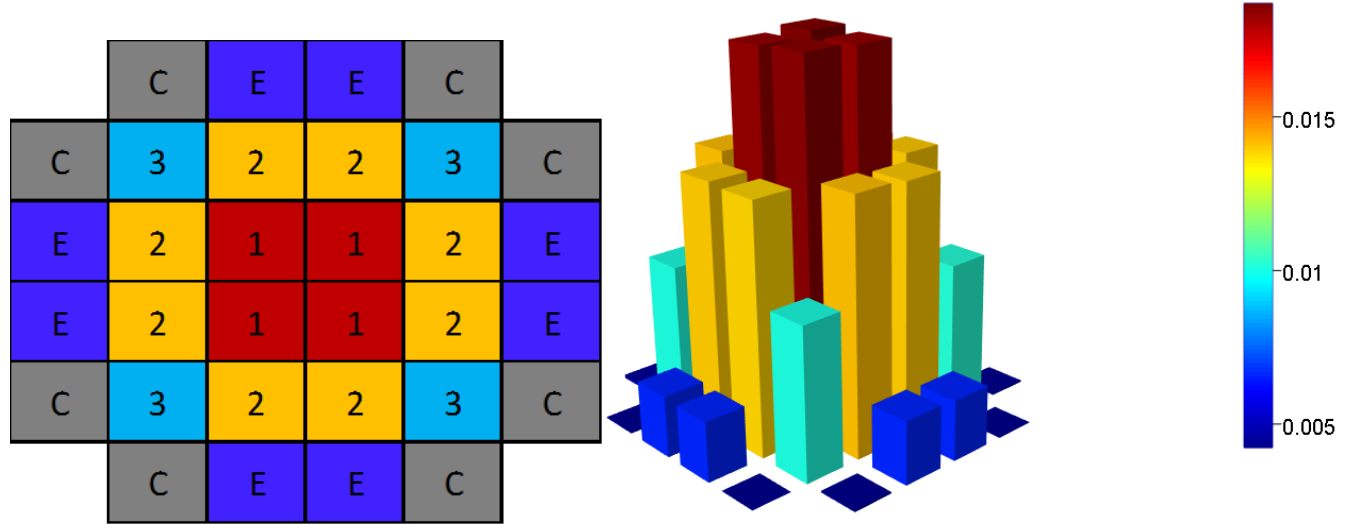

Figure C-3. A loading independent criticality importance map (left) generated by ranking the highest (indicated by 1) to lowest number of fissions generated in each position (canister cell) of a uniformly loaded MPC-32 canister. Both $\mathrm{E}$ (edge) and $\mathrm{C}$ (corner) are excluded from misloads due to high leakage. The right figure shows the fission reaction rate at each cell location.

This criticality importance map is similar to the map used in a regular uniform misload analysis in accordance to ISG-8, rev3. However, this importance map based on uniform loading is not suitable to be directly used in the as-loaded analysis.

\section{C.3.3. Single Assembly Misload Analysis for As-Loaded Canister}

Since each position in the cask for the as-loaded analysis is unique when it comes to reactivity, the most reactive position in the cask depends heavily on the loading of the canister and the reactivity of the selected assembly for misload. For the three sites evaluated in this work, two approaches were used to determine the most reactive single assembly misload.

The first approach includes analysis of the cask-specific fission density map that is automatically acquired by performing a regular as-loaded criticality analysis in UNF-ST\&DARDS (Figure C-4). ISG 8 rev. 3 recommends that the assembly be placed in the most reactive position, which corresponds to the position with the highest number of fissions. The assembly in the position with the highest number of fissions is replaced by the severely underburned assembly identified previously. 

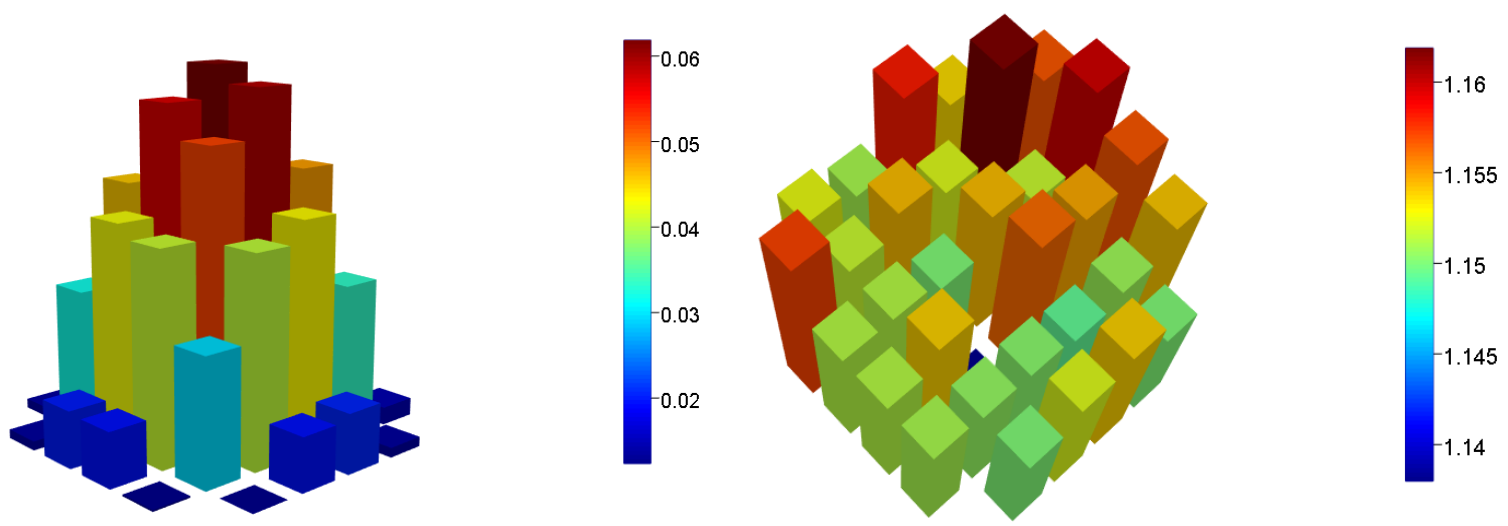

Figure C-4. Number of fissions (left) and individual assembly reactivity (right)
for each position of an as-loaded MPC-32 cask.

For most as-loaded analysis cases, this approach takes out the most reactive assembly from the center region of the canister, which, depending on the loading, could actually lower the cask reactivity. A better approach for those cases would be to replace one of the assemblies neighboring the highly reactive one to drive up the system's reactivity.

The second approach is therefore to determine which of the neighboring positions would drive the system reactivity the most if misloaded with a highly reactive assembly from the pool. The neighbors are filtered based on the importance map shown in Figure C-3 to find the neighbor closest to the center and compare the individual assembly reactivity (Figure C-4) to select the one with the lowest individual assembly reactivity value. This assembly is the one assembly impacting the most reactive position in the most significant negative direction.
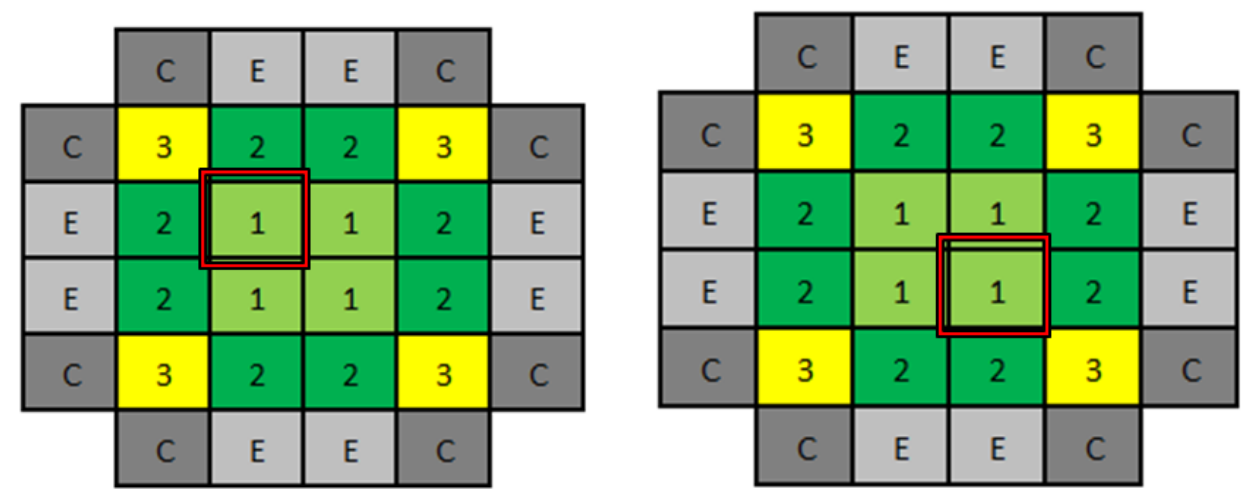

Figure C-5. Identified position for single assembly misload using highest reactivitiy approach (left) and neighbor nearest center with lowest reactivity approach (right)

These two approaches were used for the three sites analyzed to determine the highest reactivity increase in case of a misload. This methodology is expected to be consistent for all other designs and loadings. For the example cask shown in Figure C-4, the misloaded positions are shown in Figure C-5 and are both located at different locations in the center of the cask. The reactivity increase from placing the single severely underburned assembly in a position is shown in Figure C-6. In this example, the two positions with the highest reactivity increase were identified using the two approaches. 

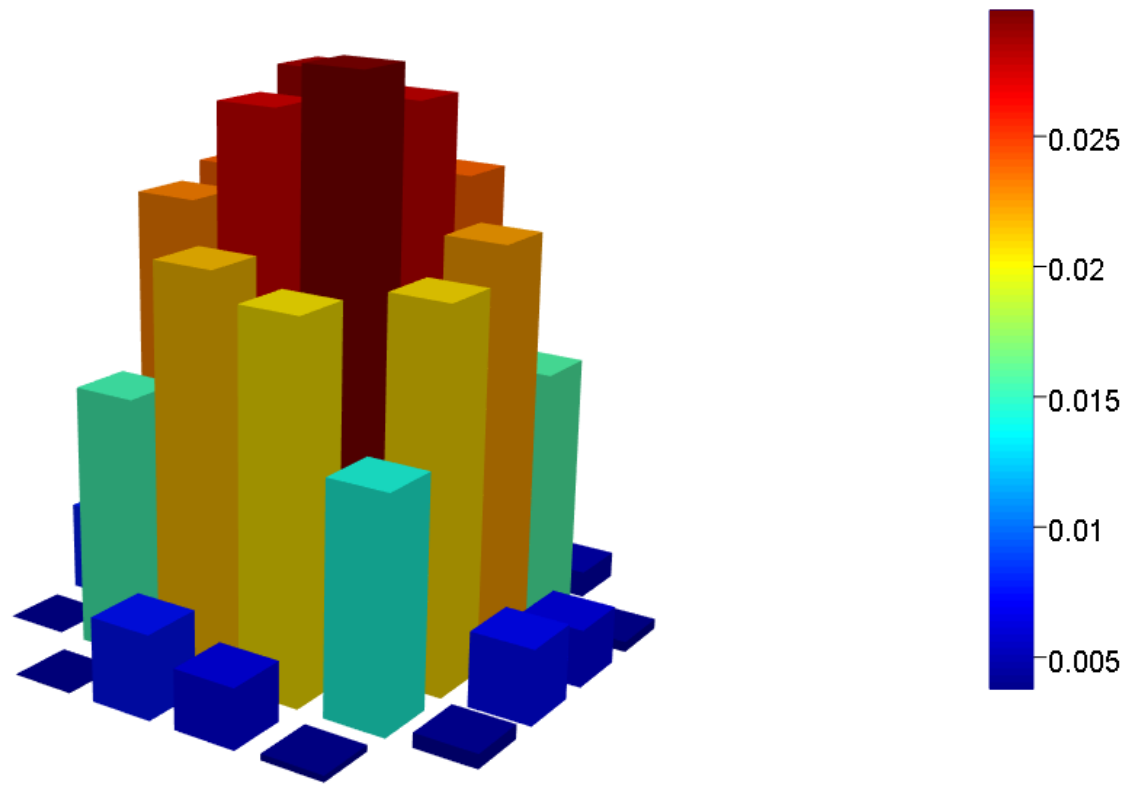

Figure C-6. Increase in reactivity from misloading the position with the single severely underburned assembly.

\section{C.3.4. Multiple Assembly Misload}

ISG 8 rev. 3 suggests that the analysis of multiple moderately underburned assemblies assumes that at least $50 \%$ of the payload is misloaded. The approach used to determine the multiple assembly misload is similar to the single position approach, but the position with the highest number of fissions does not need to be identified. Instead, the most reactive of the identified moderately underburned assemblies will be placed in the most center position according to the importance map in Figure C-3. If several positions have the same importance, the position with the lowest cell position number will be loaded. The resulting misload order for an MPC-32 canister is shown in Figure C-7.

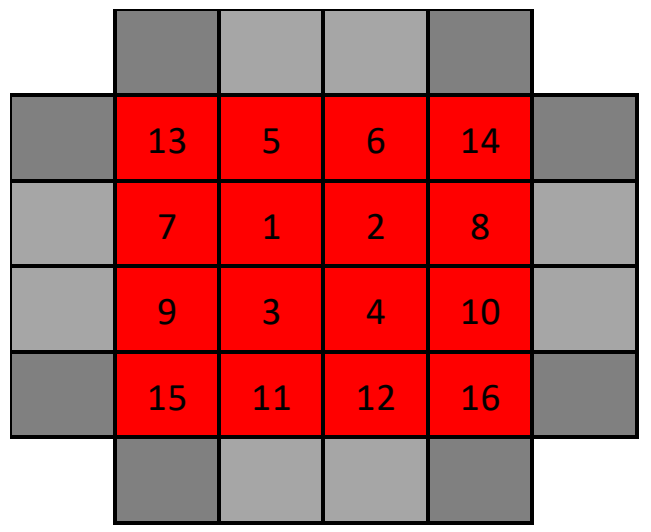

Figure C-7. Loading priority for an example as-loaded canister with multiple moderately underburned assembly misload based on the importance map and position cell number. The red positions indicate misloaded positions, while the others are still the as-loaded positions. 


\section{C.3.5. Worst and Optimal Configuration in an As-Loaded Canister}

For as-loaded analysis, a third misload must be considered that is not applicable for the regular bounding analysis. The third misload is for the case in which the correct assemblies have been loaded into the canister in the wrong order. This scenario is the most likely scenario for disposal, as the previously mentioned, single severely underburned assembly and multiple moderately underburned assembly misloads are likely to be identified long before disposal.

The approach to account for this misload scenario is to rank all assemblies by their individual reactivities and then place them in the canister with the most reactive assembly closest to the center according to the importance map.

By reversing the order as discussed above, the lowest reactive optimal configuration is achieved. This is not a misload analysis scenario, but it can be used as a measure of how reactive the actual loading is compared to the optimal and worst configuration using the same assemblies. It may also be used for planning future loading campaigns to reduce reactivity of each loaded canister to support direct disposal of DPCs.

\section{C.4. RESULTS}

The misload methodology described above was used to evaluate three different sites with three different canister designs. All canister criticality calculations presented in this section have been performed using the UNF-ST\&DARDS criticality process described in Reference C-2 for the loss-of-neutron-absorber degradation scenarios in year 9999 . This is the same process used in the previous analyses in this report described in Appendix A and Appendix B.

\section{C.4.1. Sequoyah (operating reactor site), $27 \mathrm{MPC}-32$ Canisters}

Figure C-8 shows the result from the individual assembly reactivity calculations from the pool inventory at Sequoyah. Most assemblies have $k_{\text {inf }}$ values distributed between 1.05 and 1.20, although a few assemblies have reactivity up to approximately 1.31 . This suggests that the impact of a single severely underburned assembly misload could have a significant impact on the canister reactivity.
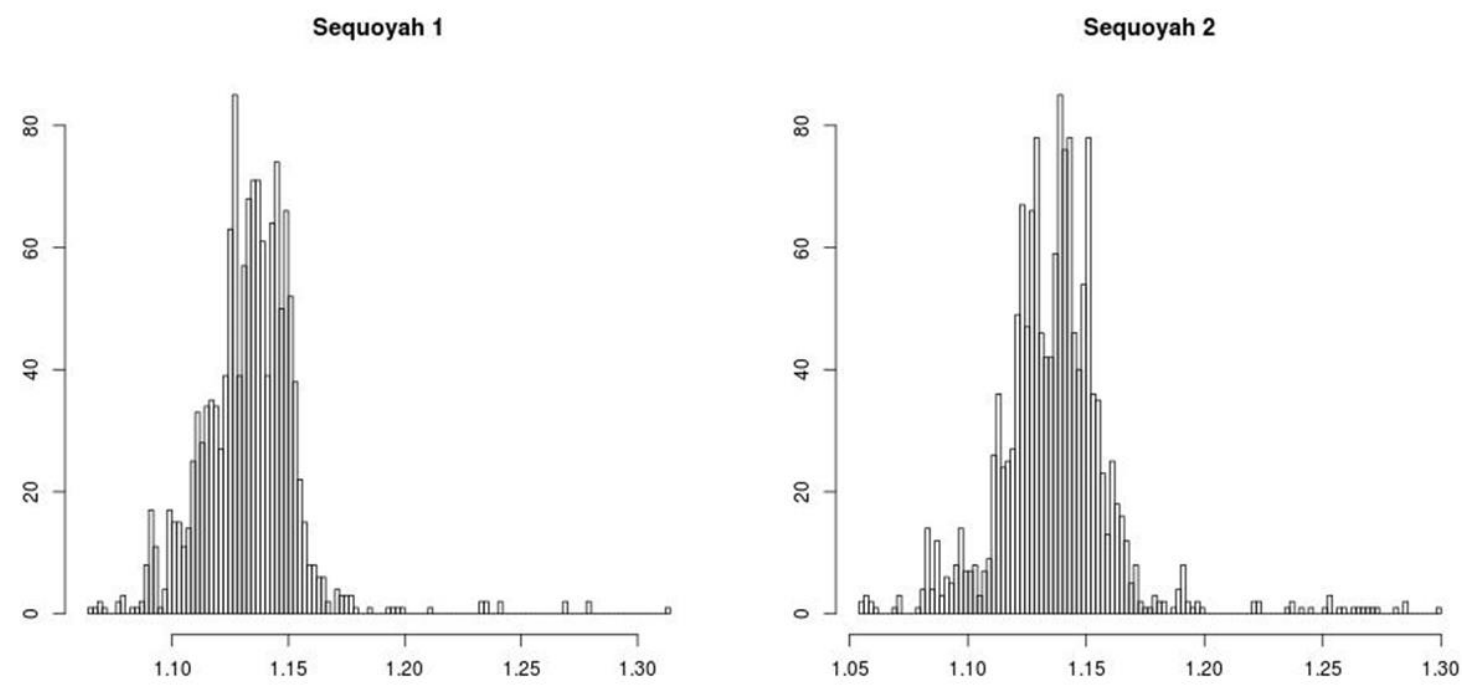

Figure C-8. Individual assembly reactivity distribution for the pool inventory at Sequoyah 1 and 2. $\mathrm{Y}$-axis shows number of assemblies in each bin. 
Figure C-9 depicts the as-loaded reactivity (presented by red dots) along with the reactivity variation between worst and optimal configurations (presented by vertical line). A large range indicates that the inventory is diverse, with some highly reactive assemblies and some low reactive assemblies, while a short range indicates a very uniform loading. An as-loaded reactivity high in the range usually indicates that the canister was loaded based on decay heat since high burnup assemblies (high decay heat and low reactivity) were placed in the outer part of the canister to limit the peak cladding temperature. An asloaded reactivity that is low in the range can indicate that the canister is loaded for low dose since it warrants placing high burnup assemblies in the inner part of the canister to be shielded by the less active (but more reactive) assemblies on the edge. In the case for Sequoyah, no clear trend can be seen.

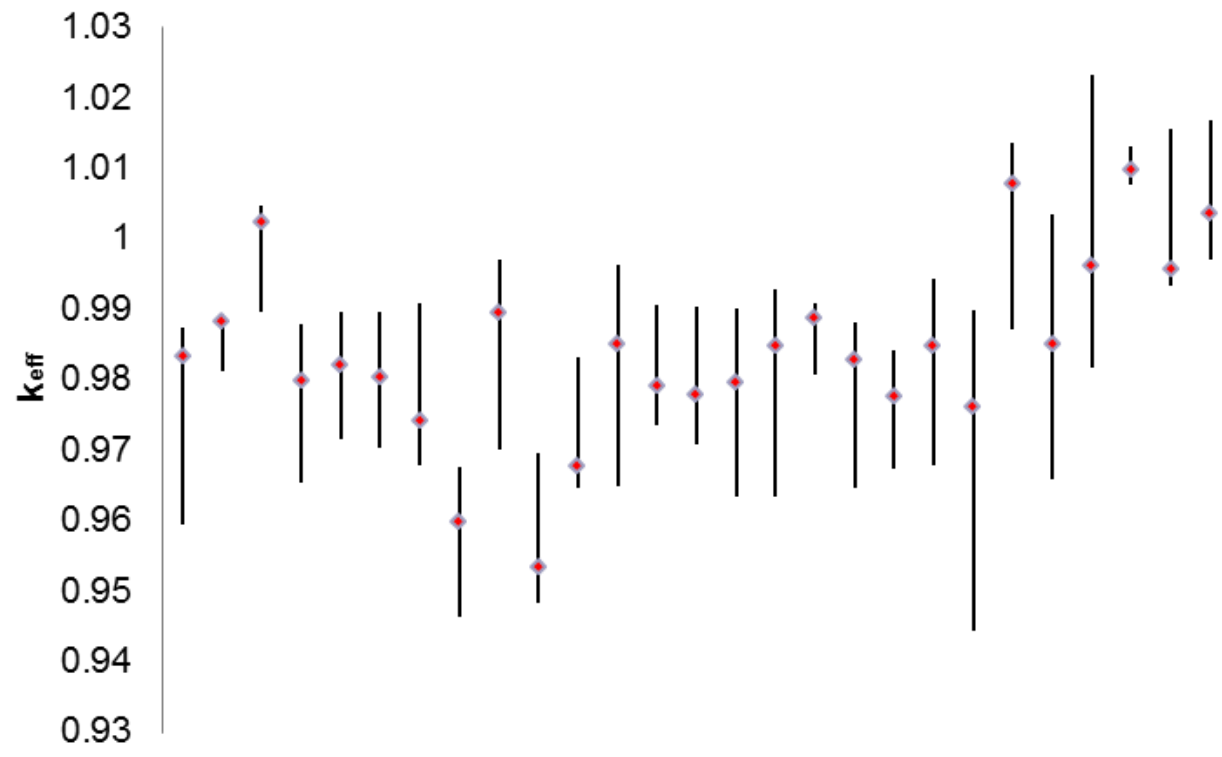

Figure C-9. The red markers indicate the reactivity of the loaded canisters at Sequoyah, and the black lines are the ranges between optimum and worst possible loading for reactivity using the same canister inventory.

Figure C-10 presents an increase in reactivity between misload and as-loaded canister in pcm for (1) twodifferent single severely underburned assembly misload approaches, (2) the multiple moderately underburned assembly misload and, (3) the worst configuration misload. It can be seen that any of the four different misload scenarios can yield highest reactivity increase, with

- single misload using highest fission density is most reactive 10 times,

- single misload using lowest reactive neighbor in the center is most reactive 12 times,

- multiple misload is most reactive 4 times, and

- worst configuration is most reactive 1 time. 


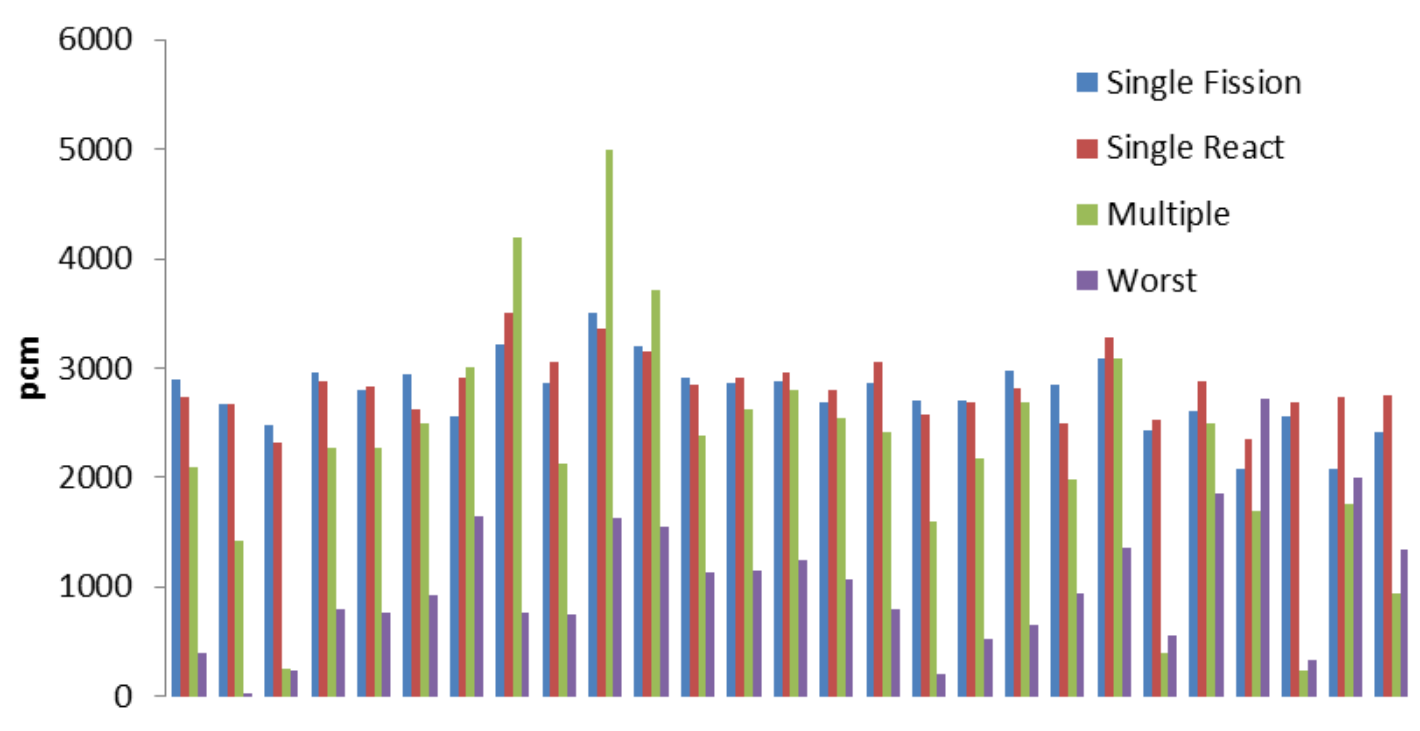

Figure C-10. Reactivity increase in pcm for each misload type and canister loaded at Sequoyah. Single Fission is the single assembly misload method misloading the position with the highest fission density, Single React is the single assembly misload method misloading the neighbor with lowest reactivity closest to the center, multiple is the multiple moderately underburned assembly misload and worst is the worst configuration misload.

The bounding misload case compared to the as-loaded calculation is presented in Figure C-11, where the average increase of reactivity from the misload analysis is $3,007 \mathrm{pcm}$ with a range of $2,487-5,000 \mathrm{pcm}$.

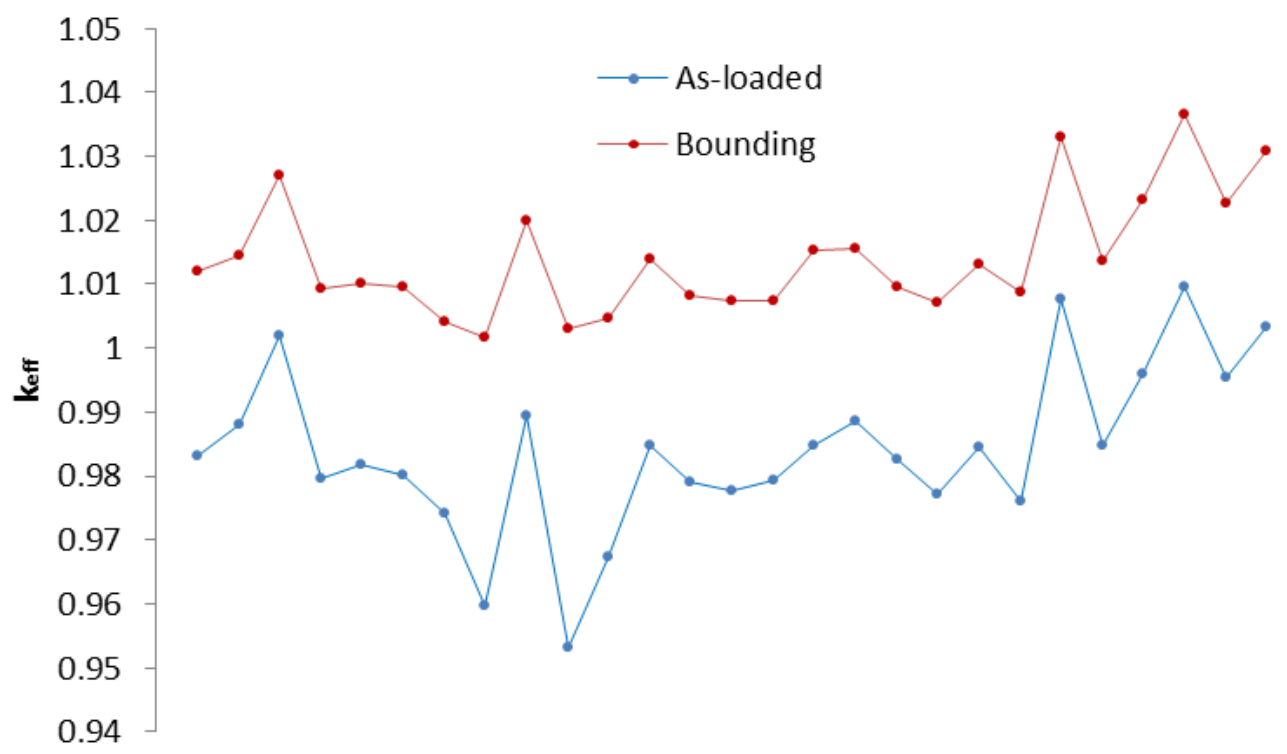

Figure C-11. The as-loaded reactivity and the most bounding of the misload types.

\section{C.4.2. Zion (shutdown reactor site), 32 TSC-37 Canisters}

Figure C-12 shows the results from the individual assembly reactivity calculations from the pool inventory at Zion. Most assemblies are distributed between 1.05-1.20, and in this case, there are also 
groups of assemblies with reactivities up to 1.30 due to high enrichments and low burnup assemblies that were in the last cycle of the reactors before shutdown. This suggests that the impact of multiple moderately underburned assembly misload could yield most impact on canister reactivity.

Zion 1

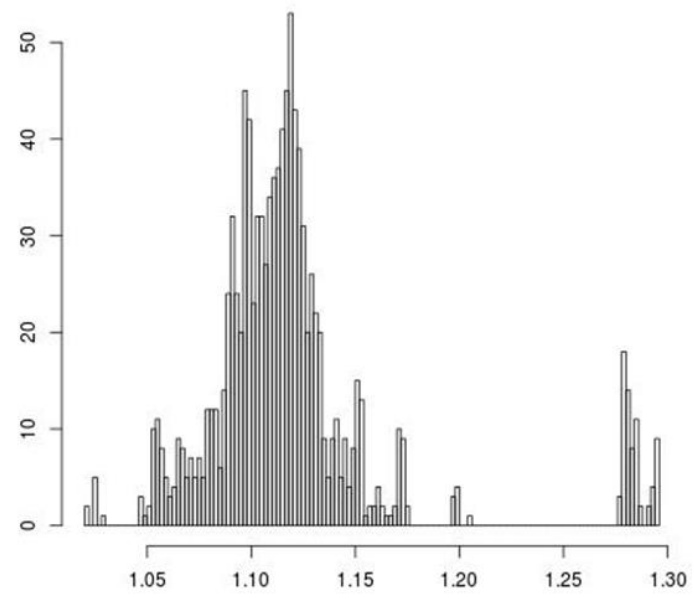

Zion 2

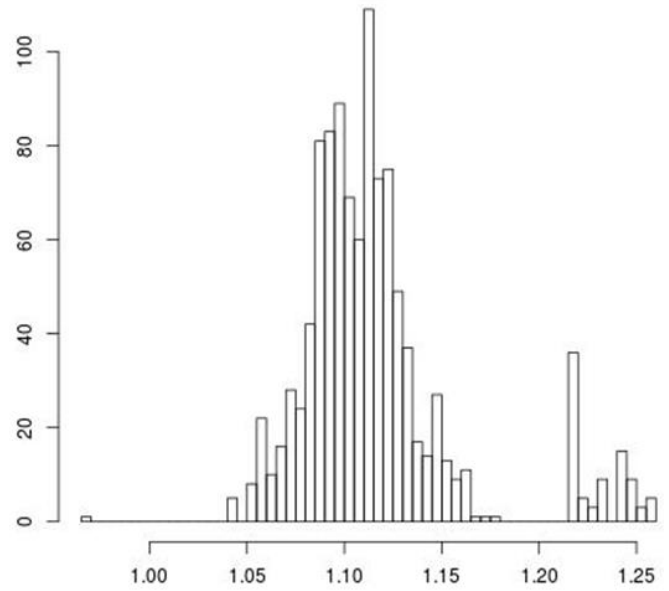

Figure C-12. Individual assembly reactivity distribution for the pool inventory at Zion 1 and 2 . Yaxis shows number of assemblies in each bin.

The difference between optimal and worst loading shown in Figure C-13 is minimal for most canisters. The as-loaded $k_{\text {eff }}$ is typically low for most of those canisters, indicating they may have been loaded based on low dose effects. The less uniformly loaded canisters containing fuel from the last cycle indicate that loading might have been designed for low temperatures.

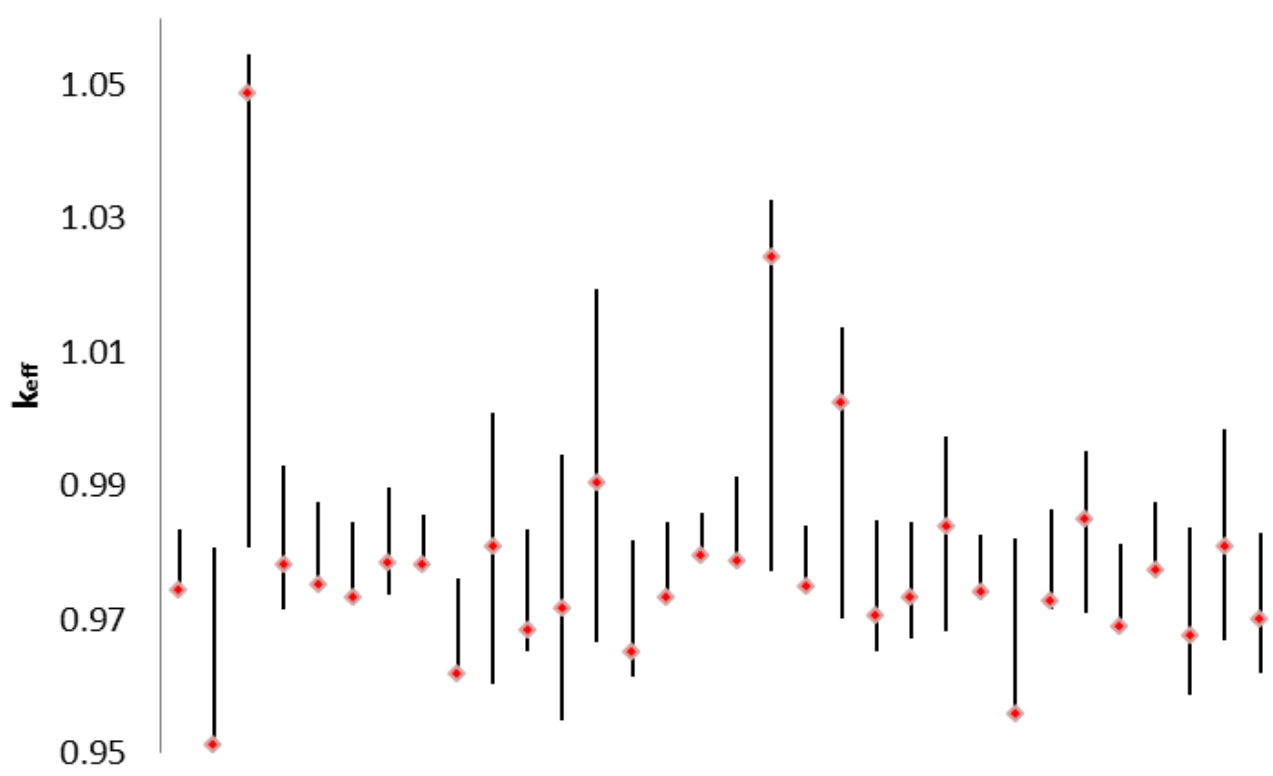

Figure C-13. Red markers indicate the reactivity of the loaded canisters at Zion, and the black lines are the ranges between optimized and worst possible loading for reactivity using the same canister inventory. 
For the two different single, severely underburned assembly misloads - the multiple moderately underburned assembly misload and the worst configuration misload - the results are shown in Figure C14 in pcm with an increase of reactivity compared to the as-loaded canister. For Zion, the multiple moderately underburned assembly misload dominate for most canisters except for those with the highest as-loaded reactivity, and those likely already had more reactive assemblies in the center locations. The figure shows the following:

- $\quad$ single misload using highest fission density is most reactive 1 time,

- single misload using lowest reactive neighbor in the center is most reactive 3 times,

- multiple misload is most reactive 28 times and,

- worst configuration never is most reactive.

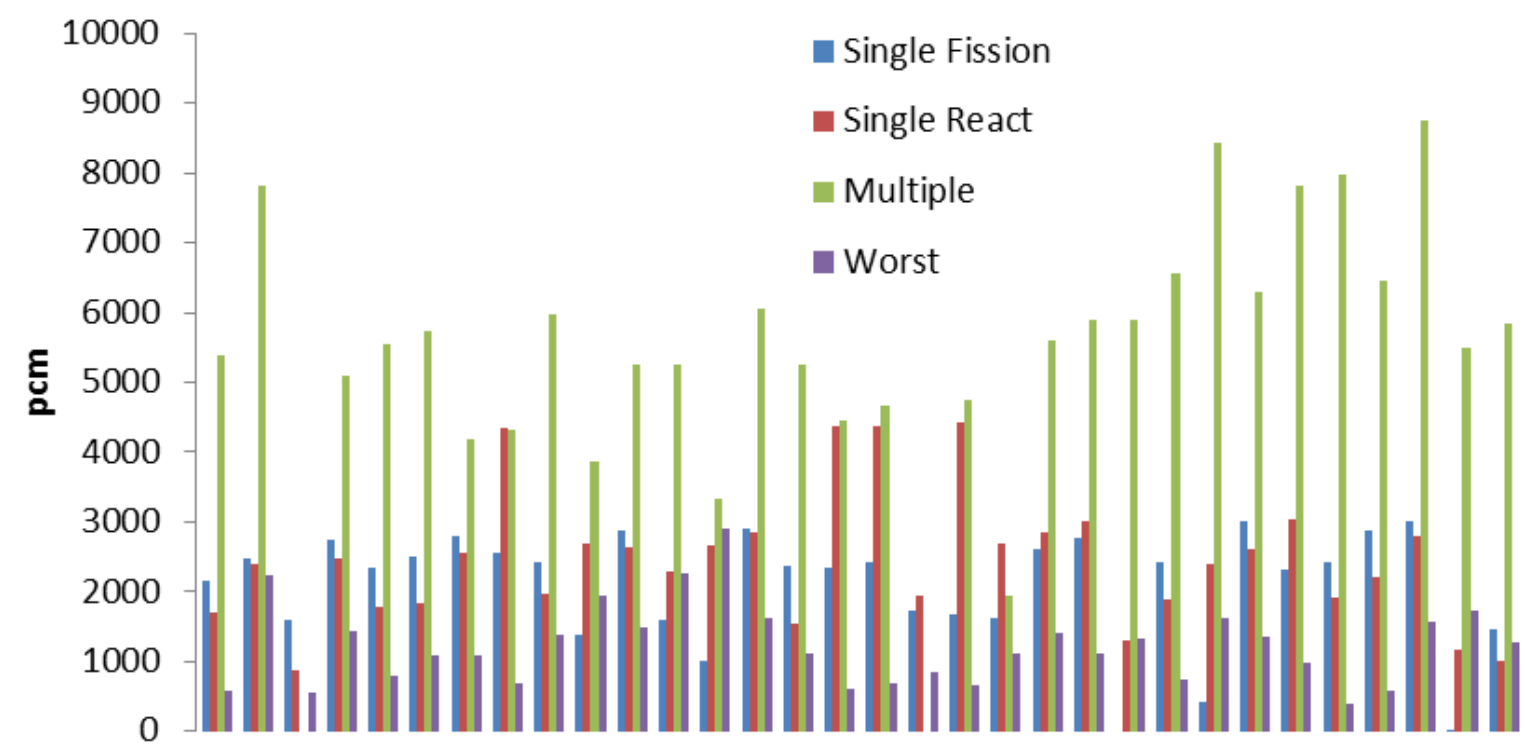

Figure C-14. Reactivity increase in pcm for each misload type and canister loaded at Zion. Single

Fission is the single assembly misload method misloading the position with the highest fission density, Single React is the single assembly misload method misloading the neighbor with lowest reactivity closest to the center, multiple is the multiple moderately underburned assembly misload and worst is the worst configuration misload.

The bounding misload case compared to the as-loaded calculation is presented in Figure C-15, where the average increase of reactivity from the misload analysis is $5,444 \mathrm{pcm}$ with a range from $1,585-8,747 \mathrm{pcm}$. 


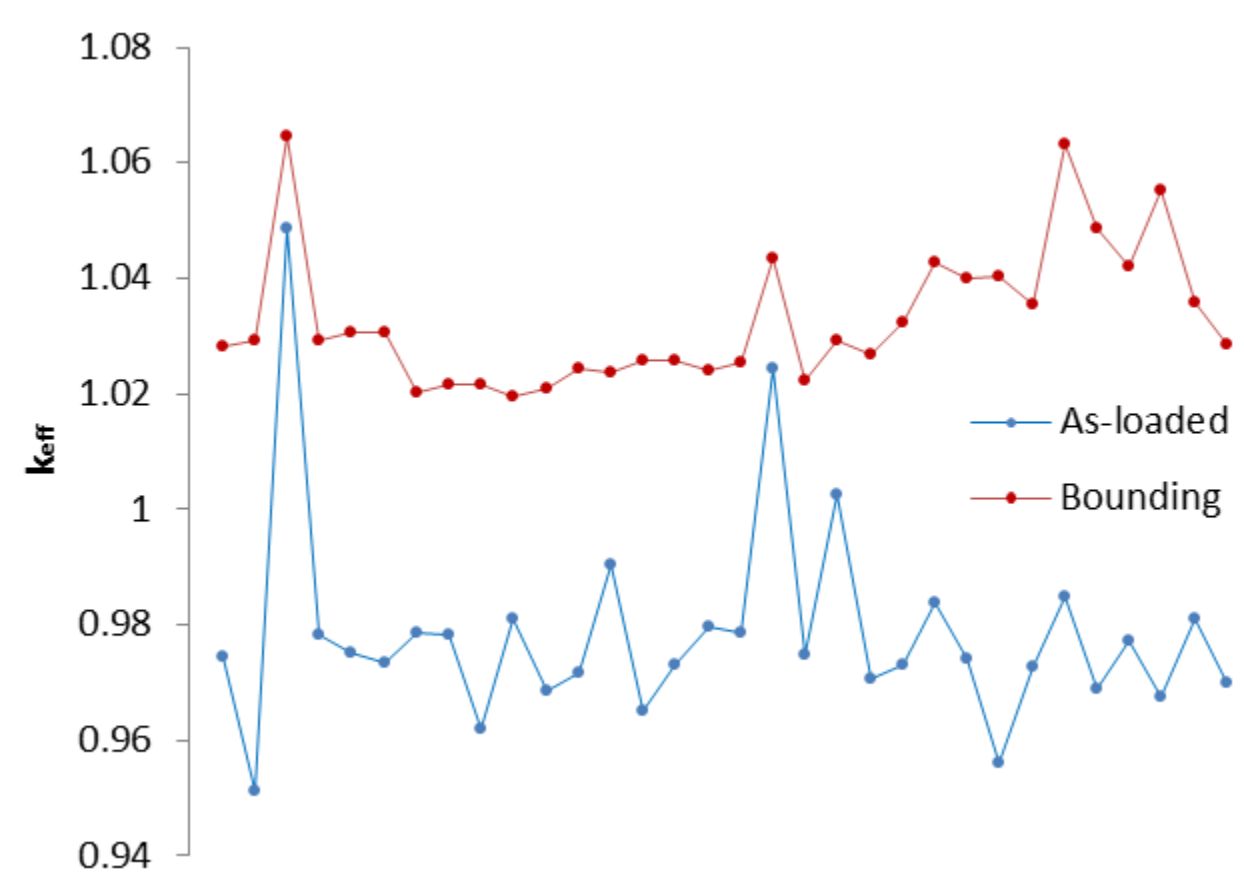

Figure C-15. The as-loaded reactivity and the most bounding of the misload types.

\section{C.4.3. Browns Ferry, 40 MPC-68 Canisters}

Figure C-16 shows the result from the individual assembly reactivity calculations from the pool inventory at Browns Ferry. Most assemblies are distributed between 1-1.10, and no assemblies with exceptionally high reactivity are available in the pools. This suggests that the impact of multiple moderately underburned assembly misload could have the highest impact on the canister reactivity.

Browns Ferry 2

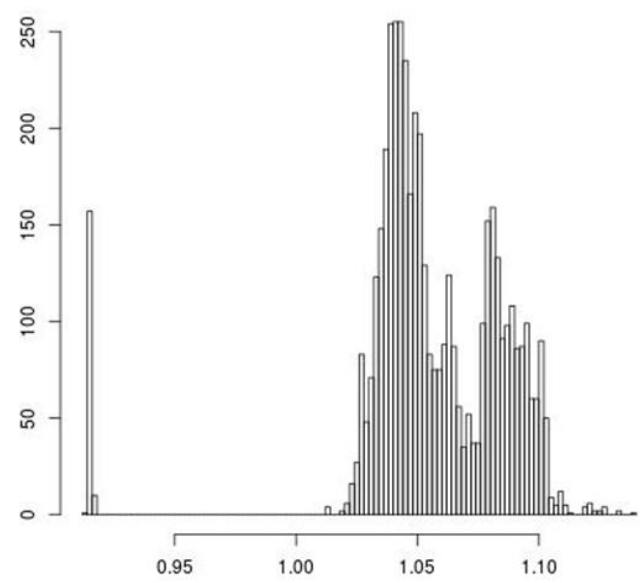

Browns Ferry 3

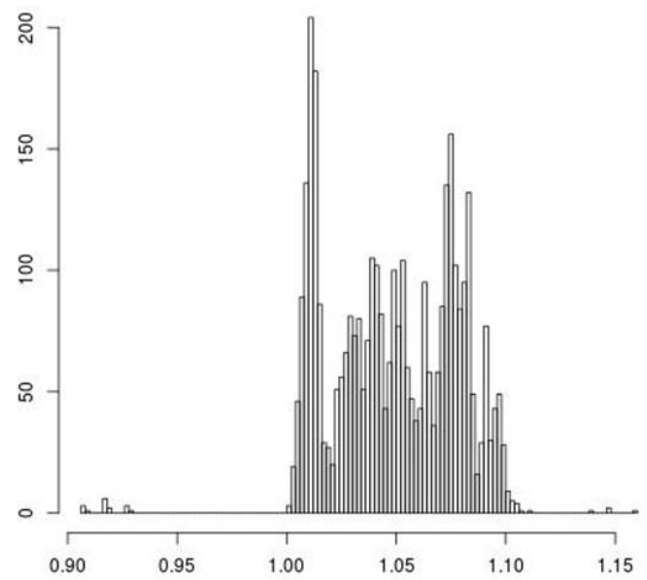

Figure C-16. Individual assembly reactivity distribution for the pool inventory at Browns Ferry 2 and 3. Y-axis shows number of assemblies in each bin.

The reactivity difference between the worst and optimal configuration is relatively small for all canisters, indicating a uniform loading and no particular bias toward being closer to worst or optimal configuration. 


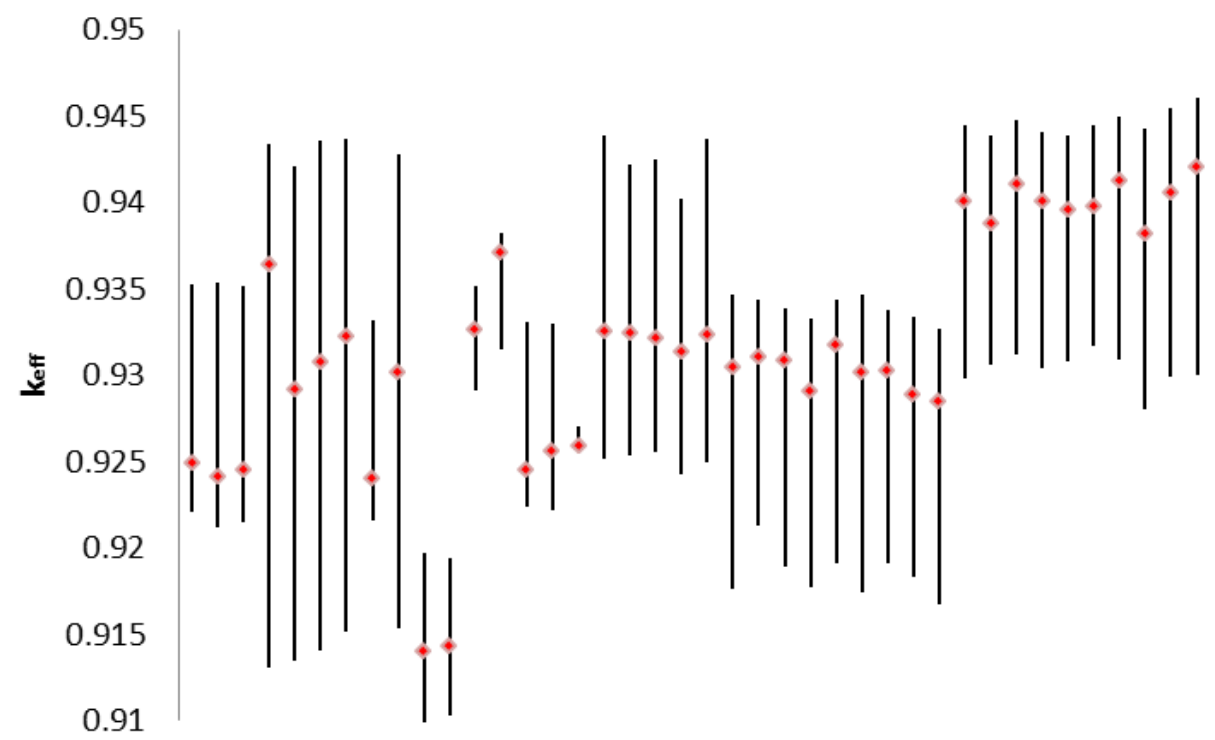

Figure C-17. Red markers indicate the reactivity of the loaded canisters at Browns Ferry, and black lines are the range between optimized and worst possible loading for reactivity using the same canister inventory. Notice that the range in $k_{\text {eff }}$ is much smaller than for Sequoyah and Zion.

For the two different single, severely underburned assembly misloads - the multiple moderately underburned assembly misload and the worst configuration misload - the results are shown in Figure C18 in pcm, with an increase of reactivity compared to the as-loaded canister. For Browns Ferry, the multiple moderately underburned assembly misload dominates all canisters due to the lack of assemblies with very high reactivity available in the pool and mostly uniformly loaded canisters.

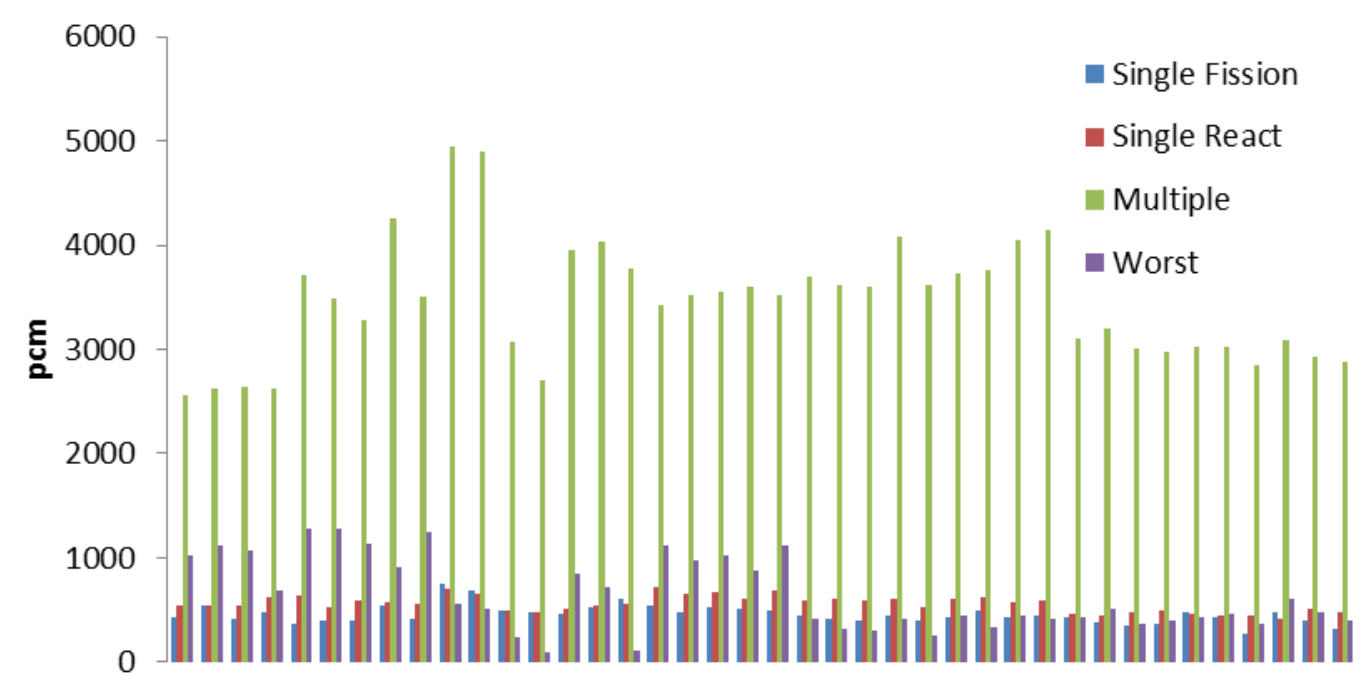

Figure C-18. Reactivity increase in pcm for each misload type and canister loaded at Browns Ferry. Single Fission is the single assembly misload method misloading the position with the highest fission density, Single React is the single assembly misload method misloading the neighbor with lowest 
reactivity closest to the center, multiple is the multiple moderately underburned assembly misload and worst is the worst configuration misload.

The bounding misload case compared to the as-loaded calculation is presented in Figure C-19, where the average increase of reactivity from the misload analysis is $3,451 \mathrm{pcm}$ with a range from $2,567-4,943 \mathrm{pcm}$.

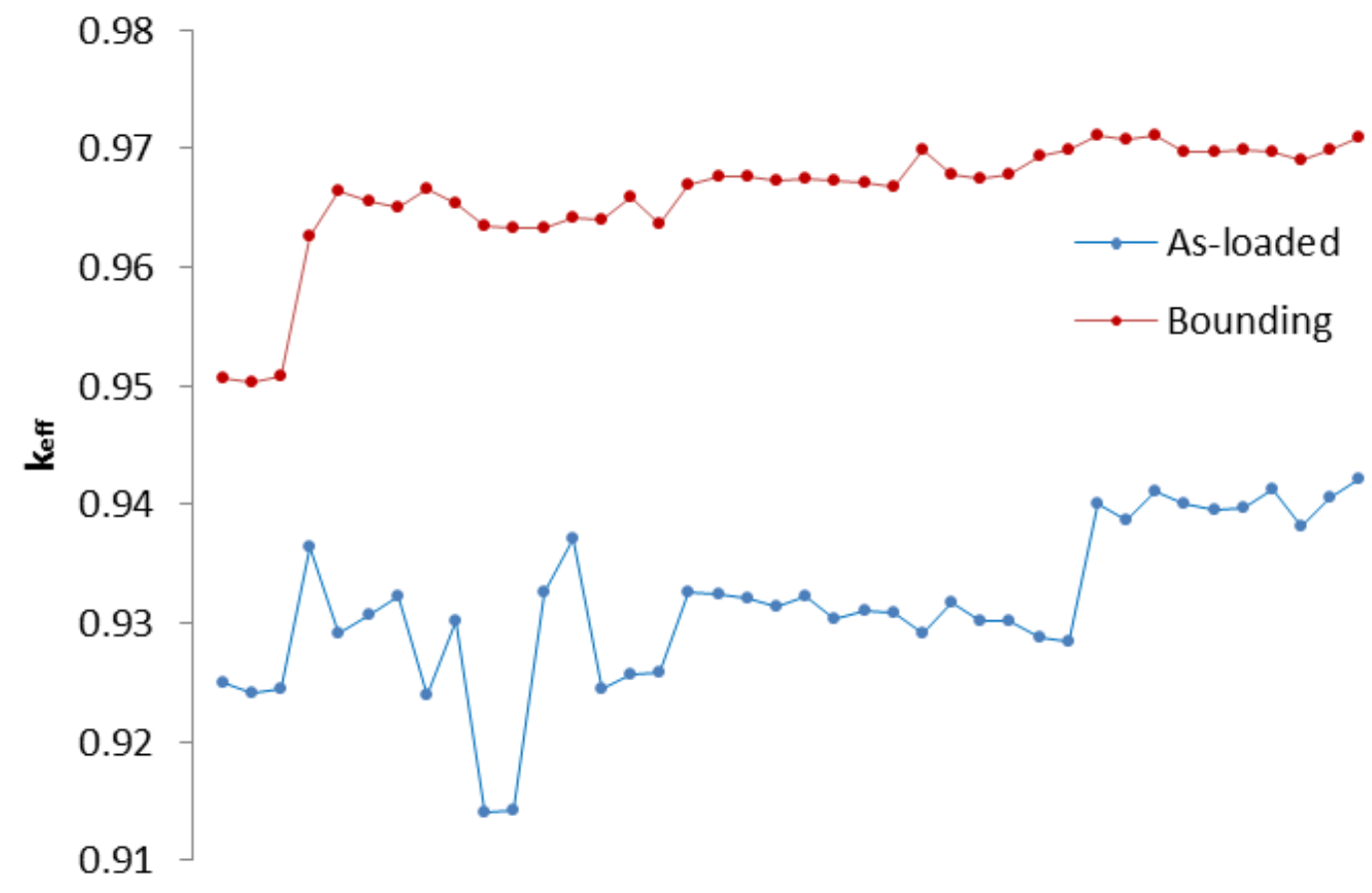

Figure C-19. The as-loaded reactivity and the most bounding of the misload types.

\section{C.5. CONCLUSION}

This appendix presents a misload methodology for as-loaded criticality analysis for a disposal scenario that includes loss-of-neutron-absorbers. The misload methodology has been applied to evaluate 99 DPCs stored at three sites. In addition to the suggested misload types in ISG 8 rev. 3, an additional type (worst case configuration) was implemented to specifically address the as-loaded criticality analysis approach, where the correct inventory was assumed to be incorrectly loaded in the most reactive configuration. This worst-case configuration is considered the most likely misload scenario for disposal as the other misload scenarios involving selection of incorrect assemblies should be detected during the subsequent loadings. If no misload has been identified for a site that completed loading of all discharged assemblies in DPCs, worst case scenario should be used to support as-loaded criticality analysis for that site. The bounding misload type and increase in reactivity is highly dependent on both the canister inventory and the spent fuel pool inventory available at the time of the loading. The selected sites have a wide range of characteristics covering PWR and BWR reactors, the most commonly used DPCs, and different assembly reactivity distributions in the spent fuel pool. The evaluation indicates that the proposed methodology is applicable to other sites and DPC models as well.

The methodology has also been implemented in UNF-ST\&DARDS for automated misload analysis for all canisters where loading maps and canister criticality models are available.

Figure C-20 presents the updated criticality roadmap from Figure 25 in the main body of this report. The development of the misload analysis methodology is considered complete, but the box will remain yellow 
until the approach has been applied to all canisters. An automated analysis will be possible as the new canister models are implemented.

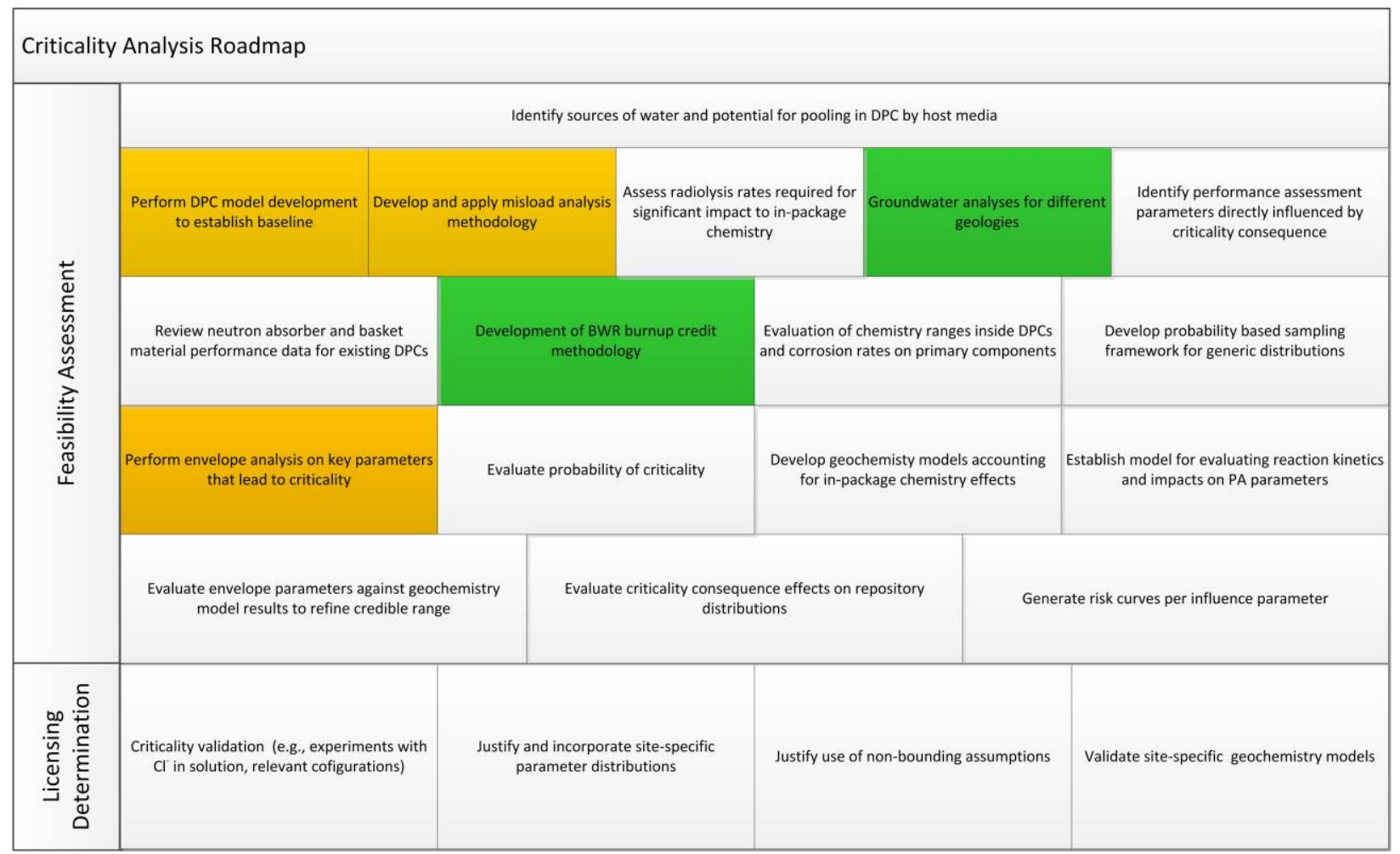

Figure C-20. DPC criticality analyses roadmap as described in Ref. [4], with the color yellow indicating a work in progress and green indicating completion.

\section{C.6. REFERENCES}

C-1. Division of Spent Fuel Storage and Transportation, Interim Staff Guidance - 8, Revision 3, Burnup Credit in the Criticality Safety Analyses of PWR Spent Fuel in Transportation and Storage Casks, U.S. Nuclear Regulatory Commission, September 26, 2012.

C-2. J. B. Clarity, H. Liljenfeldt, and K. Banerjee, Criticality Process, Modeling and Status for UNFST\&DARDS, FCRD-NFST-2015-000440, Rev. 1, US Department of Energy, Nuclear Fuel Storage and Transportation Planning Projects (July 2016). 
This page is intentionally left blank. 
APPENDIX D. FY 2018 Criticality Study 
This page is intentionally left blank. 


\section{D.1. INTRODUCTION}

This appendix documents work performed supporting the US Department of Energy (DOE) Office of Nuclear Energy (NE) Spent Fuel and Waste Disposition (SFWD) under work breakdown structure element 1.08.01.03.05 "Direct Disposal of Dual Purpose Canisters." In particular, this appendix fulfills the M4 milestone, M4SF-18OR010305013, "Update of DPC Direct Disposal Criticality Analysis Report" within work package SF-18OR01030501, "Direct Disposal of Dual Purpose Canisters - ORNL."

This appendix presents the dual-purpose canister (DPC) criticality evaluations performed in FY 2018 to support the feasibility determination of direct disposal of DPCs and extends the work reported in the main body of this report. The main objectives of the FY 2018 DPC disposal criticality study were to develop criticality calculation templates for the NUHOMS ${ }^{\circledR} 24 \mathrm{PT} 1$ [D-1] and NUHOMS ${ }^{\circledR} 32 \mathrm{PT}$ [D-2] dry shielded canisters (DSCs) and to perform as-loaded criticality analyses for sites using these two canister types and the loading maps of which are currently available in the database. A total of 60 as-loaded canisters from five sites were analyzed over the time interval between calendar years 2015 and 22,000 using the burnup credit methodology described in the previous sections of this report. The analyzed sites were San Onofre (17 canisters), Palisades (11 canisters), Millstone (18 canisters), Ginna (6 canisters), and Kewannee (8 canisters).

Criticality analyses models were developed for the intact canister configuration, applicable to normal conditions of transport and storage, and for degraded material configurations, applicable to canister repository time frame. The degraded material configurations assume two scenarios: (1) complete loss of the fixed neutron absorber (i.e., ${ }^{10} \mathrm{~B}$ ) without fuel basket geometry changes and (2) complete degradation and loss of basket materials, including neutron absorber plates and carbon steel basket components (e.g., basket support discs). The effect of canister material degradation and neutron absorber loss is a significant increase in $k_{\text {eff. }}$ The intact canister configurations were analyzed for 9 analysis dates between 2015 and 2100. The degraded material configurations were analyzed for 17 analysis dates between 2015 and 22,000 .

As mentioned in the main report, neutron moderation by water is needed for a waste package to achieve criticality. However, the groundwater (or pore water) that may flood a breached DPC will contain various dissolved aqueous species. Seventeen species were studied in the main report, and it was determined that $\mathrm{Cl}, \mathrm{Li}$, and $\mathrm{B}$ provide the maximum reduction in canister reactivity because of their large neutron absorption cross sections. However, available groundwater data indicate that chlorine (as chloride) is the only naturally abundant neutron-absorbing element in groundwater that can provide a significant reduction in reactivity and is available in most of the repository concepts under consideration in varying quantity. Analyses were performed to determine the maximum chlorine requirement to suppress criticality of canisters with the potential to form critical configuration in a repository time frame. The impact of chlorine (in terms of $\mathrm{NaCl}$ ) concentration in groundwater on the reactivity of as-loaded DPCs exceeding a $k_{\text {eff }}$ value of 0.98 was evaluated for the calendar year 22,000. Previous chlorine concentration effects on $k_{\text {eff }}$ documented in this report were evaluated for the calendar year 9,999. The impacted DPCs will be reevaluated for the calendar year 22,000 in the future. Note that within the time interval between the calendar years 2015 and 22,000, canister $k_{\text {eff }}$ initially decreases with increasing decay time, reaches a minimum value, and then increases with increasing decay time. Hence the $k_{\text {eff }}$ value for the calendar year 22,000 is slightly higher than that for the calendar year 9,999.

Canister misload analyses were performed for a worst-canister-misload configuration scenario, which is described in Sect. C.3.5. The assumption for this scenario is that the correct assemblies have been loaded into a canister but in the wrong order. The worst-misload configuration is obtained by placing fuel assemblies in the canister with the most reactive assembly closest to the canister center. The approach to misloaded assembly selection is to rank all assemblies by their individual reactivities, i.e., $k_{\text {inf }}$ values. Currently, misload $k_{\text {eff }}$ values are determined assuming all fuel assemblies in the canister have a decay time of 9,500 years. The misload analysis was performed for a total of 49 canisters containing intact fuel 
assemblies and loaded to full capacity. The 11 San Onofre Unit 1 canisters not analyzed, which contain damaged fuel and/or empty locations, will be analyzed in the future.

Filler material may be used to maintain canister subcriticality during disposal. A nonhydrogenous filler material can reduce $k_{\text {eff }}$ by displacing the pure water moderator assumed to flood a canister over the repository time frame. The height of a filler material, consisting of $68 \%$ aluminum and $32 \%$ pure water by volume, required to maintain canister subcriticality was determined for a representative canister predicted to have a $k_{\text {eff }}$ value greater than 0.98 in 22,000 assuming complete loss of neutron absorber.

Criticality models and criticality analysis results for sites using the NUHOMS ${ }^{\circledR}$ 24PT1-DSC are presented in Sect. D.2. Criticality models and criticality analysis results for sites using the NUHOMS ${ }^{\circledR}$ 32PT-DSC are presented in Sect. D.3. The filler height calculation is presented in Sect. D.4.

\section{D.2. NUHOMS ${ }^{\circledR}$ 24PT1-DSC}

The NUHOMS ${ }^{\circledR} 24 \mathrm{PT} 1-\mathrm{DSC}$ is dedicated to storage and transportation of irradiated Westinghouse (W) $14 \times 14$ pressurized water reactor (PWR) fuel assemblies and non-fuel components. This canister is a component of the NUHOMS ${ }^{\circledR}$ MP187 transportation system [D-1]. San Onofre Nuclear Generation Station (SONGS) Unit 1 (SONGS1) was a Westinghouse three-loop PWR using the W $14 \times 14$ fuel type. The power reactor was permanently shut down on November 3,1992, and the nuclear facility is undergoing decommissioning currently. Fuel assemblies discharged from the power reactor are stored at the SONGS independent spent fuel storage installation (ISFSI) in 17 NUHOMS ${ }^{\circledR} 24 \mathrm{PT} 1$-DSCs. These canisters contain 395 SONGS1 spent nuclear fuel (SNF) assemblies.

The NUHOMS ${ }^{\circledR}$ 24PT1-DSC consists of a stainless steel cylindrical shell with top and bottom carbon steel shield plugs, inner and outer bottom stainless steel closure plates, and outer top stainless steel closure plate.

The fuel basket defines 24 fuel locations and includes 26 spacer discs made of carbon steel and four support rods made of precipitation-hardened steel. The fuel tubes are made of stainless steel. The fuel basket utilizes fixed neutron absorbers to maintain subcriticality with optimum neutron moderation. The neutron absorber panel material is Boral ${ }^{\circledR}$. A bottom spacer was installed underneath each W $14 \times 14$ fuel assembly to center the fuel in the DSC.

\section{D.2.1. Criticality Model for the Intact XS014W Fuel Assembly Type}

The fuel assemblies irradiated in SONGS1 power reactor were W $14 \times 14$ fuel assemblies with stainless steel cladding identified in the nuclear fuel database [D-3] as XSO14W. Four W 14×14 zirconium-clad mixed oxide (MOX) fuel assemblies, identified as the XSO14WM type in the database, were also irradiated in the SONGS1 power reactor. A XSO14W fuel assembly has 180 fuel rods, 16 stainless steel guide tubes, and 7 spacer grids made of Inconel-718. Only the active fuel region of a fuel assembly is explicitly modeled. A horizontal cross-sectional view of the model for the fuel assembly type XSO14W through the active fuel region is shown in Figure D-1. Fuel compositions in the intact XSO14W fuel assembly model consist of oxygen and the set of isotopes reported in Table 2, which is recommended for SNF storage and transportation burnup credit criticality analyses. The active fuel region of an intact XSO14W fuel assembly is modeled as 18 uniform axial zones with nuclide concentrations based on assembly average burnup and the PWR 18-zone axial burnup profiles currently used in UNFST\&DARDS neutronics calculations (see Sect. 3.1). 


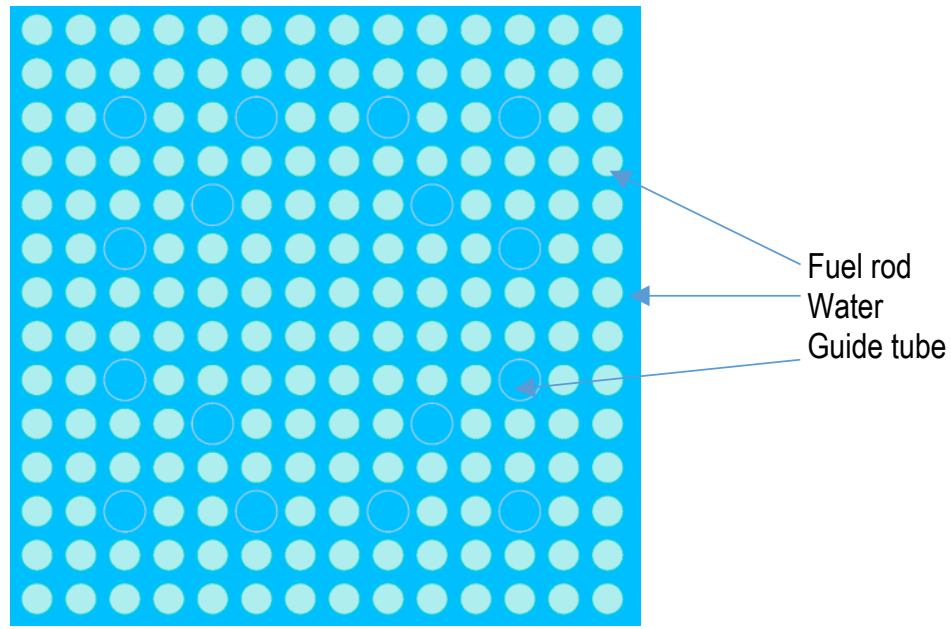

Figure D-1. Horizontal cross-sectional view of the XSO14W fuel assembly model.

\section{D.2.2. Criticality Model for Damaged $\mathrm{UO}_{2}$ Fuel Assemblies}

Nine NUHOMS ${ }^{\circledR}$ 24PT1-DSCs contain damaged $\mathrm{UO}_{2}$ fuel assemblies. The damaged fuel assemblies were placed in failed fuel cans. A NUHOMS ${ }^{\circledR} 24$ PT1-DSC may contain up to four failed fuel cans loaded in designated locations. Burnup is not credited for damaged fuel in damaged fuel cans. A damaged fuel assembly is represented as the design basis $\mathrm{UO}_{2}$ fresh fuel assembly with an initial enrichment of $4.0 \mathrm{wt} \%$ ${ }^{235} \mathrm{U}$ used in the criticality safety analysis [D-4].

\section{D.2.3. Criticality Model for Intact MOX Fuel Assemblies}

Two NUHOMS ${ }^{\circledR}$ 24PT1-DSCs contain a total of four intact MOX fuel assemblies. The intact MOX fuel assemblies were placed in failed fuel cans. A MOX fuel assembly is represented as the design-basis MOX fuel assembly used in the criticality safety analysis [D-5]. A horizontal cross-sectional view of the designbasis MOX fuel assembly and assembly plutonium loading are shown in Figure D-2.

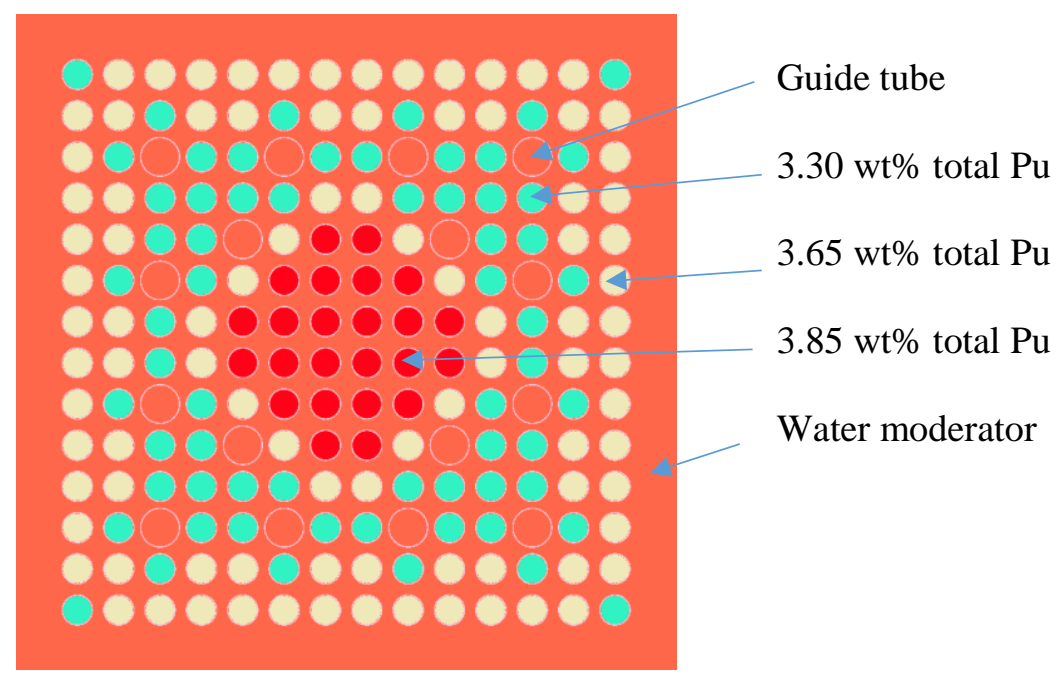

Figure D-2. Horizontal cross-sectional view of the MOX fuel assembly model. 


\section{D.2.4. SONGS1 Unit 1 Irradiated Non-Fuel Hardware}

Non-fuel components include thimble assemblies, reactor control cluster assembly, and secondary neutron source assemblies. A fuel assembly may contain one of the three different non-fuel components inserted into its guide tubes. No credit is taken for the presence of non-fuel hardware within a fuel assembly. Moderator water is modeled in place of non-fuel components, which is conservative with respect to criticality.

\section{D.2.5. Dummy Assembly}

One NUHOMS ${ }^{\circledR}$ 24PT1-DSC contains a dummy assembly in basket cell number 9. A dummy assembly is an unirradiated stainless steel-encased structure that approximates the weight and center of gravity of a fuel assembly [D-4]. Hence, the dummy fuel assembly was modeled as a typical XSO14W fuel assembly with $179 \mathrm{UO}_{2}$ fuel rods being replaced with solid stainless steel rods with a radius of approximately $0.526 \mathrm{~cm}$. This radius was deduced based on the assembly rod length of the $\mathrm{W} 14 \times 14$ steel clad fuel, $377.47 \mathrm{~cm}$ (148.61 in.), and weight per rod, $2.64 \mathrm{~kg}$ (5.82 lb) [D-6].

\section{D.2.6. Criticality Model for Intact Canister Configurations}

A criticality analysis model was developed for the intact (regular) canister configuration based on the criticality safety analysis reports used by the vendor to demonstrate compliance with both 10 CFR 71 [D4] and 10 CFR 72 requirements [D-7]. The regular canister model is intended for use in criticality analyses of canisters under normal conditions of transport/dry storage. The fuel basket is intact, fuel assemblies are centered, and the mass density of water moderator and reflector is $1 \mathrm{~g} / \mathrm{cm}^{3}$ in this model. Fuel compositions consist of oxygen and the set of isotopes reported in Table 2.

Verification of the regular canister model was performed by comparison to a reference $k_{\text {eff }}$ value provided in the Safety Analysis Report (SAR) (Ref. [D-7]) for an infinite array of transportation packages under normal conditions of transport. The package model consists of the NUHOMS ${ }^{\circledR} 24 \mathrm{PT} 1$-DSC surrounded by a packaging structural shell, gamma shield, and neutron shield. Mirror reflective conditions were specified for the package $\mathrm{X}$ and $\mathrm{Y}$ sides to simulate an infinite array of packages. The reference $k_{\text {eff }}$ value for the infinite array of packages containing W $14 \times 14$ steel-clad fuel assemblies centered in each guidesleeve is $0.8581 \pm 0.0013$ (one sigma) [D-7, Table 6.4-1]. The reference $k_{\text {eff }}$ value was obtained with the KENO-Va Monte Carlo criticality code and the 44-neutron group library based on ENDF-B/5 in the SCALE 4.4 code package [D-3]. A similar model was developed for an infinite array of packages, and the $k_{\text {eff }}$ value for this model was calculated with KENO-VI and the continuous cross-section library ce_v7 based on ENDF/B-VII in the SCALE 6.2.2 code package. The SCALE 6.2.2 $k_{\text {eff }}$ value is $0.85517 \pm$ 0.00019. The difference of $\Delta k_{\text {eff }}=0.003$ between SAR and current calculations may be attributed to differences between the SCALE code versions and cross-section libraries used in those calculations. A criticality validation of the SCALE 4.4 code package was provided in the criticality safety analysis [D-7]. That validation determined an upper subcritical limit (USL) of 0.9401 from the trending analysis of the benchmark calculations and an administrative margin of 0.05. By using a similar trending analysis, the USL value would be 0.9464 for criticality benchmark calculations using SCALE 6.2 and the ENDF/B-VII data [D-9]. Hence, these validation studies indicate an approximately $600 \mathrm{pcm}$ difference between expected $k_{\text {eff }}$ bias and bias uncertainty values for SCALE 4.4 and SCALE 6.2 criticality calculations.

\section{D.2.7. Criticality Models for Material Degradation Scenarios}

Models were developed for two degradation scenarios because the fuel basket in this canister design contains neutron absorber panels and carbon steel disc plates: (1) complete loss of neutron absorber and (2) complete loss and degradation of the neutron absorber panels and support disc plates. The former scenario is referred to as the loss-of-neutron-absorber scenario, and the latter scenario is referred to as the degraded basket material scenario. The model for the loss-of-neutron-absorber scenario uses pure water in place of basket aluminum and absorber plates. A horizontal cross-sectional view of the canister model 
assuming a loss-of-neutron absorber is shown in Figure D-3. The basket material degradation scenario has the potential of producing a compact fuel assembly geometry configuration. Figure D-4 shows a horizontal cross-sectional view of the canister model for the degraded basket material scenario. In this configuration, the spacing between fuel tubes was eliminated and fuel assemblies were displaced inward to produce the most reactive fuel configuration. Fuel compositions in these models consist of oxygen and the set of isotopes reported in Table A-1, which is recommended for post-closure burnup credit criticality analyses.

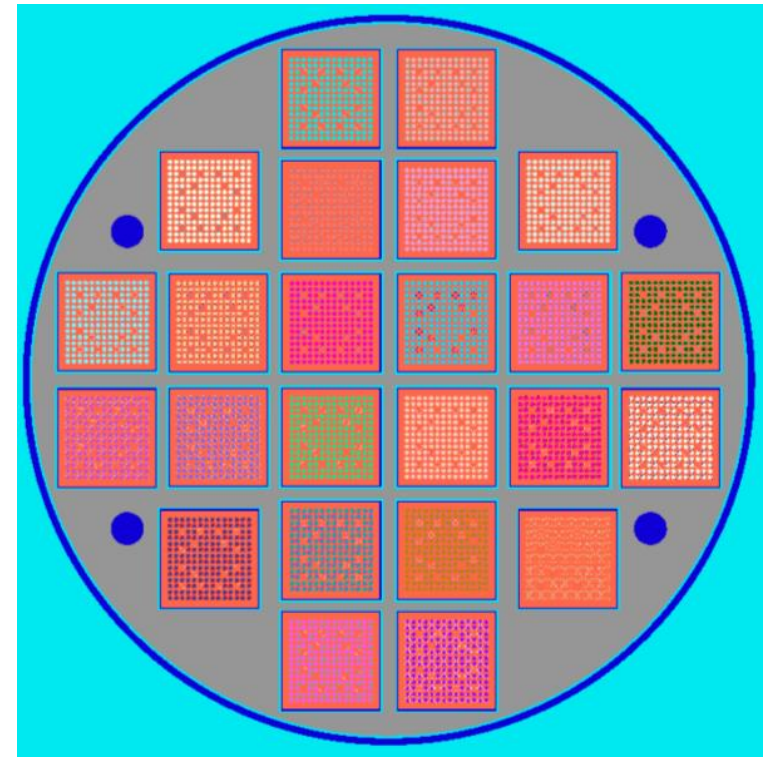

Figure D-3. Horizontal cross-sectional view of the NUHOMS ${ }^{\circledR}$ 24PT1-DSC model through a disc plate for the loss-of-neutron-absorber scenario.

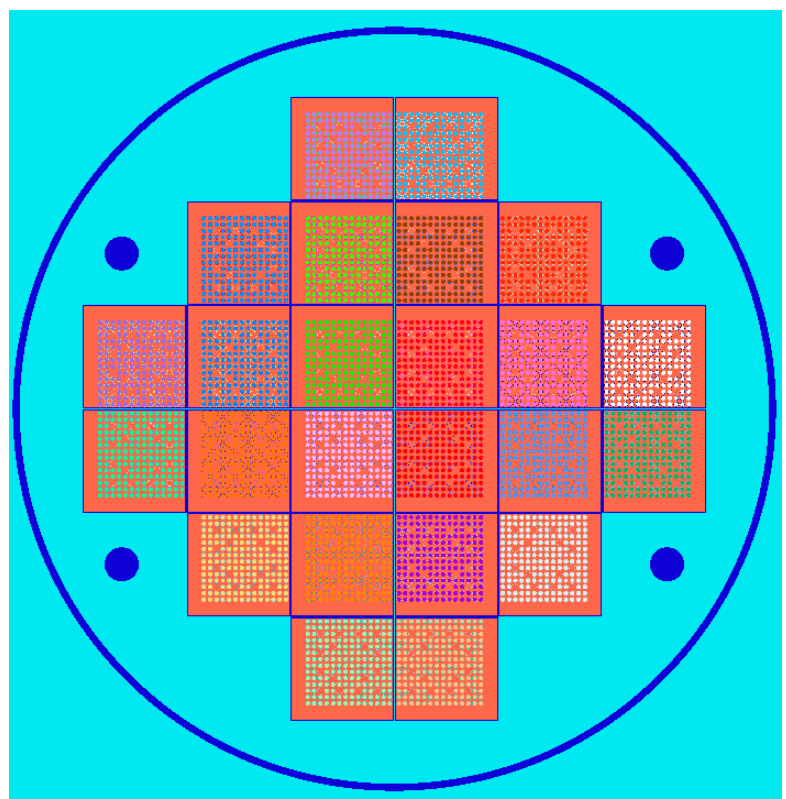

Figure D-4. Horizontal cross-sectional view of the NUHOMS ${ }^{\circledR}$ 24PT1-DSC model for the degraded basket scenario. 


\section{D.2.8. Criticality Model for Misload Calculations}

A misload criticality analysis was performed for six SONGS1 SNF canisters containing intact fuel assemblies and loaded to full capacity. A total of 11 SONGS1 SNF canisters containing damaged fuel and/or empty locations were not analyzed. The canister misload model is based on the assumption that the correct assemblies have been loaded into the canister but in the most reactive configuration. This configuration is referred to as the worst-misload configuration in Sect. C.3.5. Fuel assembly placement for the worst-misload configuration is illustrated in Figure D-5. The numbers on the figure indicate the rank of an individual fuel assembly based on assembly $k_{\text {inf }}$ values at a decay time of 9,500 years. The fuel composition for the misload model includes oxygen and the degradation disposal nuclides presented in Table A-1. The neutron absorber is neglected in this model (i.e., loss-of-neutron-absorber scenario).

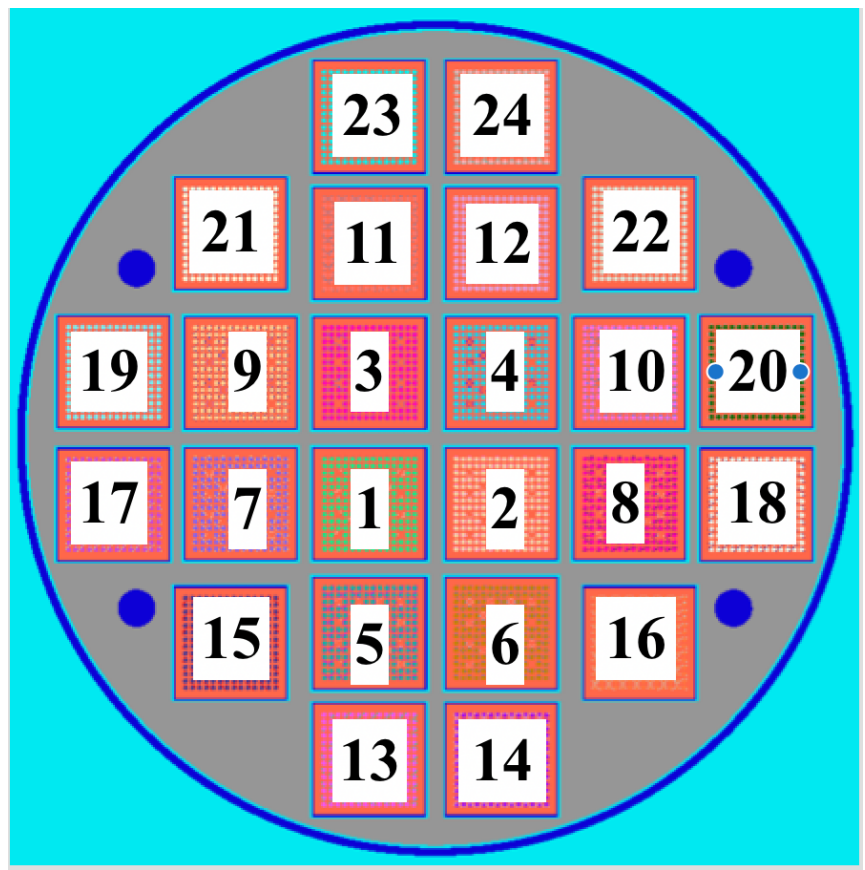

Figure D-5. Illustration of fuel assembly ranking for the worst-misload configuration of the NUHOMS ${ }^{\circledR}$ 24PT1-DSC.

\section{D.2.9. Criticality Calculations Results for SONGS1 SNF Canisters}

Criticality calculations were performed for decay times within the time interval between calendar years 2015 and 22,000 using the canister models developed for the as-loaded disposal criticality analysis of the SONGS1 SNF under three scenarios: (1) intact (or regular) fuel basket configuration, (2) loss-of-neutron absorber, and (3) degraded basket materials. Figure D-6 shows $k_{\text {eff }}$ variation as a function of calendar year. The one sigma statistical uncertainty for all $k_{\text {eff }}$ values is 0.0003 or less. In the figure, time variation between 2000 and 2100 is shown on a linear scale and time variation between 2100 and 22,000 is shown on a logarithmic scale.

The estimated $k_{\text {eff }}$ values for the 17 canisters with an intact fuel basket configuration vary between 0.6766 and 0.7985 over the time interval between calendar years 2015 and 2100; that is, all $k_{\text {eff }}$ values are below the 0.98 subcritical limit. For the loss-of-absorber scenario, the $k_{\text {eff }}$ values for the 17 canisters vary between 0.7630 and 0.8786 over the time interval between calendar years 2015 and 22,000; that is, all estimated $k_{\text {eff }}$ values are below the 0.98 subcritical limit for repository time frame. For the material 
degradation scenario, the estimated $k_{\text {eff }}$ values for the 17 canisters vary between 0.8855 and 1.0589 over the time interval between calendar years 2015 and 22,000. Out of 17 DPCs, five canisters are above the representative subcritical limit of 0.98 throughout the time interval analyzed.

For the five canisters the $k_{\text {eff }}$ values of which are predicted to exceed the $k_{\text {eff }}$ subcriticality limit of 0.98 assuming material degradation scenario, the pure water was replaced with groundwater compositions of various $\mathrm{NaCl}$ concentrations and the models thus modified were used to determine $k_{\text {eff }}$ as a function of $\mathrm{NaCl}$ concentration. Figure D-7 presents $k_{\text {eff }}$ variation as a function of $\mathrm{NaCl}$ concentration for those five canisters in the calendar year 22,000. A minimum required chlorine concentration in the groundwater of $1.092 \mathrm{~mol} / \mathrm{kg} \mathrm{H}_{2} \mathrm{O}$ is determined to maintain a subcritical state. In this context, it is also important to note that a saturated $\mathrm{NaCl}$ brine has a concentration of approximately 6 molal.

Figure D-8 shows a $k_{\text {eff }}$ increase between the worst-misload scenario and the as-loaded configuration for the six SONGS1 SNF canisters fully loaded with intact fuel assemblies. This increase varies between approximately 500 and $2000 \mathrm{pcm}$.

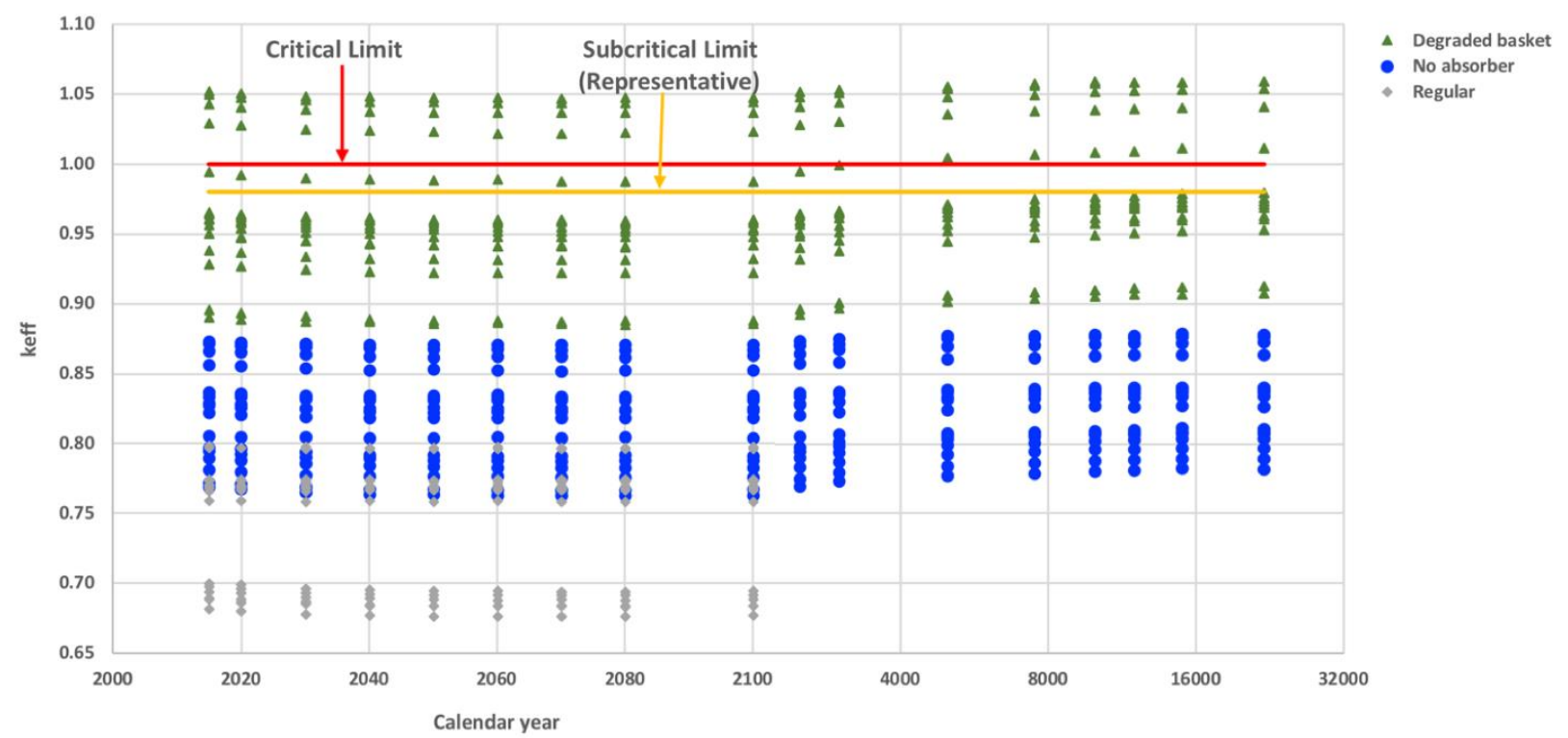

Figure D-6. $k_{\text {eff }}$ vs. calendar year for the SONGS1 SNF canisters with degraded basket materials, no neutron absorber, and regular configurations. 


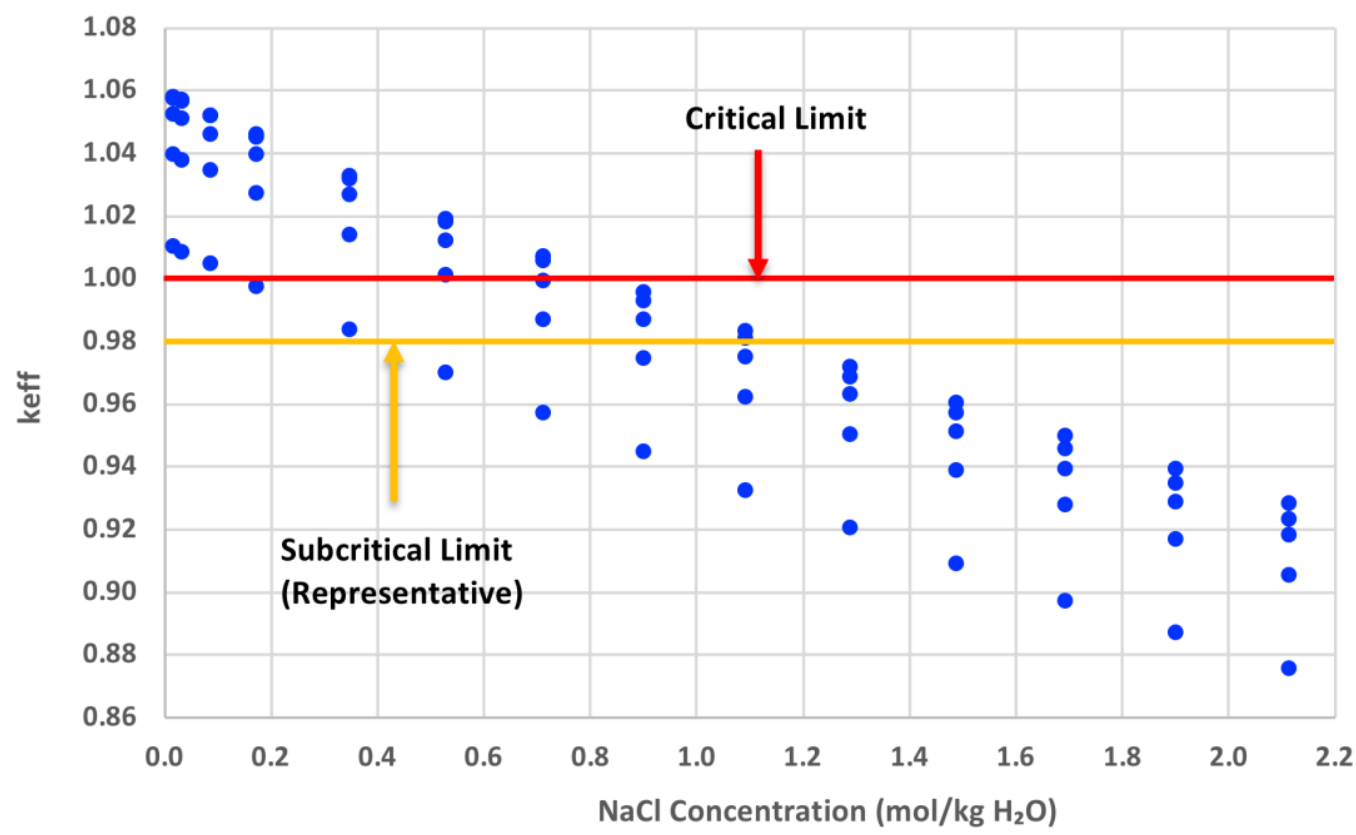

- SONGS1 [5]

Figure D-7. $\boldsymbol{k}_{\text {eff }}$ vs. $\mathrm{NaCl}$ concentration for SONGS1 SNF canisters with $\boldsymbol{k}_{\text {eff }}>\mathbf{0 . 9 8}$ for the degraded basket scenario (numbers in brackets = number of DPCs).

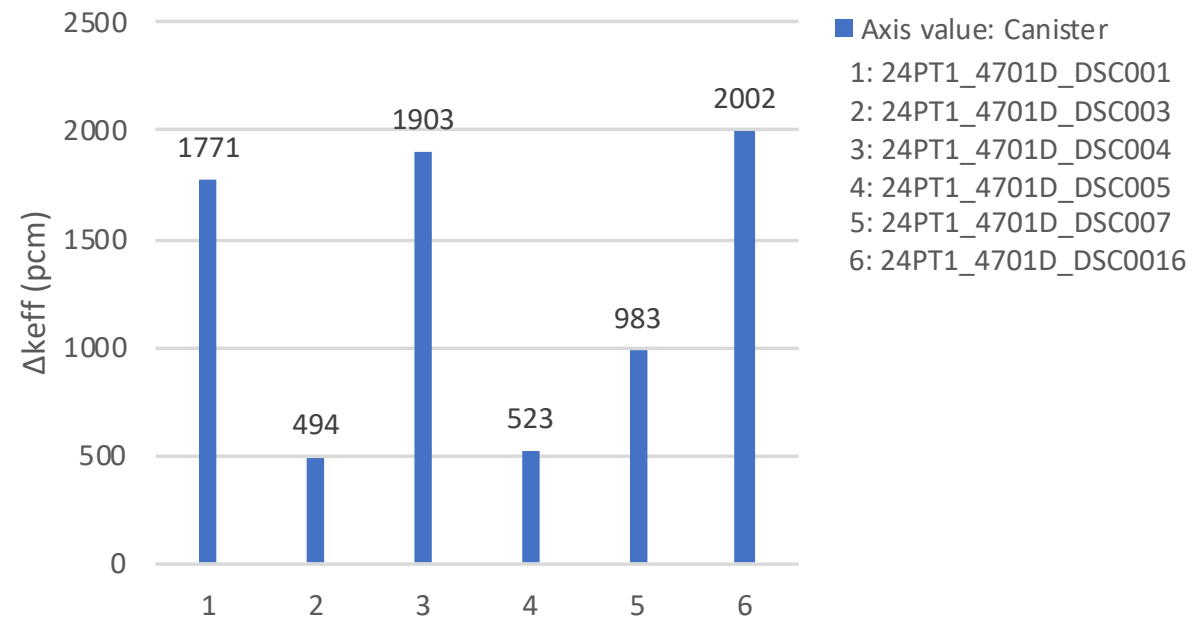

Figure D-8. $\boldsymbol{k}_{\text {eff }}$ increase between the worst-misload scenario and the as-loaded configuration for six SONGS1 SNF canisters.

\section{D.3. $\quad$ NUHOMS ${ }^{\circledR}$ 32PT-DSC}

The fuel classes authorized for loading in the NUHOMS ${ }^{\circledR} 32 \mathrm{PT}$-DSC include intact B\&W $15 \times 15$, Combustion Engineering (CE) $14 \times 14$, CE $15 \times 15$, W $17 \times 17$, W $15 \times 15$, and W $14 \times 14$ fuel assemblies (with or without control components) [D-10]. Damaged fuel assemblies are not authorized for loading in this canister. Intact fuel assemblies may contain control components (CCs), including burnable poison rod assemblies, thimble plug assemblies, control rod assemblies, control element assemblies, rod control assemblies, axial power shaping rod assemblies, orifice rod assemblies, vibration suppression inserts, neutron source assemblies, and neutron sources. Up to $32 \mathrm{CCs}$ are authorized for storage in a canister. 
The NUHOMS ${ }^{\circledR}$ 32PT-DSC consists of a stainless steel cylindrical shell with top and bottom carbon steel shield plugs, inner and outer bottom stainless steel closure plates, and outer top stainless steel closure plate. This canister has four subtypes: 32PT-S100, 32PT-S125, 32PT-L100, and 32PT-L125 defining a short canister, which has a length of $472.948 \mathrm{~cm}$ (186.2 in.), and a long canister, which has a length of $488.188 \mathrm{~cm}$ (192.2 in). The fuel basket consists of a grid assembly of welded stainless steel plates or tubes that form 32 fuel compartments.

Aluminum and/or neutron absorber plates (which are made of either borated aluminum or metal matrix) are placed within each fuel compartment. Depending on fuel assembly design, 0, 4, 8, or 16 poison rod assemblies (PRAs) may be used for criticality control. Based on the number of PRAs, a fuel basket is designated as either Type A, A1, or A2 (no PRAs), Type B (4 PRAs), Type C (8 PRAs), or Type D (16 PRAs). Types A1 and A2 have higher ${ }^{10} \mathrm{~B}$ loading for metallic plates than the other types. Within each fuel cell, either two $\mathrm{Al}$ plates (no poison) or two Al plates and two poison plates are installed, depending on the required number of PRAs. A DSC may contain either 16, 20, or 24 poison plates. Fuel assemblies containing PRAs are not authorized in the fuel basket with 16 poison plates. Information about the basket type and basket poison plate configuration of each as-loaded canister is currently unavailable in the database.

The NUHOMS ${ }^{\circledR}$ 32PT-DSC is used at the Palisades (11 canisters), Millstone (18 canisters), Ginna (6 canisters), and Kewannee (8 canisters) ISFSIs to store SNF assemblies. The fuel assemblies loaded in these canisters are represented by the RW-859 fuel assembly types XPA15C (Palisades), C1414C (Milestone 2), and W1414WL (Ginna and Kewannee). Criticality model templates for the loss-of-neutron absorber scenario were developed for the four NUHOMS ${ }^{\circledR}$ 32PT-DSC subtypes with respect to basket length (i.e., 32PT-S100, 32PT-S125, 32PT-L100, and 32PT-L125). Only the active fuel region of a fuel assembly is explicitly modeled. A model for the XPA15C fuel assembly type, irradiated in the Palisades power reactor only, was also developed. Model templates for the assembly types C1414C and W1414WL were already available in the template repository. No credit was taken for the presence of non-fuel hardware or PRAs. Moderator water is modeled in place of these components, which is conservative with respect to criticality. The models specify water moderator and reflector with a density of $0.998 \mathrm{~g} / \mathrm{cm}^{3}$ [D$10]$.

\section{D.3.1. Criticality Model for the XPA15C Fuel Assembly Type}

The fuel assemblies irradiated in the Palisades power reactor were Combustion Engineering or Exxon Nuclear $15 \times 15$ fuel assemblies with Zircaloy cladding identified in the RW nuclear fuel database [D-3] as XPA15C. A typical XPA15C fuel assembly has 216 fuel rods, 8 Zircaloy-4 guide bars, and 1 instrument tube [D-11,D-12]. A horizontal cross-sectional view of the model for the fuel assembly type XPA15C through the active fuel region is showed in Figure D-9. The guide bars are modeled as a water moderator, which is conservative with respect to fuel assembly reactivity and consistent with the fuel assembly model used in the SAR. 


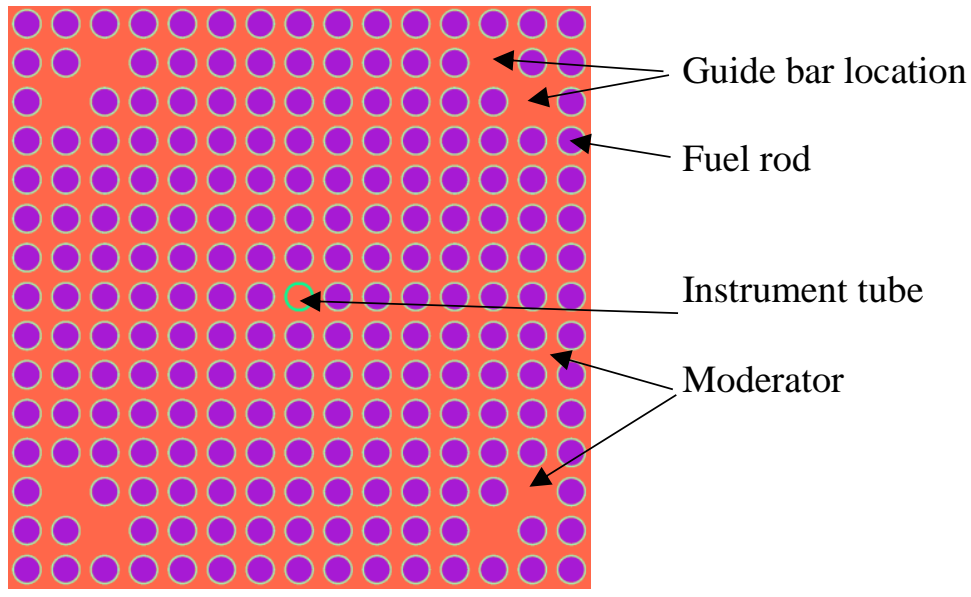

Figure D-9. Horizontal cross-sectional view of the XPA15C fuel assembly model.

\section{D.3.2. Canister Model for the Loss-of-Neutron-Absorber Scenario}

A horizontal cross-sectional view of the NUHOMS ${ }^{\circledR}$ 32PT-DSC model for the loss-of-neutron-absorber scenario is shown in Figure D-10. In this model, $\mathrm{Al}$ and poison plates are replaced by a water moderator and a fuel assembly is centered within its fuel basket cell.

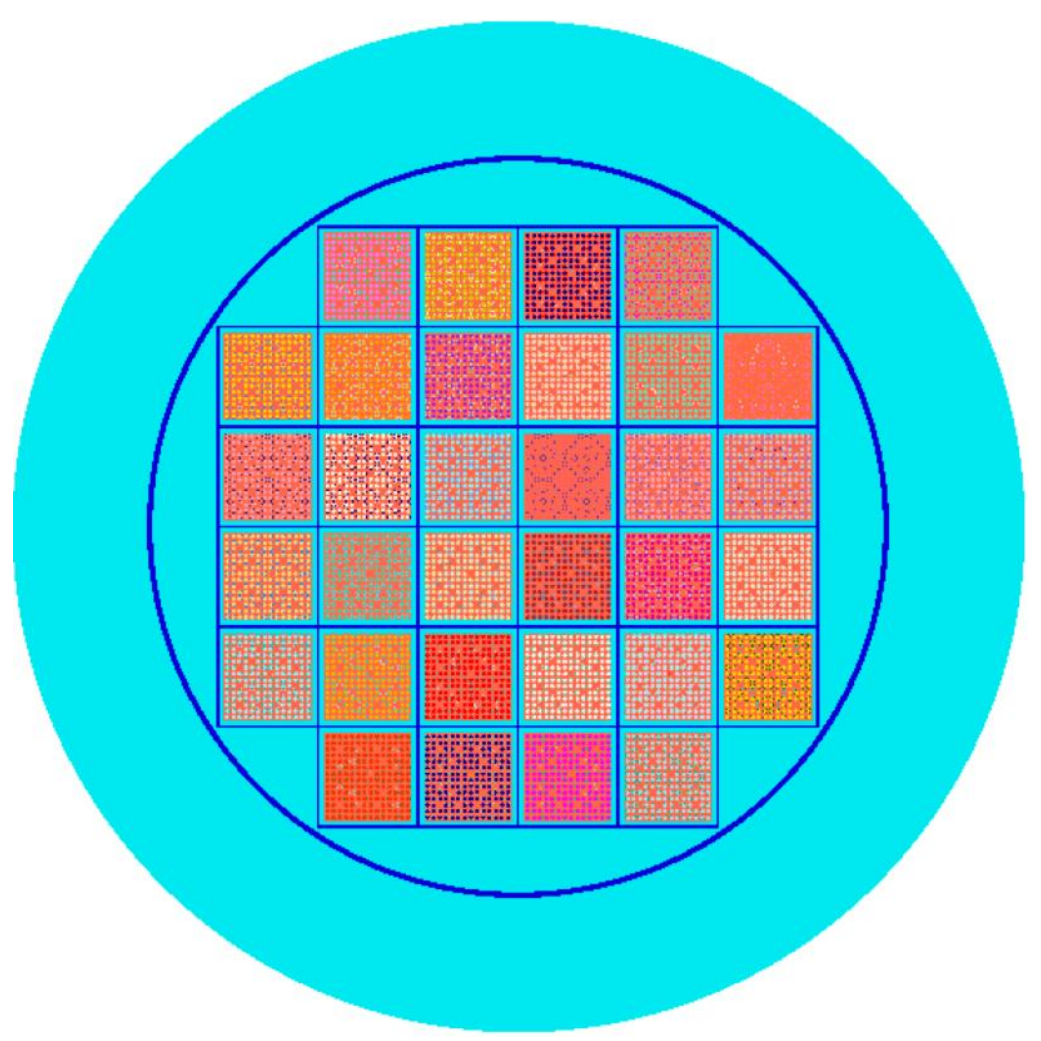

Figure D-10. Horizontal cross-sectional view of the NUHOMS ${ }^{\circledR}$ 32PT-DSC model for the loss-of-neutron-absorber scenario. 


\section{D.3.3. Criticality Model for Misload Calculations}

The canister misload model is based on the assumption that correct assemblies have been loaded into the canister but in the most reactive configuration. This configuration is referred to as a worst-misload configuration in Sect. C.3.5. Fuel assembly placement for the worst-misload configuration is illustrated in Figure D-11. The numbers indicate the rank of an individual fuel assembly based on assembly $k_{\text {inf }}$ values at a decay time of 9,500 years. The fuel composition for the misload model includes oxygen and the degradation disposal nuclides presented in Table A-1. The neutron absorber is neglected in this model (i.e., loss-of-neutron-absorber scenario).

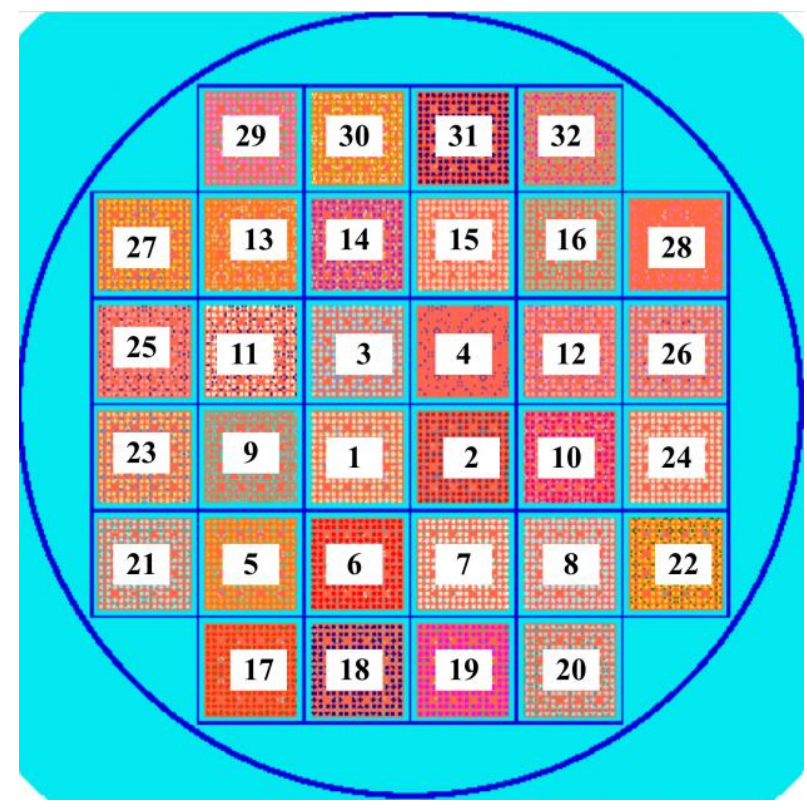

Figure D-11. Illustration of fuel assembly ranking in the worst-misload configuration for the NUHOMS ${ }^{\circledR}$ 32PT-DSC.

\section{D.3.4. Criticality Calculations Results for the NUHOMS ${ }^{\circledR}$ 32PT-DSC}

Post-closure disposal criticality calculations were performed as a function of decay time for the NUHOMS ${ }^{\circledR}$ 32PT-DSCs loaded with SNF at the Palisades (11 canisters), Ginna (6 canisters), Kewannee ( 8 canisters), and Millstone (18 canisters) ISFSIs. Results are provided for the loss-of-neutron-absorber scenario and 17 decay times within the time interval between calendar years 2015 and 22,000. Figure D12 shows $k_{\text {eff }}$ variation as a function of calendar year. The one sigma statistical uncertainty for all $k_{\text {eff }}$ values is 0.0003 or less. In the figure, time variation between 2000 and 2100 is shown on a linear scale, and time variation between 2100 and 22,000 is shown on a logarithmic scale.

The $k_{\text {eff }}$ values are predicted to vary from 0.9335 to 1.0312 for the Palisades SNF, 0.9063 to 0.9993 for the Ginna SNF, 0.9085 to 0.9572 for the Kewannee SNF, and 0.8722 to 0.9504 for the Millstone SNF canisters. Two canisters loaded with Ginna SNF and 10 canisters loaded with Palisades SNF are predicted to exceed the $k_{\text {eff }}$ subcriticality limit of 0.98 assuming a loss-of-neutron-absorber scenario. For these canisters, the pure water was replaced with groundwater compositions of various $\mathrm{NaCl}$ concentrations and the models thus modified were used to determine $k_{\text {eff }}$ as a function of $\mathrm{NaCl}$ concentration for the calendar year 22,000. Figure D-13 presents $k_{\text {eff }}$ variation as a function of $\mathrm{NaCl}$ concentration for those 12 canisters. The minimum required chlorine concentrations in the groundwater of $0.086 \mathrm{~mol} / \mathrm{kg} \mathrm{H}_{2} \mathrm{O}$ and $0.529 \mathrm{~mol} / \mathrm{kg} \mathrm{H}_{2} \mathrm{O}$ are determined to maintain a subcritical state for canisters loaded with Ginna SNF and Palisades SNF, respectively. In this context, it is also important to note that a saturated $\mathrm{NaCl}$ brine has a 
concentration of approximately 6 molal. A results summary for this canister in 22,000 is provided in Table D-1.

Figure D-14 shows the $k_{\text {eff }}$ increase between the worst-misload scenario and the as-loaded configuration for the analyzed NUHOMS ${ }^{\circledR} 32 \mathrm{PT}-D S C$. This increase varies between 27 and $7565 \mathrm{pcm}$. The NUHOMS $^{\circledR}$ 32PT-DSCs loaded with Palisades SNF would have a relatively large reactivity increase, from 1341 to $7565 \mathrm{pcm}$, between the worst-misload scenario and the as-loaded configuration.

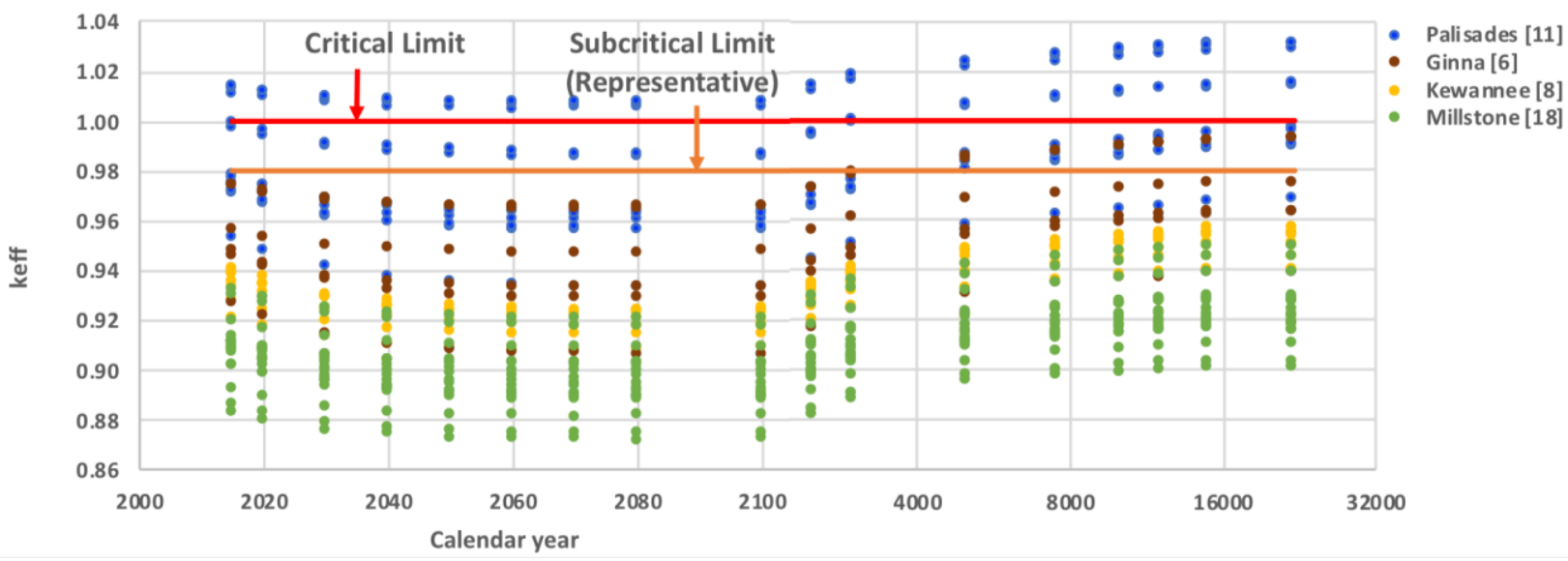

Figure D-12. $k_{\text {eff }}$ vs. calendar year for the loss-of-neutron-absorber scenario, based on actual loading and disposal isotopes (numbers in brackets = number of DPCs).

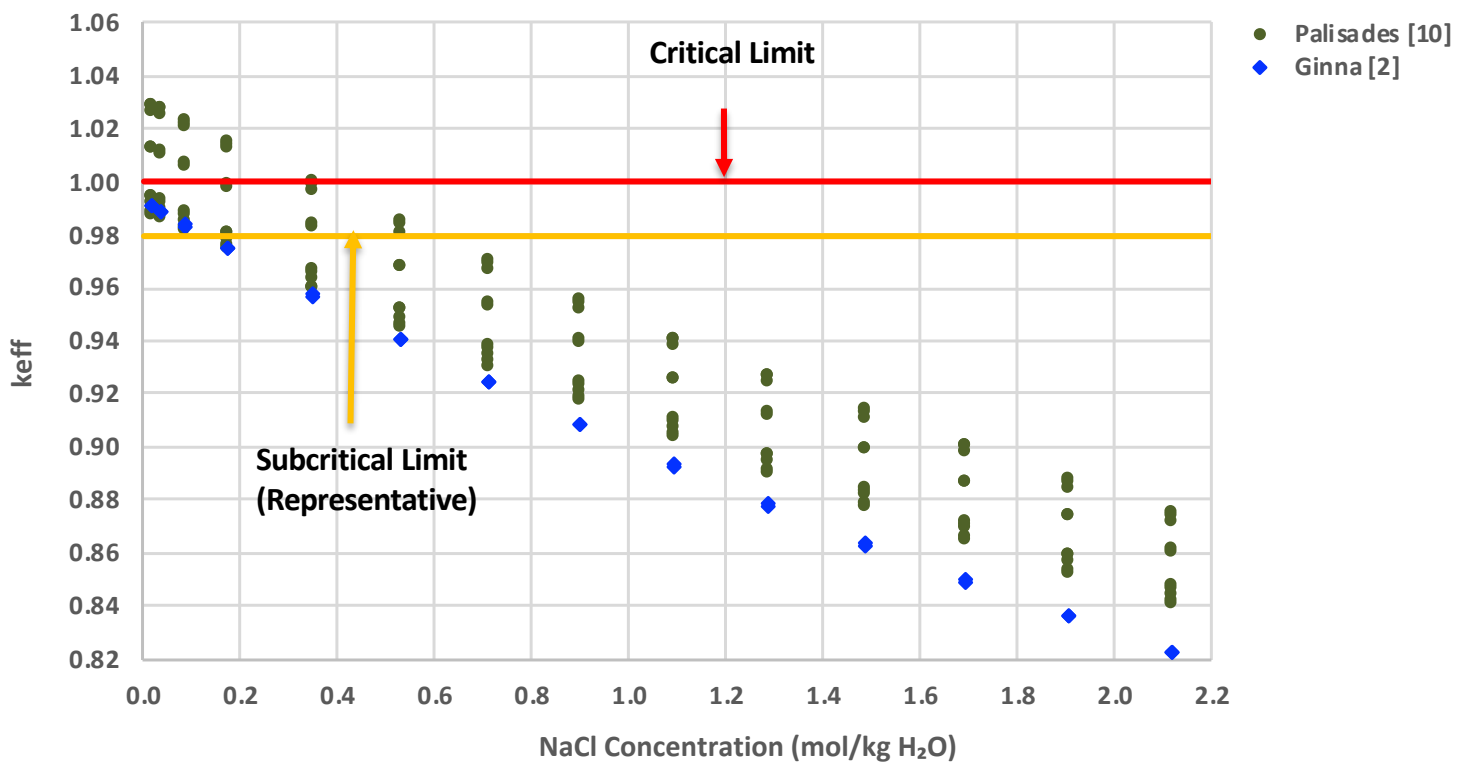

Figure D-13. $\boldsymbol{k}_{\text {eff }} \mathbf{v s . ~} \mathrm{NaCl}$ concentration for the DPCs with $\boldsymbol{k}_{\text {eff }}>\mathbf{0 . 9 8}$ for the loss-of-neutronabsorber scenario (numbers in brackets $=$ number of DPCs). 


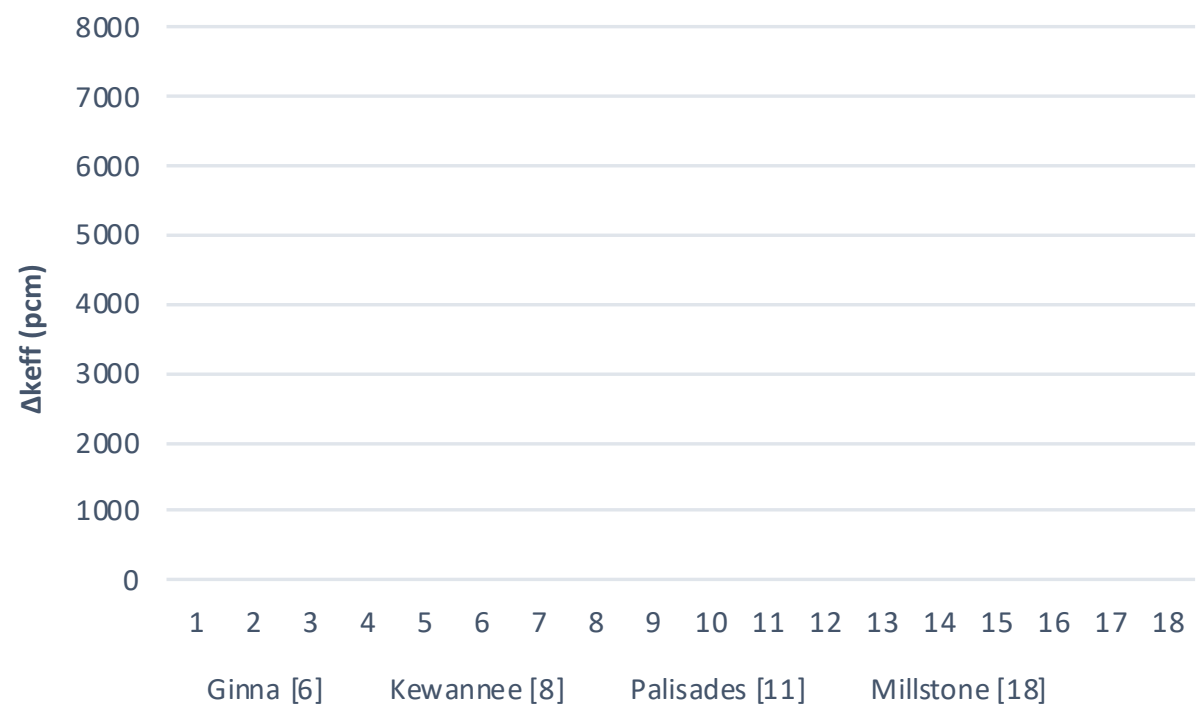

Figure D-14. $\boldsymbol{k}_{\text {eff }}$ increase between the worst-misload scenario and the as-loaded configuration (numbers in brackets $=$ number of DPCs).

Table D-1. Final NUHOMS ${ }^{\circledR}$ 32PT-DSC statistics in the year 22,000

\begin{tabular}{l|c}
\hline \multicolumn{1}{c|}{ Description } & $\begin{array}{c}\text { Values for loss of } \\
\text { neutron absorber }\end{array}$ \\
\hline Number of DSCs & 43 \\
\hline Number of DSCs with $k_{\text {eff }}>0.98$ (as-loaded analysis) & 12 \\
\hline Maximum $k_{\text {eff }}$ & 1.0312 \\
\hline Chlorine requirement for Palisades SNF canisters & $0.529 \mathrm{~mol} / \mathrm{kg} \mathrm{H}_{2} \mathrm{O}$ \\
\hline Chlorine requirement for Ginna SNF canisters & $0.086 \mathrm{~mol} / \mathrm{kg} \mathrm{H}_{2} \mathrm{O}$ \\
\hline
\end{tabular}

\section{D.4. FILLER HEIGHT SCOPING CALCULATION}

A filler height scoping calculation was performed for a representative DPC: the MPC-32-262 loaded with Farley SNF. This canister is predicted to have a $k_{\text {eff }}$ value of $1.0218 \pm 0.0003$ in the calendar year 22,000 assuming the loss-of-neutron-absorber scenario. The filler material was modeled as $68 \% \mathrm{Al}$ and $32 \% \mathrm{H}_{2} \mathrm{O}$ by volume. The disposal criticality model for the MPC-32 design was modified to enable $k_{\text {eff }}$ calculations as a function of filler height. Radially, the filler material is assumed to occupy the free space outside fuel pins and guide tubes. The guide tubes and the instrument tube are assumed to contain pure water. Vertical and horizontal cross-sectional views of the model are shown in Figure D-15. Filler height effects on $k_{\text {eff }}$ are shown in Table D-2 as a function of fuel pin axial burnup zone. For this canister, a filler height of $367.9825 \mathrm{~cm}$ (from basket bottom) is required to maintain canister subcriticality under a loss-of-neutronabsorber scenario. 

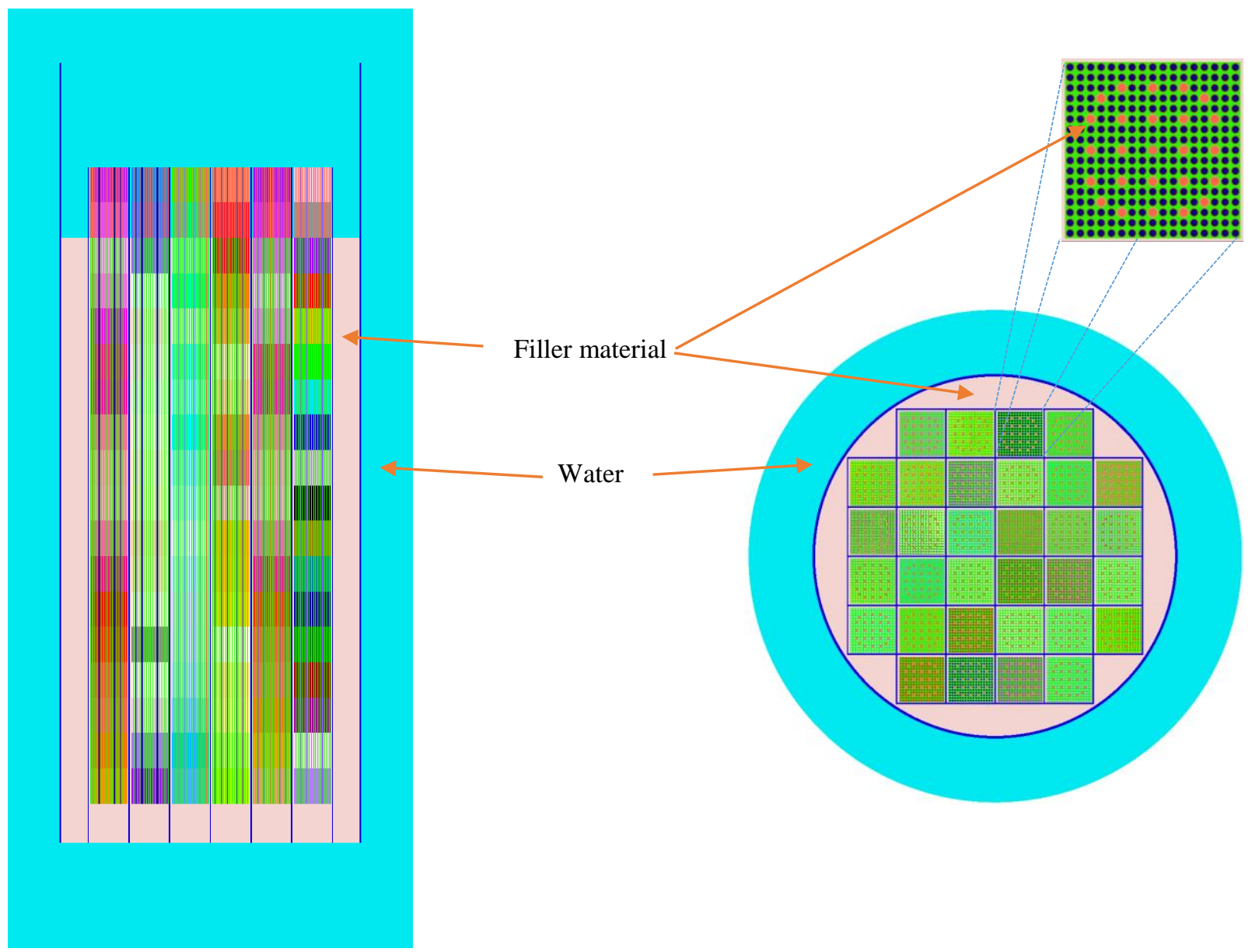

(a)

(b)

Figure D-15. (a) Vertical cross-sectional view and (b) horizontal cross-section view of the MPC-32 disposal criticality model for filler height studies.

Table D-2. $k_{\text {eff }}$ as a function of filler height.

\begin{tabular}{c|c|c|c}
\hline Outermost axial fuel zone & Filler height $^{a}$ & $\boldsymbol{k}_{\text {eff }}$ & sigma \\
\hline 14 & 307.0225 & 1.02292 & 0.00036 \\
\hline 15 & 327.3425 & 1.02065 & 0.00028 \\
\hline 16 & 347.6625 & 1.01169 & 0.00027 \\
\hline 17 & 367.9825 & 0.96016 & 0.00028 \\
\hline 18 & 388.3025 & 0.83271 & 0.00024 \\
\hline
\end{tabular}

${ }^{a}$ From basket bottom. 


\section{D.5. CONCLUSIONS}

This appendix presents criticality analysis models for the NUHOMS ${ }^{\circledR} 24 \mathrm{PT} 1-\mathrm{DSC}$ and NUHOMS ${ }^{\circledR}$ 32PT-DSC canister types. A total of 60 as-loaded canisters from five sites were analyzed over the time interval between calendar years 2015 and 22,000 using the burnup credit methodology described in this report. The analyzed sites were San Onofre (17 canisters), Palisades (11 canisters), Millstone (18 canisters), Ginna (6 canisters), and Kewannee (8 canisters).

SONGS1 SNF assemblies are currently stored in 17 NUHOMS ${ }^{\circledR}$ 21PT1-DSCs. This canister has a capacity of 24 fuel assemblies and contains 26 carbon steel discs to support the fuel basket cells. Three criticality models were developed describing (1) the regular intact canister configuration; (2) the loss-ofneutron-absorber scenario; and (3) the degraded basket material scenario. The estimated $k_{\text {eff }}$ values for the 17 canisters with an intact fuel basket configuration vary between 0.6766 and 0.7985 over the time interval between calendar years 2015 and 2100; that is, all $k_{\text {eff }}$ values are below the 0.98 subcritical limit. For the loss-of-neutron-absorber scenario, the $k_{\text {eff }}$ values vary between 0.7630 and 0.8786 over the time interval between calendar years 2015 and 22,000; that is, all estimated $k_{\text {eff }}$ values are below the 0.98 subcritical limit for repository time frame. For the basket material degradation scenario, the estimated $k_{\text {eff }}$ values vary between 0.8855 and 1.0589 over the time interval between calendar years 2015 and 22,000. Out of 17 DPCs, five canisters are predicted to be above the representative subcritical limit of 0.98 throughout the time interval analyzed. For the five canisters, the pure water in the model was replaced with groundwater compositions of various $\mathrm{NaCl}$ concentrations and the models thus modified were used to determine $k_{\text {eff }}$ as a function of $\mathrm{NaCl}$ concentration for the calendar year 22,000. A minimum required chlorine concentration in the groundwater of $1.092 \mathrm{~mol} / \mathrm{kg} \mathrm{H}_{2} \mathrm{O}$ was determined to maintain a subcritical state. The one sigma statistical uncertainty for all $k_{\text {eff }}$ values is 0.0003 or less.

Post-closure disposal criticality calculations were performed as a function of decay time for as-loaded NUHOMS ${ }^{\circledR}$ 32PT-DSCs at the Palisades (11 canisters), Ginna (6 canisters), Kewannee (8 canisters), and Millstone (18 canisters) ISFSIs. Results are provided for a loss-of-neutron-absorber scenario and 17 decay times within the time interval between calendar years 2015 and 22,000. The one sigma statistical uncertainty for all $k_{\text {eff }}$ values is 0.0003 or less. The $k_{\text {eff }}$ values are predicted to vary between 0.9335 to 1.0312 for the Palisades SNF, 0.9063 and 0.9993 for the Ginna SNF, 0.9085 and 0.9572 for the Kewannee SNF, and 0.8722 and 0.9504 for the Millstone SNF. Two canisters loaded with Ginna SNF and 10 canisters loaded with Palisades SNF are predicted to exceed the $k_{\text {eff }}$ subcriticality limit of 0.98 assuming a loss-of-neutron-absorber scenario. For these canisters, the pure water was replaced with groundwater compositions of various $\mathrm{NaCl}$ concentrations and the models thus modified were used to determine $k_{\text {eff }}$ as a function of $\mathrm{NaCl}$ concentration for the calendar year 22,000. The minimum required molal chlorine concentrations in the groundwater of $0.086 \mathrm{~mol} / \mathrm{kg} \mathrm{H}_{2} \mathrm{O}$ and $0.529 \mathrm{~mol} / \mathrm{kg} \mathrm{H}_{2} \mathrm{O}$ were determined to maintain a subcritical state for canisters loaded with Ginna SNF and Palisades SNF, respectively.

Canister misload criticality analyses were performed assuming a worst configuration in an as-loaded canister, which is based on the assumption that correct assemblies have been loaded into the canister but in the most reactive configuration. $k_{\text {eff }}$ values for worst-misload configurations were determined assuming that all fuel assemblies in the canister have a decay time of 9,500 years and the neutron absorber is completely lost. The misload analysis was performed for a total of 49 canisters containing intact fuel assemblies and loaded to full capacity. The 11 canisters not analyzed, which contain San Onofre Unit 1 damaged fuel and/or empty locations, will be analyzed in the future. The $k_{\text {eff }}$ increase between the worstmisload scenario and the as-loaded configuration for the six analyzed SONGS1 SNF canisters varies between approximately 500 and $2000 \mathrm{pcm}$. The $k_{\text {eff }}$ increase between the worst-misload scenario and the as-loaded configuration for the analyzed NUHOMS ${ }^{\circledR} 32$ PT-DSCs varies between approximately 27 and $7565 \mathrm{pcm}$. 
A filler height scoping calculation was performed for the MPC-32-262 canister loaded with Farley SNF. This canister is predicted to have a $k_{\text {eff }}$ value of 1.0218 in the calendar year 22,000 assuming a loss-ofneutron-absorber scenario. The filler material was modeled as $68 \% \mathrm{Al}$ and $32 \% \mathrm{H}_{2} \mathrm{O}$ by volume. A filler height of $367.9825 \mathrm{~cm}$ (from basket bottom) was evaluated to maintain in a subcritical state $\left(k_{\text {eff }}<0.98\right)$ under loss-of-neutron-absorber scenario.

\section{D.6. REFERENCES}

D-1. Certificate of Compliance for Radioactive Material Packages, Certificate Number 9255, Revision Number 11, US Nuclear Regulatory Commission (2013).

D-2. Certificate of Compliance for Radioactive Material Packages, Certificate Number 9302, Revision Number 7, US Nuclear Regulatory Commission (2014).

D-3. RW-859 Nuclear Fuel Data, Energy Information Administration, US Department of Energy, Washington, D.C. (Oct. 2004).

D-4. Safety Analysis Report for the NUHOMS-MP187 Multi-Purpose Cask, Rev. 11, Document No. NUH-05-151, Transnuclear West Inc. (2001).

D-5. Appendix A to Certificate of Compliance No. 1029, Technical Specifications for the Advanced NUHOMS Systems Operating Controls and Limits, ADAMS Accession Number ML05152013.

D-6. Characteristics of Spent Fuel, High-Level Waste, and Other Radioactive Wastes which May Require Long-Term Isolation, DOE/RW-0184, Volume 3, US Department of Energy (1987).

D-7. Advanced NUHOMS System Final Safety Analysis Report Rev. 0, ADAMS Accession Number: ML031040379 (2003).

D-8. SCALE Version 4.4 - A Modular Code System for Performing Standardized Computer Analyses for Licensing Evaluation, NUREG/CR-0200, Rev. 6, (ORNL/NUREG/CSD-2/R6), Oak Ridge National Laboratory, US Nuclear Regulatory Commission (2000).

D-9. W.J. Marshall, B.T. Rearden, and E.L. Jones, "Validation of SCALE 6.2 Criticality Calculations Using KENO V.A and KENO-VI," Proceedings of International Conference on Nuclear Criticality Safety, Charlotte, NC (2015).

D-10. NUHOMS ${ }^{\circledR}$-MP197 Transportation Cask Safety Analysis Report, Revision 15, Document No. NUH09.0101, Transnuclear Inc. (2014).

D-11. Palisades Final Safety Analysis Report Update, Revision 31, Chapter 3 - Reactor - Figures, ADAMS Accession Number: ML16120A359 (2016).

D-12. Palisades Final Safety Analysis Report Update, Revision 32, Chapter 3 - Reactor - Tables, ADAMS Accession Number: ML16120A32 (2016). 
This page is intentionally left blank. 

This page is intentionally left blank. 


\section{E.1. INTRODUCTION}

This appendix documents work performed supporting the US Department of Energy (DOE) Office of Nuclear Energy (NE) Spent Fuel and Waste Disposition (SFWD) under work breakdown structure element 1.08.01.03.05 "Direct Disposal of Dual Purpose Canisters." In particular, this appendix fulfills the M3 milestone, M3SF-19OR010305013, "Update of DPC Direct Disposal Criticality Analysis Report" within work package SF-19OR01030501, "Direct Disposal of Dual Purpose Canisters - ORNL."

This appendix presents the dual-purpose canister (DPC) criticality evaluations performed in FY 2019 to support the feasibility determination of direct disposal of DPCs and extends the work reported in the main body and preceding appendices of this report. The main objectives of the FY 2019 DPC disposal criticality study were to develop degraded canister criticality calculation templates for the NUHOMS ${ }^{\circledR}$ 32PTH1 [D-2] and NUHOMS ${ }^{\circledR}$ 61BT/BTH [D-2] dry shielded canisters (DSCs) from the intact models documented in the forthcoming Criticality Process, Modeling and Status for UNF-ST\&DARDS [E-1] and to perform as-loaded criticality analyses for sites using these two canister types, as well as the TSC-37 and the loading maps currently available in the database.

A total of 92 as-loaded canisters from five sites were analyzed for the time interval between calendar years 2020 and 22,000 using the burnup credit methodology described in the previous sections of this report. The analyzed canisters were at the following sites: Nine Mile Point (6 canisters), Cooper (8 canisters), Monticello (10 canisters), Crystal River (38 canisters), and Kewannee (30 canisters beyond those analyzed in Appendix D, for a total of 38 canisters).

Criticality analyses models were developed for (1) the intact canister configuration applicable to normal conditions of transport and storage as described in the UNF-ST\&DARDS status report referenced above [E-1] and (2) for degraded material configurations applicable to the canister repository time frame specified in this report. The degraded material configurations assume two scenarios: (1) complete loss of the fixed neutron absorber (i.e., ${ }^{10} \mathrm{~B}$ ) without fuel basket geometry changes and (2) complete degradation and loss of basket materials, including neutron absorber plates and aluminum and carbon steel basket components (e.g., insert plates and basket support discs). The effect of canister material degradation and neutron absorber loss is a significant increase in $k_{\text {eff. }}$ The degraded material configurations were analyzed for 10 analysis dates between 2020 and 22,000.

As mentioned in the main report, neutron moderation by water is needed for a waste package to achieve criticality. However, the groundwater (or pore water) that may flood a breached DPC will contain various dissolved aqueous species. Seventeen species were studied in the main report, and it was determined that $\mathrm{Cl}, \mathrm{Li}$, and $\mathrm{B}$ provide the maximum reduction in canister reactivity because of their large neutron absorption cross sections. However, available groundwater data indicate that chlorine (as chloride) is the only naturally abundant neutron-absorbing element in groundwater that can provide a significant reduction in reactivity and is available in most of the repository concepts under consideration in varying quantities. Analyses were performed to determine the chlorine requirement to suppress the reactivity of canisters that have the potential to form critical configuration in a repository time frame. The impact of chlorine (in terms of $\mathrm{NaCl}$ ) concentration in groundwater on the reactivity of as-loaded DPCs exceeding a $k_{\text {eff }}$ value of 0.98 was evaluated for the calendar year 22,000. Previous chlorine concentration effects on $k_{\text {eff }}$ documented in this report were evaluated for the calendar year 9,999. The impacted DPCs will be reevaluated for the calendar year 22,000 in the future. Note that within the time interval between calendar years 2020 and 22,000, canister $k_{\text {eff }}$ initially decreases with increasing decay time, reaches a minimum value, and then increases with increasing decay time. Hence the $k_{\text {eff }}$ value for the calendar year 22,000 is slightly higher than that for the calendar year 9,999.

The remainder of this appendix is organized as follows: Section E. 2 describes the NUHOMS ${ }^{\circledR}$ 61BT-DSC loss-of-neutron-absorber model, Section E.3 discusses the criticality calculations for Nine Mile Point, Cooper, and Monticello, Section E.4 provides a description of the NUHOMS ${ }^{\circledR} 32$ PTH-DSC loss-of- 
neutron absorber model, Sections E.5 and E.6 discuss the Crystal River and Kewaunee criticality calculations, Section E.7 contains the conclusions, and E.8 contains the reference.

\section{E.2. $\quad$ NUHOMS ${ }^{\circledR}$ 61BT-DSC LOSS OF NEUTRON ABSORBER MODEL}

A horizontal cross-sectional view of the NUHOMS ${ }^{\circledR}$ 61BT-DSC model for the loss-of-neutron-absorber scenario was developed based on the intact model discussed in Section A-13 of the UNF-ST\&DARDS criticality modeling status report [E-1] and is shown in Figure E-1. In this model, Al and poison plates are replaced by a full density water moderator, and a fuel assembly is centered within its fuel basket cell. The structural components of the basket are manufactured of stainless steel, so no degraded basket model is necessary.

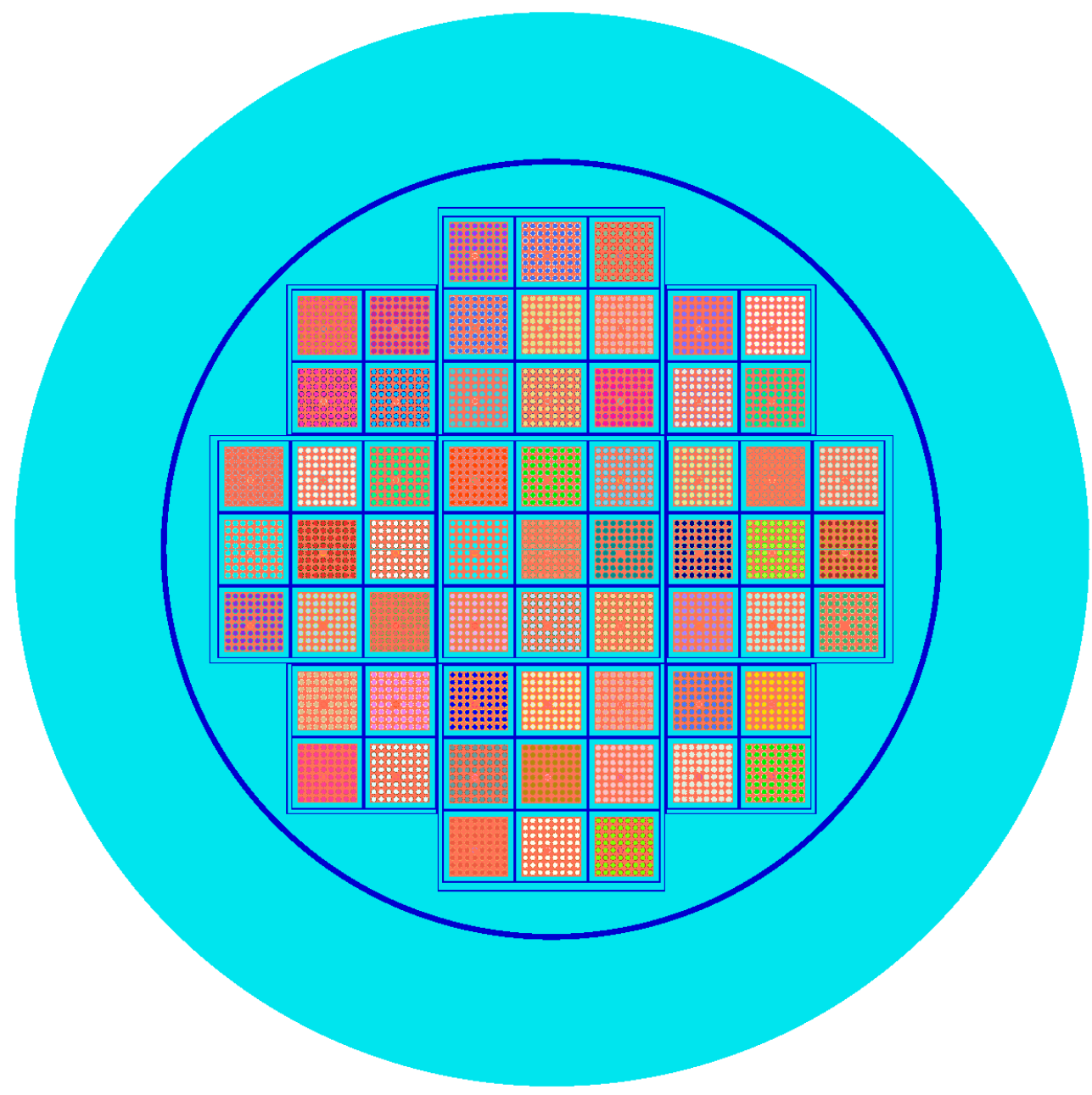

Figure E-1. Horizontal cross-sectional view of the NUHOMS® 61BT-DSC model for the loss-of-neutron-absorber scenario.

\section{E.3. NINE MILE POINT, COOPER, AND MONTICELLO CRITICALITY CALCULATIONS}

Post-closure disposal criticality calculations were performed as a function of decay time for the NUHOMS ${ }^{\circledR}$ 61BT-DSCs loaded with SNF at the Nine Mile Point (6 canisters), Cooper (8 canisters), and Monticello (10 canisters) ISFSIs. Results are provided for the loss-of-neutron-absorber scenario for 10 
decay times within the time interval between calendar years 2020 and 22,000. Figure E-2 shows $k_{\text {eff }}$ variation as a function of calendar year, along with the assumed subcritical limit of 0.98 and the critical limit of 1.0. The one sigma statistical uncertainty for all $k_{\text {eff }}$ values is 0.0003 or less for each calculation. The $k_{\text {eff }}$ values are predicted to vary from 0.88931 to 0.91339 for the Nine Mile Point SNF canisters, 0.86054 to 0.91567 for the Monticello SNF canisters, and 0.89210 to 0.90822 for the Cooper SNF canisters.

No SNF canisters loaded at the three BWR sites considered here exceeded the 0.98 representative subcritical limit, so no calculations were performed with added $\mathrm{NaCl}$ in the moderator.

Figures E-3 through E-5 show the $k_{\text {eff }}$ increase between the worst misload scenario and the loss-ofneutron-absorber, as-loaded configuration for the analyzed NUHOMS ${ }^{\circledR} 61$ BT-DSCs at Nine Mile Point, Cooper, and Monticello. This increase varies between 830 and $1,525 \mathrm{pcm}$ for the Nine Mile Point canisters, between 407 and 572 pcm for the Cooper SNF canisters, and between 158 and 3,150 pcm for the Monticello SNF canisters.

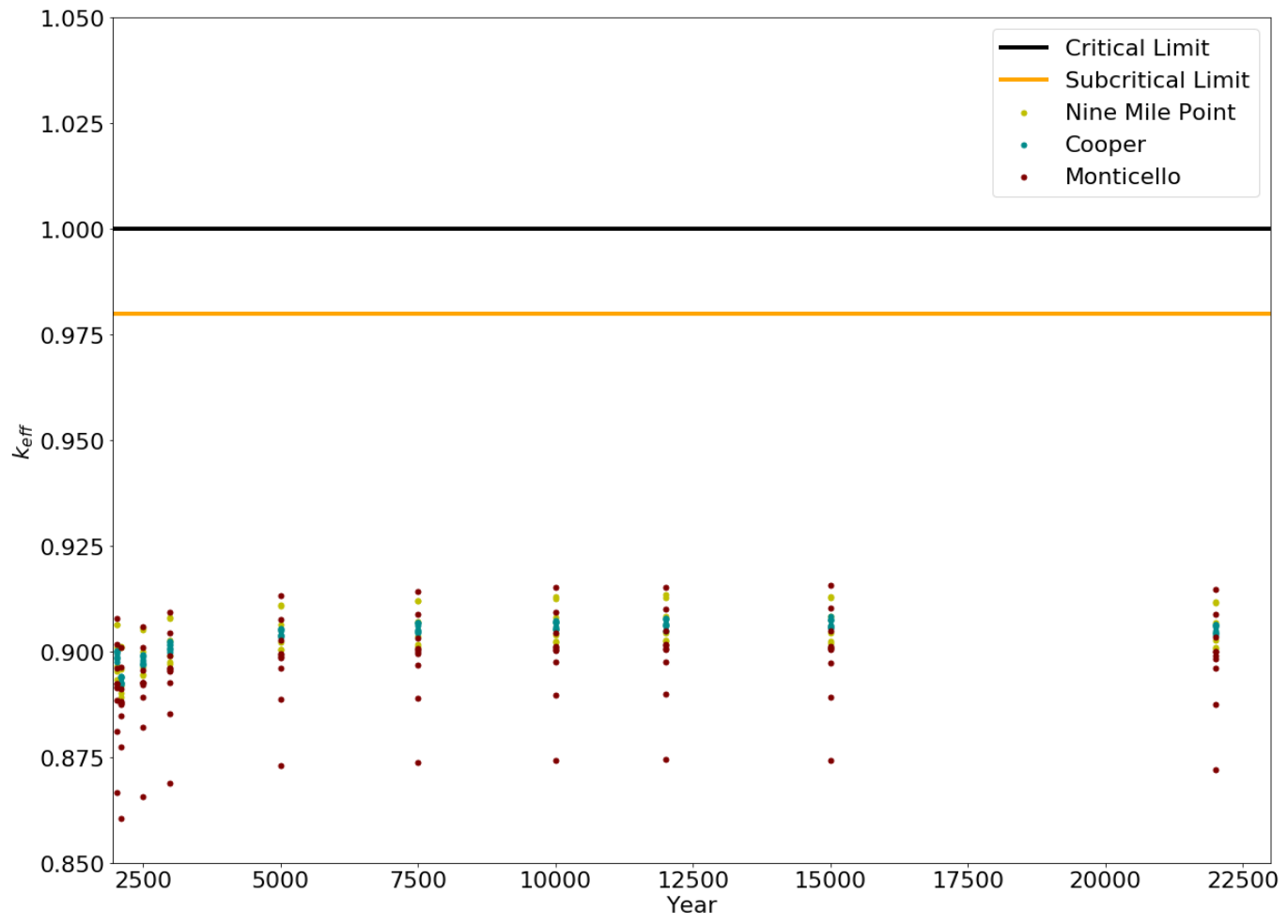

Figure E-2. $\boldsymbol{k}_{\text {eff }}$ vs. calendar year for the loss-of-neutron-absorber scenario based on actual loading and disposal isotopes for SNF canisters at Nine Mile Point, Cooper, and Monticello. 


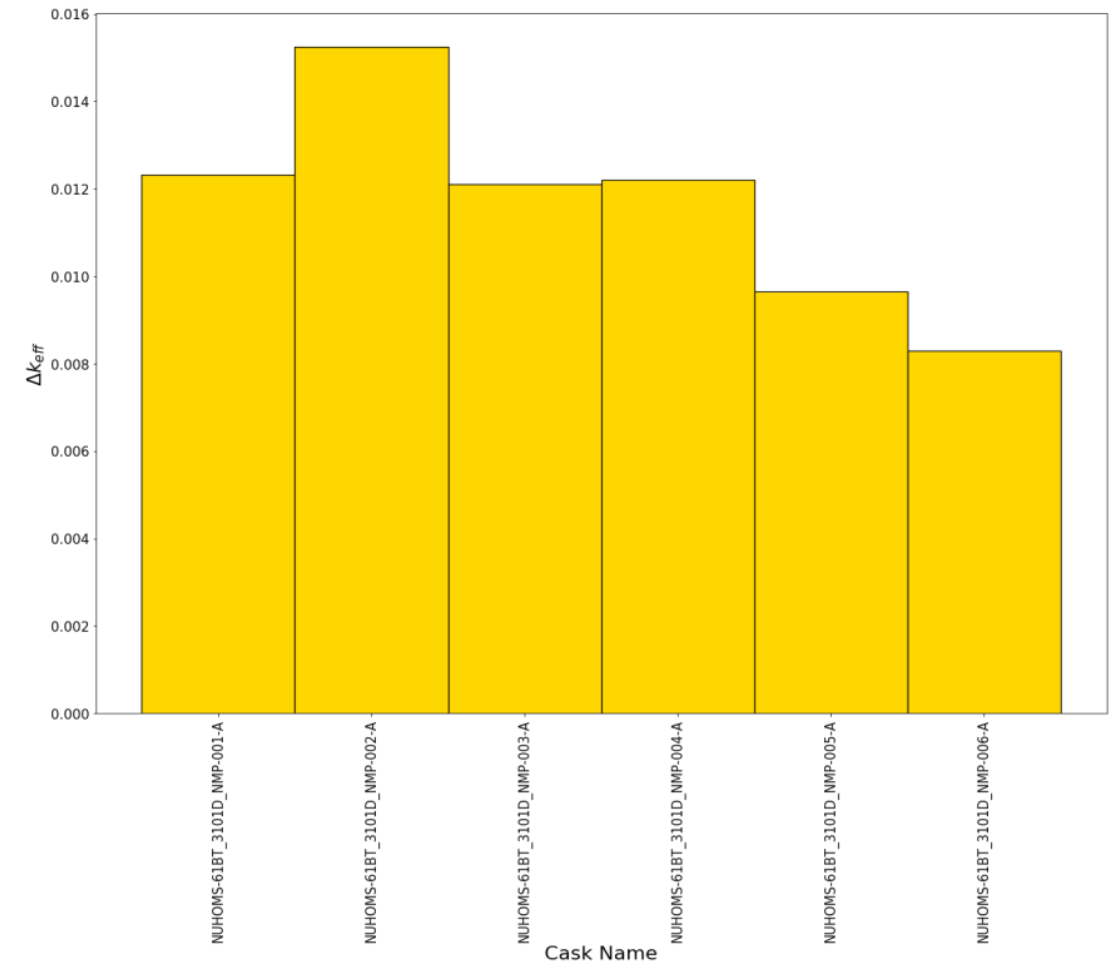

Figure E-3. $\boldsymbol{k}_{\text {eff }}$ increase between the worst-misload scenario and the as-loaded configuration for 6 Nine Mile Point SNF canisters.

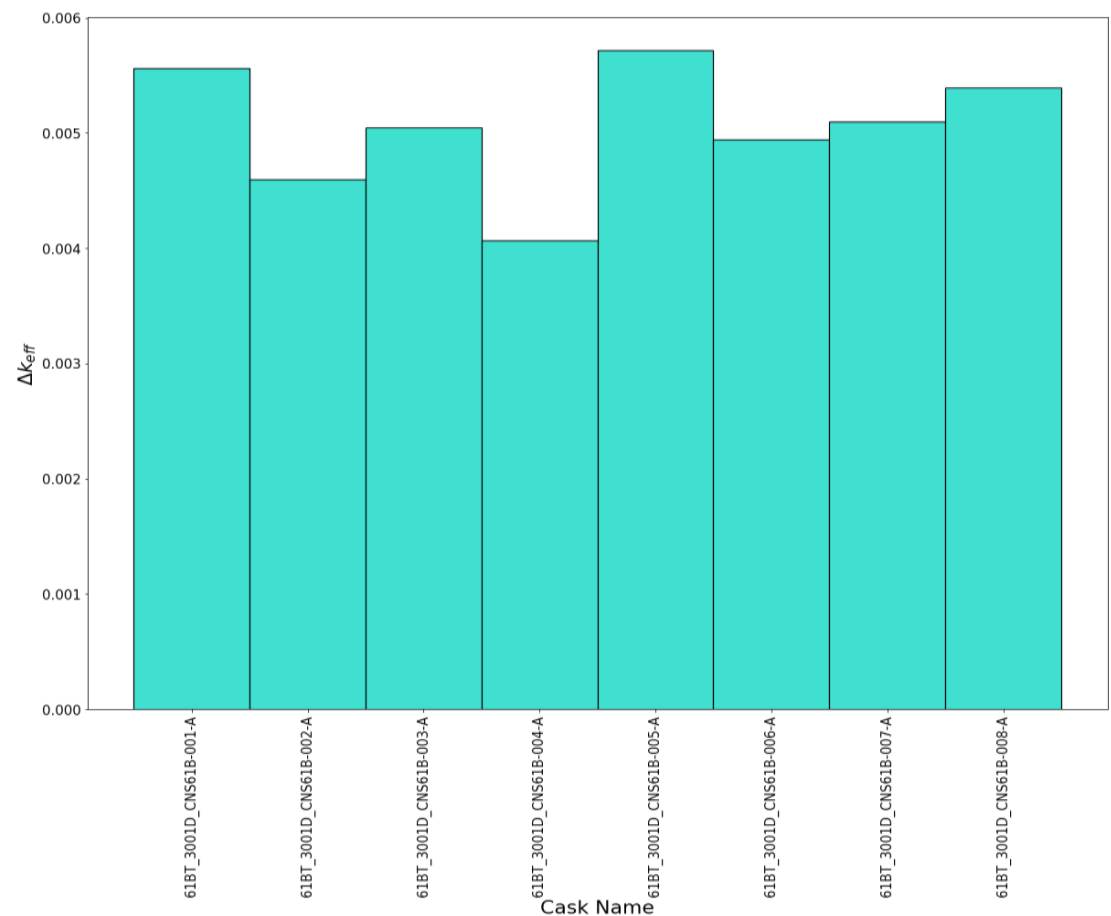

Figure E-4. $k_{e f f}$ increase between the worst-misload scenario and the as-loaded configuration for 8 Cooper SNF canisters. 


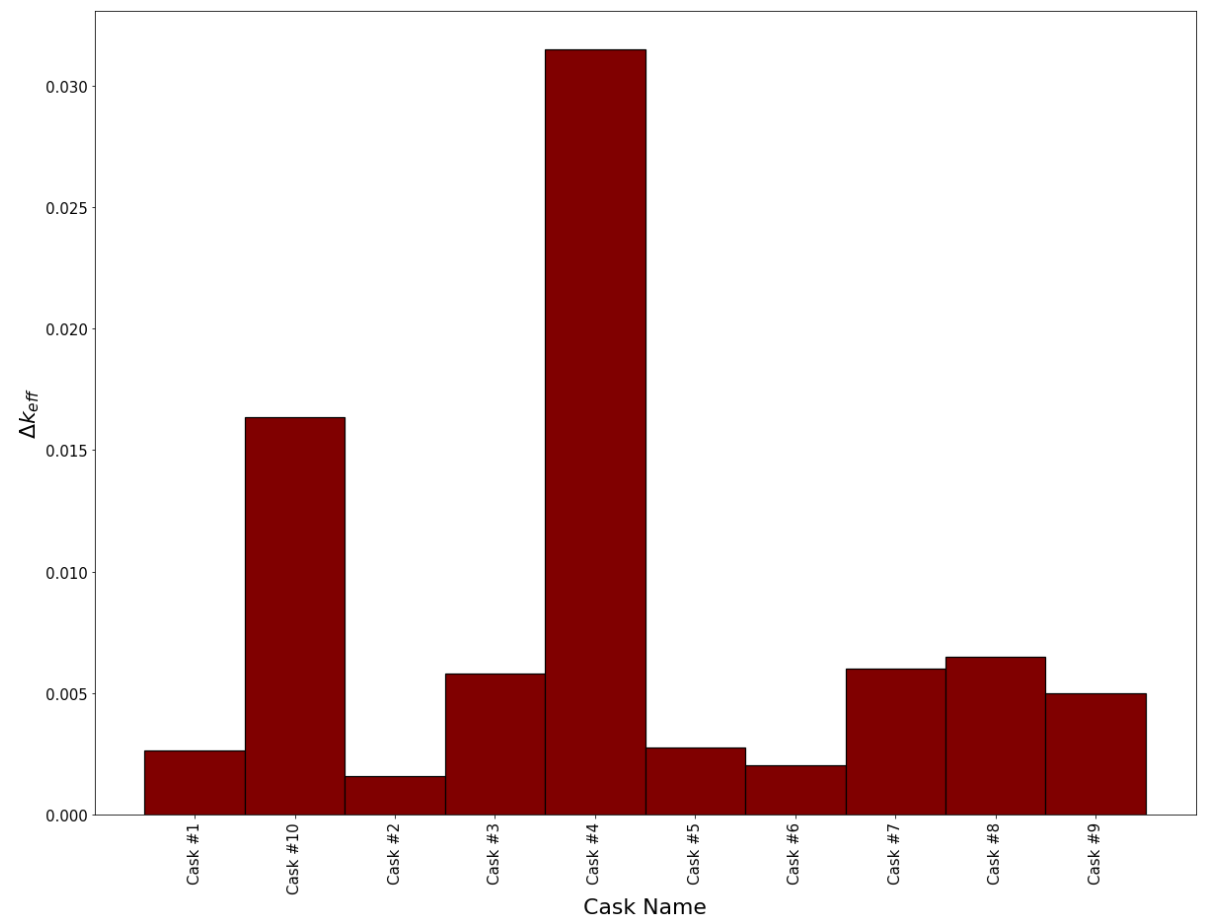

Figure E-5. $k_{\text {eff }}$ increase between the worst misload scenario and the as-loaded configuration for 10 Monticello SNF canisters.

\section{E.4. NUHOMS ${ }^{\circledR}$ 32PTH-DSC LOSS OF NEUTRON ABSORBER MODEL}

A NUHOMS $^{\circledR}$ 32PTH-DSC model for the loss-of-neutron-absorber scenario was developed based on the intact model discussed in Section A-14 of the UNF-ST\&DARDS criticality status report [E-1] and a horizontal cross-sectional view of the model is shown in Figure E-6. In this model, Al and poison plates are replaced by a water moderator, and a fuel assembly is centered within its fuel basket cell. The structural components of the basket are manufactured of stainless steel, so no degraded basket model is necessary. 


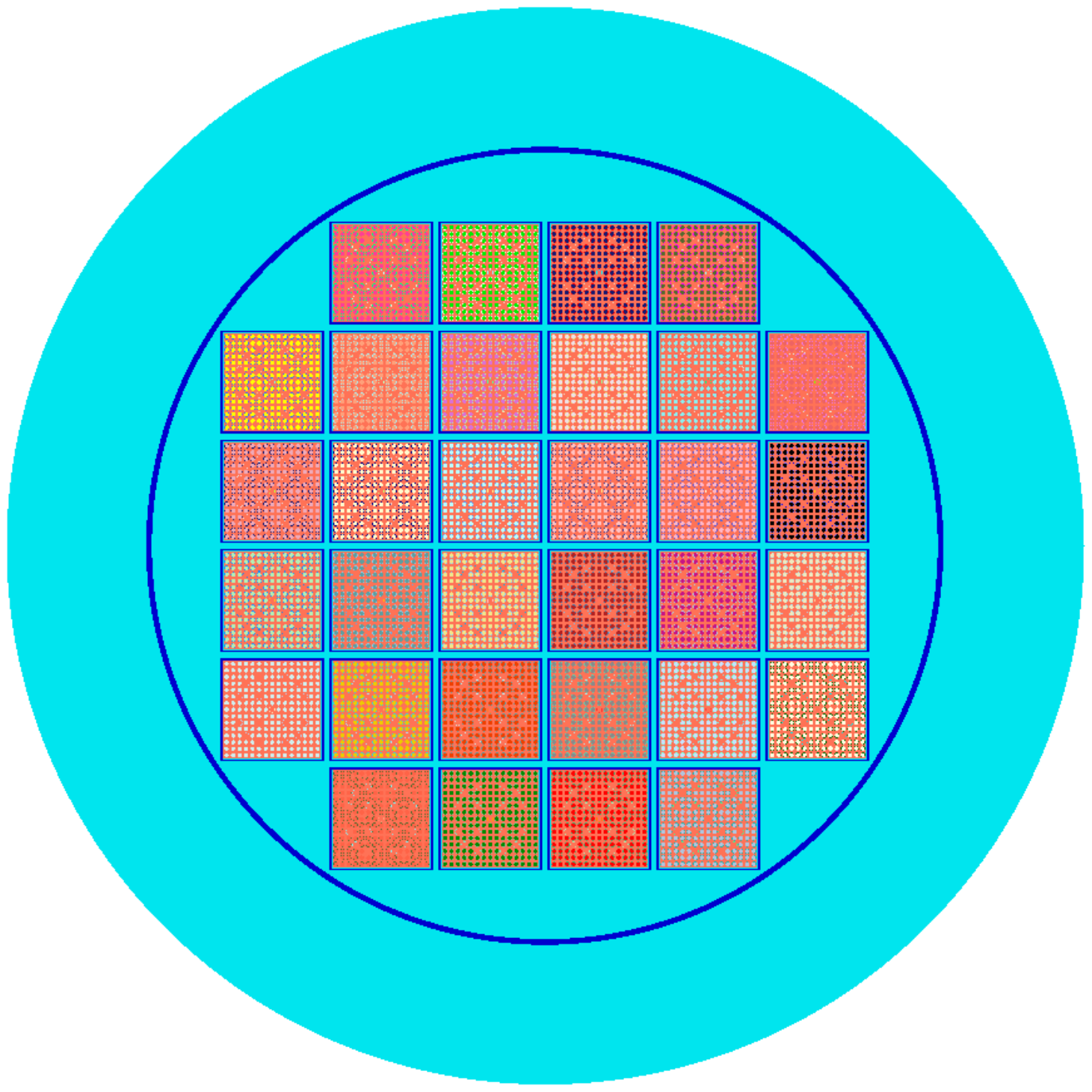

Figure E-6. Horizontal cross-sectional view of the NUHOMS ${ }^{\circledR}$ 32PTH-DSC model for the loss-of-neutron-absorber scenario.

\section{E.5. CRYSTAL RIVER CRITICALITY CALCULATIONS}

Post-closure disposal criticality calculations were performed as a function of decay time for the NUHOMS $^{\circledR}$ 32PTH-DSCs loaded with SNF at the Crystal River (38 canisters) ISFSI. Results are provided for the loss-of-neutron-absorber scenario for 10 decay times within the time interval between calendar years 2020 and 22,000. Figure E-7 shows $k_{\text {eff }}$ variation as a function of calendar year, along with the assumed representative subcritical limit of 0.98 and the critical limit of 1.0. The one sigma statistical uncertainty for all $k_{\text {eff }}$ values is 0.0003 or less for each calculation.

The $k_{\text {eff }}$ values are predicted to vary from 0.88026 to 0.97838 for the Crystal River SNF canisters.

No SNF canisters loaded at Crystal River considered here exceeded the 0.98 subcritical limit, so no calculations were performed with added $\mathrm{NaCl}$ in the moderator.

Figure E- 8 shows the $k_{\text {eff }}$ increase between the worst-misload scenario and the as-loaded configuration for 37 of the 38 analyzed NUHOMS ${ }^{\circledR} 32$ PTH-DSCs. One canister was not analyzed because the current 
worst-case misload methodology cannot be applied to short loaded canisters. This increase varies between 729 and 9,091 pcm.

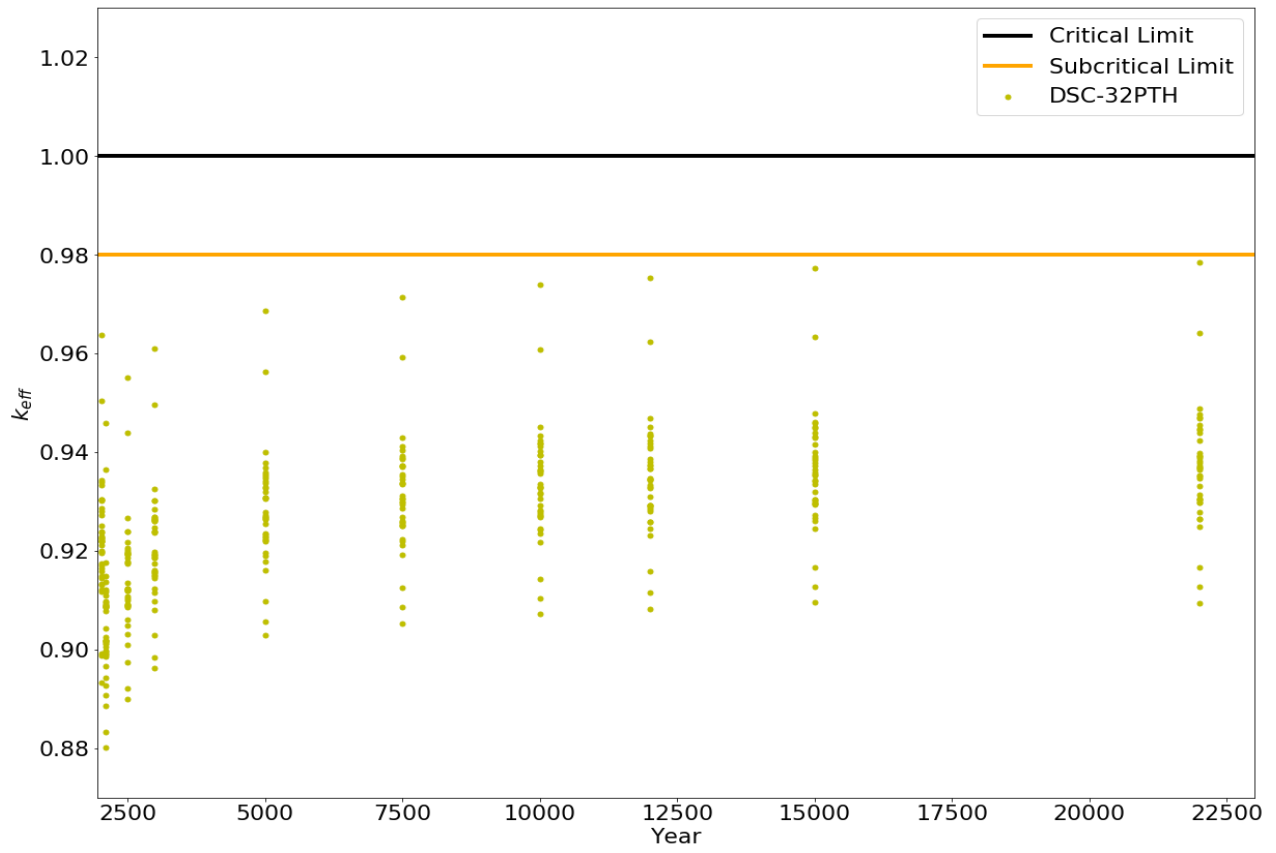

Figure E-7. $k_{\text {eff }}$ vs. calendar year for the loss-of-neutron-absorber scenario based on actual loading and disposal isotopes for SNF canisters at Crystal River.

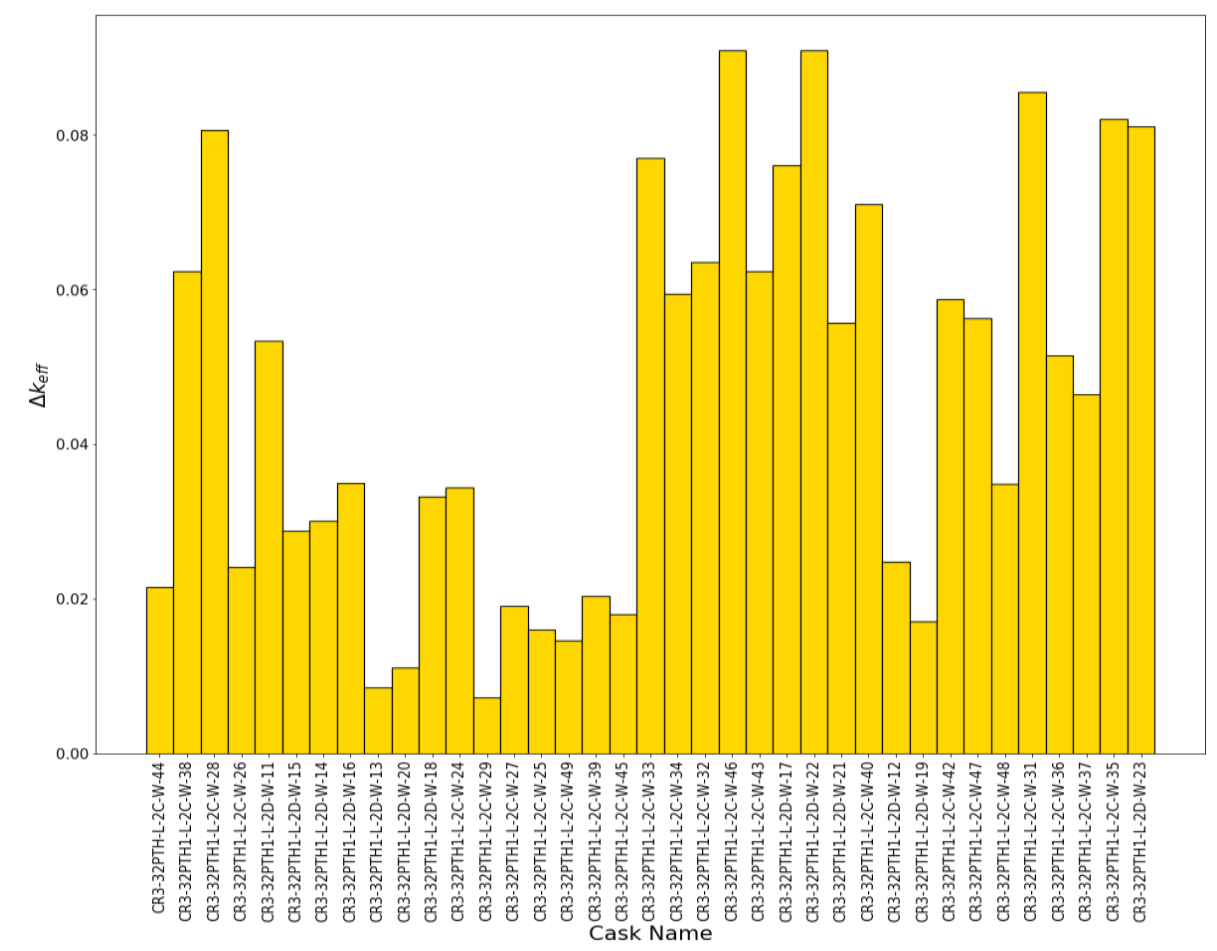

Figure E-8. $\boldsymbol{k}_{\text {eff }}$ increase between the worst misload scenario and the as-loaded configuration for Crystal River SNF canisters. 


\section{E.6. KEWAUNEE CRITICALITY CALCULATIONS}

Post-closure disposal criticality calculations were performed as a function of decay time for the 38 SNF canisters at the Kewaunee ISFSI. Of the 38 SNF canisters, 14 are NUHOMS ${ }^{\circledR} 32$ PT-DSCs (including the 8 canisters analyzed in Appendix D, which are included here for completeness), and 24 are TSC-37s. Figure E-9 and Figure E-10 show results for the loss-of-neutron-absorber scenario and the degradedbasket scenario for 10 decay times within the time interval between calendar years 2020 and 22,000. The results in Figure E-9 and Figure E-10 show $k_{\text {eff }}$ variation as a function of calendar year. The one sigma statistical uncertainty for all $k_{\text {eff }}$ values is 0.0003 or less. The TSC-37 has structural components fabricated from carbon steel, while the NUHOMS ${ }^{\circledR} 32 \mathrm{PT}-\mathrm{DSC}$ does not contain any carbon steel structural components. Therefore, only the TSC-37 is evaluated for the degraded basket scenario.

The $k_{\text {eff }}$ values are predicted to vary from 0.90962 to 0.97323 for the NUHOMS ${ }^{\circledR} 32 \mathrm{PT}$-DSCs. The $k_{\text {eff }}$ values are predicted to vary from 0.90976 to 0.97352 for the TSC-37s under the loss-of-neutron absorber scenario and from 0.98128 to 1.05163 for the TSC-37s under the degraded-basket scenario. For the TSC-37 canisters in the degraded basket scenario, calculations were performed in which the pure water was replaced with groundwater compositions of various $\mathrm{NaCl}$ concentrations, and the models thus modified were used to determine $k_{\text {eff }}$ as a function of $\mathrm{NaCl}$ concentration for the calendar year 22,000 (most reactive date). Figure E-11 presents $k_{\text {eff }}$ variation as a function of $\mathrm{NaCl}$ concentration for those 24 canisters. Examining the results presented in Figure E-11, it is clear that $0.50 \mathrm{~mol} \mathrm{NaCl} / \mathrm{kg} \mathrm{H}_{2} \mathrm{O}$ is sufficient to demonstrate subcriticality for all of the Kewaunee canisters. In this context, it is also important to note that a saturated $\mathrm{NaCl}$ brine has a concentration of approximately 6 molal.

Figure E-12 shows the $k_{\text {eff }}$ increase between the worst misload scenario and the as-loaded configuration for the analyzed NUHOMS ${ }^{\circledR}$ 32PT-DSCs under the loss-of-neutron-absorber scenario, and Figure E-13 shows the same information for the TSC-37 canisters. It is noted that misloading calculations are performed for 23 of the 24 TSC-37 because one is short loaded, and the misload methodology does not currently support less-than-full canisters. The increase in $k_{\text {eff }}$ varies between -30 and 2,137 pcm for the NUHOMS $^{\circledR}$ 32PT-DSCs and between 768 and 11,241 pcm for the TSC-37 canisters. It is observed that canister KPS32PT-S100-A16-HZ013 has a negative change in $k_{\text {eff }}$ under the worst case reloading misload configuration. The inputs for both the base line and misloaded cases were checked and found to be correct. It is apparent that the base line loading of KPS32PT-S100-A16-HZ013 has many of the most reactive assembly positioned in a face adjacent orientation with one another, and is not substantially different from the misloaded configuration. It is also noted that the $30 \mathrm{pcm}$ change is an approximately one standard deviation change in $k_{\text {eff }}$ and could easily be accounted for due to the calculation-tocalculation variation in Monte Carlo calculations. 


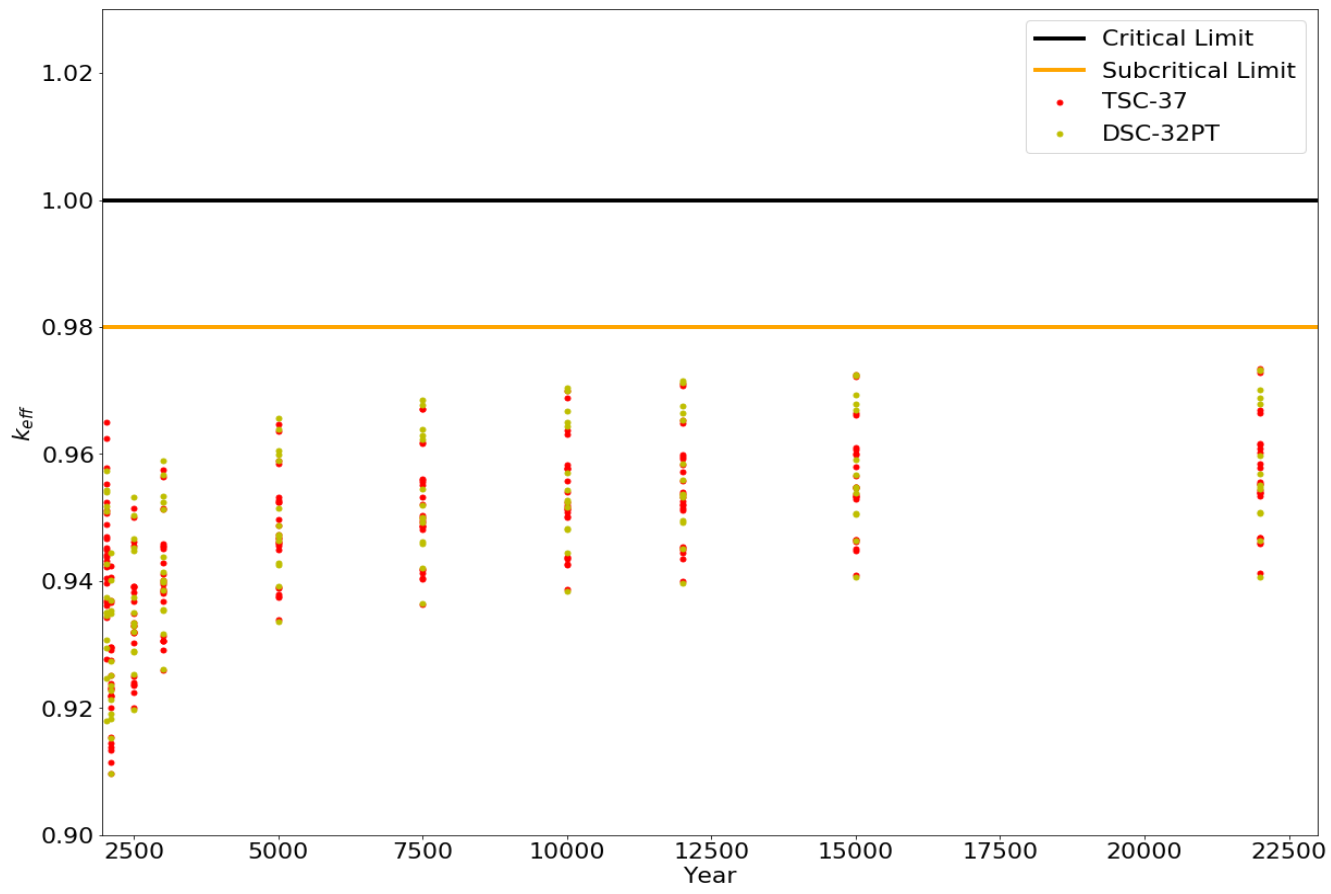

Figure E-9. $\boldsymbol{k}_{\text {eff }}$ vs. calendar year for the loss-of-neutron-absorber scenario based on actual loading and disposal isotopes for all SNF canisters at Kewaunee.

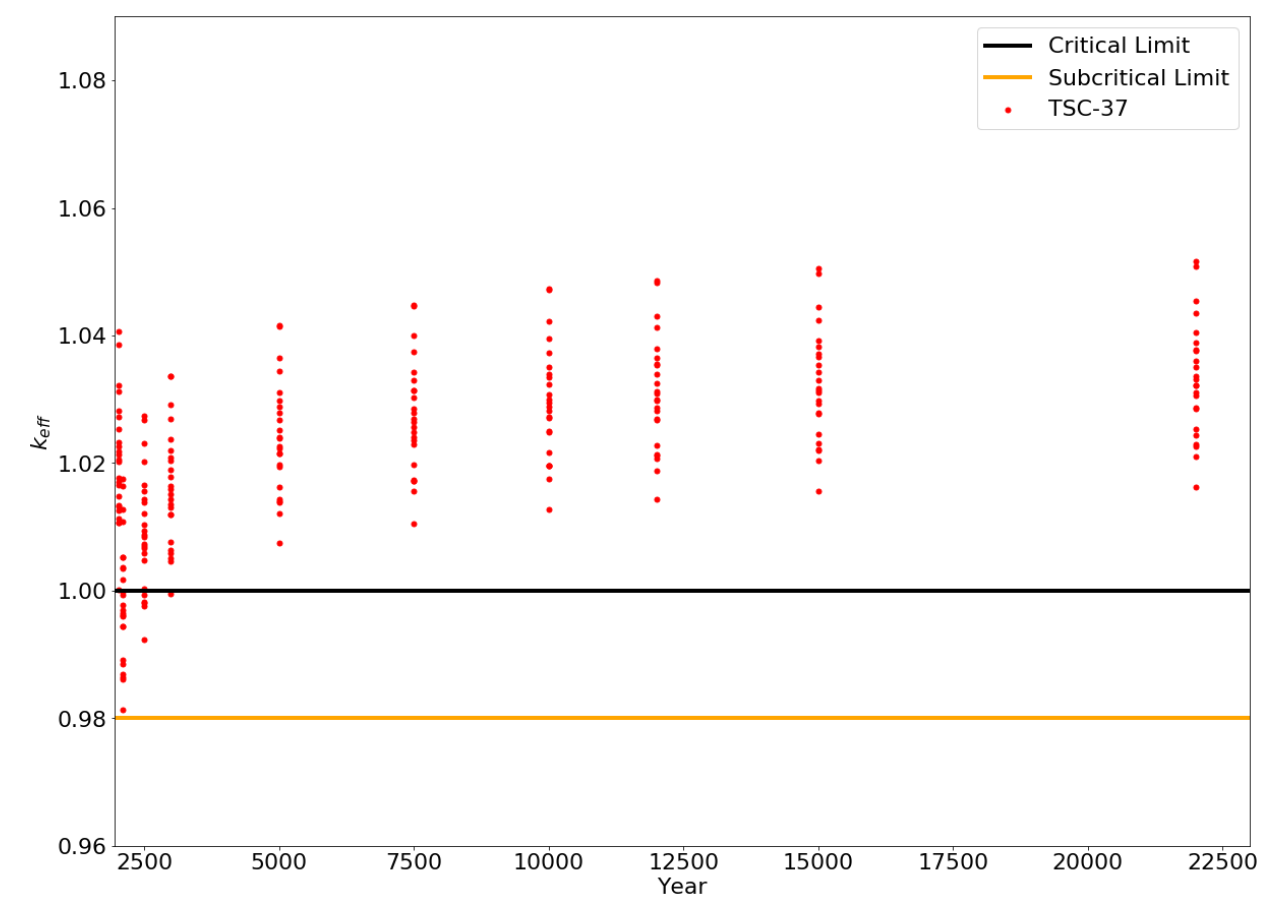

Figure E-10. $\boldsymbol{k}_{\text {eff }}$ vs. calendar year for the degraded basket scenario, based on actual loading and disposal isotopes for the TSC-37 canisters at Kewaunee. 


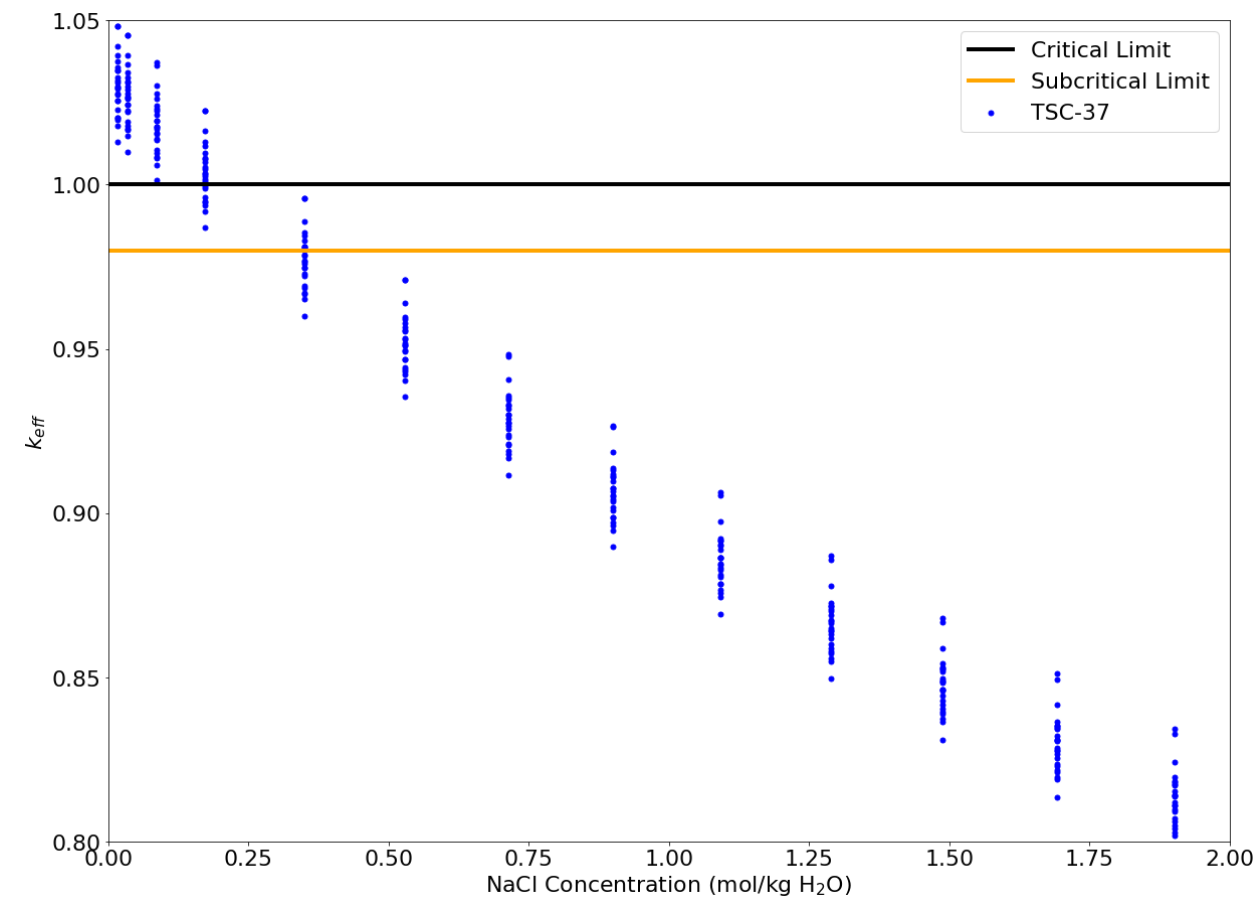

Figure E-11. $\boldsymbol{k}_{\text {eff }} \mathrm{vs.} \mathrm{NaCl}$ concentration for the DPCs with $\boldsymbol{k}_{\text {eff }}>\mathbf{0 . 9 8}$ for the

TSC-37 canisters at Kewaunee under the degraded basket scenario.

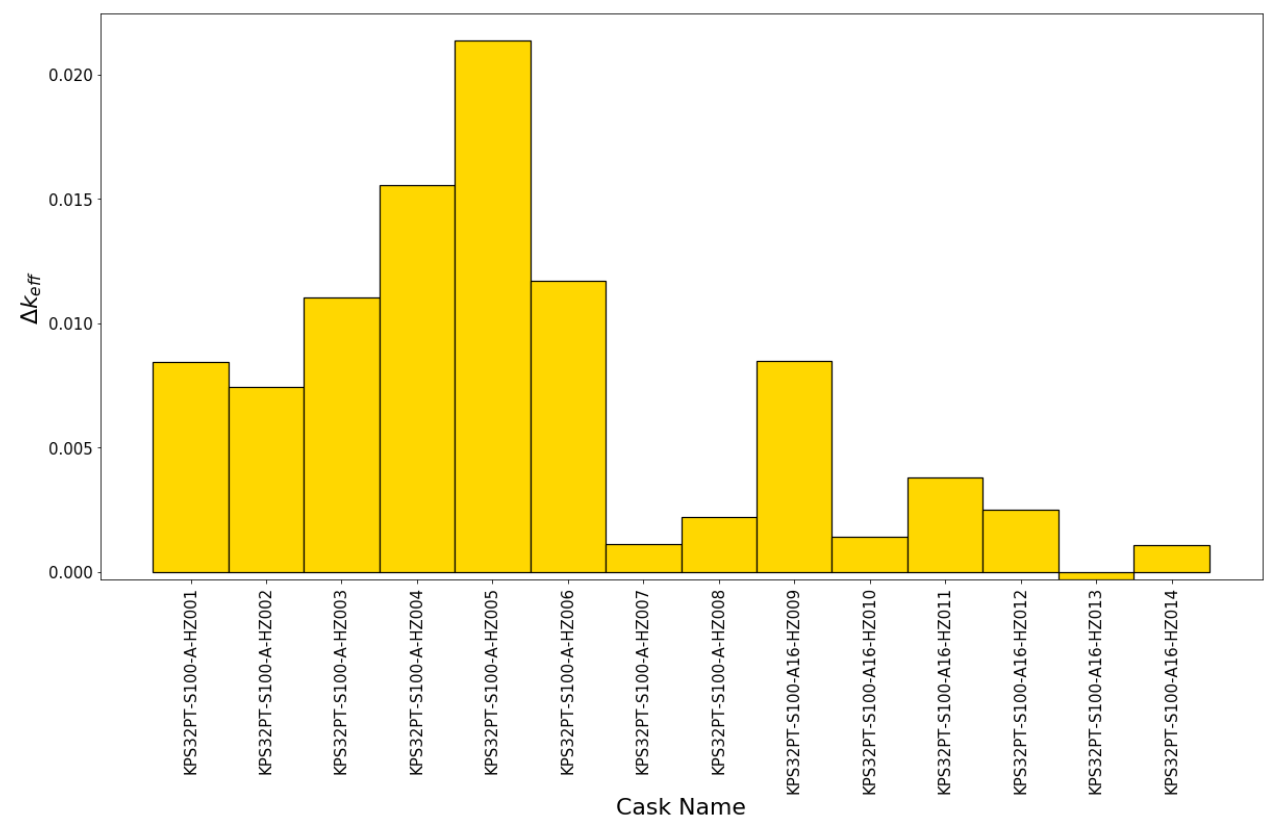

Figure E-12. $k_{\text {eff }}$ increase between the worst-misload scenario and the as-loaded configuration for the NUHOMS ${ }^{\circledR}$ 32PTH-DSCs at Kewaunee. 


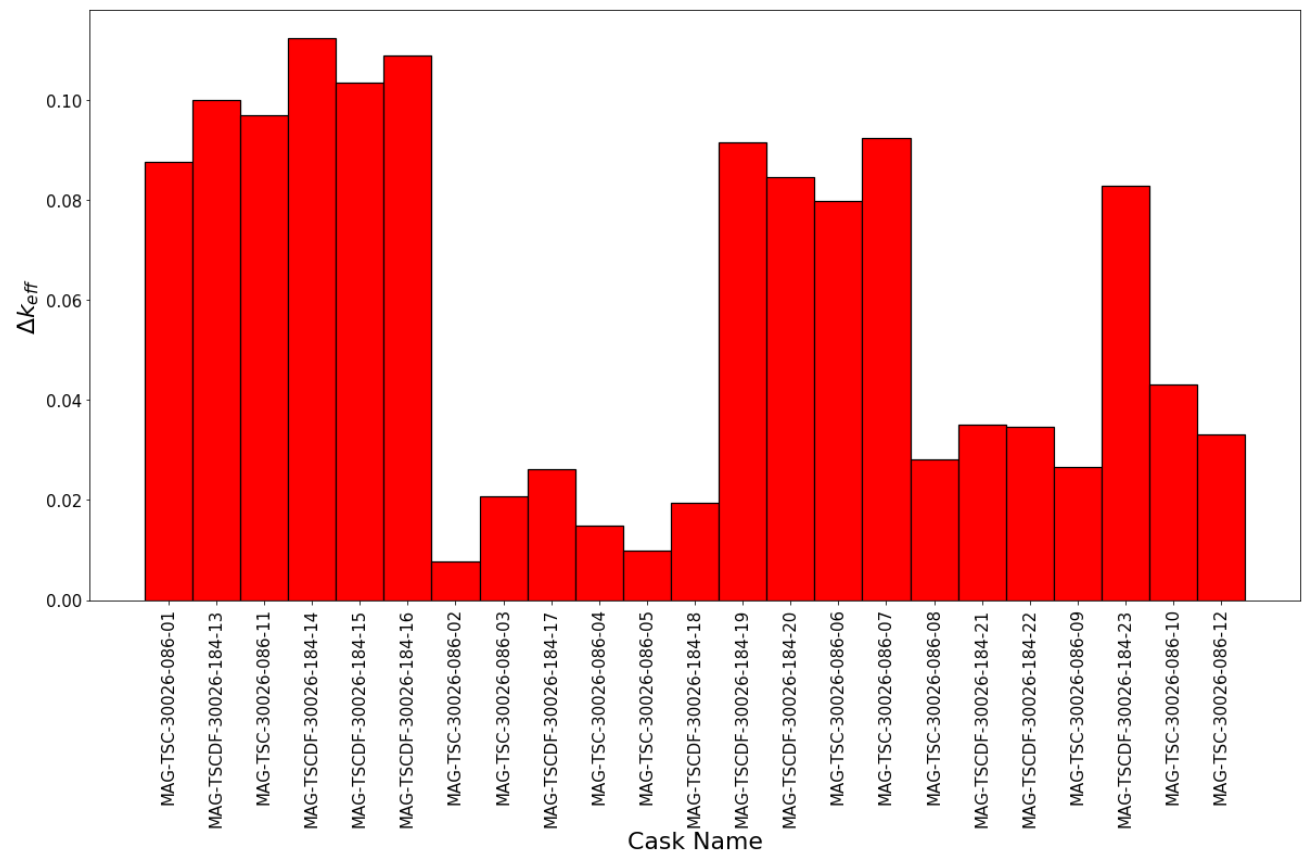

Figure E-13. $k_{\text {eff }}$ increase between the worst-misload scenario and the as-loaded configuration for the TSC-37 SNF canisters at Kewaunee. 


\section{E.7. CONCLUSIONS}

This appendix presents criticality analysis models for the NUHOMS ${ }^{\circledR}$ 61BT-DSC and NUHOMS ${ }^{\circledR}$ 32PTH-DSC canister types. A total of 92 as-loaded canisters from five sites were analyzed over the time interval between calendar years 2020 and 22,000 using the burnup credit methodology described in this report. The analyzed sites were Nine Mile Point (6 canisters), Cooper (8 canisters), Monticello (10 canisters), Crystal River (38 canisters), and Kewaunee (30 canisters beyond those analyzed in Appendix $\mathrm{D}$, for a total of 38 canisters).

The intact configurations of both the NUHOMS ${ }^{\circledR}$ 61BT-DSC and NUHOMS ${ }^{\circledR} 32 \mathrm{PTH}-\mathrm{DSC}$ canister types are described in detail in the UNF-ST\&DARDS criticality status report [E-1]. Degraded loss-of-neutronabsorber models are developed from those intact models. Since both canisters contain stainless steel structural components, no additional degraded basket models were needed. A number of canisters at the Kewaunee ISFSI are of the TSC-37 design. Models for the TSC-37 loss-of-neutron-absorber and degraded-basket scenarios that are available from previous years' efforts were used in this work.

Post-closure disposal criticality calculations were performed as a function of decay time for as-loaded canisters at the sites previously discussed. Results are provided for a loss-of-neutron-absorber scenario and for 10 decay times within the time interval between calendar years 2020 and 22,000 for all canisters analyzed. The $k_{\text {eff }}$ values are predicted to vary from 0.88931 to 0.91339 for the Nine Mile Point SNF canisters, 0.86054 to 0.91567 for the Monticello SNF canisters, 0.89210 to 0.90822 for the Cooper SNF canisters, 0.88026 to 0.97838 for the Crystal River SNF canisters, 0.90962 to 0.97323 for the NUHOMS ${ }^{\circledR}$ 32PT-DSCs, and from 0.90976 to 0.97352 for the TSC-37s at Kewaunee under the loss of neutronabsorber scenario. The $k_{\text {eff }} \mathrm{s}$ varied from 0.98128 to 1.05163 for the 24 TSC-37s under the degradedbasket scenario. For all of TSC-37s under the degraded-basket scenario that exceeded the 0.98 subcritical limit, calculations were performed with variable $\mathrm{NaCl}$ concentrations in the water, and it was determined that a 0.5 molal concentration was sufficient to demonstrate subcriticality.

Canister misload criticality analyses were performed assuming a worst configuration in an as-loaded canister, which is based on the assumption that correct assemblies have been loaded into the canister, but they are in the most reactive configuration. $k_{\text {eff }}$ values for worst misload configurations were determined assuming that all fuel assemblies in the canister have a decay time of 22,000 years, and the neutron absorber is completely lost. The misload analysis was performed for a total of 90 canisters containing intact fuel assemblies that were loaded to full capacity. The 2 canisters not analyzed contain empty locations and will be analyzed in the future. The $k_{\text {eff }}$ increase varied between 830 and $1,525 \mathrm{pcm}$ for the Nine Mile Point canisters, between 407 and 572 pcm for the Cooper SNF canisters, between 158 and 3,150 for the Monticello SNF canisters, between 729 and 9,091 pcm for the Crystal River SNF canisters, between -30 and 2,137 pcm for the NUHOMS ${ }^{\circledR}$ 32PT-DSCs, and between 768 and 11,241 pcm for the TSC-37 canisters at Kewaunee.

A summary of the direct disposal criticality calculations is provided in Table E-1. There are 708 canisters that have been analyzed through FY19 for the project. Of the canisters analyzed it was shown that $79 \%$ would remain subcritical under the loss-of-neutron-absorber scenario. When considering complete degradation of the baskets of canisters with non-stainless-steel structural components $68 \%$ of the canisters are shown to be subcritical. When further considering the potential for the worst-case arrangement of the most reactive fuel assemblies in each canister it is show that $63 \%$ of canisters would remain subcritical. 
Table E-1. Summary of the number of canisters meeting the subcritical limit.

\begin{tabular}{lc}
\hline Description (Analysis Dates: 2020-22000) & Value \\
\hline Total DPCs analyzed & 708 \\
\hline $\begin{array}{l}\text { Total DPCs below subcritical limit with loss of } \\
\text { neutron absorber (design-basis loading) }\end{array}$ & $\mathbf{0}(\mathbf{0 \%})$ \\
$\begin{array}{l}\text { Total DPCs below subcritical limit with loss of } \\
\text { neutron absorber (as-loaded) }\end{array}$ & $\mathbf{5 5 6}(\sim 79 \%)$ \\
$\begin{array}{l}\text { Total DPCs below subcritical limit with loss of } \\
\text { neutron absorber and carbon steel structures } \\
\text { (as-loaded) }\end{array}$ & $\mathbf{4 8 3 ( \sim 6 8 \% )}$ \\
\hline $\begin{array}{l}\text { Total DPCs below subcritical limit with loss of } \\
\text { neutron absorber and carbon steel structures } \\
\text { (as-loaded) considering misload }\end{array}$ & $\mathbf{4 4 5 ( \sim 6 3 \% )}$ \\
\hline
\end{tabular}

\section{E.8. REFERENCE}

E-1. J. B. Clarity, K. Banerjee, and L. P. Miller, Criticality Process, Modeling and Status for UNF-ST\&DARDS, FCRD-NFST-2015-000440, Rev. 2, US Department of Energy, Nuclear Fuel Storage and Transportation Planning Projects (Forthcoming, September 2019). 



\section{APPENDIX F. FY 2020 Criticality Study}




\section{F.1. INTRODUCTION}

This appendix documents work performed supporting the US Department of Energy (DOE) Office of Nuclear Energy (NE) Spent Fuel and Waste Disposition (SFWD) under work breakdown structure element 1.08.01.03.05 "Direct Disposal of Dual Purpose Canisters." In particular, this appendix fulfills the M3 milestone, M3SF-20OR010305015, "Update of DPC Direct Disposal Criticality Analysis Report" within work package SF-20OR01030501, "Direct Disposal of Dual Purpose Canisters - ORNL."

This appendix presents the dual-purpose canister (DPC) criticality evaluations performed in FY 2020 to support the feasibility determination of direct disposal of DPCs and extends the work reported in the main body and preceding appendices of this report. The main objectives of the FY 2020 DPC disposal criticality study were as follows:

- To extend the analysis timeline of the calculations through FY19 for the set of 708 canisters from the year 22,000 to the year 1,100,000.

- To examine the impact of candidate cementitious DPC filler materials on disposal criticality scenarios.

- To analyze an additional 66 as-loaded canisters from four sites for the time interval between calendar years 2020 and 1,100,000 using the burnup credit methodology described in the previous sections of this report. The analyzed canisters were at the following sites: Seabrook (16 canisters), Vogtle (26 canisters), Hope Creek (13 canisters), and Salem (11 canisters).

Criticality analysis models were developed for the intact canister configuration applicable to normal conditions of transport and storage as described in the UNF-ST\&DARDS status report [E-2]. The models were then modified for degraded material configurations applicable to the canister repository timeframe specified in this report. The degraded material configurations assume two scenarios: (1) complete loss of the fixed neutron absorber (i.e., ${ }^{10} \mathrm{~B}$ ) without fuel basket geometry changes, and (2) complete degradation and loss of basket materials, including neutron absorber plates and aluminum and carbon steel basket components (e.g., insert plates and basket support discs). Canister material degradation and neutron absorber loss leads to a significant increase in $k_{\text {eff. }}$ The degraded material configurations were analyzed for 27 analysis dates between 2020 and 1,100,000 years.

As mentioned in the main report, neutron moderation by water is needed for a waste package to achieve criticality. However, the groundwater (or pore water) that may flood a breached DPC will contain various dissolved aqueous species. Seventeen species were studied as described in the main report, and it was determined that $\mathrm{Cl}, \mathrm{Li}$, and $\mathrm{B}$ provide the maximum reduction in canister reactivity because of their large neutron absorption cross sections. However, available groundwater data indicate that chlorine (as chloride) is the only naturally abundant neutron-absorbing element in groundwater that can provide a significant reduction in reactivity and is available in most of the repository concepts under consideration in varying quantities. Analyses were performed to determine the chlorine requirement to suppress the reactivity of canisters with the potential to form a critical configuration in a repository timeframe. The impact of chlorine (in terms of $\mathrm{NaCl}$ ) concentration in groundwater on the reactivity of as-loaded DPCs exceeding a $k_{\text {eff }}$ value of 0.98 was evaluated for calendar year 22,000. Previous chlorine concentration effects on $k_{\text {eff }}$ documented in this report were evaluated for calendar year 9,999. The impacted DPCs will be reevaluated for calendar year 22,000, the year of maximum reactivity, in the future.

The remainder of this appendix is organized as follows: Section F.2 describes the work performed to extend the analytical time line from the year 22,000 to the year 1,100,000, Section F.3 discusses the criticality calculations that evaluate cementitious filler materials, Section F.4 documents the calculations for Seabrook, Section F.5 documents the calculations for Vogtle, Section F.6 documents the calculations for Hope Creek, Section F.7 documents the calculations for Salem, Section F.8 contains the conclusions, and F.9 contains the references. 


\section{F.2. EXTENSION OF DPC CALCULATIONS TO BEYOND $1,000,000$ YEARS}

Analyses increasing the period of time over which the $k_{\text {eff }}$ of the canisters was assessed from the calendar year 22,000 until the calendar year 1,100,000 were documented earlier this year in [F-1] and are included in this work to consolidate all of the work performed on this project in FY20. This work will allow for the assessment of criticality implications for a longer postclosure period.

The degraded absorber condition was modeled for all canisters in the database, and the degraded basket scenario was modeled for canisters that have non-stainless steel structural components. The disposal isotope set was used for all calculations. The times at which the reactivity of the DPCs was assessed was increased to add evaluation dates of July 1 of the years 25,000, 50,000, 75,000, 100,000, 200,000, $300,000,500,000,700,000,900,000,1,000,000$, and 1,100,000.

The results of the degraded absorber calculations are presented in Figure F-1 for pressurized water reactor (PWR) DPCs and in Figure F-2 for boiling water reactor (BWR) DPCs, and the degraded basket calculations are presented in Figure F-3 for PWR DPCs (there are no BWR DPCs that have non-stainless steel structural components). The results in Figures F-1 through F-3 show that the reactivity for each of the canisters follows a similar trajectory with time. The reactivity initially starts off at a local maximum and decreases over the first 100 years as a result of the decay of fissile ${ }^{241} \mathrm{Pu}$ to absorbing ${ }^{241} \mathrm{Am}$. The reactivity then rises to its peak for all of the canisters between 10,000 and 25,000 years because of the decay of the ${ }^{241} \mathrm{Am}$ and ${ }^{240} \mathrm{Pu}$. Following the peak, the reactivity of the canisters declines, reaching a minimum at about 200,000 years because of decay of ${ }^{239} \mathrm{Pu}$. Following the minimum, there is a gradual rise for the remainder of the time period considered due to the ingrowth of ${ }^{233} \mathrm{U}$.

To more clearly show the reactivity evolution that a canister experiences during the disposal period, a representative canister's reactivity was plotted as a function of time using the same dates that are used in Figures F.1-F.3. Canister MAG-TSC-30026086-004 from Kewaunee was selected to show this effect. The reactivity trajectory of MAG-TSC-30026086-004 is plotted in F-4 for the degraded absorber case and F-5 for the degraded basket case. By examining the results in Figures F-4 and F-5, it can be seen that the initial drop in reactivity to the global minimum over the first 100 years is $0.025 \Delta k_{\text {eff }}$ for the degraded absorber case and $0.026 \Delta k_{\text {eff }}$ for the degraded basket case. The rise from the global minimum at the year 2100 to the global maximum at 22,000 years is $0.034 \Delta k_{\text {eff }}$ for the degraded absorber case and $0.038 \Delta k_{\text {eff }}$ for the degraded basket case. The reactivity then drops $0.028 \Delta k_{\text {eff }}$ for both the degraded absorber and degraded basket cases to a local minimum in the year 200,000. The rise from the local minimum to the end of the period analyzed is approximately $0.007 \Delta k_{\text {eff }}$ for both cases. 


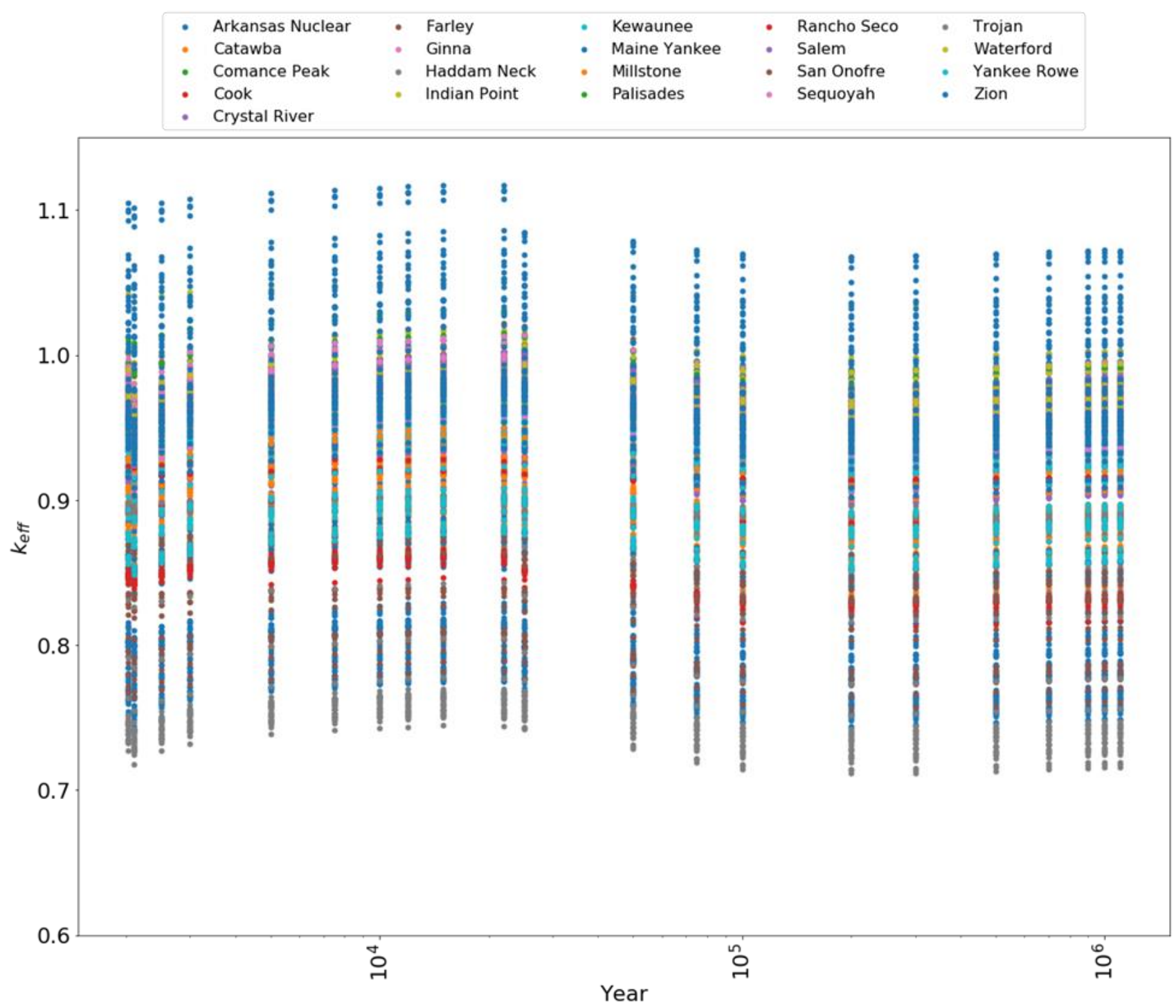

Figure F-1. Degraded absorber calculations for PWR DPCs. 


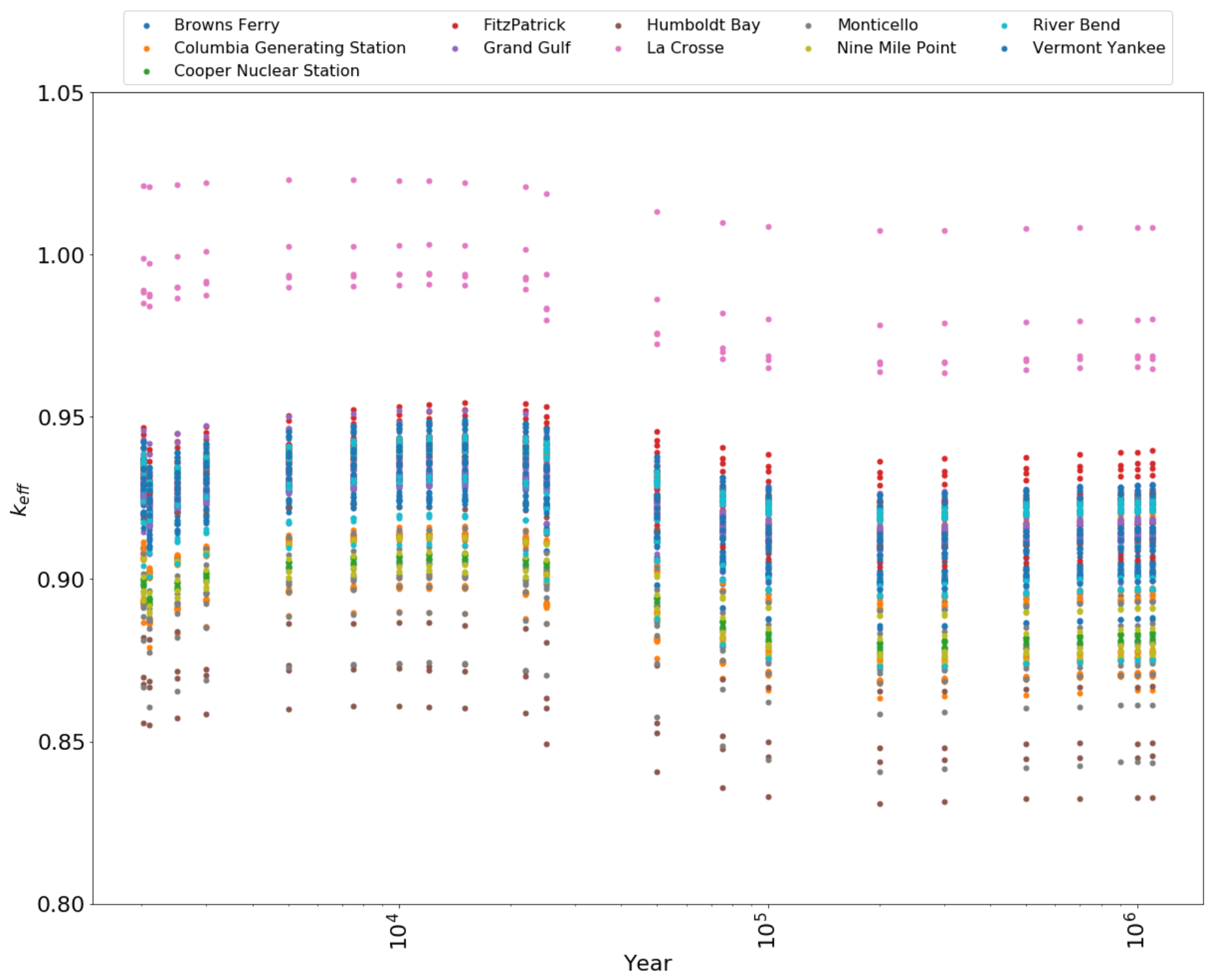

Figure F-2. Degraded absorber calculations for BWR DPCs. 


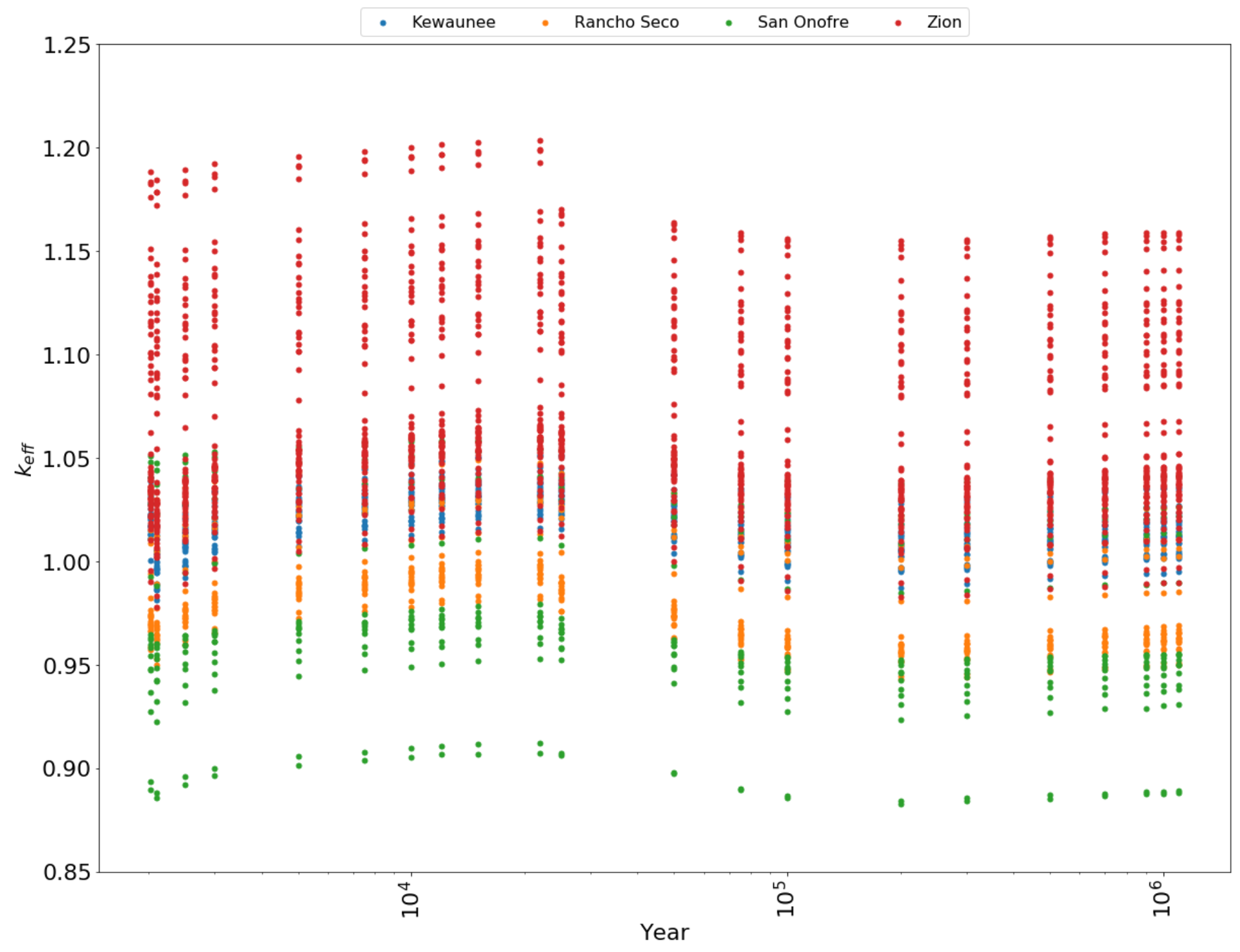

Figure F-3.Degraded basket calculations for PWR DPCs. 


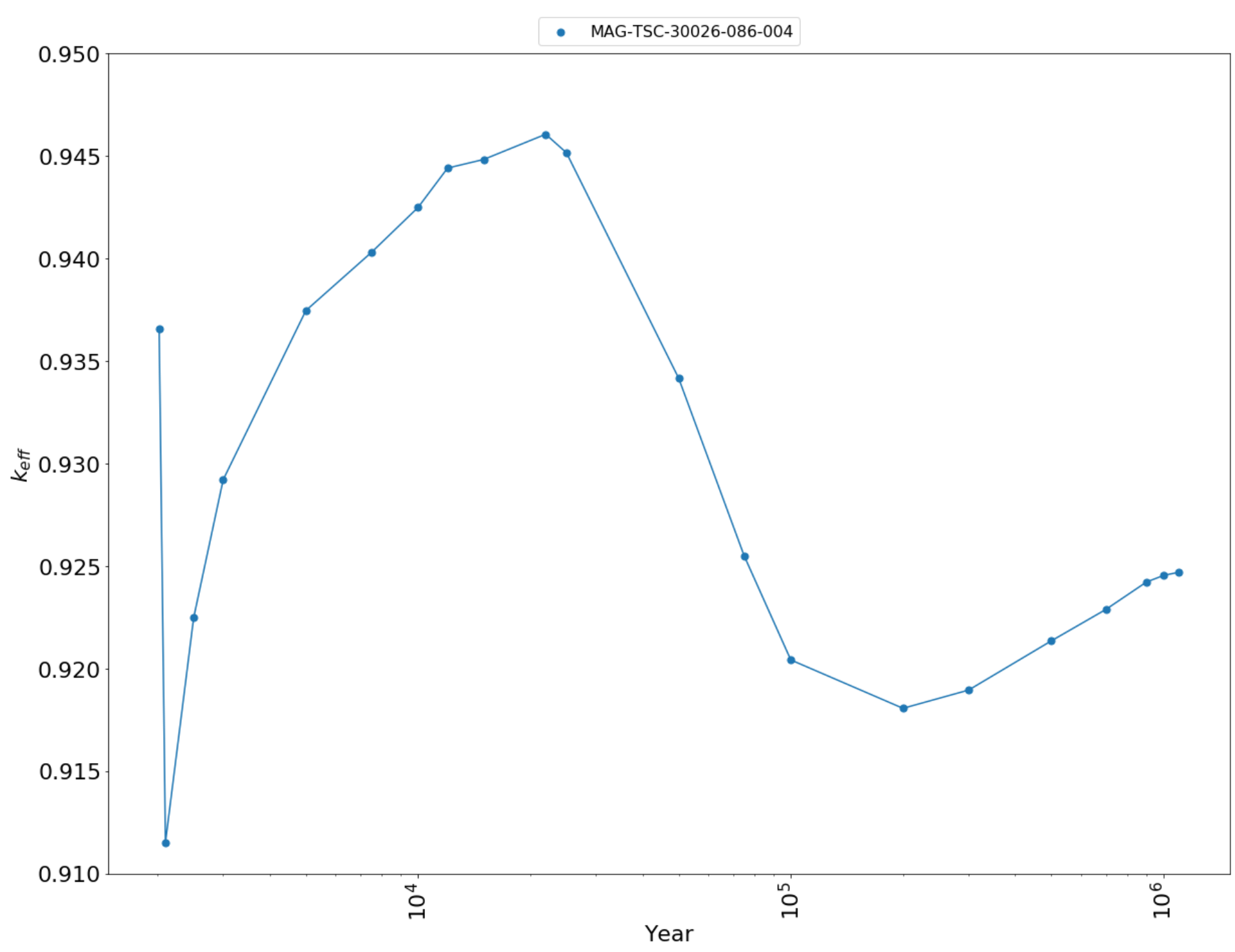

Figure F-4. Degraded absorber reactivity trajectory for TSC-37 canister MAG-TSC-30026086-004 at Kewaunee. 


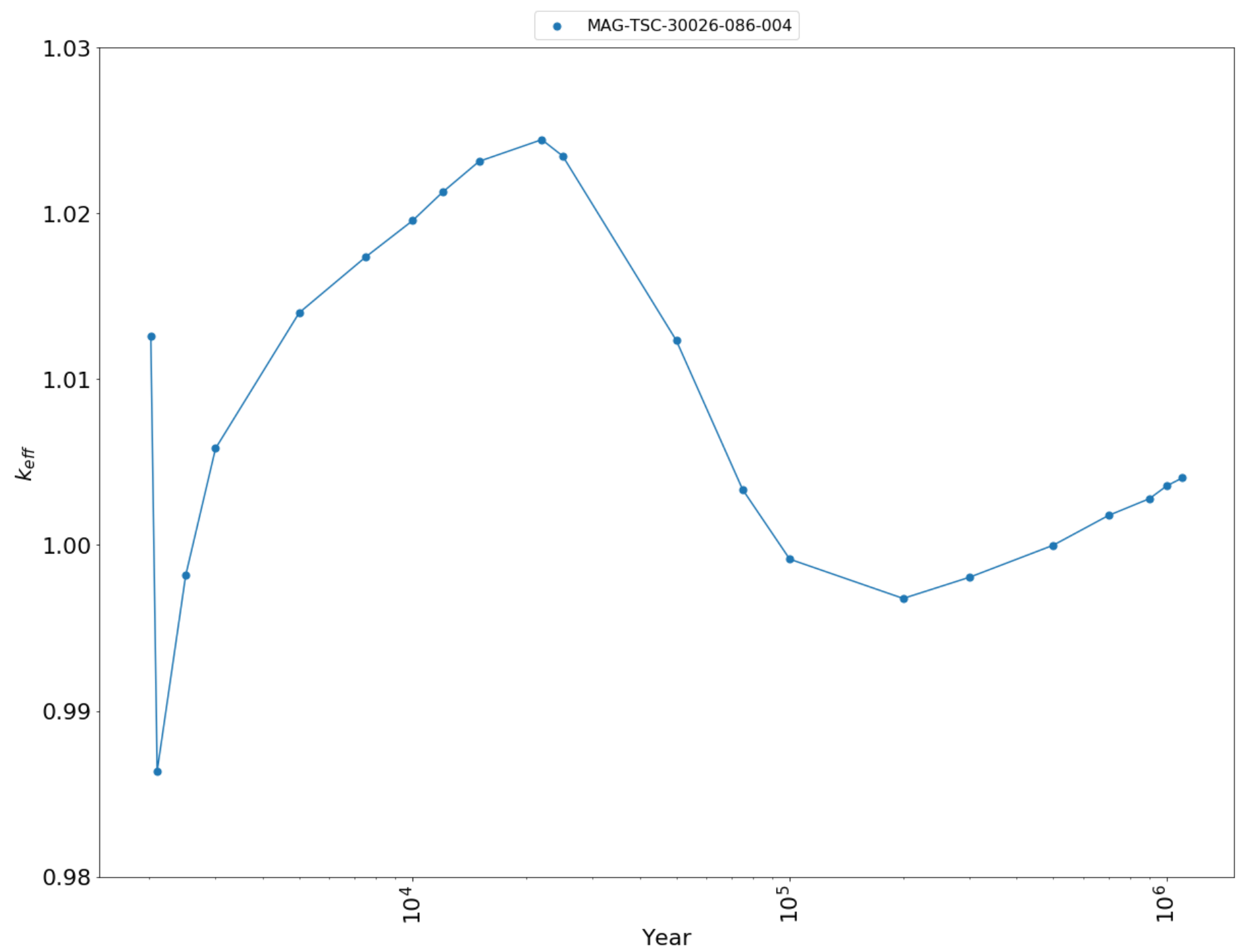

Figure F-5. Degraded basket reactivity trajectory for TSC-37 canister MAG-TSC-30026086-004 at Kewaunee. 


\section{F.3. EVALUATION OF CEMENTITIOUS FILLER MATERIALS FOR CRITICALITY CONTROL}

This section documents calculations performed to assess the impact of the addition of cementitious filler materials on post closure criticality safety for a single canister from the Zion site. The filler materials considered in this analysis have been provided by Sandia National laboratories and include (1) a mixture of wollastonite and calcium phosphate, (2) a mixture of aluminum oxide and aluminum phosphate, (3) a hydroxide-based calcium phosphate cement, and (4) a chloride-based calcium phosphate cement. A summary of the chemical composition of the filler materials used is provided in Table F-1.

Table F-1. Chemical composition of filler materials.

\begin{tabular}{|c|c|c|}
\hline Filler material & Component & $\begin{array}{c}\text { Weight percentage of } \\
\text { component }\end{array}$ \\
\hline \multirow{2}{*}{ Wollastonite / calcium phosphate } & $\mathrm{CaSiO}_{3}$ & $40 \%$ \\
\cline { 2 - 3 } & $\mathrm{Ca}_{10}\left(\mathrm{PO}_{4}\right)_{6}(\mathrm{OH})_{2}$ & $60 \%$ \\
\hline \multirow{2}{*}{$\begin{array}{c}\text { Aluminum oxide / aluminum } \\
\text { phosphate }\end{array}$} & $\mathrm{Al}_{2} \mathrm{O}_{3}$ & $86.4 \%$ \\
\cline { 2 - 3 } & $\mathrm{AlPO}_{4}\left(\mathrm{H}_{2} \mathrm{O}\right)_{2}$ & $13.6 \%$ \\
\hline Calcium phosphate cement $(\mathrm{OH})$ & $\mathrm{Ca}_{10}\left(\mathrm{PO}_{4}\right)_{6}(\mathrm{OH})_{2}$ & $100 \%$ \\
\hline Calcium phosphate cement $(\mathrm{Cl})$ & $\mathrm{Ca}_{10}\left(\mathrm{PO}_{4}\right)_{6}(\mathrm{Cl})_{2}$ & $100 \%$ \\
\hline
\end{tabular}

\section{F.3.1. Calculations}

The canister used to perform this assessment (TSCD-37-TSCDF-015) was selected because it was the highest reactivity canister of those analyzed to date. Further, it was determined that the canister decay date of July 1, 22,000, represented the peak reactivity over the first 1.1 million years of its life, so the fuel isotopic compositions from this date were used in the calculations.

Each set of calculations was performed with two basket configurations, the degraded neutron absorber (NA) model and the degraded basket (DB) model. The NA model considers the intact basket structure while removing the neutron absorber material that is placed in the basket for criticality control during storage and transportation. The DB model removes the basket structural material and replaces it with water to simulate the corrosion of the basket following emplacement.

Calculations performed for this assessment can be subdivided into four categories based on the amount of coverage of the canister by the filler material. The first set of calculations simulates a complete filling of the basket with filler material so that the entire inner volume of the canister that is not occupied by the fuel or structural material is modeled as being comprised of filler material. The second set of calculations assumes that it will not be possible to place filler material in the damaged fuel cans located in the oversized cells at the four corners on the minor axes of the basket, but filler is otherwise able to fill the basket. The third set of calculations analyzes filler exclusion from the guide tubes and instrumentation tubes of the fuel assemblies. If the basket is filled from the bottom to the top, then the dashpot entry ways for guide tubes may be too small to allow for filler ingress. The fourth set of calculations analyzes the incomplete axial filling of each fuel tube. These calculations assume that there is no filler material the entire length of the guide tubes and instrumentation tube and that a variable portion of the top part of the assembly is unable to be filled. 
SCALE-generated renderings of the scenarios modeled are shown in Figures F-6 through F-9. In each figure, light blue represents the portion of the canister with filler material, pink represents portions of the canister occupied by fresh water, and red represents the basket's structural material. Figure F-6 shows the radial views of the NA and DB models for the complete filling case, Figure F-7 shows the NA and DB models for the damaged fuel filler exclusion case, Figure F-8 shows the NA and DB models for the guide tube filler exclusion case, and Figure F-9 shows an axial depiction of the incomplete axial filling case.

For the complete filling and damaged fuel filler exclusion cases, calculations were performed using each of the four filler materials and varying the porosity of the material in 5\% increments, from 0 to $100 \%$. In this work, the term porosity means the volume fraction of the filler material that is occupied by water. Based on the results of those calculations, it was determined that the behavior of wollastonite / calcium phosphate, aluminum oxide / aluminum phosphate, and calcium phosphate cement $(\mathrm{OH})$ was so similar that it was only necessary to perform calculations for the guide tube exclusion cases and the incomplete axial filling cases with one of those fillers and the calcium phosphate cement $(\mathrm{Cl})$ material. The incomplete axial filling case used calculations which assumed that the filler material present in the remainder of basket had a porosity of $50 \%$, since SNL staff stated this porosity level was likely obtainable.
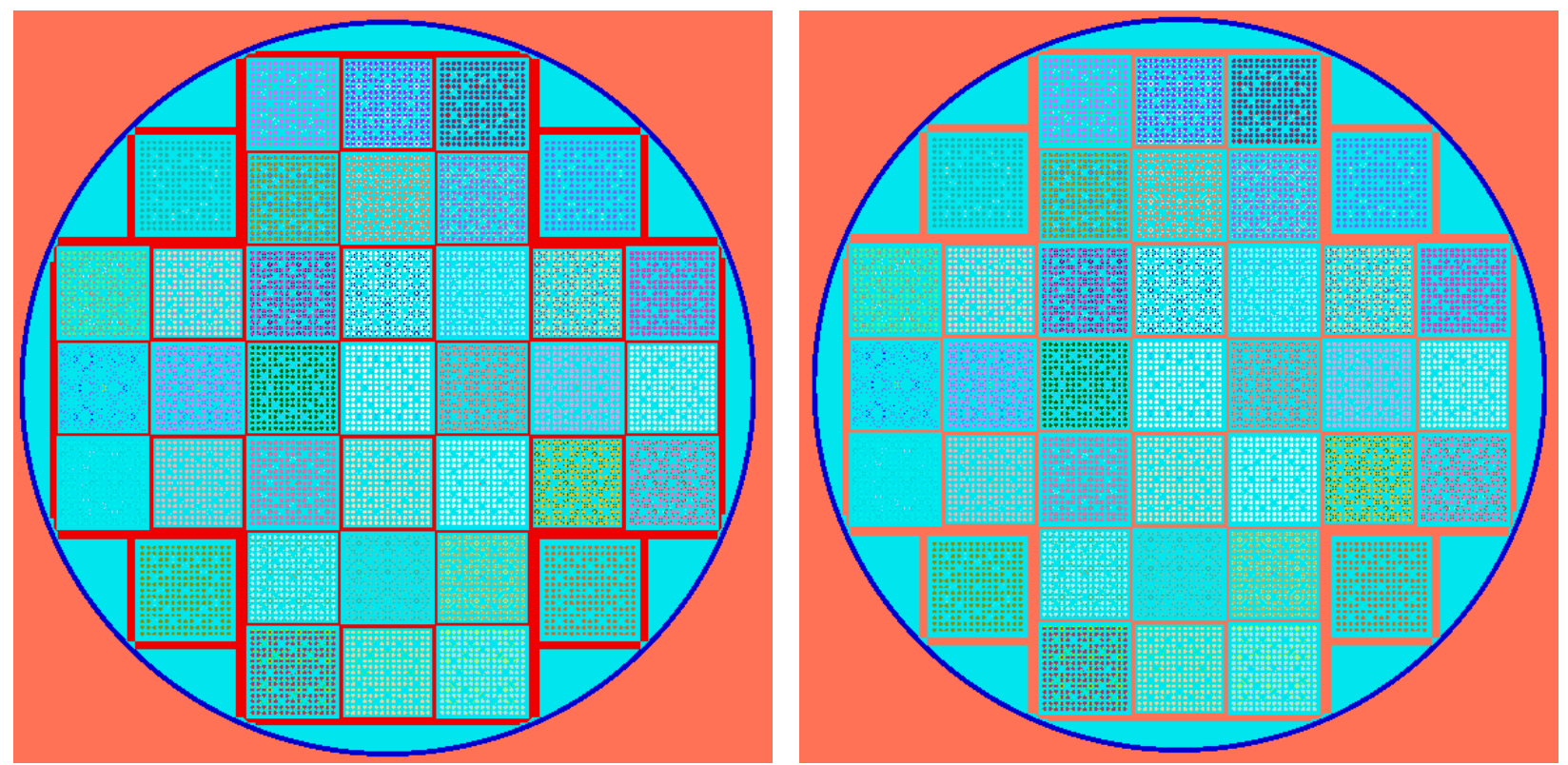

Figure F-6. Radial view of the complete filling models for the NA case (left) and the DB case (right). 

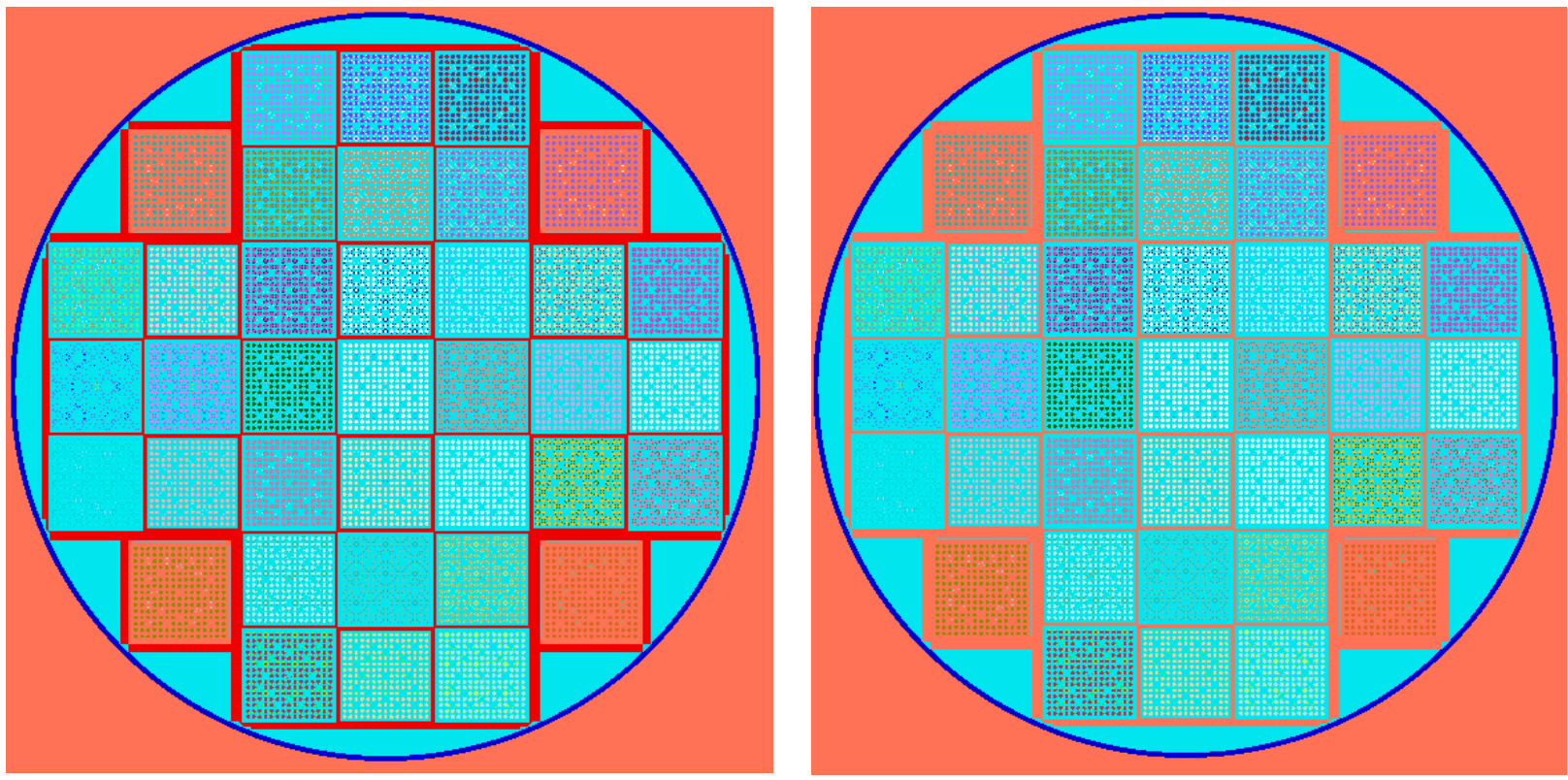

Figure F-7. Radial view of the damaged fuel filler exclusion models for the NA case (left) and the DB case (right).
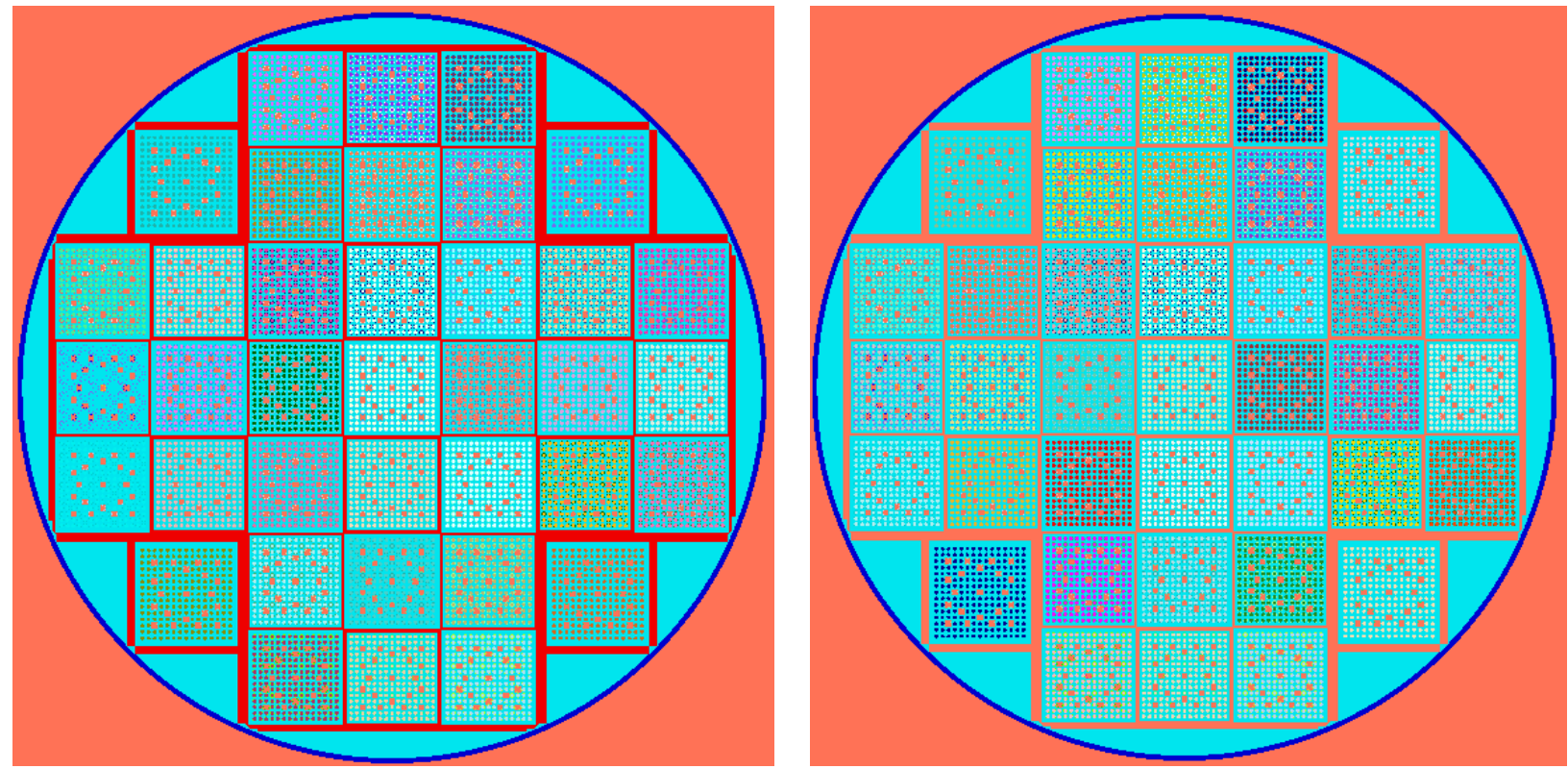

Figure F-8. Radial view of the guide tube filler exclusion models for the NA case (left) and the DB case (right). 


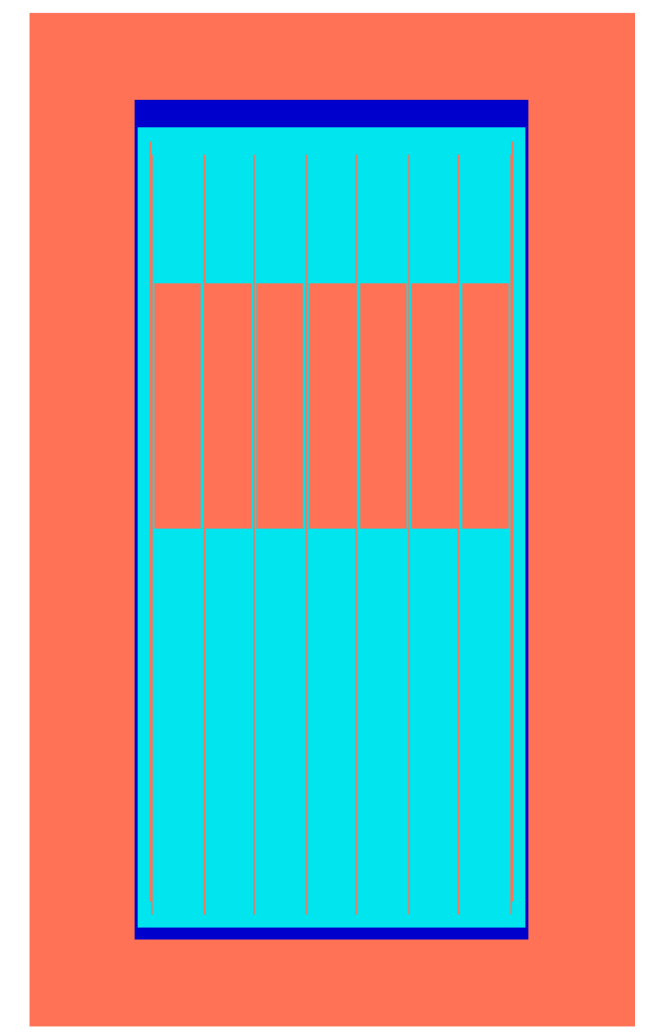

\section{Figure F-9. Axial view of the incomplete axial filling model showing the top seven of 18 nodes unfilled.}

\section{F.3.2. Results}

The results for the complete filling and damaged fuel exclusion models are presented in Figure F-10 for the NA case and in Figure F-11 for the DB case. An estimated subcritical 0.98 is used for comparison. A few observations may be made based on the results shown in Figures F-10 and F-11. The first observation is that all of the filler types except the calcium phosphate cement $(\mathrm{Cl})$ perform similarly to one another across the full porosity range (except perhaps at $<10 \%$, which does not appear to be achievable). The chloride-based calcium phosphate cement provides better criticality control over all porosities because ${ }^{35} \mathrm{Cl}$ is a neutron absorber. The second observation is that excluding the filler material from the damaged fuel locations results in the canister's reactivity plateauing below $70 \%$ porosity for the chloride-based cement and below somewhere between 40 and $50 \%$ porosity for the other filler materials. The plateauing occurs because the $k_{\text {eff }}$ of the system switches away from being driven by the center of the canister where additional filler material is added and is driven by the damaged fuel locations, which do not have any filler material. The third observation is that for the NA case, the porosity required to meet a hypothetical $k_{\text {eff }}$ limit of 0.98 is approximately $85 \%$ or less for the chloride-based cement and $65 \%$ or less for the other filler materials. For the DB case, a porosity of less than $75 \%$ would be required for the chloride-based cement, and a porosity of less than $45 \%$ would be required for the other filler materials.

In order to assess the impact of not being able to fill the guide tubes and instrumentation tubes with filler material, additional calculations were performed using the wollastonite/calcium phosphate and chloridebased cement for the NA and DB cases. The results of these calculations, along with the corresponding complete filling cases for comparison, are presented in Figure F-12 for the NA case and Figure F-13 for the DB case. The results of these calculations show that the increase in $k_{\text {eff }}$ associated with having water rather than filler material in the guide tubes is largest at the lowest values of porosity, and it decreases as the porosity of the filler material increases. This due to the relative scarcity of other sources of ${ }^{1} \mathrm{H}$ as a 
neutron moderator at lower porosity levels and relative abundance at higher porosity levels. The 0.98 hypothetical $k_{\text {eff }}$ limit decreases the allowable porosity values $7-10 \%$ for the wollastonite/calcium phosphate filler materials, and it decreases the allowable porosity about $5 \%$ for the chloride-based cement necessary to meet this value.

The final set of calculations aimed to determine how important it is to completely fill the axial extent of the fuel basket. This calculation removed the filler material from each node of the cases that excluded filler material from the guide tubes and instrument tubes. The filler material in the remainder of the basket was taken to be $50 \%$ porosity. The results of these calculations are presented in Figure F-14, and they show that regardless of the filler material or basket configuration, the $k_{\text {eff }}$ of the canister rises quickly with the decrease in filler height to the point that virtually all impact of the filler material is lost after about 15 inches.

\section{F.3.3. Cementitious Filler Conclusions}

In this work, a series of calculations using the TSCDF-37-TSCDF-15 cask from the Zion site were performed to determine the impact of adding filler material to canisters on post-closure criticality. The analysis presented here includes both the NA and DB cases and considers four separate filler materials, which are presented in Table F-1. Of the four filler materials, the chloride-based calcium phosphate cement provided superior criticality control to the other filler materials at the same porosity level. It was also shown that almost the entire canister must be filled in order to achieve criticality control. Having approximately 15 inches of uncovered fuel returns canister reactivity to levels very close to baseline $k_{\text {eff }}$ values. 


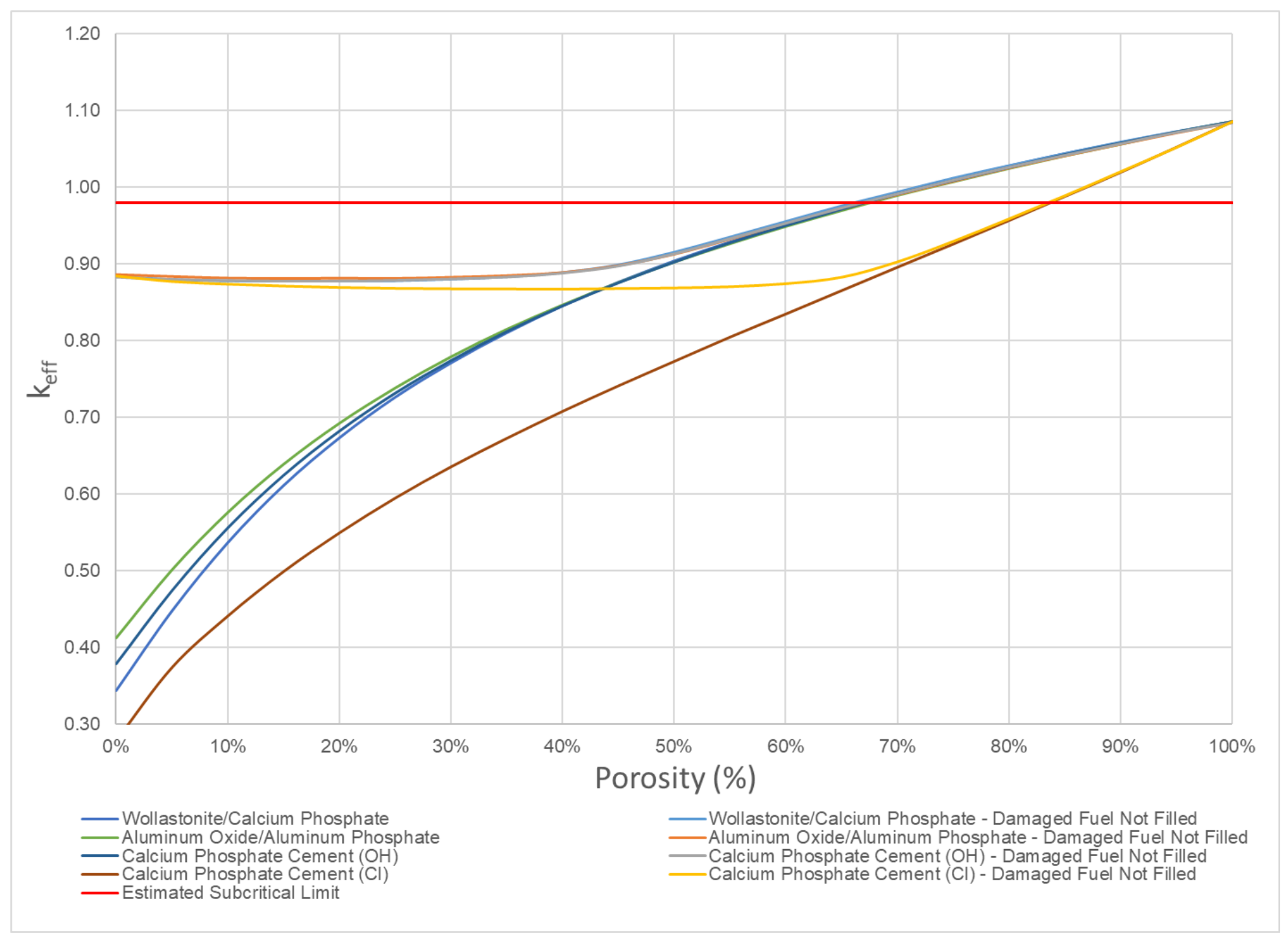

Figure F-10. Canister reactivity vs. porosity for the complete filling and damaged fuel exclusion NA cases. 


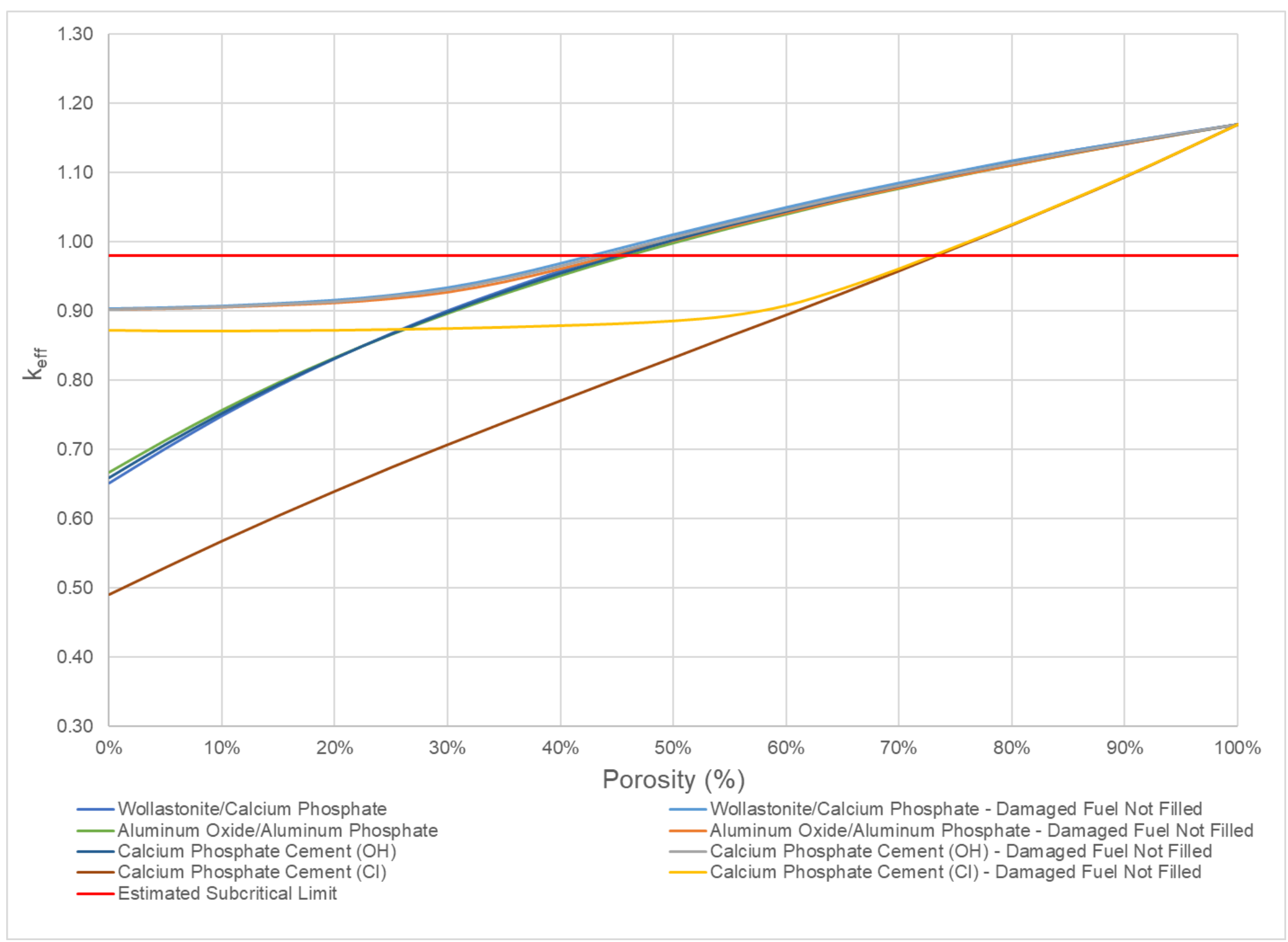

Figure F-11. Canister reactivity vs. porosity for the complete filling and damaged fuel exclusion DB cases. 


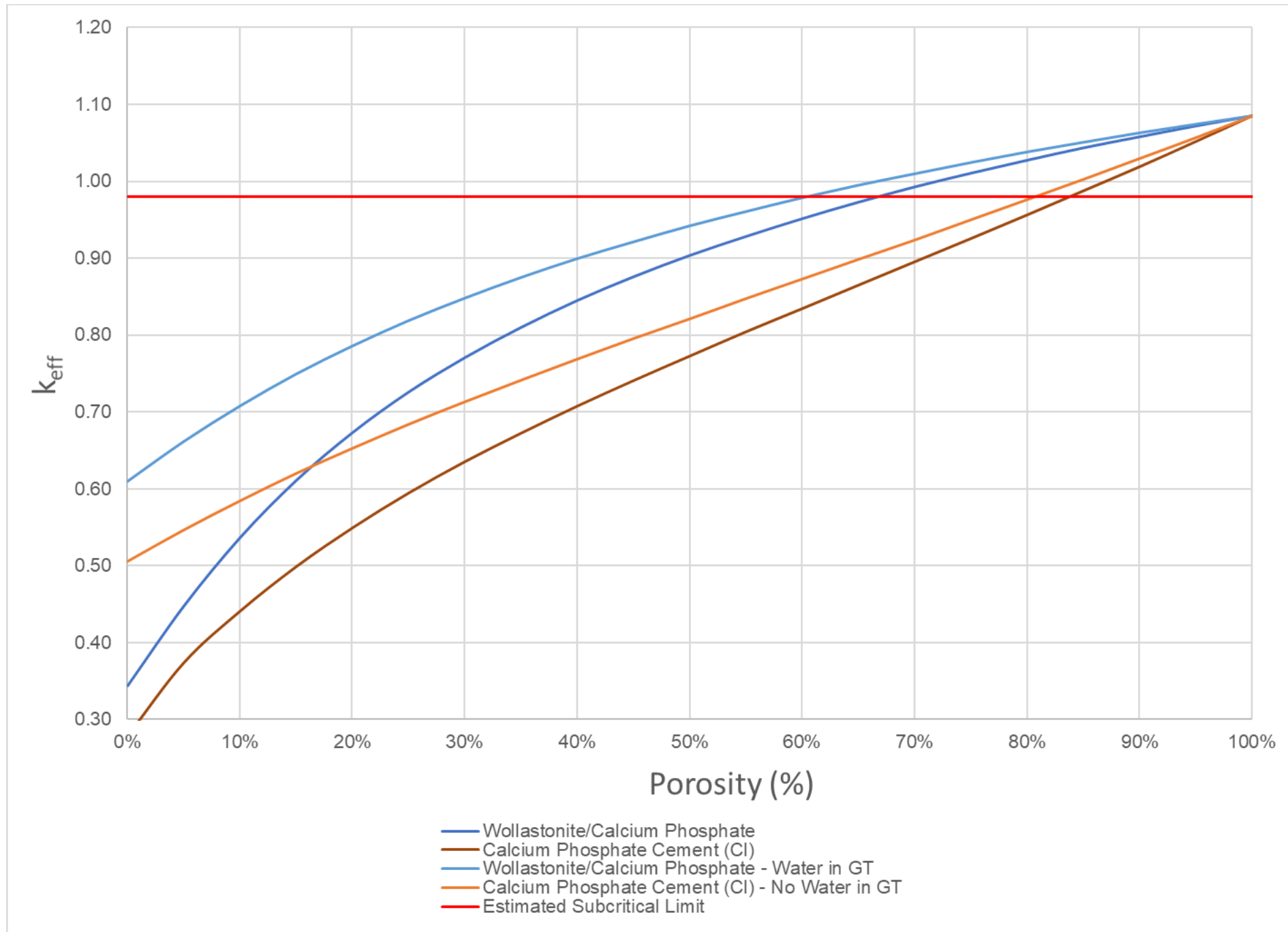

Figure F-12. Canister reactivity vs. porosity for the guide tube filler exclusion NA case. 


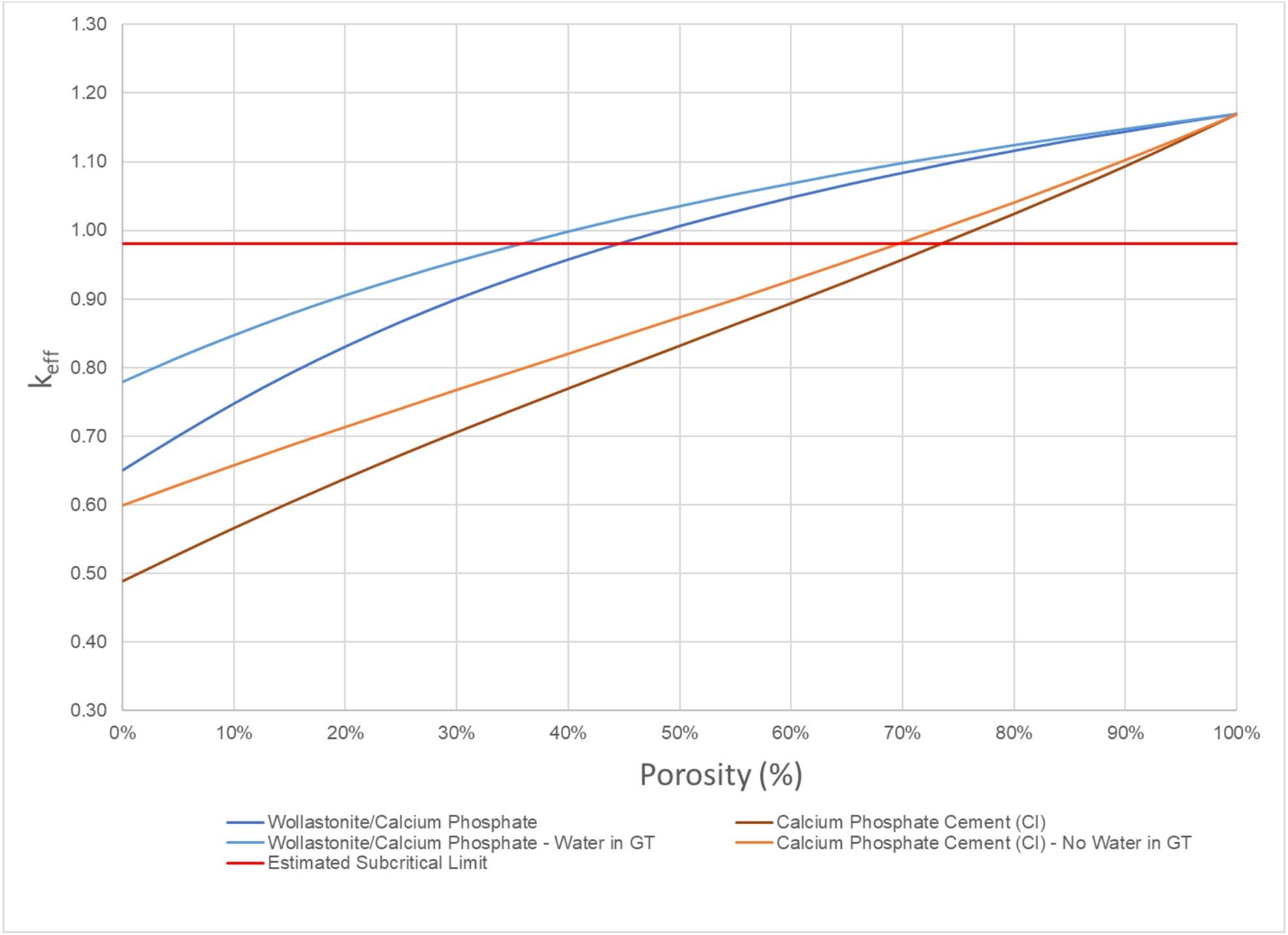

Figure F-13. Canister reactivity vs. porosity for the guide tube filler exclusion DB case. 


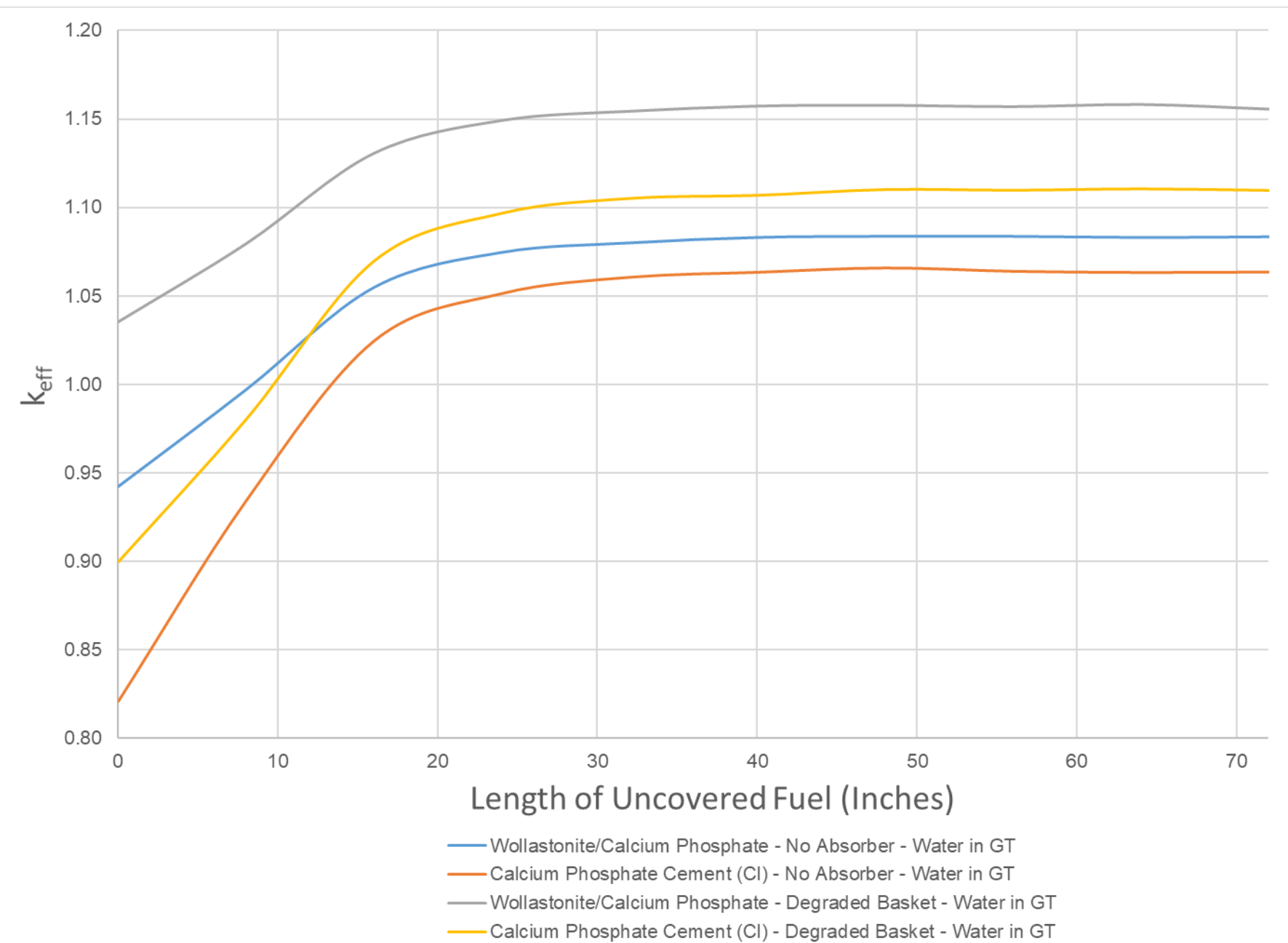

Figure F-14. Canister reactivity vs. length of top portion of assembly uncovered for NA and DB cases (guide tubes water filled, $50 \%$ porosity elsewhere). 


\section{F.4. SEABROOK CRITICALITY CALCULATIONS}

Post-closure disposal criticality calculations were performed as a function of decay time for the $16 \mathrm{SNF}$ canisters at the Seabrook independent spent fuel storage installation (ISFSI). All of the 16 SNF canisters are NUHOMS ${ }^{\circledR} 32 \mathrm{PTH}-D S C$. The NUHOMS ${ }^{\circledR} 32 \mathrm{PTH}$-DSC does not contain any carbon steel structural components, so only the loss-of-neutron-absorber scenario is analyzed. Figure F-15 shows results for the loss-of-neutron-absorber scenario for 27 decay times within the time interval between calendar years 2020 and 1,100,000. The results in Figure F-15 show $k_{\text {eff }}$ variation as a function of calendar year. The one sigma statistical uncertainty for all $k_{\text {eff }}$ values is 0.0003 or less for all cases.

The $k_{\text {eff }}$ values are predicted to vary from 0.8915 to 1.0570 for the NUHOMS ${ }^{\circledR} 32$ PTH-DSCs under the loss-of-absorber scenario. For canisters which had $k_{\text {eff }}$ values greater than 0.98 under the loss-of-neutronabsorber scenario, calculations were performed in which the pure water was replaced with groundwater compositions of various $\mathrm{NaCl}$ concentrations, and the models thus modified were used to determine $k_{\text {eff }}$ as a function of $\mathrm{NaCl}$ concentration for the calendar year 22,000 (most reactive date). Figure F-16 presents $k_{\text {eff }}$ variation as a function of $\mathrm{NaCl}$ concentration for those 7 canisters. Examining the results presented in Figure F-16, it is clear that $1.1 \mathrm{~mol} \mathrm{NaCl} / \mathrm{kg} \mathrm{H}_{2} \mathrm{O}$ is sufficient to demonstrate subcriticality $\left(k_{\text {eff }}<0.98\right)$ for all of the Seabrook canisters. In this context, it is also important to note that a saturated $\mathrm{NaCl}$ brine has a concentration of approximately 6 molal.

Figure F-17 shows the $k_{\text {eff }}$ increase between the worst misload scenario and the as-loaded configuration for the 16 analyzed Seabrook canisters at the calendar year 22,000. The increase in $k_{\text {eff }}$ varies between 498 and 3,309 pcm for Seabrook canisters.

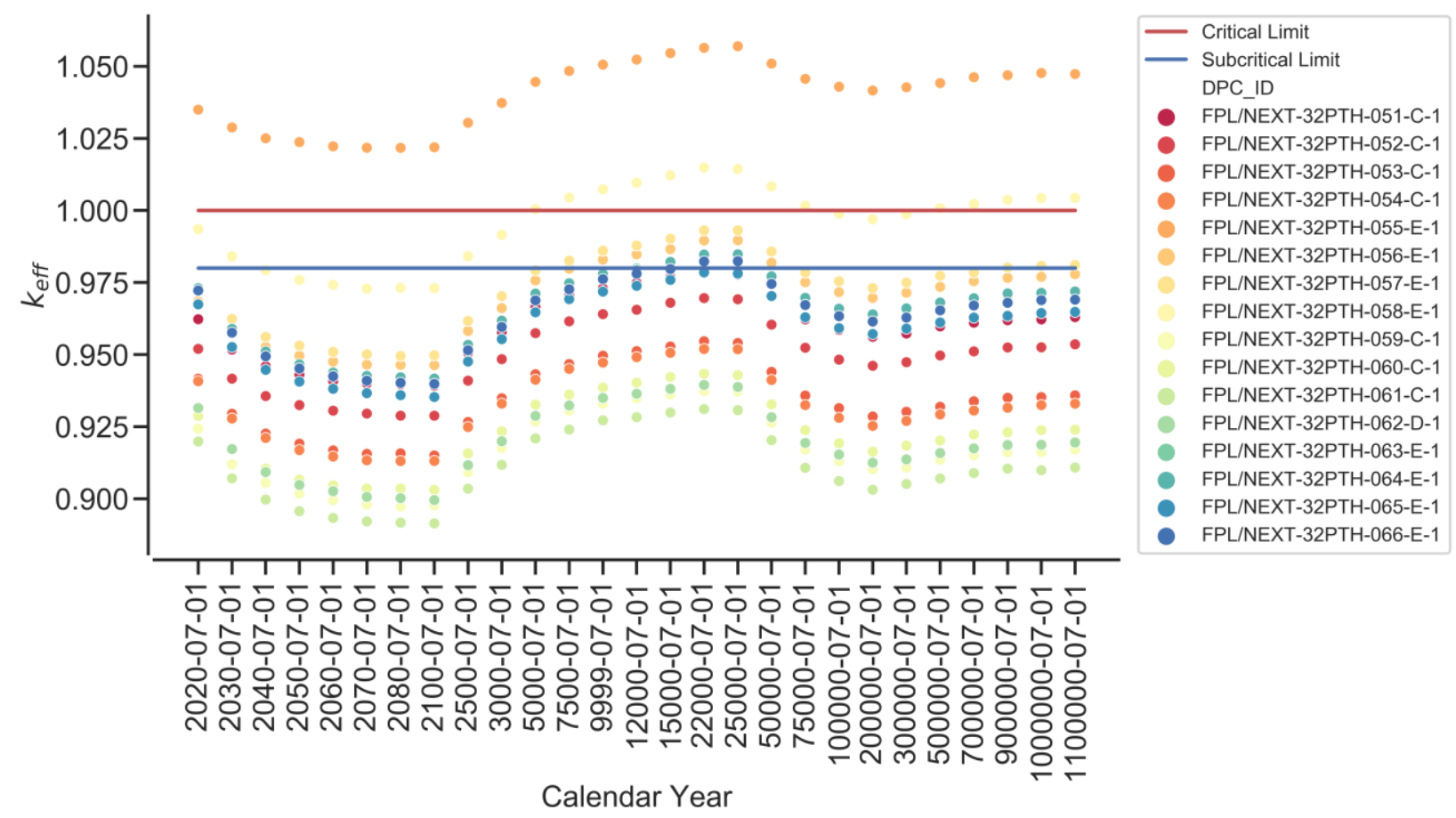

Figure F-15. $\boldsymbol{k}_{\text {eff }}$ vs. calendar year for the loss-of-neutron-absorber scenario based on actual loading and disposal isotopes for the SNF canisters at Seabrook. 


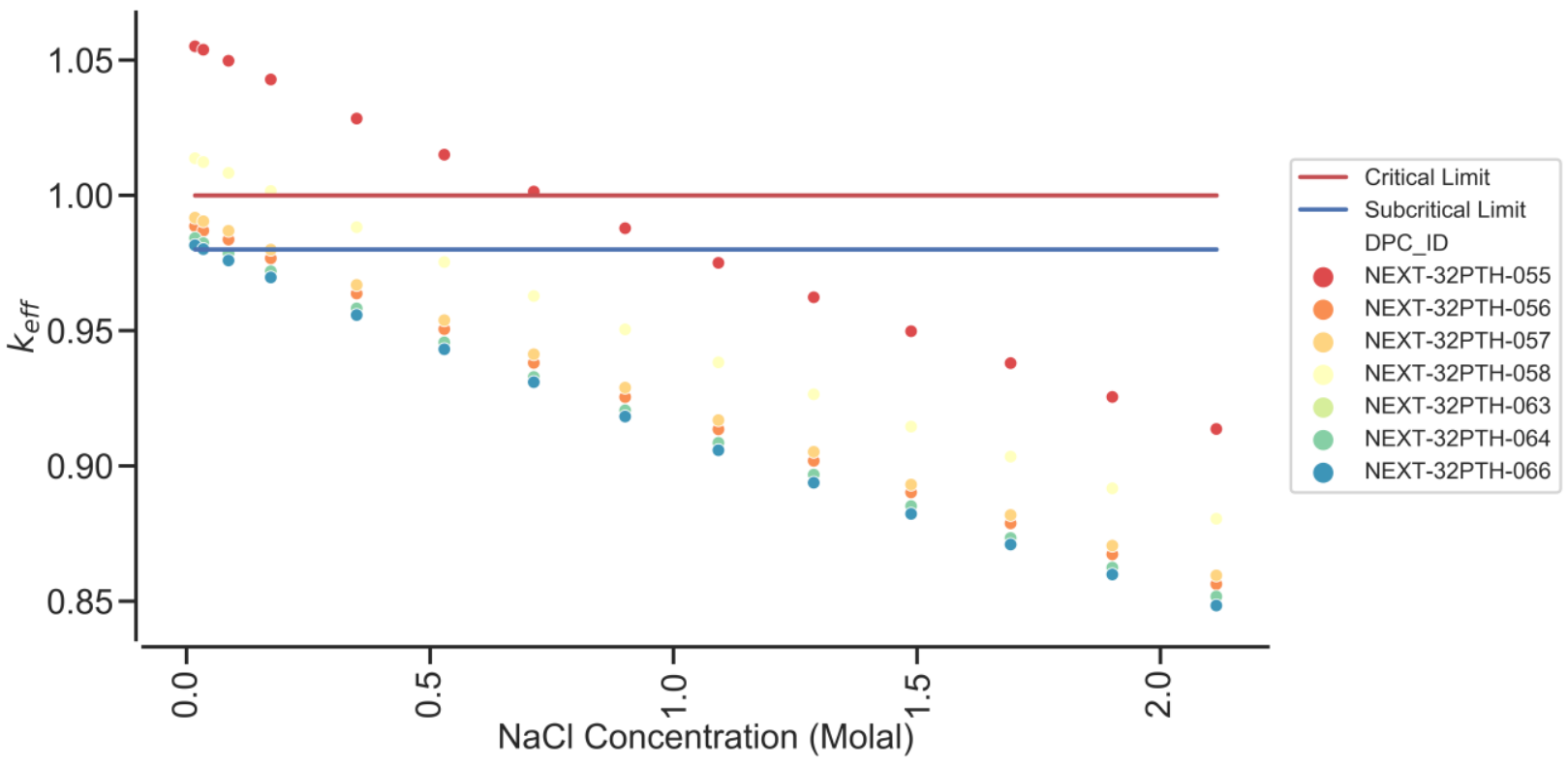

Figure F-16. $\boldsymbol{k}_{\text {eff }}$ vs. NaCl concentration for the DPCs with $\boldsymbol{k}_{\text {eff }}>\mathbf{0 . 9 8}$ for the canisters at Seabrook under the loss-of-neutron-absorber scenario (calendar year 22,000).

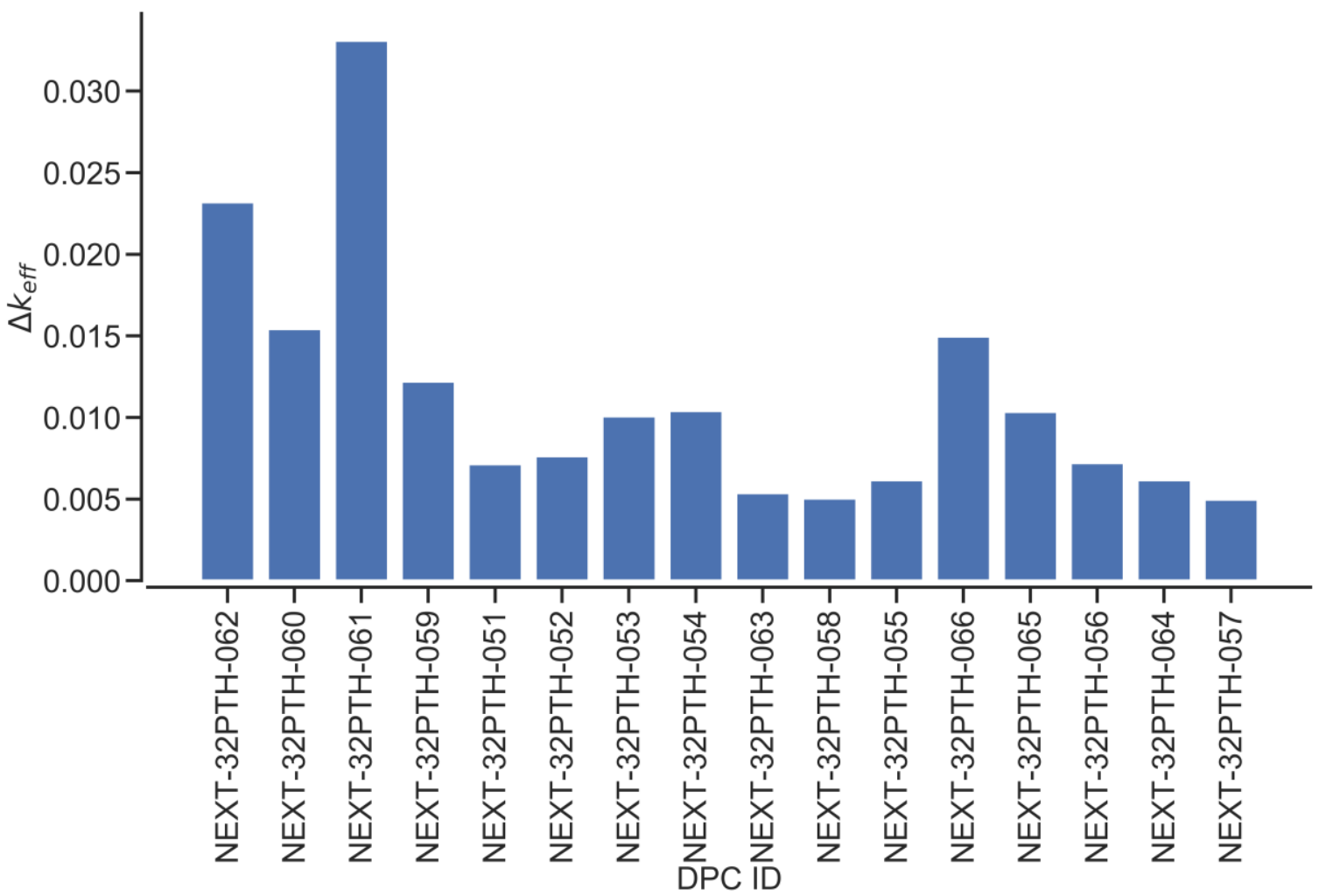

Figure F-17. $\boldsymbol{k}_{\text {eff }}$ increase between the worst-misload scenario and the as-loaded configuration for the NUHOMS ${ }^{\circledR}$ 32PTH-DSCs at Seabrook (calendar year 22,000). 


\section{F.5. VOGTLE CRITICALITY CALCULATIONS}

Post-closure disposal criticality calculations were performed as a function of decay time for the $26 \mathrm{SNF}$ canisters at the Vogtle ISFSI. All of the 26 SNF canisters are of the Holtec MPC-32 design. The MPC-32 does not contain any carbon steel structural components, so only the loss-of-neutron-absorber scenario is analyzed. Figure F-18 shows results for the loss-of-neutron-absorber scenario for 27 decay times within the time interval between calendar years 2020 and 1,100,000. The results in Figure F-18 show $k_{\text {eff }}$ variation as a function of calendar year. The one sigma statistical uncertainty for all $k_{\text {eff }}$ values is 0.0003 or less for all cases.

The $k_{\text {eff }}$ values are predicted to vary from 0.9112 to 1.0105 for the MPC-32 under the loss-of-absorber scenario. For canisters which had $k_{\text {eff }}$ values greater than 0.98 under the loss-of-neutron-absorber scenario, calculations were performed in which the pure water was replaced with groundwater compositions of various $\mathrm{NaCl}$ concentrations, and the models thus modified were used to determine $k_{\text {eff }}$ as a function of $\mathrm{NaCl}$ concentration for the calendar year 22,000 (most reactive date). Figure F-19 presents $k_{\text {eff }}$ variation as a function of $\mathrm{NaCl}$ concentration for those 7 canisters. Examining the results presented in Figure F-19, it is clear that $0.5 \mathrm{~mol} \mathrm{NaCl} / \mathrm{kg} \mathrm{H} \mathrm{H}_{2} \mathrm{O}$ is sufficient to demonstrate subcriticality $\left(k_{\text {eff }}<0.98\right)$ for all of the Vogtle canisters. In this context, it is also important to note that a saturated $\mathrm{NaCl}$ brine has a concentration of approximately 6 molal.

Figure F-17 shows the $k_{\text {eff }}$ increase between the worst misload scenario and the as-loaded configuration for the 26 analyzed Vogtle canisters at the calendar year 22,000. The increase in $k_{\text {eff }}$ varies between 579 and 3,808 pcm for Vogtle canisters.

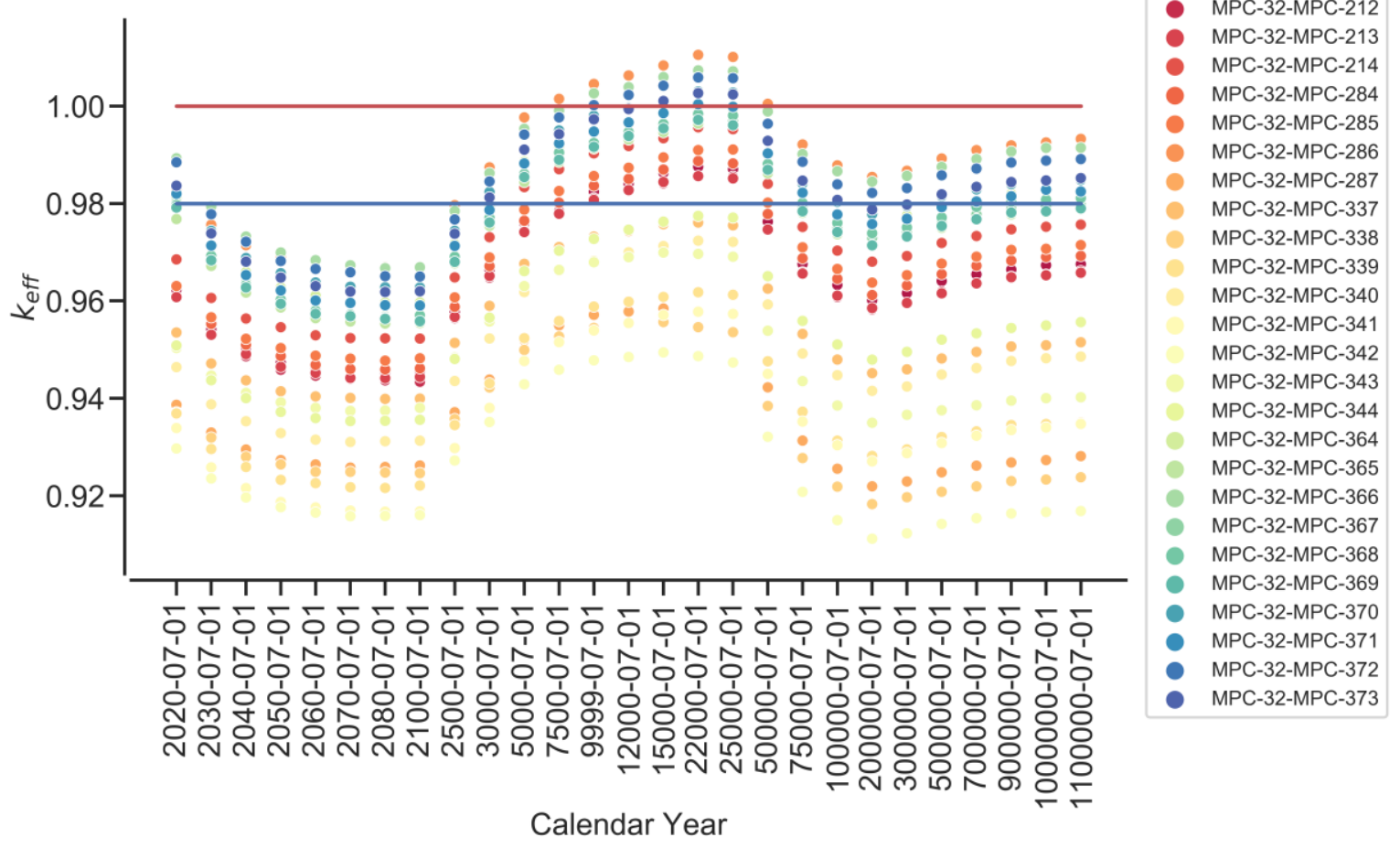

Figure F-18. $\boldsymbol{k}_{\text {eff }}$ vs. calendar year for the loss-of-neutron-absorber scenario based on actual loading and disposal isotopes for the SNF canisters at Vogtle. 


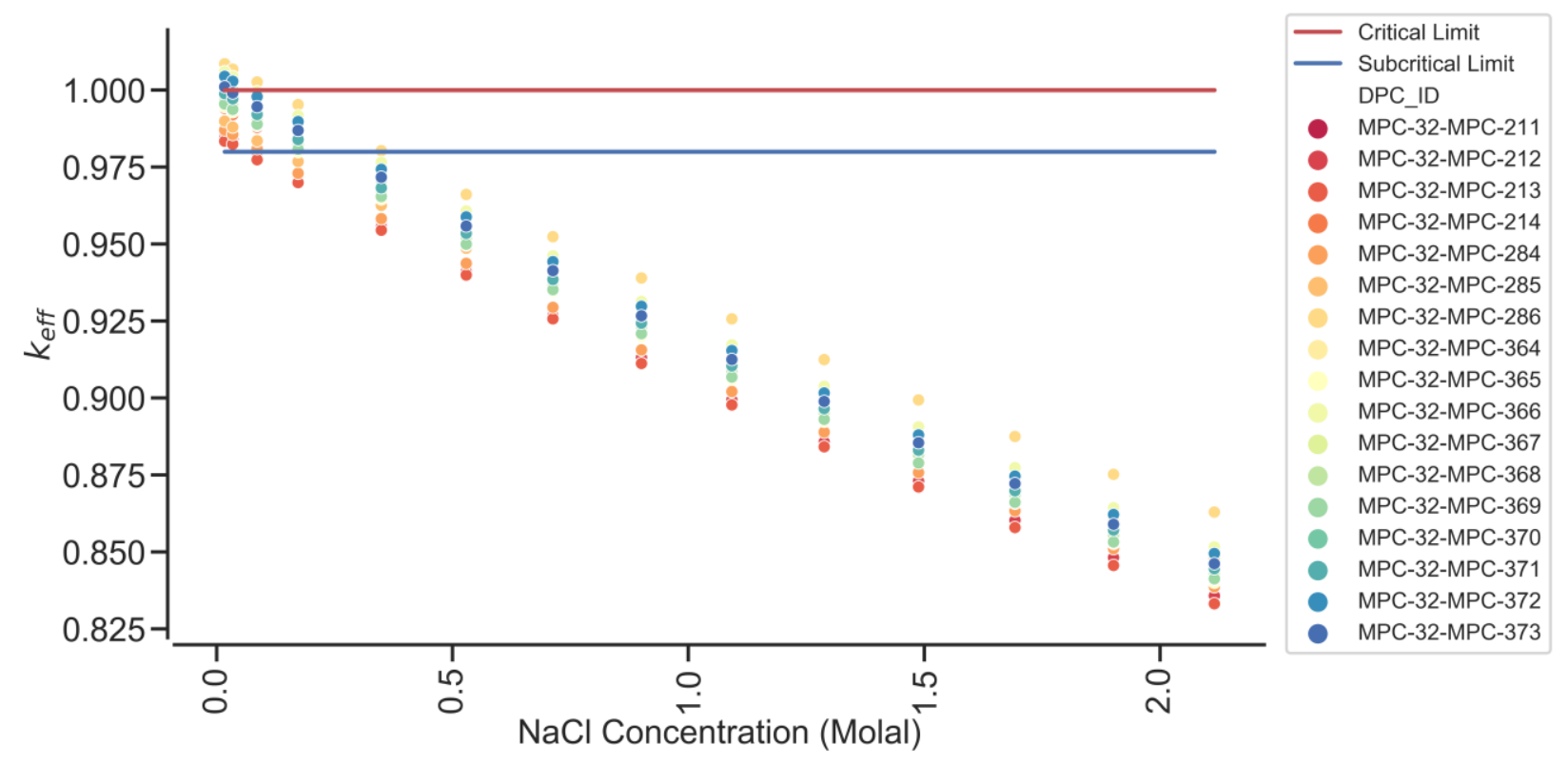

Figure F-19. $\boldsymbol{k}_{\text {eff }}$ vs. NaCl concentration for the DPCs with $\boldsymbol{k}_{\text {eff }}>0.98$ for the canisters at Vogtle under the loss-of-neutron-absorber scenario (calendar year 22,000).

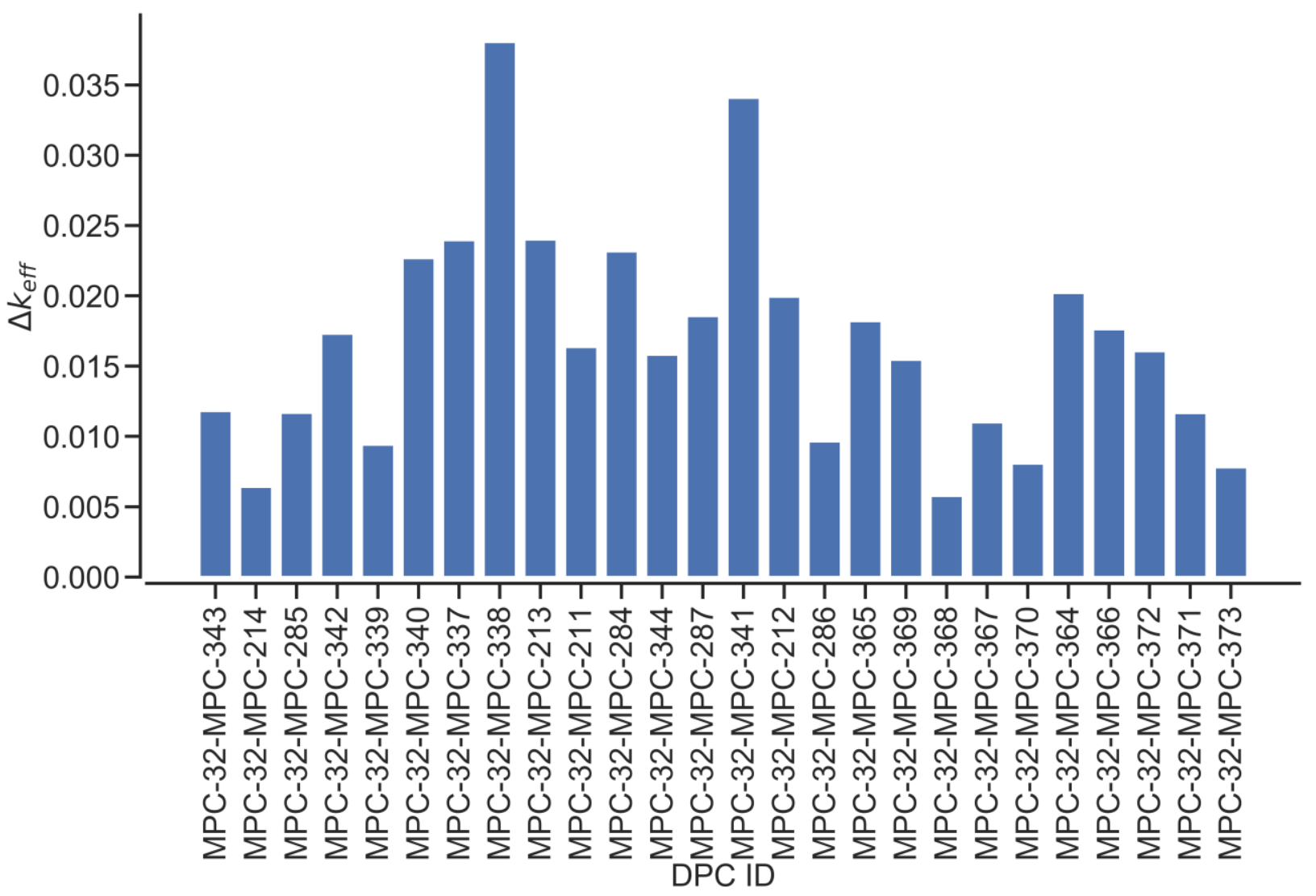

Figure F-20. $k_{\text {eff }}$ increase between the worst-misload scenario and the as-loaded configuration for the MPC-32s at Vogtle (calendar year 22,000). 


\section{F.6. HOPE CREEK CRITICALITY CALCULATIONS}

Post-closure disposal criticality calculations were performed as a function of decay time for the $13 \mathrm{SNF}$ canisters at the Hope Creek ISFSI. All of the 13 SNF canisters are of the Holtec MPC-68 design. The MPC-68 does not contain any carbon steel structural components, so only the loss-of-neutron-absorber scenario is analyzed. Figure F-21 shows results for the loss-of-neutron-absorber scenario for 27 decay times within the time interval between calendar years 2020 and 1,100,000. The results in Figure F-21 show $k_{\text {eff }}$ variation as a function of calendar year. The one sigma statistical uncertainty for all $k_{\text {eff }}$ values is 0.0003 or less for all cases.

The $k_{\text {eff }}$ values are predicted to vary from 0.9004 to 0.9366 for the MPC-68 under the loss-of-absorber scenario. No canisters had $k_{\text {eff }}$ values greater than 0.98 under the loss-of-neutron-absorber scenario, so no $\mathrm{NaCl}$ calculations were performed for Hope Creek.

Figure F-22 shows the $k_{\text {eff }}$ increase between the worst misload scenario and the as-loaded configuration for the 13 analyzed Hope Creek canisters at calendar year 22,000. The increase in $k_{\text {eff }}$ varies between 520 and $1,331 \mathrm{pcm}$ for the Hope Creek canisters.

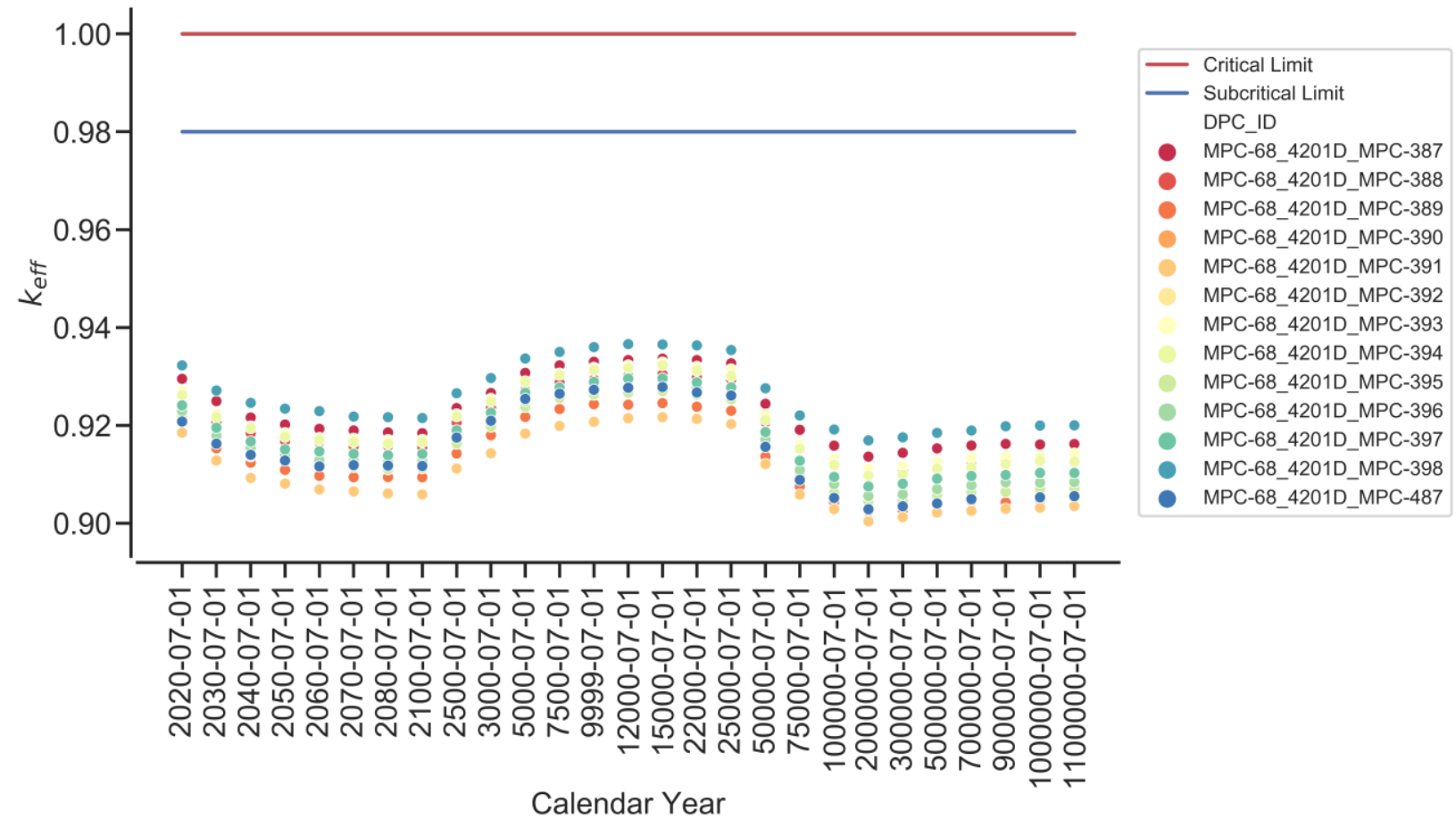

Figure F-21. $\boldsymbol{k}_{\text {eff }}$ vs. calendar year for the loss-of-neutron-absorber scenario based on actual loading and disposal isotopes for the SNF canisters at Hope Creek. 


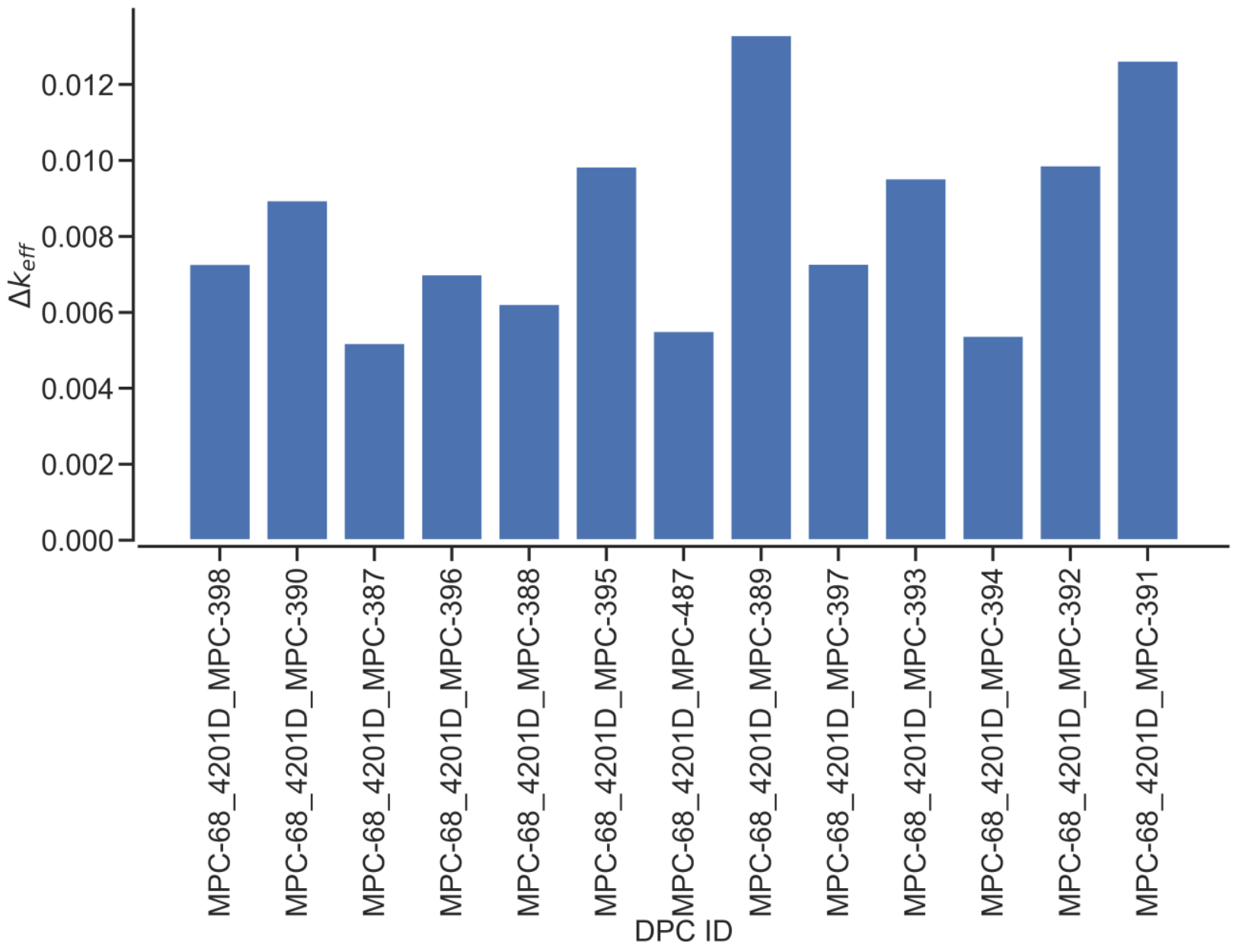

Figure F-22. $\boldsymbol{k}_{\text {eff }}$ increase between the worst-misload scenario and the as-loaded configuration for the MPC-68s at Hope Creek (calendar year 22,000). 


\section{F.7. SALEM CRITICALITY CALCULATIONS}

Post-closure disposal criticality calculations were performed as a function of decay time for the 11 SNF canisters at the Salem ISFSI. All of the 11 SNF canisters are of the Holtec MPC-32 design. The MPC-32 does not contain any carbon steel structural components, so only the loss-of-neutron-absorber scenario is analyzed. Figure F-23 shows results for the loss-of-neutron-absorber scenario for 27 decay times within the time interval between calendar years 2020 and 1,100,000. The results in Figure F-23 show $k_{\text {eff }}$ variation as a function of calendar year. The one sigma statistical uncertainty for all $k_{\text {eff }}$ values is 0.0003 or less for all cases.

The $k_{\text {eff }}$ values are predicted to vary from 0.9486 to 1.0101 for the MPC-32 under the loss-of-absorber scenario. For canisters which had $k_{\text {eff }}$ values greater than 0.98 under the loss-of-neutron-absorber scenario, calculations were performed in which the pure water was replaced with groundwater compositions of various $\mathrm{NaCl}$ concentrations, and the models thus modified were used to determine $k_{\text {eff }}$ as a function of $\mathrm{NaCl}$ concentration for the calendar year 22,000 (most reactive date). Figure F-24 presents $k_{\text {eff }}$ variation as a function of $\mathrm{NaCl}$ concentration for those 11 canisters. Examining the results presented in Figure F-24, it is clear that $0.5 \mathrm{~mol} \mathrm{NaCl} / \mathrm{kg} \mathrm{H} \mathrm{H}_{2} \mathrm{O}$ is sufficient to demonstrate subcriticality $\left(k_{\text {eff }}<0.98\right)$ for all of the Salem canisters. In this context, it is also important to note that a saturated $\mathrm{NaCl}$ brine has a concentration of approximately 6 molal.

Figure F-25 shows the $k_{\text {eff }}$ increase between the worst misload scenario and the as-loaded configuration for the 11 analyzed Salem canisters at calendar year 22,000. The increase in $k_{\text {eff }}$ varies between 542 and $2,573 \mathrm{pcm}$ for the Salem canisters.

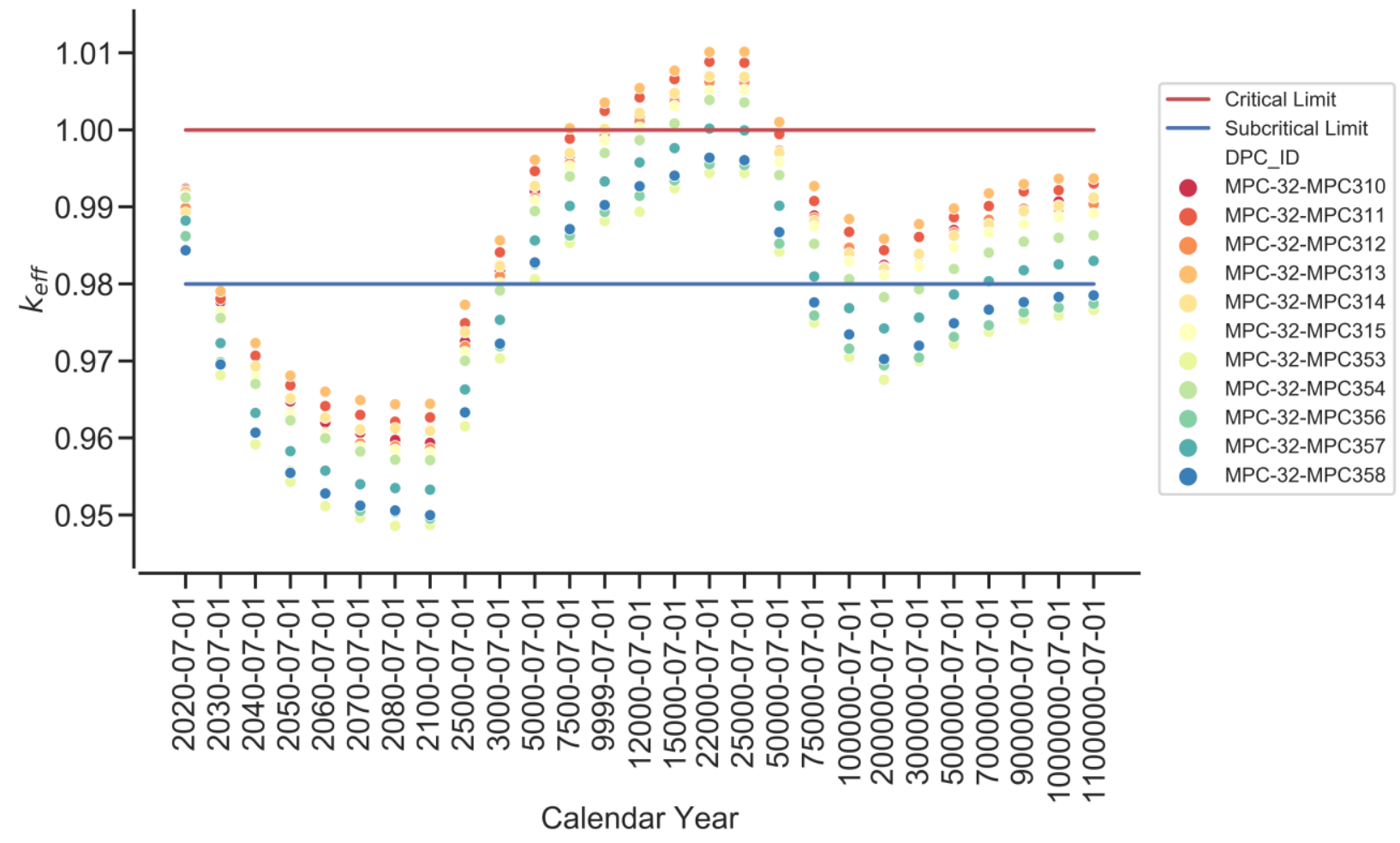

Figure F-23. $\boldsymbol{k}_{\text {eff }}$ vs. calendar year for the loss-of-neutron-absorber scenario based on actual loading and disposal isotopes for the SNF canisters at Salem. 


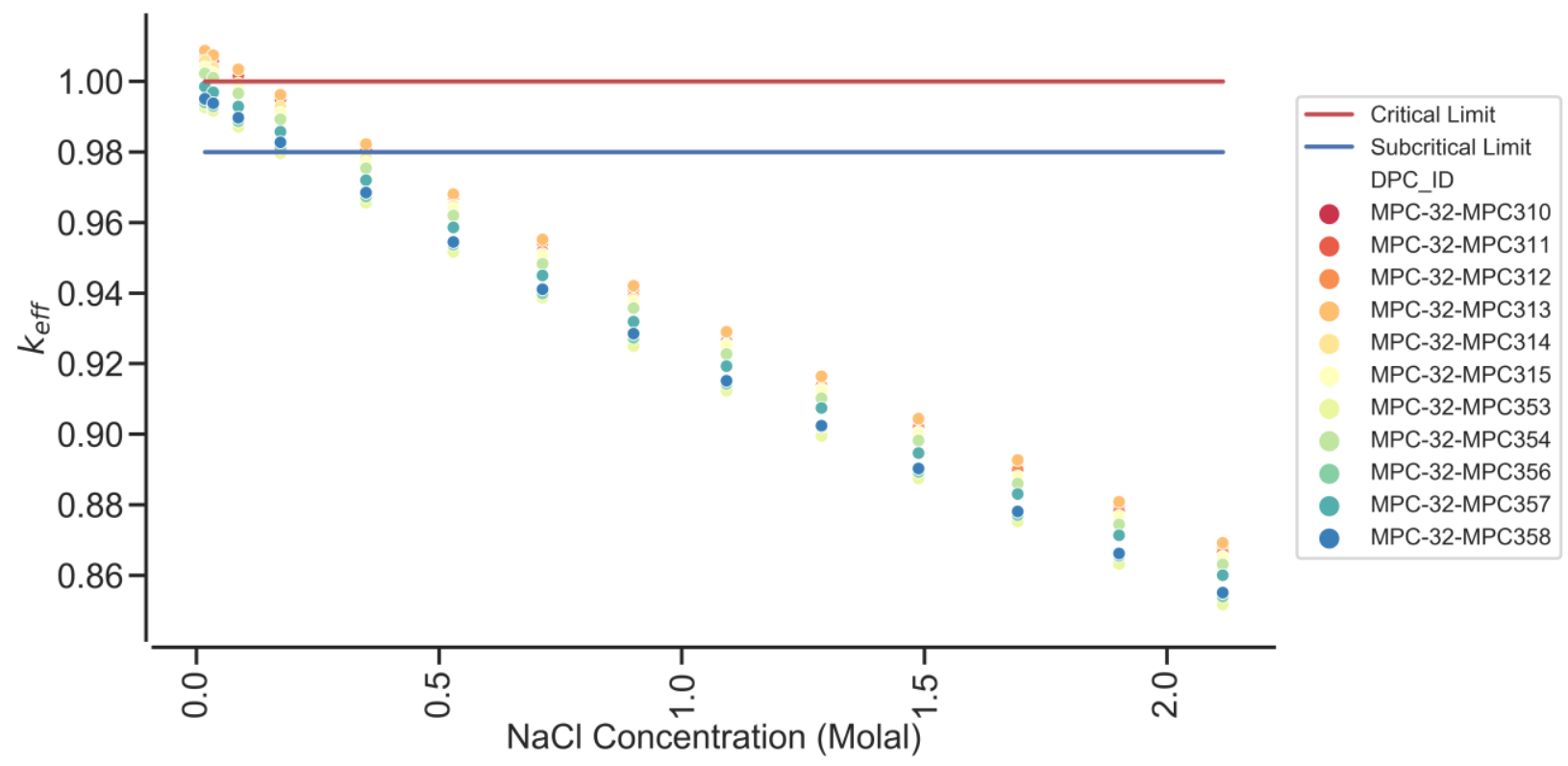

Figure F-24. $\boldsymbol{k}_{\text {eff }}$ vs. NaCl concentration for the DPCs with $\boldsymbol{k}_{\text {eff }}>\mathbf{0 . 9 8}$ for the canisters at Salem under the loss-of-neutron-absorber scenario (calendar year 22,000).

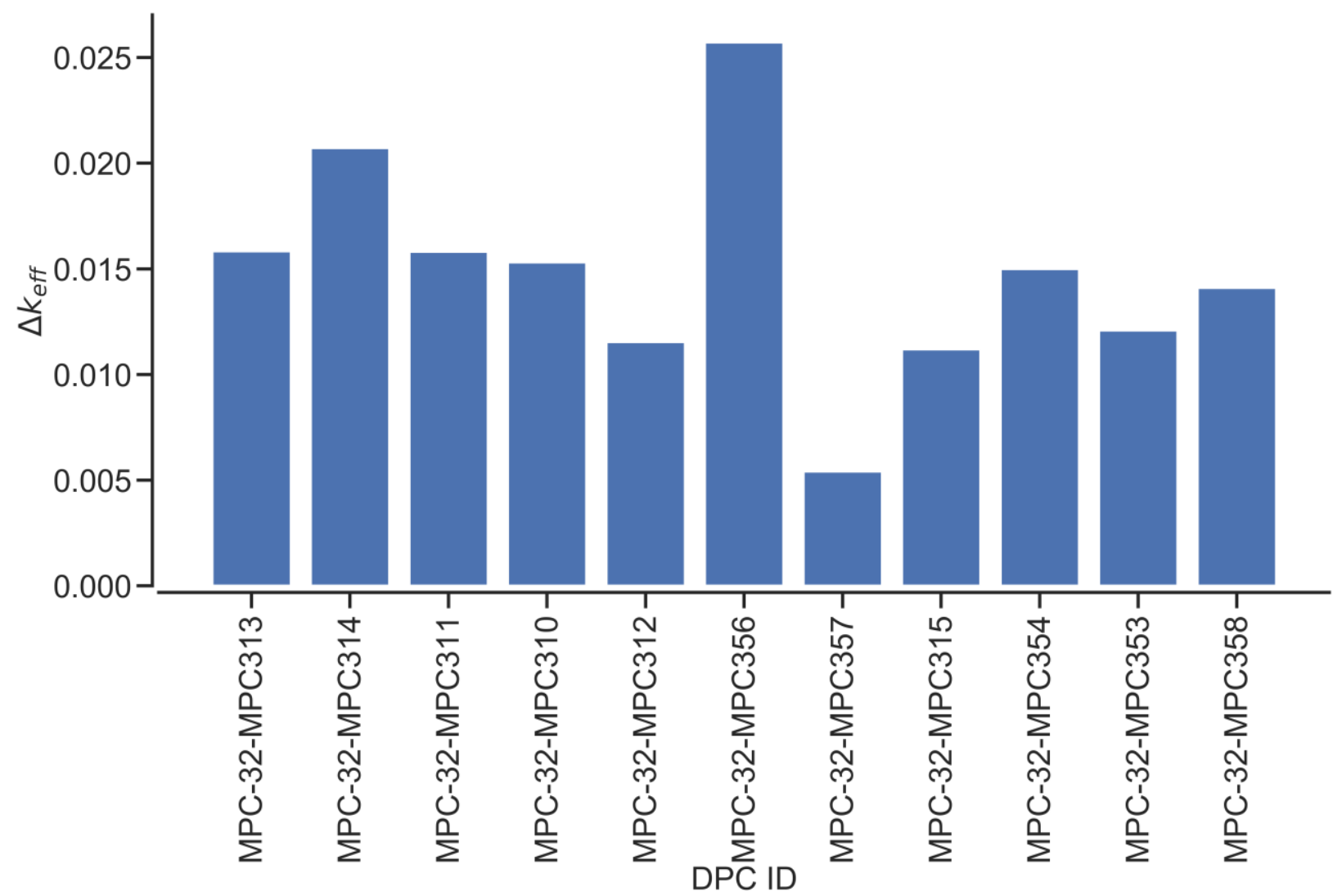

Figure F-25. $k_{\text {eff }}$ increase between the worst-misload scenario and the as-loaded configuration for the MPC-32s at Salem (calendar year 22,000). 


\section{F.8. CONCLUSIONS}

This appendix presents criticality analysis models for the extension of the 708 canisters modeled through FY19 from the year 22,000 out to the year 1,100,000 and the evaluation of cementitious filler materials for criticality control. Post closure criticality analysis was performed for a total of 66 new as-loaded canisters from four sites over the time interval between calendar years 2020 and 1,100,000 using the burnup credit methodology described in this report. The analyzed canisters were at the following sites: Seabrook (16 canisters), Vogtle (26 canisters), Hope Creek (13 canisters), and Salem (11 canisters).

The work performed to extend the analytical timeline of the post closure criticality calculations from previous years' work from 22,000 years to $1,100,000$ years showed that the reactivity of the canisters peaked at 22,000 years then dropped to a minimum at approximately 200,000 years, and then increased throughout the remainder of the period analyzed, but not to the level obtained at 22,000 years.

The cementitious filler work included a series of calculations using the TSCDF-37-TSCDF-15 cask from the Zion site to determine the impact on post closure criticality of adding filler material to canisters. The analysis presented here includes both the NA and DB cases and considers four separate filler materials, which are presented in Table F-1. Of the four filler materials, the chloride-based calcium phosphate cement provided superior criticality control compared to the other filler materials at the same porosity level. It was also shown that almost the entire canister must be filled in order to achieve criticality control. Approximately 15 inches of uncovered fuel returns the canister's reactivity to levels very close to baseline $k_{\text {eff }}$ values.

Post-closure disposal criticality calculations were performed as a function of decay time for as-loaded canisters at the sites previously discussed. Results are provided for a loss-of-neutron-absorber scenario at 27 decay times within the time interval between calendar years 2020 and 1,100,000 for all canisters analyzed. The $k_{\text {eff }}$ values are predicted to vary from 0.89146 to 1.0570 for the Seabrook SNF canisters, 0.9112 to 1.0105 for the Vogtle SNF canisters, 0.9004 to 0.9366 for the Hope Creek SNF canisters, and 0.9486 to 1.0101 for the Salem SNF canisters under the loss of neutron-absorber scenario. None of the canisters modeled for this year's effort had carbon steel structural components, and none were analyzed under the degraded-basket scenario. All canisters that were shown to exceed the 0.98 subcritical limit were analyzed to determine the groundwater $\mathrm{NaCl}$ concentrations necessary to show subcriticality. The $\mathrm{NaCl}$ concentrations necessary to demonstrate subcriticality were determined to be a maximum of 0.5 molal for the Vogtle and Salem canisters and 1.1 molal for the Seabrook canisters.

Canister misload criticality analyses were performed assuming a worst configuration in an as-loaded canister, which is based on the assumption that correct assemblies have been loaded into the canister, but they are loaded in the most reactive configuration. $k_{\text {eff }}$ values for worst misload configurations were determined assuming that all fuel assemblies in the canister have a decay time of 22,000 years, and the neutron absorber is completely lost. The misload analysis was performed for a total of 66 new canisters containing intact fuel assemblies that were loaded to full capacity. The $k_{\text {eff }}$ increase varied between 498 and 3,309 pcm for the Seabrook canisters, between 579 and 3,808 pcm for the Vogtle SNF canisters, between 520 and 1,331 for the Hope Creek SNF canisters, and between 542 and 2,573 pcm for the Salem SNF.

A plot of the canisters analyzed this year, along with the remainder of the canisters at Salem, is shown in Figure F-26. The loss-of-neutron-absorber case is shown as a gray line, and the best- and worst-case misload calculations are shown as a pink band around the gray line. Figure F-26 shows that a DPC loading strategy by taking criticality aspect into account can improve the disposability of loaded DPCs. A summary of the direct disposal criticality calculations is provided in Table F-2. For this project, 774 canisters have been analyzed through FY20. Of the canisters analyzed, it was shown that $76 \%$ would remain subcritical under the loss-of-neutron-absorber scenario. When considering complete degradation of the baskets of canisters with non-stainless-steel structural components, $66 \%$ of the canisters are shown 
to be subcritical. When further considering the potential for the worst-case arrangement of the most reactive fuel assemblies in each canister, it is show that $65 \%$ of canisters would remain subcritical.

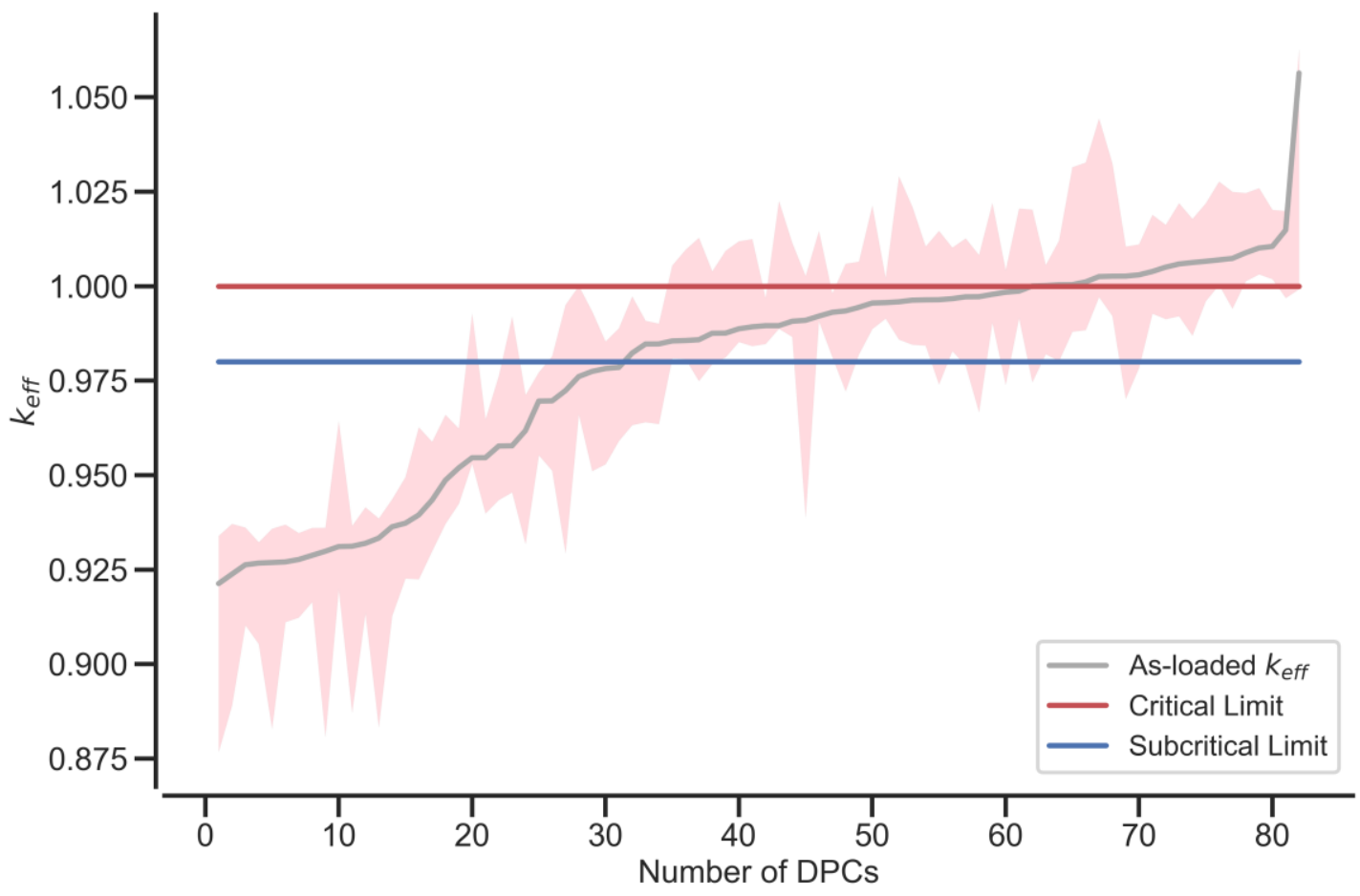

Figure F-26. Summary plot of the post closure criticality calculations performed this year (66 DPCs + other canisters at Salem) including as-loaded (gray line) and best- and worst-case misload (pink band) scenarios.

Table F-2. Summary of the number of canisters meeting the subcritical limit.

\begin{tabular}{lc}
\hline Description (analysis dates: $2020-1,100,000)$ & Value \\
\hline Total DPCs analyzed & 774 \\
\hline $\begin{array}{l}\text { Total DPCs below subcritical limit with loss of } \\
\text { neutron absorber (design-basis loading) }\end{array}$ & $\mathbf{0}(\mathbf{0 \%})$ \\
\hline $\begin{array}{l}\text { Total DPCs below subcritical limit with loss of } \\
\text { neutron absorber (as-loaded) }\end{array}$ & $\mathbf{5 9 1}(\sim 76 \%)$ \\
\hline $\begin{array}{l}\text { Total DPCs below subcritical limit with loss of } \\
\text { neutron absorber and carbon steel structures } \\
\text { (as-loaded) }\end{array}$ & $\mathbf{5 1 4}(\sim 66 \%)$ \\
\hline $\begin{array}{l}\text { Total DPCs below subcritical limit with loss of } \\
\text { neutron absorber and carbon steel structures } \\
\text { (as-loaded) considering misload }\end{array}$ & $\mathbf{5 0 3 ( \sim 6 5 \% )}$ \\
\hline
\end{tabular}




\section{F.9. REFERENCE}

F-1. J. B. Clarity, K. Banerjee, and L. P. Miller, Extension of Direct Disposal Criticality Calculations to 1,000,000 Years, M5SF-20OR0103050123, US Department of Energy, Spent Fuel and Waste Disposition, June 2020. 